\title{
Processamento de eventos complexos nativo de nuvem para cidades inteligentes
}

Fernando Freire Scattone

\author{
DisSERTAÇÃO APRESENTADA \\ $\mathrm{AO}$ \\ Instituto De Matemática e EstatísticA \\ DA \\ UniversidAde DE SÃo PAUlo \\ PARA \\ OBTENÇÃO DO TÍTULO \\ $\mathrm{DE}$ \\ Mestre em CiÊnCIAS \\ Programa: Ciência da Computação \\ Orientadora: Profa. Dra. Kelly Rosa Braghetto
}

Durante o desenvolvimento deste trabalho o autor recebeu auxílio financeiro da Coordenação de Aperfeiçoamento de Pessoal de Nível Superior - Brasil (CAPES) - Código de Financiamento 001.

São Paulo, 22 de dezembro de 2020 


\section{Processamento de eventos complexos nativo de nuvem para cidades inteligentes}

Esta versão da dissertação contém as correções e alterações sugeridas pela Comissão Julgadora durante a defesa da versão original do trabalho, realizada em 22/02/2021. Uma cópia da versão original está disponível no

Instituto de Matemática e Estatística da Universidade de São Paulo.

Comissão Julgadora:

- Prof $^{\mathrm{a}}$. Dr ${ }^{\mathrm{a}}$. Kelly Rosa Braghetto (orientadora) - USP

- Prof. Dr. Álvaro Luiz Fazenda - UNIFESP

- Prof. Dr. Francisco José da Silva e Silva - UFMA 


\section{Agradecimentos}

Durante o tempo de duração do mestrado, passei por várias fases de aprendizado, onde tive a sorte de encontrar várias pessoas que se tornaram meus colegas e amigos. Primeiramente, tenho que reconhecer o valor do apoio que meus amigos da graduação, que influenciaram na minha decisão de vir para o IME-USP na pós-graduação e me apoiaram psicologicamente durante todo o curso o mestrado, sempre que pedia ajuda, Fernando Augusto Joaquim, Lucas Magno, Rafaela Gesing, Naim Elias Comar, Fábio Chagas da Silva, Rodrigo Frausino e muitos outros que conheci durante minha graduação no Instituto de Física. No primeiro ano, onde cursei todas as disciplinas obrigatórias, as quais não tinha certeza de que estava preparado para cursar, foi ótimo poder me aproximar e contar com o apoio, técnico e emocional, da minha colega de orientadora e amiga próxima, Fernanda de Camargo Magano e da sua turma de amigos do curso de Computação, Shayenne da Luz Moura, Eduardo Delgado Coloma Bier e Florence Alyssa Sakuma Shibata, os quais se tornaram amigos próximos e queridos. Ao entrar para o grupo de pesquisa de Sistemas de Software, alguns alunos foram instrumentais em me auxiliar a decidir meu tema de mestrado e no seu desenvolvimento, especialmente Arthur Del Esposte, Tallys Martins, Lucas Kanashiro, Giuliano Belinassi e mais outros que foram prestativos quando tinha dúvidas.

Durante o final do segundo ano do mestrado e pelo tempo seguinte, tive a oportunidade de participar e me tornar um membro do grupo de extensão USPCodeLab. Esta experiência foi ótima para me colocar em contato com novas ideias e participar de atividades que eu nunca teria pensado em me inserir, tenho muito a agradecer a todos os membros, especialmente aos amigos Felipe Marques e Carolina Arenas, que me ajudaram a entender como é a experiencia de alunos de Computação em outros institutos da USP (EACH e ICMC, respectivamente). Junto com o Renato Cordeiro Ferreira, uma pessoa que admiro muito e que se tornou um ótimo amigo, pude desenvolver um projeto de co-orientação de iniciações científicas dentro do grupo de extensão, uma experiência ótima para entender como é orientar uma pessoa e lidar com o aparato burocrático para ir atrás de verba para o projeto de pesquisa. Mesmo que não tenhamos alcançado nosso objetivo inicial, o projeto ADA é algo que eu sempre vou me orgulhar de ter feito e tenho que agradecer todas as pessoas que se comprometeram com o projeto do início ao fim, os doutorandos, os quais posso considerar que se tornaram amigos pela jornada de dificuldades que enfrentamos juntos: Carlos Eduardo Leão Elmadjian, Guilherem Feulo do Espiríto Santo e especialmente Thatiane de Oliveira Rosa, com quem pude compartilhar a orientação da Aléxia Carolina Sheffer, referente a microsserviços do projeto.

Também gostaria de agradecer aos professores do grupo de Sistemas de Software e ao técnico do Laboratório, Nelson Lago, que tirou várias dúvidas minhas referentes a assuntos os quais não tive a oportunidade de ver durante a graduação. Em especial, tenho que agradecer a minha orientadora, professora Kelly Rosa Braghetto, que estava sempre disposta a me ajudar quando tinha dúvidas. Concomitantemente, gostaria de agradecer as contribuições e colaborações do professor Francisco 
Silva e seu Aluno, Jesseildo, por construírem uma parte importante do meu sistema e ao professor Álvaro Luiz Fazenda, por financiar os créditos de nuvem usados para executar o experimento. Por fim, gostaria de agradecer a minha família, que nunca duvidou da minha capacidade de enfrentar os problemas da pós-graduação mesmo nos momento em que eu não compartilhava desta confiança e especialmente a minha cachorra Lana, que ficou ao meu lado desde o inicio do meu Ensino Médio e veio a falecer no início deste ano.

Ao terminar este trabalho, tenho uma consciência muito maior sobre o poder do conhecimento que adquiri neste período. Mais do que nunca, a influência do uso da computação nos direitos pessoais e coletivos da sociedade é algo que todo cientista da computação tem o dever de saber. Pretendo sempre levar em consideração a influência que meu código pode ter quando em execução e basear minhas escolhas de projetos futuros para que meu trabalho tenha uma influência positiva no âmbito que se propor a atingir.

Meu aprendizado não passou só pelo conhecimento técnico, mas especialmente pelo aprendizado de solucionar problemas em conjunto com outros e na capacidade de aprender a achar soluções por conta própria. Aprendi a ter coragem de admitir quando há problemas, principalmente aqueles que não sei resolver. Aprendi a ter perseverança que qualquer empecilho do desenvolvimento nunca seria uma dificuldade única e que, com paciência e sem cair no desespero, tudo tinha solução, mesmo que fosse drástica. Aprendi que improvisação é mais importante que eu imaginava e que saber lidar com desafios ao longo do caminho é tão útil quanto ter uma plano para toda a jornada. No entanto o aprendizado que mais se destaca na minha consciência é o que chamamos na computação de entrega contínua, fazer uma parte pequena e útil do projeto toda semana, de forma que existe uma comparação frequente da expectativa e realidade. Desta forma, nenhum indício de erro tem a capacidade de se integrar ao núcleo do projeto e possibilitando testes a cada alteração. Estes aprendizados não são importantes somente na escrita de código, mas também ao iniciar e construir projetos de qualquer natureza.

O conhecimento que eu tenho hoje e a minha opinião atual sobre a computação como área de conhecimento e matéria de estudo científico foi moldada por fatos e pela troca de opiniões que tive com pessoas de cada um dos grupos citados acima. Posso dizer que minha imaginação e minhas expectativas na graduação sobre o que seria essa jornada foram bem diferentes da realidade, com surpresas e desafios que nunca teria imaginado. Todos aqueles que me ajudaram a progredir tem meu sincero agradecimento. 


\section{Resumo}

SCATTONE, F. F. Processamento de eventos complexos nativo de nuvem para cidades inteligentes. 2020. Dissertação - Instituto de Matemática e Estatística, Universidade de São Paulo, São Paulo, 2020.

Ao longo dos últimos anos, o conceito de Cidades Inteligentes vem ganhando popularidade, sendo promovido com os propósitos de aumentar a sustentabilidade e melhorar a qualidade de vida para os residentes de centros urbanos. Processamento de Eventos Complexos (CEP - Complex Event Processing) é uma das técnicas mais usadas para processar dados em tempo real em grande volume e velocidade, como os provenientes de Cidades Inteligentes. CEP considera cada novo dado coletado como um evento e permite definir novos tipos de eventos a partir da identificação de padrões de ocorrência específicos de outros eventos. Escalabilidade e tolerância a falhas no ambiente de execução são requisitos não funcionais para o processamento de fluxos de dados que sofrem grande variação de volume ao longo do tempo, como em Cidades Inteligentes. O cumprimento desses requisitos é essencial para manter o sistema em funcionamento com a latência de detecção de eventos em patamares aceitáveis para sistemas de tempo real. O uso de plataformas de nuvem é conveniente para realizar o processamento de eventos de forma distribuída e escalável, pois permite o gerenciamento dinâmico de recursos computacionais. As soluções atuais de software livre de CEP não oferecem suporte nativo para a execução em ambientes de nuvem, ou mesmo distribuídos. Este trabalho apresenta uma arquitetura de microsserviços para CEP distribuído nativa de nuvem, que gerencia dinamicamente os recursos computacionais usados na execução. Nela, o processamento de eventos complexos é dividido entre múltiplas instâncias de um mesmo microsserviço. O estilo arquitetural de coreografia foi usado, no qual a distribuição do processamento é coordenada entre as instâncias e não há um serviço central que comanda todo o sistema. Isso resulta em uma maior tolerância a falhas, pois uma falha em uma única instância não afeta a detecção de eventos nas outras. Um protótipo da arquitetura de microsserviços foi implementado, utilizando somente ferramentas de software livre, de forma integrada à plataforma de cidades inteligentes InterSCity. Para avaliar o desempenho do sistema, um cenário experimental de cidades inteligentes foi criado: a detecção de problemas de tráfego a partir de dados reais de posições de ônibus do transporte público da cidade de São Paulo. Quatro métricas foram analisadas: latência, vazão, número total de eventos detectados e tempo de uso de recursos computacionais. Os resultados do experimento mostraram que o sistema escala automaticamente, aumentando o número de instâncias conforme sua carga de entrada aumenta. Além disso, as latências normalmente ficaram abaixo de cem milissegundos, satisfazendo os requisitos de processamento em tempo real do cenário considerado.

Palavras-chave: Cidades Inteligentes, Processamento de Eventos Complexos, Processamento de Big Data, Computação Nativa de Nuvem, Escalabilidade, Microsserviços. 


\section{Abstract}

SCATTONE, F. F. Cloud-native complex event processing for smart cities. 2020. Dissertation (Masters) - Instituto de Matemática e Estatística, Universidade de São Paulo, São Paulo, 2020.

Over the last few years, Smart City concepts have gained popularity because of their purposes of increasing sustainability and improving quality of life for large cities' residents. Complex Event Processing is one of the most used techniques to process real-time data, with large volume and velocity, such as the data coming from Smart Cities. In CEP each new piece of data is treated as an event and can be defined by an event type. New event types can be registered by defining a query using CEP operators to detect specific patterns on incoming events from other event types. In order to process real-time data for Smart Cities, scalability and fault tolerance are the main requirements to be fulfilled. Satisfying these requirements is essential to maintain a functioning system with acceptable latency levels for Smart Cities situation detection. Using cloud providers is a convenient method to distribute and scale complex event processing since cloud providers can dynamically manage computational resource usage. Current open-source CEP implementations do not offer official cloud-native execution support, or even official distributed execution support. This work presents a cloud-native microservice architecture for distributed CEP. Event processing is distributed across several instances of the same microservice, which can be dynamically created or destroyed based on resource usage. These instances use a choreography style of communication among each other, where there are no central nodes controlling all other instances. Instead, they must agree on any multi-instance action. This style of communication ensures greater fault tolerance since failures in one instance do not affect event processing in all other instances. A prototype of this architecture was developed, using open source tools, integrated with the InterSCity Smart City Platform. To evaluate the performance of the system, an experimental scenario of Smart Cities was designed: the detection of traffic problems from real data of bus positions of public transport in São Paulo. Four metrics were analyzed: latency, throughput, number of events detected, and resource time usage. Results showed the system achieved self-scalability, creating new CEP nodes as the input load increased while maintaining acceptable levels of latency. Furthermore, latencies were typically below a hundred milliseconds, satisfying real-time processing requirements of the Smart City scenario.

Keywords: Smart Cities, Complex Event Processing, Cloud-Native Computing, Big Data Processing, Scalability, Microservices. 


\section{Sumário}

Lista de Abreviaturas $\quad$ xi

Lista de Figuras $\quad$ xiii

Lista de Tabelas $\quad$ xvii

1 Introdução $\quad 1$

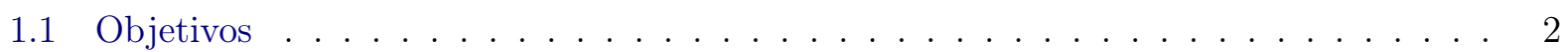

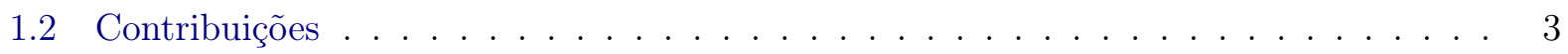

1.3 Organização do Trabalho . . . . . . . . . . . . . . . . . . . . . . . . 4

2 Conceitos $\quad 5$

2.1 Processamento de Eventos Complexos . . . . . . . . . . . . . . . . . . 5

2.1 .1 Operadores de CEP $\ldots \ldots \ldots \ldots \ldots \ldots$

2.1.2 Contexto em CEP . . . . . . . . . . . . . . . . . . . . . 12

2.1 .3 Estado em CEP . . . . . . . . . . . . . . . . . . . . . . . . . . . 13

2.1.4 Principais Ferramentas . . . . . . . . . . . . . . . . . . . . . . 13

2.1.5 Distribuição de Processamento das Ferramentas de Software Livre . . . . . . 15

2.2 Isolamento de Ambiente e Processamento em Nuvem . . . . . . . . . . . . . . . . . 16

2.2.1 Sistemas Nativos de Nuvem . . . . . . . . . . . . . . . . . . . . . . . 16

2.3 Arquitetura de Microsserviços . . . . . . . . . . . . . . . . . . . . . . . . . . 17

2.3 .1 Comunicação . . . . . . . . . . . . . . . . . . . . . . . . . . . . . 18

2.3 .2 Orquestração e Coreografia . . . . . . . . . . . . . . . . . . . . 18

2.4 Escalabilidade . . . . . . . . . . . . . . . . . . . . . . . . . . . . . . . 19

2.4.1 Escalabilidade para Microsserviços sem Estado . . . . . . . . . . . . . . . . 20

2.4.2 Escalabilidade para Microsserviços com Estado . . . . . . . . . . . . . . . 20

2.5 Considerações do Capítulo . . . . . . . . . . . . . . . . . . . . . . . . 21

3 Trabalhos Relacionados $\quad 23$

3.1 Distribuição de Processamento de Eventos . . . . . . . . . . . . . . . . . . . . . 23

3.1.1 Distribuição de Tipos de Eventos com Dependências Similares . . . . . . . . . 23

3.1 .2 Distribuição da Deteç̧ão de um Único Tipo de Evento . . . . . . . . . . . . . . 24

3.1.3 Distribuição de Tipos de Evento Baseada em Desempenho . . . . . . . . . . . 25

3.2 Tolerância a Falhas . . . . . . . . . . . . . . . . . . . . . . . 25

3.3 CEP em Nuvem e Borda . . . . . . . . . . . . . . . . . . . . 26

3.3.1 Comparação de CEP com Funções-como-Serviço . . . . . . . . . . . . . . 26 
3.4 Considerações . . . . . . . . . . . . . . . . . . . . . . . . 27

4 Arquitetura para a Distribuição do Processamento de Eventos Complexos 29

4.1 Arquitetura CEP Handler . . . . . . . . . . . . . . . . . . . . . . . . . . . . . . 29

4.1.1 Microsserviço CEP Cataloger . . . . . . . . . . . . . . . . . . . . 30

4.1 .2 Microsserviço Event Composer . . . . . . . . . . . . . . . . . . 30

4.1.3 Sistema Gerenciador de Banco de Dados Chave-Valor . . . . . . . . . . . . . 31

4.1.4 Microsserviço Event Sender . . . . . . . . . . . . . . . . . . . . 31

4.1 .5 Microsserviço CEP Worker . . . . . . . . . . . . . . . . . . . . 31

4.2 Método de Realocação . . . . . . . . . . . . . . . . . . . . . . . . . . . . 34

4.3 Algoritmos de Distribuição de Carga . . . . . . . . . . . . . . . . . . . . . . 36

4.3.1 Algoritmo de Balanceamento de Carga por Uso de Estado . . . . . . . . . . 36

4.3.2 Algoritmo de Balanceamento de Carga por Similaridade de Entrada . . . . . 37

4.4 Escalabilidade e Tolerância a Falhas . . . . . . . . . . . . . . . . . . . 38

5 Protótipo e Ferramentas Selecionadas $\quad 41$

5.1 Ferramenta de Processamento de Eventos . . . . . . . . . . . . . . . . . . . . 42

5.1 .1 Limitações . . . . . . . . . . . . . . . . . . . . . . . . . . 43

5.2 Microsserviços sem Estado . . . . . . . . . . . . . . . . . . . . . . . . 43

5.3 Gerenciamento Dinâmico de Recursos . . . . . . . . . . . . . . . . . . . . 43

5.4 Transmissão Assíncrona . . . . . . . . . . . . . . . . . . . . . 44

5.5 Sistema Gerenciador de Banco de Dados . . . . . . . . . . . . . . . . . . . . 44

6 Experimentos de Avaliação de Desempenho do CEP Handler $\quad 47$

6.1 Caracterização dos Dados de Posição de Ônibus . . . . . . . . . . . . . . . . . . . . . 47

6.2 Tipos de Evento Detectados . . . . . . . . . . . . . . . . . . . . 47

6.3 Arquitetura dos Experimentos . . . . . . . . . . . . . . . . . . 52

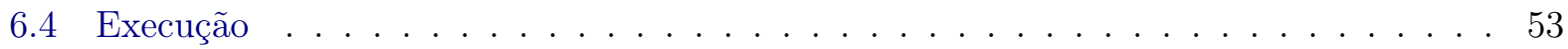

7 Resultados $\quad 55$

7.1 Dados Detectados . . . . . . . . . . . . . . . . . . . 55

7.2 Auto-Escalabilidade do Sistema . . . . . . . . . . . . . . . . . 57

7.3 Tempo de Uso de Recursos . . . . . . . . . . . . . . . . . . . . . . 62

7.4 Número de Eventos Detectados . . . . . . . . . . . . . . . . . . . . . . 63

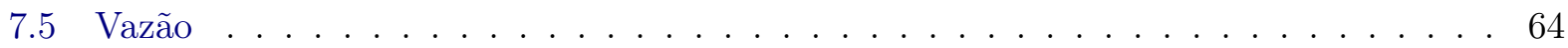

7.6 Latência . . . . . . . . . . . . . . . . . . . . . . . . 67 67

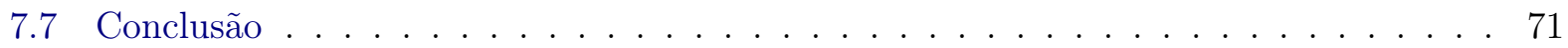

8 Conclusões $\quad 73$

8.1 Considerações Finais . . . . . . . . . . . . . . . . . . . . . . 74

8.2 Sugestões para Pesquisas Futuras . . . . . . . . . . . . . . . . . 75

$\begin{array}{ll}\text { A Gráficos das Execuções do Experimento } & 77\end{array}$

$\begin{array}{ll}\text { Referências Bibliográficas } & 109\end{array}$ 


\section{Lista de Abreviaturas}

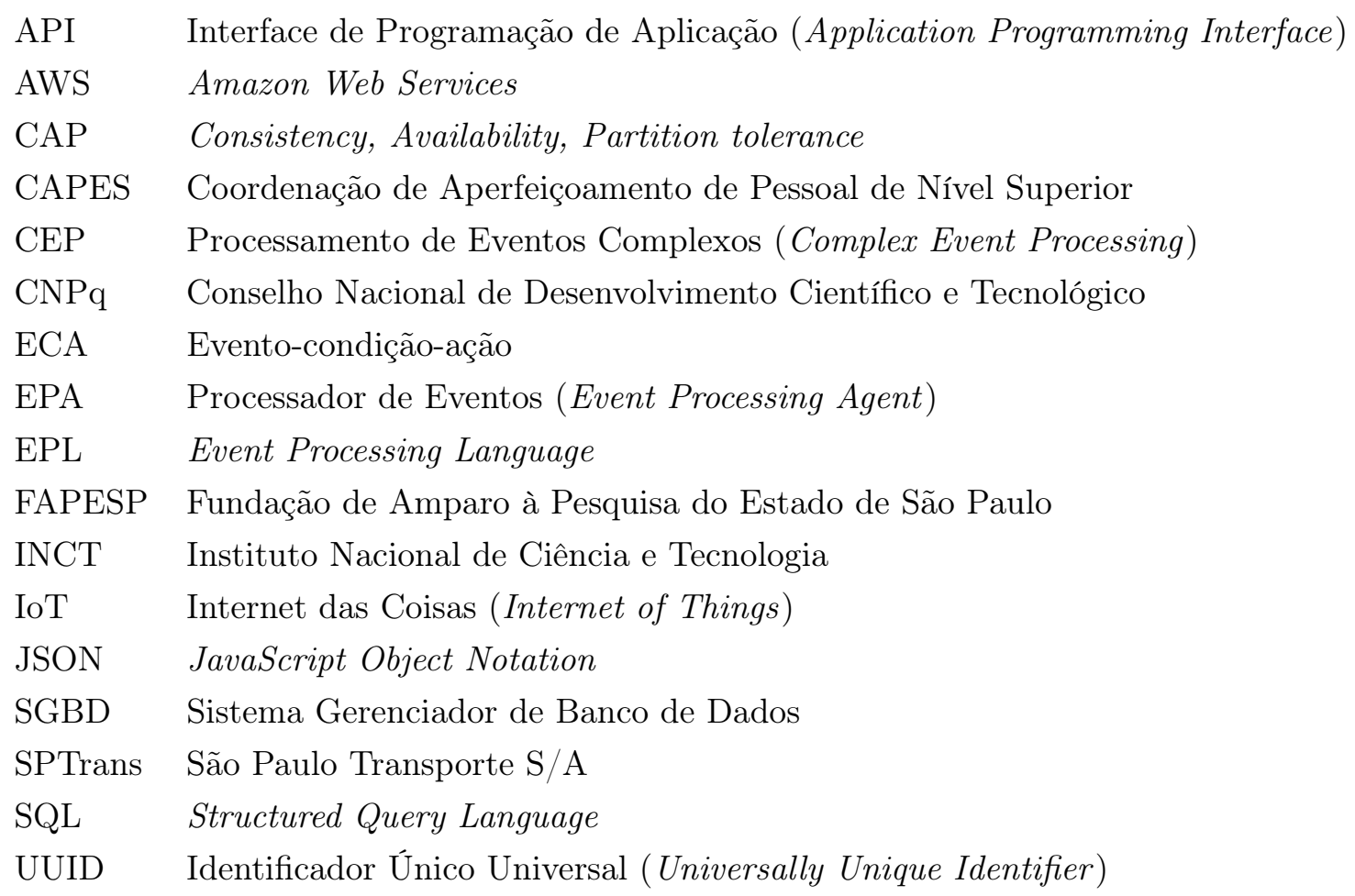




\section{Lista de Figuras}

4.1 Arquitetura CEP Handler para processamento distribuído de eventos complexos. . 29

4.2 Diagrama de representação do algoritmo de balanceamento de carga por Uso de Estado. 37

4.3 Diagrama de representação do algoritmo de balanceamento de carga por Similaridade de Entrada. . . . . . . . . . . . . . . . . . . . . . . . . . . . . . 38

5.1 Protótipo da arquitetura do CEP Handler. . . . . . . . . . . . . . . . 41

6.1 Rede de processamento de eventos de localização de ônibus. . . . . . . . . . . . . . . 48

6.2 Arquitetura de processamento dos experimentos. . . . . . . . . . . . . . . . 53

7.1 Velocidades médias no corredor de ônibus Guarapiranga para uma execução do ex-

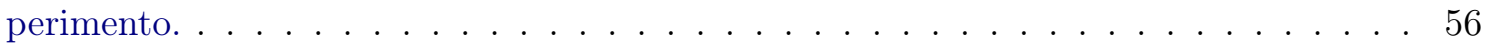

7.2 Histograma do número de ocorrências de agrupamento de ônibus para uma execução

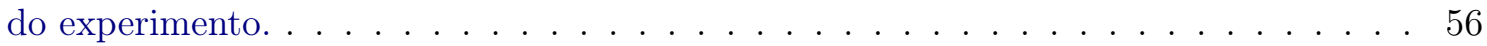

7.3 Número de eventos entrando no sistema (em vermelho) e número de instâncias de CEP Worker (em azul) em função do tempo nas execuções do experimento utilizando o algoritmo de balanceamento de carga por Uso de Estado. Algumas instâncias são iniciadas antes do início do envio de eventos pois nesse período o cadastro de tipos de eventos já ocupa toda a memória disponível de algumas instâncias. A criação de novas instâncias depende de vários fatores que são descritos no Capítulo 4.1.5 . . . 58

7.4 Número de eventos entrando no sistema (em vermelho) e número de instâncias de CEP Worker (em azul) em função do tempo nas execuções do experimento utilizando o algoritmo de balanceamento de carga por Similaridade de Entrada. Algumas instâncias são iniciadas antes do início do envio de eventos pois nesse período o cadastro de tipos de eventos já ocupa toda a memória disponível de algumas instâncias. A criação de novas instâncias depende de vários fatores que são descritos no Capítulo

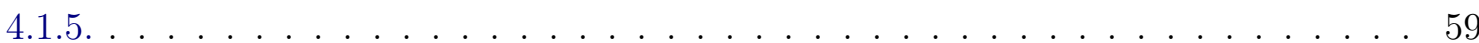

7.5 Número de eventos entrando no sistema (em vermelho) e número de instâncias de CEP Worker (em azul) em função do horário do dia nas execuções do experimento utilizando o algoritmo de balanceamento de carga por Uso de Estado. . . . . . . . . 60

7.6 Número de eventos entrando no sistema (vermelho) e número de instâncias de CEP Worker (em azul) em função do horário do dia nas execuções do experimento utilizando o algoritmo de balanceamento de carga por Similaridade de Entrada. . . . . . . 6

7.7 Vazão de eventos detectados pelo sistema nas execuções do experimento utilizando o algoritmo de de balanceamento por Uso de Estado. 
7.8 Vazão de eventos detectados pelo sistema nas execuções do experimento utilizando o algoritmo de balanceamento por Similaridade de Entrada. . . . . . . . . . . . . . . 66

7.9 Latência para velocidade instantânea nas execuções do experimento para cada algoritmo de balanceamento de carga. . . . . . . . . . . . . . . . . . 6 67

7.10 Latência para filtro de velocidade nas execuções do experimento para cada algoritmo de balanceamento de carga. . . . . . . . . . . . . . . . . . . . 6 68

7.11 Latência para velocidade média de ônibus nos corredores nas execuções do experimento para cada algoritmo de balanceamento de carga. . . . . . . . . . . . . . . 68

7.12 Latência para velocidade média de cada corredor nas execuções do experimento para cada algoritmo de balanceamento de carga. . . . . . . . . . . . . . . . . 69

7.13 Latência para deteç̧ão de agrupamento de ônibus nas execuções do experimento para cada algoritmo de balanceamento de carga.

7.14 Latências das categorias de tipos de evento por intervalos de cinco minutos ao longo da execução 2 do experimento utilizando o algoritmo de balanceamento de carga por Similaridade de Entrada. . . . . . . . . . . . . . . . . . . . . . . . . . . . .

A.1 Vazão de eventos detectados pelo sistema na execução 1 do experimento utilizando o algoritmo de balanceamento por Uso de Estado. . . . . . . . . . . . . . . . .

A.2 Número de eventos entrando no sistema (em vermelho) e número de instâncias de CEP Worker (em azul) na execução 1 do experimento utilizando o algoritmo de balanceamento de carga por Uso de Estado. Algumas instâncias são iniciadas antes do início do envio de eventos pois nesse período o cadastro de tipos de eventos já ocupa toda a memória disponível de algumas instâncias.

A.3 Diagramas de caixa das latências por intervalos de cinco minutos ao longo da execução 1 do experimento utilizando o algoritmo de balanceamento de carga por Uso de Estado. 79

A.4 Vazão de eventos detectados pelo sistema na execução 1 do experimento utilizando o algoritmo de balanceamento por Similaridade de Entrada. . . . . . . . . . . . . . .

A.5 Número de eventos entrando no sistema (em vermelho) e número de instâncias de CEP Worker (em azul) na execução 1 do experimento utilizando o algoritmo de balanceamento de carga por Similaridade de Entrada. Algumas instâncias são iniciadas antes do início do envio de eventos pois nesse período o cadastro de tipos de eventos já ocupa toda a memória disponível de algumas instâncias. . . . . . . . . . . . . .

A.6 Diagramas de caixa das latências por intervalos de cinco minutos ao longo da execução 1 do experimento utilizando o algoritmo de balanceamento de carga por Similaridade de Entrada. . . . . . . . . . . . . . . . . . . . . . . .

A.7 Vazão de eventos detectados pelo sistema na execução 2 do experimento utilizando o algoritmo de balanceamento por Uso de Estado.

A.8 Número de eventos entrando no sistema (em vermelho) e número de instâncias de CEP Worker (em azul) na execução 2 do experimento utilizando o algoritmo de balanceamento de carga por Uso de Estado. Algumas instâncias são iniciadas antes do início do envio de eventos pois nesse período o cadastro de tipos de eventos já ocupa toda a memória disponível de algumas instâncias.

A.9 Diagramas de caixa das latências por intervalos de cinco minutos ao longo da execução 2 do experimento utilizando o algoritmo de balanceamento de carga por Uso de Estado. 85 
A.10 Vazão de eventos detectados pelo sistema na execução 2 do experimento utilizando o algoritmo de balanceamento por Similaridade de Entrada. . . . . . . . . . . . . 86

A.11 Número de eventos entrando no sistema (em vermelho) e número de instâncias de CEP Worker (em azul) na execução 2 do experimento utilizando o algoritmo de balanceamento de carga por Similaridade de Entrada. Algumas instâncias são iniciadas antes do início do envio de eventos pois nesse período o cadastro de tipos de eventos já ocupa toda a memória disponível de algumas instâncias. . . . . . . . . . . . . . 87

A.12 Diagramas de caixa das latências por intervalos de cinco minutos ao longo da execução 2 do experimento utilizando o algoritmo de balanceamento de carga por Similaridade de Entrada. . . . . . . . . . . . . . . . . . . . . . . 88

A.13 Vazão de eventos detectados pelo sistema na execução 3 do experimento utilizando o algoritmo de balanceamento por Uso de Estado. . . . . . . . . . . . . . . . . 89

A.14 Número de eventos entrando no sistema (em vermelho) e número de instâncias de CEP Worker (em azul) na execução 3 do experimento utilizando o algoritmo de balanceamento de carga por Uso de Estado. Algumas instâncias são iniciadas antes do início do envio de eventos pois nesse período o cadastro de tipos de eventos já ocupa toda a memória disponível de algumas instâncias. . . . . . . . . . . . . . . . 90

A.15 Diagramas de caixa das latências por intervalos de cinco minutos ao longo da execução 3 do experimento utilizando o algoritmo de balanceamento de carga por Uso de Estado. 91

A.16 Vazão de eventos detectados pelo sistema na execução 3 do experimento utilizando o algoritmo de balanceamento por Similaridade de Entrada. . . . . . . . . . . . . . 92

A.17 Número de eventos entrando no sistema (em vermelho) e número de instâncias de CEP Worker (em azul) na execução 3 do experimento utilizando o algoritmo de balanceamento de carga por Similaridade de Entrada. Algumas instâncias são iniciadas antes do início do envio de eventos pois nesse período o cadastro de tipos de eventos já ocupa toda a memória disponível de algumas instâncias. . . . . . . . . . . . . 93

A.18 Diagramas de caixa das latências por intervalos de cinco minutos ao longo da execução 3 do experimento utilizando o algoritmo de balanceamento de carga por Similaridade de Entrada. . . . . . . . . . . . . . . . . . . . . . . . . . . 94 94

A.19 Vazão de eventos detectados pelo sistema na execução 4 do experimento utilizando o algoritmo de balanceamento por Uso de Estado. . . . . . . . . . . . . . . . 95

A.20 Número de eventos entrando no sistema (em vermelho) e número de instâncias de CEP Worker (em azul) na execução 4 do experimento utilizando o algoritmo de balanceamento de carga por Uso de Estado. Algumas instâncias são iniciadas antes do início do envio de eventos pois nesse período o cadastro de tipos de eventos já ocupa toda a memória disponível de algumas instâncias. . . . . . . . . . . . . . 96

A.21 Diagramas de caixa das latências por intervalos de cinco minutos ao longo da execução 4 do experimento utilizando o algoritmo de balanceamento de carga por Uso de Estado. 97

A.22 Vazão de eventos detectados pelo sistema na execução 4 do experimento utilizando o algoritmo de balanceamento por Similaridade de Entrada. . . . . . . . . . . . . 98 
A.23 Número de eventos entrando no sistema (em vermelho) e número de instâncias de CEP Worker (em azul) na execução 4 do experimento utilizando o algoritmo de balanceamento de carga por Similaridade de Entrada. Algumas instâncias são iniciadas antes do início do envio de eventos pois nesse período o cadastro de tipos de eventos já ocupa toda a memória disponível de algumas instâncias. . . . . . . . . . . . . . . . 99

A.24 Diagramas de caixa das latências por intervalos de cinco minutos ao longo da execução 4 do experimento utilizando o algoritmo de balanceamento de carga por Similaridade de Entrada. . . . . . . . . . . . . . . . . . . . . . . . . 100

A.25 Vazão de eventos detectados pelo sistema na execução 5 do experimento utilizando o algoritmo de balanceamento por Uso de Estado. . . . . . . . . . . . . . . . . . . . 101

A.26 Número de eventos entrando no sistema (em vermelho) e número de instâncias de CEP Worker (em azul) na execução 5 do experimento utilizando o algoritmo de balanceamento de carga por Uso de Estado. Algumas instâncias são iniciadas antes do início do envio de eventos pois nesse período o cadastro de tipos de eventos já ocupa toda a memória disponível de algumas instâncias. . . . . . . . . . . . . . . . . 102

A.27 Diagramas de caixa das latências por intervalos de cinco minutos ao longo da execução 5 do experimento utilizando o algoritmo de balanceamento de carga por Uso de Estado.103

A.28 Vazão de eventos detectados pelo sistema na execução 5 do experimento utilizando o algoritmo de balanceamento por Similaridade de Entrada. . . . . . . . . . . . . . . 104

A.29 Número de eventos entrando no sistema (em vermelho) e número de instâncias de CEP Worker (em azul) na execução 5 do experimento utilizando o algoritmo de balanceamento de carga por Similaridade de Entrada. Algumas instâncias são iniciadas antes do início do envio de eventos pois nesse período o cadastro de tipos de eventos já ocupa toda a memória disponível de algumas instâncias. . . . . . . . . . . . . . . . 105

A.30 Diagramas de caixa das latências por intervalos de cinco minutos ao longo da execução 5 do experimento utilizando o algoritmo de balanceamento de carga por Similaridade de Entrada. . . . . . . . . . . . . . . . . . . . . . . . . . 106

A.31 Velocidade média de cada corredor detectada pelos tipos de eventos da categoria corr ao longo do horário do dia de coleta dos dados. . . . . . . . . . . . . . . . . . . 107

A.32 Velocidade média de cada corredor detectada pelos tipos de eventos da categoria corr ao longo do horário do dia de coleta dos dados. . . . . . . . . . . . . . . . . . 108 


\section{Lista de Tabelas}

7.1 Tempo de uso de recursos em minutos de cada execução do experimento. . . . . . . . 62

7.2 Número de eventos detectados em cada execução do experimento. . . . . . . . . . . . . 63

7.3 Número de eventos detectados por categoria de tipo de evento em cada execução do experimento com o algoritmo de balanceamento por Uso de Estado. . . . . . . . . . . 63

7.4 Número de eventos detectados por categoria de tipo de evento em cada execução do experimento com o algoritmo de balanceamento por Similaridade de Entrada. . . . . 64 


\section{Capítulo 1}

\section{Introdução}

Ao longo dos últimos anos, o conceito de Cidades Inteligentes vem ganhando popularidade, sendo promovido com os propósitos de aumentar a sustentabilidade e melhorar a qualidade de vida para os residentes de centros urbanos (Kon e Santana, 2016). Cidades Inteligentes podem ser definidas como cidades que usam uma infraestrutura de tecnologia da informação para otimizar o uso de recursos municipais, com o objetivo de aumentar a qualidade de vida de seus cidadãos (Caragliu et al., 2011).

Os investimentos feitos em infraestrutura física estão usualmente associados à implementação de tecnologias da informação e comunicação nos diferentes setores de uma cidade (transporte, saúde, educação, comércio, etc.), feita por meio de dispositivos eletrônicos, como sensores e atuadores. O uso desses sensores gera uma grande quantidade de dados a todo momento, com os quais é possível melhorar a gestão da cidade, aprimorar os serviços públicos e privados ou oferecer novos serviços. Exemplo disso são os sensores da frota de ônibus do sistema de transporte público da cidade de São Paulo, SP. Eles geram cerca de dez mil registros de dados por minuto sobre posições de ônibus. Esses dados são coletados pela São Paulo Transporte S/A (SPTrans), empresa que administra o transporte público por ônibus da cidade, e disponibilizados publicamente por meio do site Olhovivo ${ }^{1}$, permitindo que os cidadãos melhor planejem suas viagens.

Os dados dos diferentes serviços de uma cidade podem ter um volume massivo, ser coletados em tempo real e ter uma grande variedade de informações, além de distintas representações dessas informações, de forma que são classificados como Big Data pela comunidade científica (Ward e Barker, 2013). É possível realizar o processamento desses dados usando ferramentas que trabalham com dados de forma discreta, ou seja, que processam os dados em lotes após coletá-los e armazená-los. Esse tipo de abordagem de processamento já foi bastante estudado e documentado na literatura da área (Dean e Ghemawat, 2010; Moniruzzaman e Hossain, 2013; Shahrivari, 2014). Mas em cenários nos quais o valor que a informação tem é dado em função do tempo, o atraso que esse tipo de abordagem gera pode causar perda de relevância da informação derivada, a depender da quantidade de processamento e do volume de dados que está sendo processado.

Um acidente de trânsito que ocorreu momentos atrás, um princípio de incêndio ou um assalto em andamento são algumas das situações para as quais existem mais formas de tratamento quanto mais rapidamente forem identificadas. Essas situações podem ser descobertas utilizando dados de diferentes fontes, tanto de sensores como de pessoas. Nesses casos, são necessárias ferramentas que processem os dados de toda a cidade em tempo real, idealmente com mínima latência e máxima vazão. Para conseguir detectar e reagir a situações em tempo real, é necessário que se saiba quais padrões as medições mostrarão quando as situações de interesse ocorrerem e quais ações devem ser realizadas em resposta. Com o suporte de especialistas de diferentes setores da cidade, é possível reconhecê-las e modelar as respostas apropriadas para cada uma delas.

Uma das técnicas mais adequadas para detectar essas situações é o Processamento de Eventos Complexos (CEP - Complex Event Processing), visto que ferramentas de CEP fornecem modos de declarar eventos que são definidos a partir da ocorrência de um padrão de chegada de dados. O CEP considera cada dado coletado como um evento e utiliza operadores sobre esses eventos, como

\footnotetext{
${ }^{1}$ http://olhovivo.sptrans.com.br
} 
filtros e detecção de padrões, para disparar a detecção de outros eventos (Etzion e Niblett, 2010). O CEP pode ser utilizado para modelar a deteç̧ão de situações de interesse a partir de quaisquer fluxos de dados contínuos.

Sistemas de processamento de dados em tempo real para Cidades Inteligentes precisam ser escaláveis, para lidar com a grande variação do volume de dados, e devem ser tolerantes a falhas no ambiente de execução, para se manterem disponíveis. O uso de plataformas de nuvem facilita o cumprimento desses requisitos, pois os recursos em uma plataforma podem ser requisitados automaticamente caso a carga de processamento aumente e a manutenção física do ambiente de execução é de responsabilidade do provedor de nuvem. Sistemas que usam infraestrutura de execução em nuvem e cumprem esses requisitos, auto-escalabilidade e tolerância a falhas, são caracterizados como sistemas nativos de nuvem (Garrison e Nova, 2017).

As solução de software livre de CEP disponíveis na atualidade ${ }^{2}$ não oferecem suporte nativo para a execução em ambientes de nuvem, ou mesmo distribuídos. Mas há muita pesquisa na área de distribuição de processamento de eventos e, em particular, de métodos de balanceamento da carga de trabalho nos nós do sistema. Trabalhos como os de Isoyama et al. (2012), Martins et al. (2014) e Balkesen et al. (2013) propuseram diferentes tipos de abordagens para tratar esse problema. As principais técnicas já apresentadas se resumem a reunir num mesmo nó os processamentos de tipos de evento com dependências similares ou separá-los com base no uso de recursos que cada processamento de tipo de evento usa. Em todos esses trabalhos, foram usadas arquiteturas orquestradas, em que uma parte central executa todas as ações principais do sistema. Esse estilo organizacional pode levar a um sistema no qual a ocorrência de uma falha no nó central afeta todo o sistema (Newman, 2015).

\subsection{Objetivos}

O objetivo principal deste trabalho é a criação de uma arquitetura de Processamento de Eventos Complexos nativa de nuvem para o processamento de dados de cidades inteligentes, que satisfaz os requisitos de auto-escalabilidade e tolerância a falhas no ambiente de execução.

A solução, chamada de CEP Handler, foi desenhada seguindo o estilo arquitetural de microsserviços, no qual o sistema é construído como um conjunto de serviços pequenos e autônomos, que podem ser implantados e escalados de forma independente. Na arquitetura CEP Handler, o processamento dos eventos é dividido entre múltiplas instâncias de um microsserviço de processamento de eventos, cada uma alocada em um nó diferente do sistema. Os microsserviços se coordenam para a realização das funções e a distribuição do processamento de eventos nos nós do sistema, ou seja, a coordenação se dá por meio de coreografia. Isso resulta em maior disponibilidade (que a provida por arquiteturas orquestradas) em caso de falhas pontuais, pois uma falha em uma única instância não afeta a deteç̧ão de eventos nas outras.

O sistema atinge a auto-escalabilidade a partir do monitoramento constante do uso de recursos por cada instância. O sistema também pode requisitar, para o serviço de gerenciamento dinâmico de recursos, a criação de novos nós de processamento durante altas cargas de entrada ou a remoção de nós para cargas baixas de entrada. Isso significa que é utilizado um modelo de escalabilidade horizontal.

Com base em trabalhos relacionados, foram criados dois algoritmos para o balanceamento de carga entre as instâncias do microsserviço de processamento de eventos. Um dos algoritmos seleciona os tipos de evento a serem realocados de uma instância para outra de acordo com o tempo necessário para reconstruir seu estado de detecção (isto é, o conjunto de dados necessários para o cálculo dos atributos de cada evento de saída). O outro algoritmo seleciona os tipos de evento de acordo com a similaridade dos seus tipos de evento de entrada, procurando agrupar numa mesma instância o processamento de tipos de evento que possuem os mesmos tipos de entrada, minimizando, assim, a transmissão de eventos para os nós de processamento.

\footnotetext{
${ }^{2}$ http://esper.espertech.com/, http://www.drools.org/, https://docs.wso2.com/display/CEP420
} 
Um protótipo da arquitetura CEP Handler foi implementado, utilizando somente ferramentas de software livre, integrado à plataforma de cidades inteligentes InterSCity (Esposte et al., 2019), do Instituto Nacional de Ciência e Tecnologia (INCT) da Internet do Futuro para Cidades Inteligentes ${ }^{3}$. O INCT da Internet do Futuro para Cidades Inteligentes é financiado por CNPq (proc. 465446/20140), Coordenação de Aperfeiçoamento de Pessoal de Nível Superior - Brasil (CAPES) - Código de Financiamento 001 e FAPESP (procs. 14/50937-1 e 15/24485-9).

Para avaliar o desempenho do sistema, um cenário experimental de cidades inteligentes foi criado, a partir de dados reais de posições de ônibus da frota do sistema de transporte público da cidade de São Paulo, SP. Nos experimentos, o fluxo de dados simulado a partir de frequências reais variou de seis a dez mil eventos por minuto. O propósito foi verificar se o sistema realmente atingia a auto-escalabilidade, requisitando e integrando mais nós de processamento de acordo com o aumento de dados entrando no sistema continuamente. A avaliação foi realizada separadamente para os dois algoritmos de balanceamento de carga, com o intuito de verificar o impacto do uso de cada um deles. Quatro métricas foram analisadas: latência, vazão, número total de eventos detectados e tempo de uso dos recursos computacionais do ambiente de execução.

Os resultados mostraram que o sistema escala automaticamente, aumentando o número de instâncias conforme sua carga de entrada aumenta. O terceiro quartil das latências medidas durante todas as execuções ficou sempre abaixo de cem milissegundos, o que satisfaz os requisitos de processamento em tempo real do cenário considerado. O número de eventos detectados sofreu uma pequena varição entre uma execução e outra, que pode ser atribuída à variação de latência. Não foi observada diferença significativa na média do tempo de uso de recursos computacionais dos dois algoritmos de balanceamento de carga implementados.

\subsection{Contribuições}

As principais contribuições deste trabalho são as seguintes:

1. Criação de uma arquitetura de microsserviços coreografada para a distribuição de processamento de eventos complexos nativa de nuvem, ou seja, que possui um mecanismo de tolerância a falhas no ambiente de execução e é auto-escalável horizontalmente.

2. Implementação de um protótipo, com a arquitetura proposta, para o processamento de dados em tempo real por CEP com base em ferramentas de software livre. Esse sistema foi desenvolvido para funcionar juntamente com a plataforma de software livre para cidades inteligentes InterSCity.

3. Desenho e execução de um experimento relacionado a cidades inteligentes, utilizando a simulação de dados reais do transporte público por ônibus na cidade de São Paulo, para analisar o desempenho do protótipo num cenário de variação da carga de dados de entrada por meio das seguintes métricas: capacidade de auto-escalabilidade, tempo de uso de recursos computacionais, latência e vazão do sistema.

4. Uma publicação sobre o presente trabalho em 2018 em The 1st Workshop on the Distributed Smart City (WDSC'2018) do 37th IEEE International Symposium on Reliable Distributed Systems, intitulada: A Microservices Architecture for Distributed Complex Event Processing in Smart Cities (Scattone e Braghetto, 2018).

5. Uma publicação sobre o presente trabalho em 2020 na Escola Regional de Alto Desempenho São Paulo, intitulada: Processamento Distribuído de Eventos Complexos Aplicado à Detecção de Eventos no Trânsito em Tempo Real (Scattone e Braghetto, 2020).

\footnotetext{
${ }^{3}$ https://interscity.org/
} 


\subsection{Organização do Trabalho}

O Capítulo 2 introduz os principais conceitos relacionados a Processamento de Eventos Complexos, arquitetura de microsserviços e técnicas de distribuição de processamento com estado. O Capítulo 3 apresenta trabalhos que estudam a distribuição de CEP a partir de diferentes técnicas, aborda a execução de CEP em plataformas de nuvem e compara as conclusões sobre as pesquisas nessas áreas. No Capítulo 4, descreve-se com detalhes a arquitetura de microsserviços criada neste trabalho. Um protótipo de implementação da arquitetura e as ferramentas utilizadas nele são apresentados em 5. O desenho do experimento utilizado para avaliar o sistema é apresentado no Capítulo 6 e os resultados do experimento em si são apresentados no Capítulo 7. Finalmente, o Capítulo 8 discute os resultados e possíveis contribuições futuras. 


\section{Capítulo 2}

\section{Conceitos}

Este capítulo apresenta as principais definições e fundamentos relacionados ao processamento de eventos complexos e às arquiteturas de distribuição desse tipo de processamento. Além disso, o capítulo introduz conceitos fundamentais das arquiteturas de microsserviços, abordando os seus diferentes estilos e tipos de escalabilidade, bem como técnicas de comunicação e organização de dados. Ao final, discute-se a relação entre microsserviços e contêineres e soluções de instanciação de contêineres em plataformas de nuvem.

\subsection{Processamento de Eventos Complexos}

O Processamento de Eventos Complexos (CEP, do inglês Complex Event Processing) foi primeiramente introduzido por Luckham (2001). É uma técnica para tratar dados vindos de várias fontes diferentes e extrair novas informações, em tempo real, das combinações dos diferentes dados. Existem três tipos de entidades principais relacionados a CEP:

Produtores de Eventos são responsáveis por introduzir novos eventos no sistema a partir do mundo exterior. Cada produtor de eventos pode estar associado a um sensor que envia dados em tempo real, a um aplicativo ou rede social que recebe eventos diretamente de pessoas ou a qualquer sistema que envie informações de forma contínua.

Consumidores de Eventos são responsáveis por receber eventos do sistema e repassar os dados sobre tais eventos para as partes interessadas no mundo exterior. Esses dados podem ser repassados na forma de notificações a usuários ou atuadores no mundo real. Consumidores e produtores de eventos não fazem parte do sistema de CEP em si, mas são abstrações para entidades externas que interagem com o sistema.

Processadores de Eventos (EPAs, do inglês Event Processing Agents) são as entidades que realmente compõem o sistema de CEP. Cada EPA é responsável por aplicar um ou mais operadores nos eventos recebidos e emitir novos eventos ou repassar eventos que foram filtrados. Quando vários EPAs são conectados, de forma que os eventos resultantes do processamento de um EPA são enviados diretamente a outro, forma-se uma Rede de Processamento de Eventos (EPN, do inglês Event Processing Network).

É essencial destacar a diferença entre tipo de evento e evento. Todo evento que entra no sistema de CEP pertence a um tipo específico, que possui uma estrutura estática bem definida dentro do sistema. Um evento que entra no sistema é apenas uma instância de um tipo de evento. Qualquer outro evento que possua a mesma estrutura é classificado como sendo do mesmo tipo de evento. Por exemplo, um sensor captando dados de temperatura e pressão envia as medidas para o sistema. Cada medida é um evento distinto, enquanto que o formato e a estrutura dos dados enviados fazem parte do mesmo tipo de evento. 


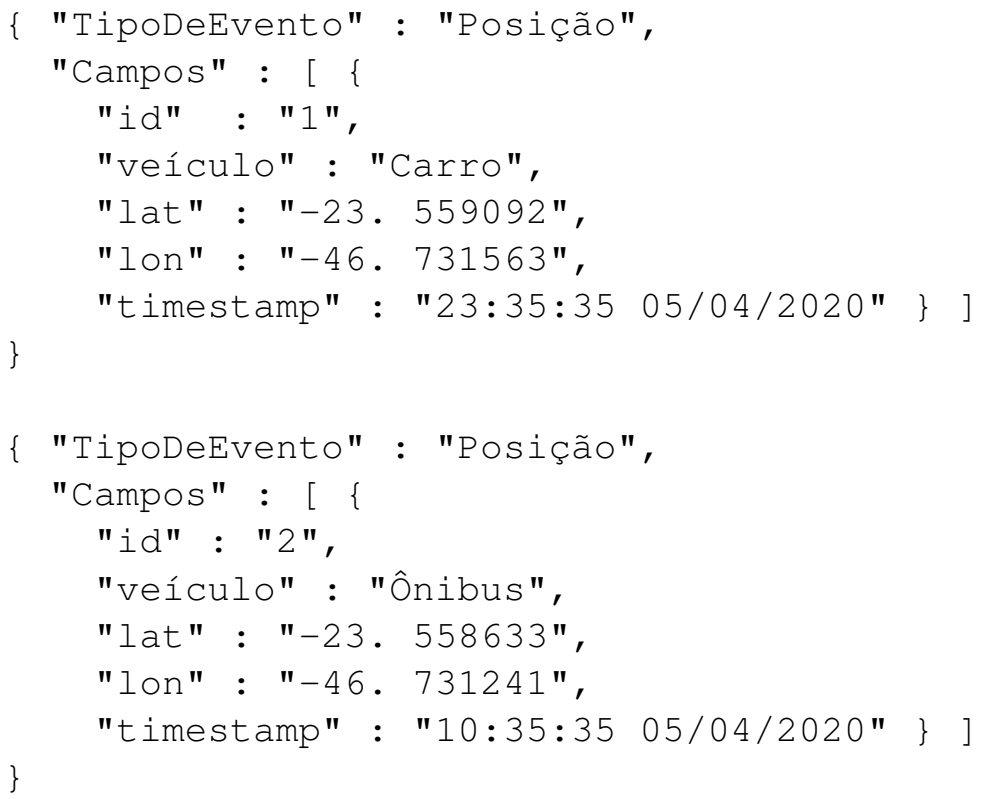

Exemplo 1: Eventos de posição - latitude e longitude - de veículos e timestamp da coleta da informação.

O Exemplo 1 apresenta um exemplo de dois eventos de um mesmo tipo (Posição) que será usado a seguir para ilustrar o funcionamento dos operadores, não representando nenhuma implementação específica de CEP em uso.

\subsubsection{Operadores de CEP}

Os principais operadores que um EPA pode implementar são: Filtragem, Projeção, Tradução, Enriquecimento, Agregação, Composição, Divisão e Detecção de Padrão (Etzion e Niblett, 2010). Normalmente, eles são separados em três grupos - Filtragem, Deteç̧ão de Padrão e Transformação - sendo que este último grupo contém todos os outros operadores. Esta distinção é feita pelo fato de a aplicação de um filtro não precisar alterar a definição do tipo de evento, enquanto que a transformação e a deteç̧ão de padrões inevitavelmente necessitam de uma nova definição. A seguir, as operações são explicadas brevemente e têm seu uso ilustrado com base no Exemplo 1.

- Filtragem: um EPA pode filtrar eventos baseando-se no valor de seus atributos. Por exemplo, ao aplicar um filtro que seleciona apenas eventos que ocorreram após às 11 horas da noite do dia 5 de abril de 2020 no Exemplo 1, somente o evento cujo campo veículo contém o valor Carro estará no resultado, como mostrado no Exemplo 2. Um evento que passa por uma filtragem não tem sua estrutura modificada, então o evento de saída pode ser considerado do mesmo tipo que o evento de entrada.

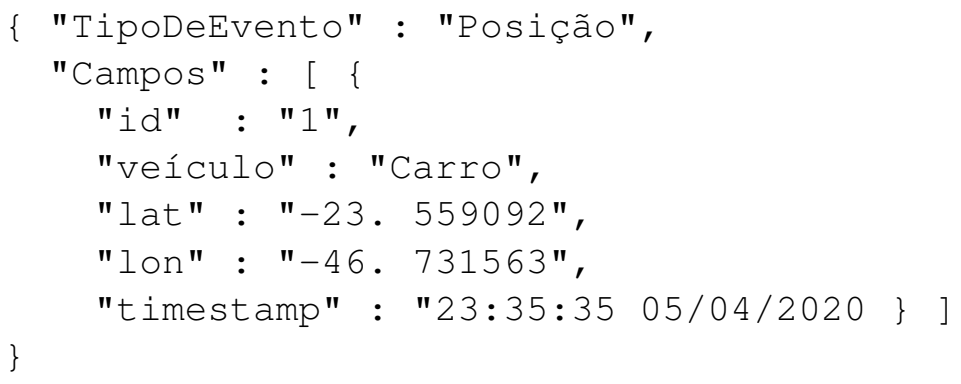

Exemplo 2: Uma filtragem sobre os eventos do Exemplo 1. 
- Projeção: ao fazer a projeção de eventos, apenas alguns dos atributos do evento original são mantidos, de forma que o tipo do evento de saída é diferente. Por exemplo, no processamento dos eventos do Exemplo 1, caso os únicos atributos de interesse sejam a posição geográfica e temporal dos veículos, uma projeção para eliminar os outros atributos teria como resultado os eventos mostrados no Exemplo 3.

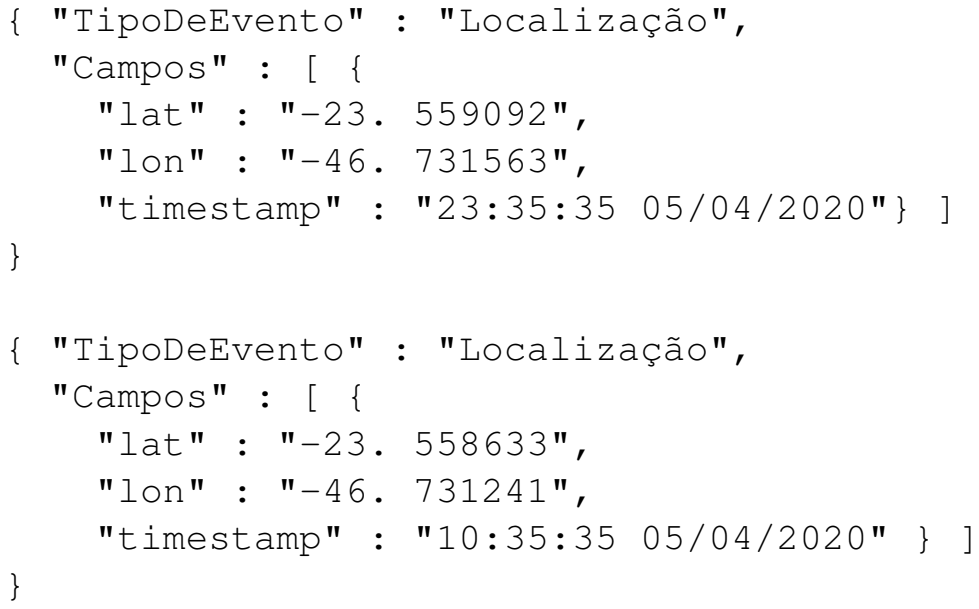

Exemplo 3: Uma projeção sobre os eventos do Exemplo 1.

- Tradução: a tradução pode manter atributos do evento original e também pode adicionar novos atributos, além de modificar os valores de atributos já definidos. No Exemplo 1, é possível usar uma tradução para alterar o valor de timestamp para quantos minutos se passaram no dia da detecção do evento, retirando a latitude e a longitude. O Exemplo 4 mostra essa tradução. A tradução só pode utilizar valores já presentes nos atributos de cada evento para modificá-lo.

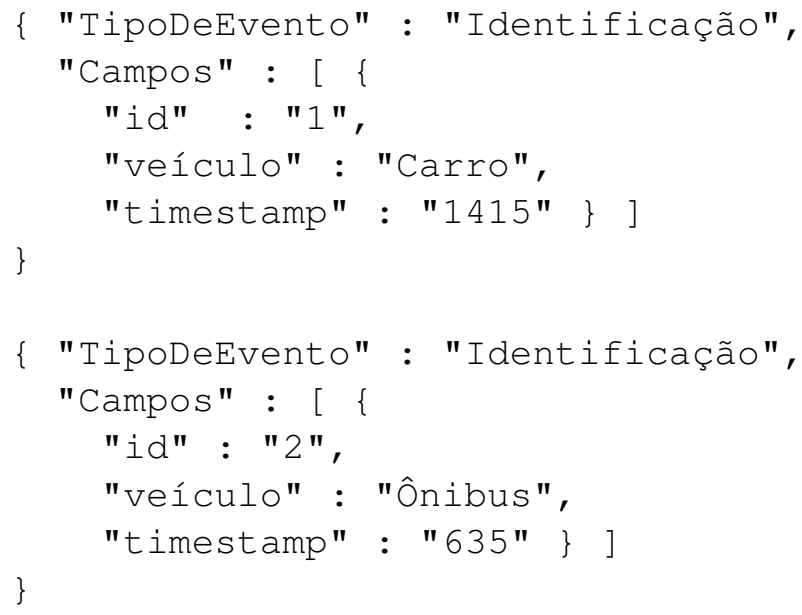

Exemplo 4: Uma tradução sobre os eventos do Exemplo 1.

- Enriquecimento: o operador de enriquecimento pode retirar atributos do evento, adicionar novos atributos ou modificar os valores de atributos existentes, assim como a tradução. A diferença entre os dois é o fato de que o enriquecimento pode consultar um estado externo à aplicação para adquirir informações e utilizá-las no processamento. Por exemplo, ao adicionar nos eventos do Exemplo 1 um campo para indicar o bairro onde o veículo está, os eventos estão sendo enriquecidos, pois é necessário consultar a latitude e a longitude de cada novo 
evento em uma aplicação externa que retorna o bairro da localização. O resultado é mostrado no Exemplo 5.

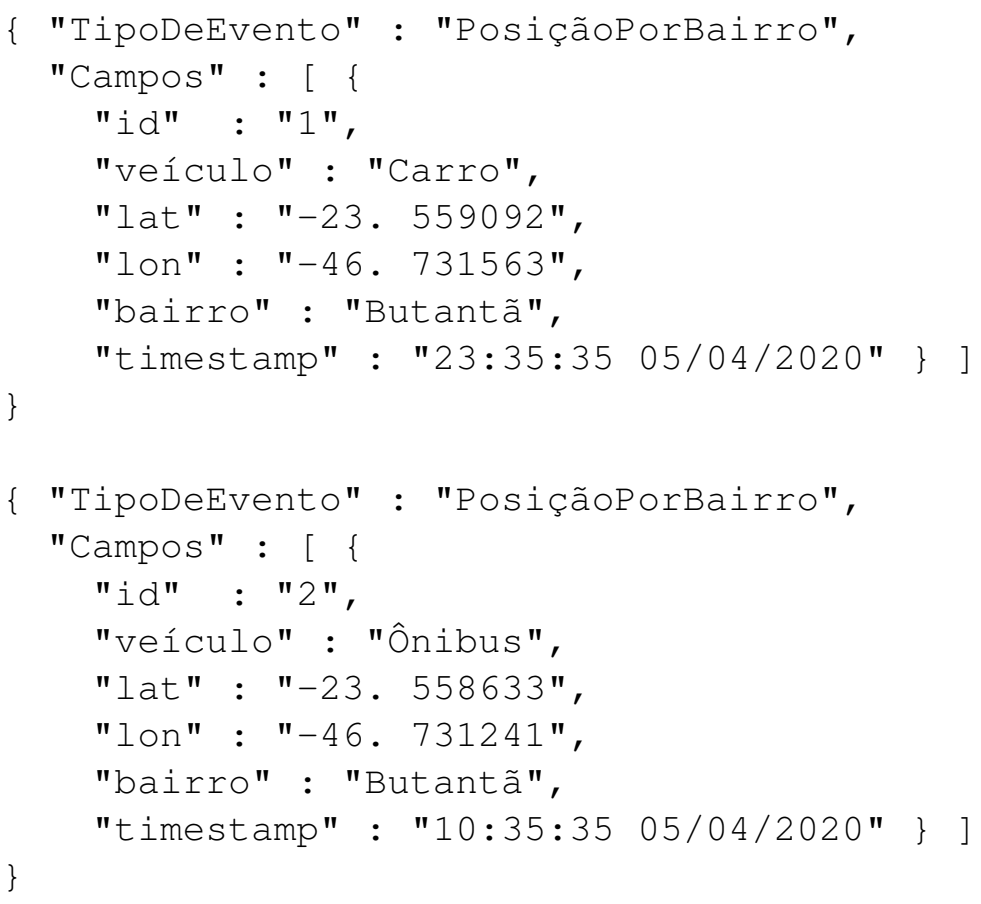

Exemplo 5: Um enriquecimento dos eventos do Exemplo 1.

- Divisão: na divisão, a entrada de um único evento gera a criação de um conjunto de eventos, sendo que os eventos de saída podem ser iguais ao original ou uma transformação dele. Por exemplo, a deteç̧ão de um evento do tipo Posição perto do IME-USP tarde da noite pode gerar dois novos eventos por divisão, um de veículo próximo e um de alerta de número de veículos circulando à noite, como mostrado no Exemplo 6.

A divisão pode ser estática, de forma que a entrada de um evento sempre gera o mesmo número de eventos na saída, ou iterativa, de forma que o número de eventos gerados pela divisão é definido a partir dos atributos do evento de entrada a cada nova chegada de evento.

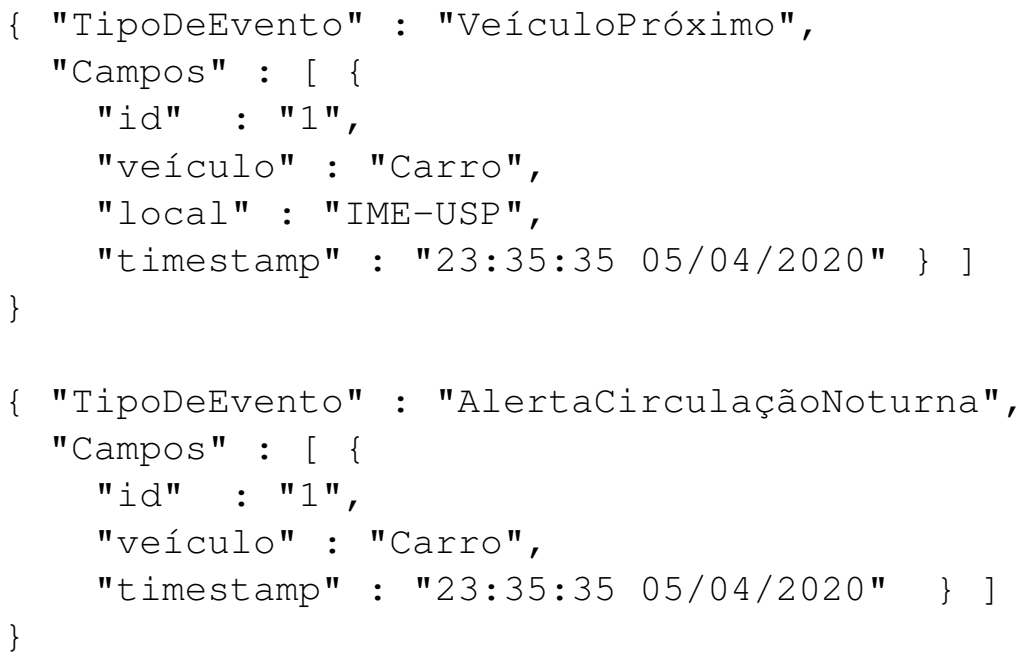

Exemplo 6: Divisão sobre os eventos do Exemplo 1.

- Agregação: a agregação define que um cálculo seja feito a partir dos valores numéricos de 


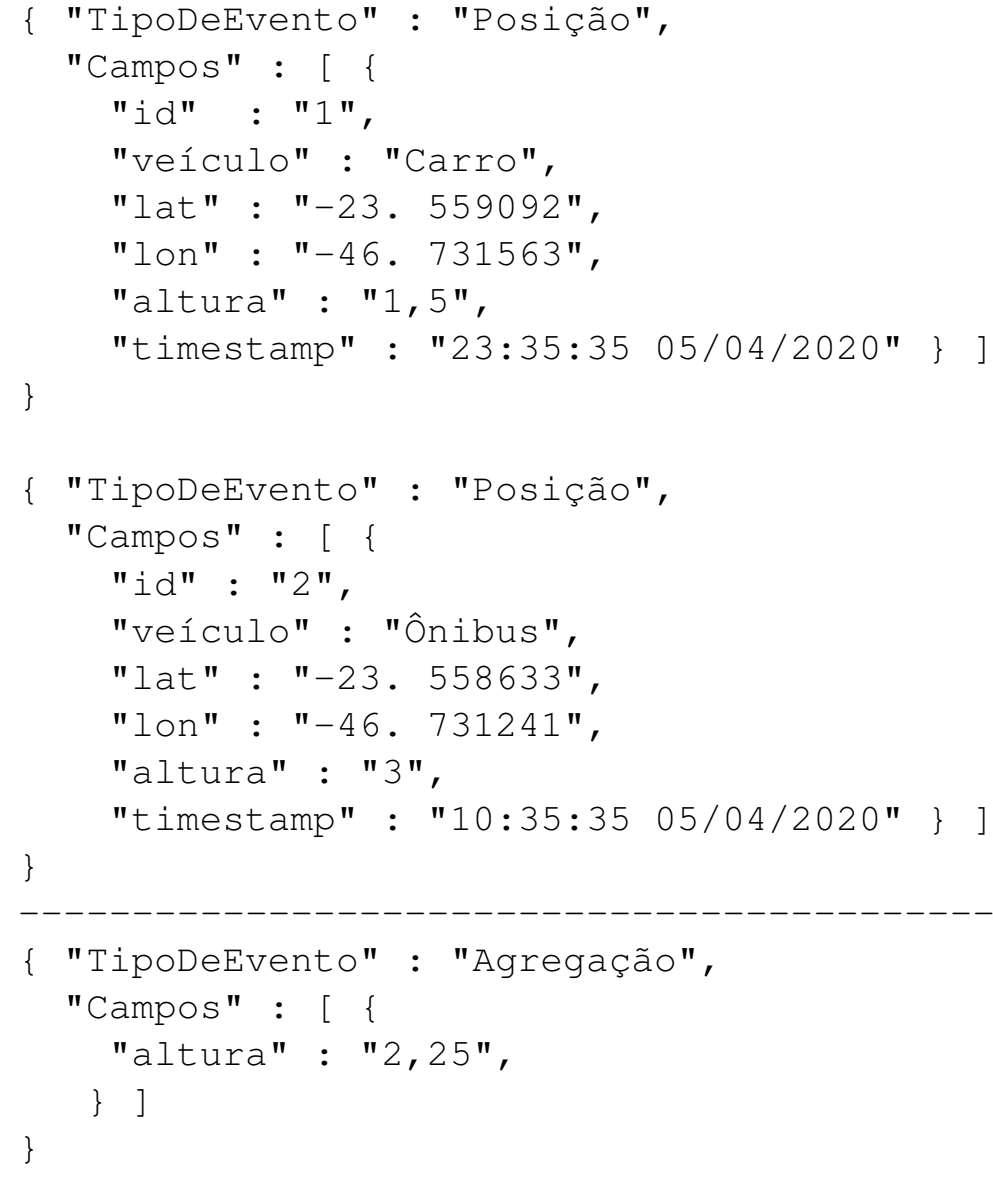

Exemplo 7: Agregação de eventos (cálculo da média das alturas).

um dado atributo em vários eventos do mesmo tipo, e o resultado é convertido em um novo evento. As agregações mais comuns são as operações: first (primeiro valor), last (último valor), any (qualquer valor), min (menor valor), max (maior valor), sum (soma dos valores), avg (média dos valores), stdev (desvio padrão dos valores) e distinct (valores sem repetição). Cada agregação é definida juntamente com o contexto que será considerado para o agrupamento dos eventos. Considerando o Exemplo 7, se a agregação avg for utilizada no campo altura e os eventos forem agrupados por dia, será calculada a altura média entre todos eventos detectados naquele dia. É possível agregar eventos em contextos temporais e espaciais, como será explicado na Seção 2.1.2.

- Composição: um EPA de composição junta eventos vindos de duas fontes diferentes, verifica se o critério de junção se aplica a eles e cria eventos derivados a partir disso. A principal diferença entre a composição e a agregação é que a primeira é feita com eventos de tipos diferentes e a segunda, com eventos do mesmo tipo. Como exemplo, imagine que o sistema efetuou o enriquecimento dos eventos do Exemplo 1 introduzindo o atributo de bairro da localização. Agora, considere que um Produtor de Eventos envia para o sistema de CEP o evento no Exemplo 8, notificando que, no horário especificado, foi detectada chuva no bairro do Butantã, que terminou ao meio-dia e começou aproximadamente três horas antes. Um operador de composição pode receber os eventos de Chuva e de Posição e verificar se algum veículo ficou na chuva naquele dia. No caso, é possível verificar que o Ônibus tomou chuva, pois estava lá naquele dia e horário, mas o Carro não, pois o evento Chuva mostra que ela já havia parado quando o Carro foi detectado.

Operadores de composição precisam especificar algumas políticas de tratamento de eventos de entrada: 


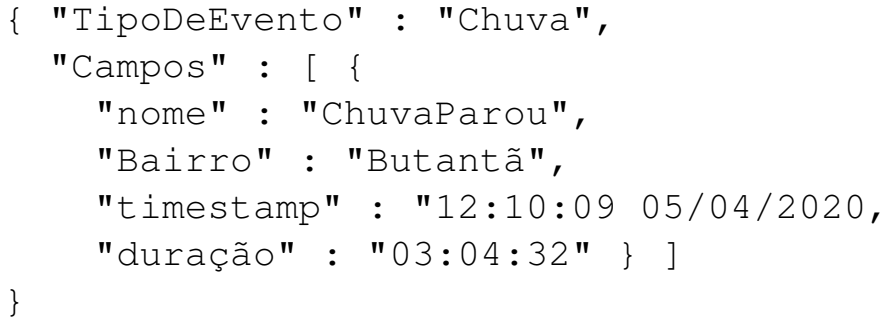

Exemplo 8: Evento de deteç̧ão de chuva.

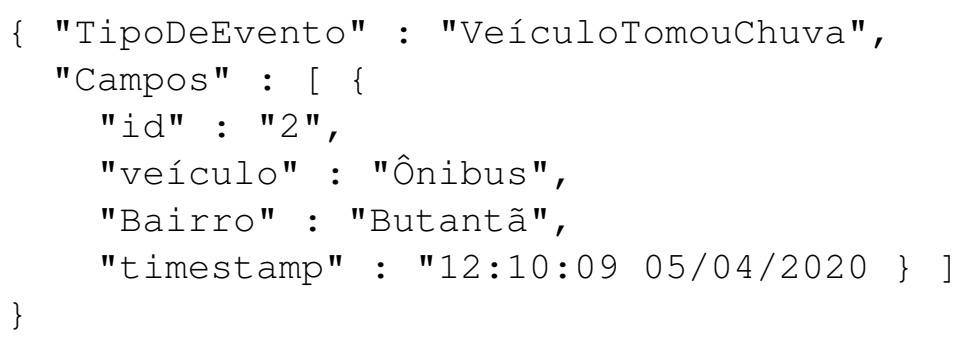

Exemplo 9: Composição dos eventos dos exemplos 1 e 8.

- Política de buffer: define quantos eventos de cada tipo devem ser armazenados até que sejam pareados com eventos de outros tipos. Usando o Exemplo 8, poderia ser necessário esperar que três eventos de posição mostrassem o veículo dentro da região atingida.

- Política de evento não pareado: define o que o sistema deve fazer caso um evento não se pareie com nenhum outro para fazer uma composição. Citando o Exemplo 8, se a composição fosse definida para ocorrer somente com veículos automotores e um evento de Posição de carroça fosse enviado, esta política seria utilizada.

- Condição de composição: define como os eventos devem ser pareados, ou seja, qual critério deve ser usado para identificar quais pares ou conjuntos de eventos formam uma composição. No caso do Exemplo 8, a condição é que os timestamps dos dois eventos coincidam e que o veículo seja automotivo.

- Detecção de Padrão: é o principal operador de CEP. Ele diferencia CEP de outras ferramentas de processamento de dados em tempo real. Um EPA com esta operação detecta se os eventos (possivelmente de tipos diferentes) seguiram um padrão ao passarem no sistema. Um detector de padrão de eventos tem seis propriedades que devem ser definidas para que ele possa atuar de forma correta:

1. Lista de tipos de evento relevantes: lista quais tipos de eventos precisam ser enviados para o EPA para que o padrão seja detectado. Por exemplo, caso o único tipo de evento relevante fosse o do tipo Posição (Exemplo 1), eventos do tipo Chuva (Exemplo 8) não entrariam no processamento do padrão.

2. Eventos participantes: são um conjunto de eventos de entrada reconhecidos pelo padrão de acordo com o valor dos campos. Por exemplo, se sete eventos forem introduzidos no sistema, mas apenas os cinco primeiros satisfizerem o padrão, somente estes cinco farão parte dos eventos participantes.

3. Conjunto de reconhecimento do padrão: é um subconjunto dos eventos participantes que são enviados como resposta quando o padrão é detectado.

4. Políticas do padrão: determinam quais ações tomar caso vários subconjuntos de eventos de entrada satisfaçam o padrão. 
5. Tipo de padrão: define que comportamento dos eventos de entrada se deseja detectar. São divididos em dois tipos principais, Básicos e Dimensionais, e cada um deles tem vários subtipos.

- Padrões Básicos: são os que não dependem da ordem dos eventos de entrada. Podem ser de quatro subtipos:

* Padrões de Operadores Lógicos (all, any, absence) verificam se existem eventos de cada tipo da lista de tipos de eventos relevantes no conjunto de Eventos Participantes. All verifica se há um de cada tipo, any verifica se há eventos de pelo menos um tipo e absence verifica se não há nenhum evento dos tipos da lista. O conjunto de reconhecimento é composto por todos os eventos que respeitam o padrão, ou seja, todos os eventos em all, apenas os eventos que foram detectados em any e nenhum evento em absence. Utilizando os Exemplos 1 e 8, caso a lista de eventos relevantes contivesse os tipos de eventos dos dois exemplos, mas os eventos relevantes fossem somente os do Exemplo 8, poderia se detecar um evento de CarroSeco caso utilizasse o operador absence num fluxo que recebesse eventos dos dois tipos

* Padrões de Limiar, como valor máximo, valor mínimo, valor médio e contagem são padrões que são satisfeitos quando todo o conjunto de eventos participantes não ultrapassa o limiar definido. Neste caso, o conjunto inteiro de eventos participantes é o mesmo de reconhecimento do padrão. Caso fosse definido um tipo de evento com este tipo de padrão que recebesse como entrada eventos do Exemplo 7 , ele poderia detectar se em todo o conjunto nenhum veículo ultrapassou 3 metros de altura.

* Padrões de Subconjunto selecionam um subconjunto dos eventos participantes, normalmente aqueles com os maiores ou menores valores para um atributo específico, e somente estes eventos compõem o conjunto de reconhecimento do padrão. Esse tipo de seleção é conhecida como top- $k$. Usando o Exemplo 7, poderia-se detectar o subconjunto de veículos com os maiores valores no campo altura.

* Padrões Modais detectam se todos os eventos participantes respeitam uma dada regra. Se o padrão modal for do tipo always, todo o conjunto de eventos participantes deve respeitar a regra. Se for sometimes, só alguns eventos participantes devem respeitá-la. Sempre que o padrão é detectado, todo o conjunto de eventos participantes se torna o conjunto de reconhecimento do padrão. No caso do Exemplo 1, este padrão poderia detectar se todos eventos entrando no sistema são de veículos automotivos.

- Padrões Dimensionais são caracterizados por se relacionarem com a dimensão temporal e/ou espacial, quando os eventos tem esses atributos. Assim como os padrões básicos, podem ser divididos em quatro subtipos:

* Padrões de Ordem Temporal são definidos de forma que o conjunto de reconhecimento do padrão seja composto seguindo a ordem temporal dos timestamps dos eventos, com os primeiros $n$ eventos, os últimos $n$ eventos ou todos os eventos participantes em sequência temporal. Com base no Exemplo 1, poderia-se definir um tipo de evento que gera eventos a partir dos eventos de Posição que tem os timestamps mais próximos do horário atual.

* Padrões de Tendência ocorrem quando eventos participantes chegam em uma ordem temporal e um atributo apresenta uma dada característica, como se manter estável ou aumentar ou diminuir de valor ao longo do tempo. Um possível uso deste padrão seria detectar se eventos de Posição do Exemplo 1 chegam no mesmo horário, no mesmo local, em vários dias distintos.

* Padrões Espaciais são um subtipo de padrão que lida com o comportamento 
da posição dos eventos ao longo do tempo. Como exemplo deste padrão, podese citar a detecção de eventos com a maior distância, menor distância ou a distância média relativa a um ponto fixo ou a um outro evento. Se dois eventos de Posição Ônibus do Exemplo 1 forem detectados com os campos latitude e longitude sempre próximos, poderia ser gerado um evento de Agrupamento de Onibus com este padrão.

* Padrões Espaço-Temporais, assim como os Padrões Espaciais, lidam com a posição dos eventos em relação ao tempo, porém com foco na velocidade do movimento ao invés da posição relativa. Poderiam detectar se um Veículo do Exemplo 1 está parado, se movendo em um sentido fixo ou em direção a outro produtor de eventos, por exemplo.

6. Parâmetros do padrão: consistem nos demais parâmetros que o padrão precisa ter para ser detectado.

\subsubsection{Contexto em CEP}

Em alguns casos, a deteç̧ão de eventos é feita de acordo com o contexto no qual o evento está sendo avaliado. Processar os eventos por contexto ajuda a avaliar as informações que cada evento traz ao sistema ao ser inserido. Contexto é definido em CEP como a característica que diferencia eventos do mesmo tipo (Etzion e Niblett, 2010). Tecnicamente, significa separar o eventos de entrada de um mesmo tipo em partições que possuem atributos similares. A partir do Exemplo 1, é possível usar contexto para separar os eventos do tipo Posição utilizando o atributo veículo como característica de separação, onde cada valor distinto de veículo leva à criação de uma partição de contexto diferente, na qual todos os eventos com o mesmo valor para esse atributo são inseridos. Neste caso, existem dois possíveis valores de veículo (Carro e Ônibus), o que leva à criação de uma partição apenas para eventos Posição de carros e outra apenas para eventos Posição de ônibus. Qualquer operador que use contexto é aplicado a cada partição separadamente, de forma que eventos de entrada em uma partição não influenciam o processamento em outras partições

Alguns operadores, como agregação e composição, lidam com mais de um evento de entrada por detecção. Dessa forma, eles necessariamente usam um contexto para separar os eventos de entrada que serão considerados para realizar cada detecção. Cada partição usa um ou mais atributos do evento como dimensões de separação, onde os possíveis valores podem ser divididos em intervalos. Cada evento também pode estar contido em diferentes contextos ao mesmo tempo. Um contexto é classificado de acordo com as dimensões que utiliza para criar as partições, podendo ser:

- Temporal: cria partições para os eventos em intervalos de acordo com o timestamp do evento. É usado principalmente em agregações e composições. O contexto temporal pode ser empregado de quatro maneiras:

- Intervalo fixo: utiliza uma janela temporal fixa para a partição (por exemplo, de 23:50:00 até 23:54:59) para definir se o evento de entrada será inserido na partição ou não. Neste caso, é possível criar outras partições para intervalos de tempo no futuro, como de 23:55:00 até 23:59:59, porém sem a sobreposição de janelas temporais.

- Intervalo de eventos: similar ao intervalo fixo, mas cada partição é criada a partir da entrada de um evento de um tipo específico e terminada a partir do recebimento de um outro evento de tipo específico ou após um certo período de tempo, similar a uma sessão temporal. Um exemplo possível seria criar uma agregação com a criação de uma partição para cada evento de entrada do tipo Chuva, a qual agregaria toda a duração presente nos eventos até 12 horas depois da chegada do evento inicial, gerando ao final um evento com o nível médio de precipitação durante a sessão.

- Intervalo fixo deslizante: nesse caso, assim como no intervalo fixo, as janelas de deteç̧ão tem uma duração predeterminada, porém são iniciadas periodicamente. Essas 
janelas só são sobrepostas se o intervalo de abertura de uma nova janela $y$ for menor que o intervalo de duração da janela $x$.

- Intervalo de eventos deslizante: funcionam de forma similar ao intervalo fixo deslizante, mas em vez de usar um intervalo de tempo y para cada nova janela temporal, cada nova janela de deteç̧ão é iniciada a partir da chegada de um número específico $n$ de eventos de um tipo. Como exemplo, a cada 3 eventos de Posição, é iniciada uma nova janela que usa as posições e timestamps para calcular a velocidade média dos veículos. Nesse tipo de partição não há sobreposição de janelas.

- Espacial: cria partições para os eventos por intervalos geográficos, utilizando latitude e longitude para separar as partições. O contexto espacial pode ser utilizado de três maneiras:

- Local fixo: cada área geográfica constitui uma partição diferente, seja ela um país, um estado, uma cidade, um bairro, uma rua, uma casa ou qualquer outra área.

- Distância da entidade ao local: cada partição é definida por intervalos fixos de raios de distância entre um local específico e a posição especificada no evento.

- Distância do evento ao local: uma nova partição é iniciada a partir da entrada de um evento de um tipo específico. Eventos subsequentes só entram na partição caso suas localizações estejam suficientemente perto do evento inicial, ou seja, até uma certa distância máxima especificada.

- Orientado a segmentação: cria uma partição para cada valor que um ou mais atributos venham a receber. Normalmente, é utilizado quando o atributo tem um número pequeno de valores possíveis.

- Orientado a estado: neste caso, só existe uma única partição por contexto. Um valor de estado, que é externo aos eventos, é consultado a cada chegada de eventos novos e controla quais eventos serão inseridos na partição e quais não serão.

É possível criar contextos compostos, que dividem as partições a partir de duas ou mais dimensões. Considerando os eventos do Exemplo 1 novamente, caso um contexto fosse criado para separar as partições por hora de detecção e por bairro, cada um dos eventos seria processado por uma partição diferente, pois, mesmo com a posição no mesmo bairro, eles foram detectados em horas diferentes.

\subsubsection{Estado em CEP}

O uso de estado na detecção de eventos está fortemente ligado ao contexto escolhido para detectá-los. Com a exceção do operador de Enriquecimento, que utiliza um estado externo à ferramenta, a quantidade de memória usada para armazenar estado depende do número de partições do contexto escolhido, da quantidade de eventos por partição e da velocidade de chegada de eventos (Etzion e Niblett, 2010). Operadores mais simples, como Filtragem, Projeção, Divisão e Tradução, podem não usar estado algum para detectar eventos quando não separam a detecção por contextos específicos. Em contraste, os operadores Agregação, Composição e Detecção de Padrão devem inevitavelmente usar estado, pois sempre lidam com mais de um evento de entrada. Sejam os eventos de entrada do mesmo tipo, como em Agregação, ou de tipos diferentes, como em Composição, é preciso armazenar o estado do processamento, de forma que exista pelo menos uma partição de um contexto em que os eventos de entrada são agrupados.

\subsubsection{Principais Ferramentas}

Existem várias implementações de sistemas de processamento de eventos complexos disponíveis. As ferramentas mais populares na atualidade são: a WSO2 Siddhi CEP, a TIBCO, a Esper, a Red 


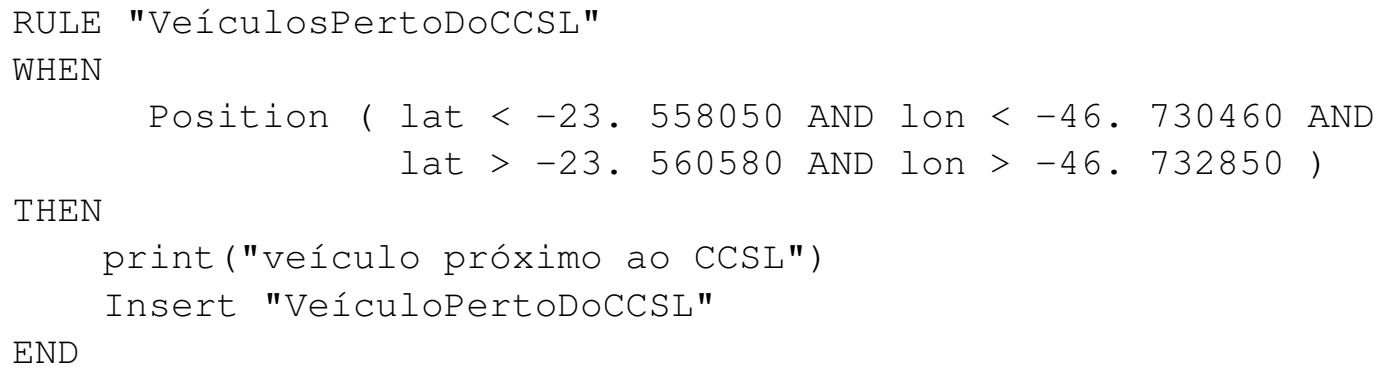

Exemplo 10: Exemplo de regra ECA definida na ferramenta Drools Fusion.

Hat Drools Fusion, a Informatica RulePoint e a Apache Flink ${ }^{1}$, sendo que a principal diferença entre elas é o tipo de linguagem utilizado para a definição dos eventos. Segundo Margara e Cugola (2011), as linguagens para CEP podem ser classificadas como linguagens orientadas a fluxos ou linguagens orientadas a regras.

Eventos definidos em linguagens orientadas a regras, também chamadas de regras EventoCondição-Ação (ECA), devem necessariamente conter três informações:

- Evento: nome da regra que define o evento.

- Condição: operadores que devem ser utilizados para detectar o evento.

- Ação: o que deve ser feito caso o evento seja detectado.

Em contraste, eventos definidos em linguagens orientadas a fluxos se baseiam fortemente na sintaxe da linguagem SQL (Structured Query Language), utilizada por sistemas gerenciadores de banco de dados relacionais, com a principal diferença de que, como os tipos de eventos ficam continuamente produzindo novos resultados, a saída de um tipo de evento pode ser usada diretamente como entrada em outro tipo de evento, o que não é comum em SQL.

O Exemplo 10 mostra como uma regra ECA pode ser definida na ferramenta Drools Fusion e o Exemplo 11 mostra uma definição de evento feita em Event Processing Language (EPL) pela ferramenta Esper. Ambos definem que, na ocorrência de um evento do tipo Posição, deve-se verificar se as coordenadas do evento se encontram perto do prédio do Centro de Competência em Software Livre (CCSL) do IME-USP. Assim, os eventos VeículosPertoDoCCSL só serão enviados caso essa condição seja satisfeita. Além da Esper, a Siddhi CEP e a TIBCO também utilizam linguagens orientadas a fluxos para a definição de eventos em seus respectivos sistemas. Já a Drools Fusion e a RulePoint utilizam linguagens orientadas a regras. A Apache Flink, em contraste com as outras abordagens apresentadas, implementa os operadores como funções diretamente nas linguagens de programação suportadas como cliente pelo programa (Java e Scala).

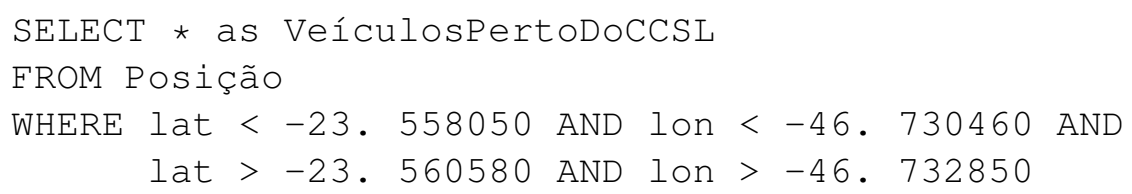

Exemplo 11: Definição de evento feita em Event Processing Language (EPL) na ferramenta Esper.

Processamento de Fluxos de Dados Contínuos (do termo inglês Stream Processing) é uma outra caracterização de ferramentas para processar dados em tempo real, mas que não têm o conceito de

\footnotetext{
${ }^{1}$ TIBCO : https://www.tibco.com/products/tibco-businessevents, Apache Flink https://flink.apache.org, Siddhi https://github.com/wso2/siddhi, Informatica: https://network.informatica.com/community/informatica-network/ products/complex_event_processing/, DroolsFusion : https://www.drools.org/, Esper : https://www.espertech. com/esper/
} 
eventos definido dentro delas. No processamento de fluxos de dados contínuos, os dados são processados de acordo com workflows especificados pelo usuário, onde é possível utilizar filtros, junções, agregações e outros tipos de operadores nos dados. Normalmente, as ferramentas de processamento de fluxos têm um grande foco em paralelizar o processamento e usam técnicas avançadas para fazer isso em grande escala. Mas, diferentemente das ferramentas de CEP, não costumam fornecer linguagens específicas para a definição dos dados a serem detectados (Margara e Cugola, 2011).

\subsubsection{Distribuição de Processamento das Ferramentas de Software Livre}

As ferramentas de CEP de software livre - Apache Flink, Drools Fusion, Esper e Siddhi possuem organização, arquitetura e origens distintas. A Apache Flink ${ }^{2}$ é uma ferramenta criada para processar fluxos de dados contínuos em tempo real em ambientes distribuídos. Sua capacidade de processar eventos vem do fato de a ferramenta disponibilizar o uso de todos os operadores de CEP. Porém, isso só pode ser feito utilizando os operadores de CEP como funções das linguagems de programação suportadas (Java e Scala), a ferramenta não disponibiliza nenhuma das linguagens mencionadas anteriormente para definição de eventos.

A ferramenta Drools Fusion ${ }^{3}$ foi imaginada inicialmente como um Sistema para Processamento de Regras de Negócio, que é utilizado por companhias para administrar o funcionamento correto de processos internos empresariais. O processamento de eventos complexos foi uma característica adicionada tempos depois, com o propósito de tornar a aplicação Drools em um sistema completo para modelagem de comportamento. A ferramenta em si é uma aplicação monolítica que não fornece meios para distribuir seu processamento nativamente.

A Esper ${ }^{4}$ é uma das ferramentas de CEP que oferecem linguagens orientadas a fluxo para a definição de eventos. A Esper é utilizada por meio de bibliotecas próprias. As funções oferecidas pelas bibliotecas são usadas na definição, deteç̧ão e resposta dos eventos detectados. A Esper tem uma versão com suporte a escalabilidade horizontal e balanceamento de carga, porém essa versão é de código fechado ${ }^{5}$.

O Siddhi CEP é o motor de processamento de eventos usado por duas ferramentas distintas: WSO2 Complex Event Processor e WSO2 Stream Processor (WSO2FAQ, 2020). O WSO2 Complex Event Processor ${ }^{6}$ utiliza oficialmente Apache Storm para distribuir o processamento de eventos. A Apache Storm ${ }^{7}$ é uma ferramenta de processamento de fluxos de dados contínuos que opera em ambientes distribuídos. Ela utiliza grafos dirigidos acíclicos para representar os fluxos de dados, onde cada nó representa uma operação e cada aresta, um caminho que o dado deve percorrer. A Apache Storm é usada juntamente com ferramentas de CEP para distribuir o processamento de eventos, com as ferramentas de CEP sendo usadas nos nós. Uma grande desvantagem de uso da Apache Storm é que qualquer reorganização na topologia do grafo requer que todo o sistema seja parado para a implementação de mudanças, ou seja, sempre que o sistema é reorganizado, os estados dos operadores são perdidos. Portanto, a distribuição não é dinâmica.

O WSO Stream Processor ${ }^{8}$, por sua vez, tem recursos nativos para a execução de um sistema com várias instâncias de processamento. Ele utiliza uma arquitetura orquestrada para coordenar a alocação de eventos, com a ferramenta de mensagens Apache Kafka ${ }^{9}$ para comunicação assíncrona entre instâncias e o banco de dados MySQL para armazenar metadados dos tipos de eventos. O WSO Stream Processor usa anotações feitas pelo usuário na definição dos tipos de eventos para decidir como distribuir e paralelizar o processamento dos eventos. Essa abordagem pode levar a desperdício de recursos, visto que o usuário tem que saber sobre o funcionamento interno do sistema para configurar uma boa distribuição do processamento de eventos.

\footnotetext{
${ }^{2}$ https://flink.apache.org

${ }^{3}$ https://www.drools.org/

${ }^{4}$ http://www.espertech.com/esper

${ }^{5}$ http://www.espertech.com/esper-enterprise-edition

${ }^{6}$ https://docs.wso2.com/display/CEP420

${ }^{7}$ https://storm.apache.org

${ }^{8}$ https://docs.wso2.com/display/SP410

${ }^{9}$ https://kafka.apache.org
} 


\subsection{Isolamento de Ambiente e Processamento em Nuvem}

Para executar as ferramentas de CEP em plataformas de computação em nuvem, o uso de provedores de nuvem é necessário. Serviços de computação em nuvem, como o Google Cloud Platform - GCP, o Microsoft Azure - Azure e o Amazon Web Services - AWS ) ${ }^{10}$, são definidos como um modelo para permissão de acesso sob-demanda e configurável de recursos computacionais, que podem ser provisionados ou descartados rapidamente (Cloud Computing, 2020).

A instanciação de serviços em ambientes de nuvem pode ser feita de várias maneiras. Uma das técnicas mais utilizadas é o isolamento de ambiente de execução. Isolar o ambiente de execução de cada instância de qualquer ferramenta é importante para garantir que não haja uma interação inesperada entre os processos rodando concomitantemente. Atualmente dois tipos de técnicas se destacam para garantir esse isolamento:

- Máquinas Virtuais: quando todo um sistema operacional é emulado para cada ferramenta ou conjunto de ferramentas que se deseja rodar concomitantemente.

- Contêineres: quando a instância da ferramenta usa o mesmo sistema operacional, porém com uma camada de isolamento que garante separação de variáveis de ambiente e bibliotecas necessárias para seu funcionamento.

O uso de máquinas virtuais gasta mais recursos do sistema simplesmente por ter que rodar todo um outro sistema operacional sobre o da máquina hospedeira. Em comparação, a instanciação de contêineres em um máquina hospedeira gasta bem menos recursos e garante o mesmo nível de isolamento. De acordo com Felter et al. (2015), os contêineres podem atingir e até superar o desempenho de máquinas virtuais em relação a economia do uso de CPU e memória RAM.

Para fazer a interface entre o desenvolvedor de contêineres e os recursos disponíveis na nuvem, existem vários tipos de sistemas de gerenciamento dinâmico de recursos, chamados de serviços de orquestração de contêineres (como Apache Mesos, Kubernetes e Docker Swarm.) ${ }^{11}$. Esses sistemas fornecem várias operações que facilitam a administração das aplicações, sendo algumas delas:

- Fácil visualização de logs e descrição do uso de recursos de cada contêiner.

- Configuração individual do uso de recursos por cada contêiner.

- Instanciação automática de contêineres sem estado para escalabilidade horizontal.

- Balanceamento de carga automático entre contêineres provendo o mesmo serviço externo.

- Uso de nuvens de diferentes provedores para o mesmo sistema.

\subsubsection{Sistemas Nativos de Nuvem}

Sistemas nativos de nuvem podem ser definidos como sistemas que cumprem os requisitos de auto-escalabilidade, ou seja, são capazes de regular seu próprio uso de recursos computacionais, e tolerância a falhas no ambiente de execução, ou seja, são capazes de se recuperar de quaisquer falhas a um estado de funcionamento normal (Garrison e Nova, 2017; Gilbert, 2018). Esses dois requisitos são fundamentais para o aproveitamento do ambiente de nuvem. A tolerância a falhas é necessária pois nenhuma nuvem garante um ambiente de execução sem falhas de processamento ou comunicação a qualquer momento, logo os sistemas devem ser construídos com mecanismos de recuperação para esses tipos de falhas. A auto-escalabilidade é necessária para a modulação do uso de recursos computacionais a somente o necessário para o correto funcionamento do sistema, reduzindo custos operacionais. Como a maioria dos ambientes de nuvem cobram por quantidade e tempo de uso de cada recurso, uma economia de recursos computacionais normalmente significa uma economia financeira.

\footnotetext{
${ }^{10}$ https://cloud.google.com/, https://aws.amazon.com/, https://azure.microsoft.com/

${ }^{11}$ https://mesos.apache.org, https://kuberetes.io, https://docs.docker.com/engine/swarm/
} 
Para satisfazer os requisitos de auto-escalabilidade e tolerância a falhas, é importante que a especificação da infraestrutura do ambiente de execução seja descrita em código, que pode de ser lido por ferramentas que realizam o gerenciamento dinâmico de recursos computacionais da nuvem, como é o caso dos sistemas de orquestração de contêineres. Dessa forma, um serviço em falha pode ser removido e re-instanciado automaticamente utilizando a mesma quantidade de recursos computacionais, ou ainda um serviço em sobrecarga pode ter uma segunda instância criada com as mesmas especificações de infraestrutura de ambiente.

Outras práticas normalmente associada ao desenvolvimento de sistemas nativos de nuvem é o uso de ferramentas de isolamento de ambiente de execução, como contêineres, para o desenvolvimento de cada um dos serviços que compõe o sistema. Dessa forma, cada parte do sistema pode ser desenvolvida na linguagem de programação mais apropriada para o serviço proposto. Além disso, sistemas nativos de nuvem também são caracterizados por serem desenvolvidos levando em conta o uso, nos casos apropriados, dos serviços providos pela própria plataforma de nuvem, como as Funções-como-Serviço (FaaS, do inglês Function-as-a-Service).

\subsection{Arquitetura de Microsserviços}

O desenvolvimento de sistemas nativos de nuvem geralmente se baseiam em arquiteturas de microsserviços (Garrison e Nova, 2017). Newman (2015) define microsserviços como serviços pequenos e autônomos que trabalham bem como um conjunto. Pequenos pois devem ter uma função e escopo bem definidos, de forma que um microsserviço só deve oferecer operações de um mesmo domínio, assim como uma classe só contem métodos de um mesmo domínio dentro de uma aplicação. Autônomos pois um microsserviço deve ser claramente separado dos outros componentes do sistema, de forma que possa ter uma instância sozinha em uma máquina, sem a necessidade de nenhum outro componente do sistema ser executado concomitantemente. Uma aplicação pode usar a arquitetura de microsserviços para separar suas operações internas, de forma que cada componente possua um alto grau de modularidade.

Os principais requisitos que uma arquitetura de microsserviços atende são:

- Heterogeneidade de tecnologias: como cada microsserviço é separado do restante do sistema, não há necessidade de escolher uma tecnologia ou linguagem específica que seja compatível com todo ele.

- Resiliência: em contraste com serviços monolíticos, nos quais uma falha em uma função resulta em uma falha no sistema inteiro, uma falha em um microsserviço não afeta a execução correta de outros microsserviços. O fato dos microsserviços poderem ser instanciados sem depender de outros possibilita que o sistema ainda possa exercer funções não relacionadas a um microsserviço específico que falhou, enquanto este não é instanciado novamente.

- Fácil versionamento: cada mudança feita no código de um sistema monolítico requer que uma nova versão do sistema inteiro seja lançada. O uso de microsserviços permite que cada microsserviço tenha sua própria versão, diminuindo o impacto que alterações feitas em um ponto específico tem em todo o sistema.

- Composicionalidade: como cada microsserviço tem uma função separada, é possível reutilizar microsserviços em diferentes contextos. A função que cada um executa é agnóstica em relação ao propósito pelo qual foi chamada. Logo, um microsserviço pode executar a mesma função para entradas diferentes que serão utilizadas por entidades diferentes no sistema, sem a necessidade de criar um microsserviço novo para entradas e funções similares.

- Substituição otimizada: pelo fato de os microsserviços serem pequenos, qualquer mudança se torna mais fácil de ser realizada. Tarefas como a refatoração interna, a construção de um novo microsserviço para substituir um já existente ou a simples remoção de um único microsserviço podem ser feitas em um período relativamente curto, o que facilita a manutenção do sistema como um todo. 
- Escalabilidade: para um sistema monolítico conseguir lidar com uma alta variação de uso, é necessário que ele seja modificado e instanciado novamente para cada nova escala que pretende atender. Em uma arquitetura de microsserviços, a escalabilidade de cada microsserviço é separada e permite que o desempenho de um microsserviço específico não seja afetado pelo estado de outros serviços.

O uso de microsserviços permite a construção de aplicações distribuídas sem que exista uma relação fixa de integração entre as diferentes partes. Consequentemente, o sistema pode ser construído e utilizado de formas mais flexíveis, já que microsserviços desnecessários em certas ocasiões não precisam ser executados concomitantemente com o restante do sistema.

\subsubsection{Comunicação}

O desacoplamento gerado pelo uso de uma arquitetura de microsserviços traz a vantagem da execução de cada um poder ser feita em ambientes separados. A interação entre microsserviços de um mesmo sistema, ou mesmo de sistemas distintos, pode ser feita de duas formas diferentes e esperar ou não respostas dos microsserviços contatados.

Newman (2015) descreve que os serviços podem se comunicar de forma síncrona ou assíncrona. Uma comunicação feita de forma síncrona requer que o serviço que faz a chamada externa tenha de esperar até que haja uma resposta. O uso dessa comunicação, se feito corretamente, garante uma resposta a um pedido remoto, seja ela de sucesso ou não, permitindo que o microsserviço que requisita a chamada saiba o que aconteceu. Na comunicação assíncrona, por outro lado, o serviço que faz a chamada não espera nenhuma resposta para completar a operação. O fato de não existir nenhum bloqueio enquanto uma resposta não é retornada diminui a latência, pois não há necessidade de manter a conexão aberta até que haja uma resposta. Além disso, a comunicação assíncrona pode ser mais viável para a comunicação entre serviços que rodam por longos períodos de tempo ininterruptos, caso em que manter uma conexão aberta não é prático.

Além dos modos de comunicação, uma aplicação também precisa decidir qual estilo de colaboração usar entre microsserviços. Fowler (2006) discute a diferença do estilo de comunicação pedido/resposta em comparação ao estilo baseado em eventos. Em pedido/resposta, o serviço que inicia a comunicação envia um pedido e espera por uma resposta. Este modelo se alinha muito bem com a comunicação síncrona, mas também pode funcionar para a comunicação assíncrona quando a resposta demora a ser enviada. Em uma colaboração baseada em eventos, o serviço envia uma informação sobre algo que aconteceu e espera que os receptores saibam o que fazer com esta informação, de forma que nenhum serviço recebe ordens diretas sobre o que fazer. A colaboração baseada em eventos é altamente desacoplada por natureza, e assim novos microsserviços podem ser adicionados para receber eventos de um outro microsserviço, sem este precisar de alterações em seu código.

A comunicação assíncrona baseada em eventos é o tipo de comunicação que as ferramentas de CEP descritas na Seção 2.1.4 realizam internamente. Cada nó de processamento recebe um evento e o utiliza para detectar outros eventos por conta própria, sem a necessidade de uma chamada externa para realizar esta operação. Dessa forma, o uso desse estilo de comunicação é o mais apropriado para a transferência de eventos entre diferentes instâncias de ferramentas de CEP.

\subsubsection{Orquestração e Coreografia}

Newman (2015) também discute como a separação e a organização das funções de diversos microsserviços em um sistema podem ser feitas de duas formas diferentes: com um agente comandando o que cada microsserviço faz, o que é chamado de orquestração, ou esperando que cada microsserviço saiba o que fazer por conta própria, chamado de coreografia.

\section{Orquestração}

Assim como uma orquestra é regida por um maestro, um sistema de microsserviços pode ter um serviço no comando das operações principais do sistema. Um sistema com este tipo de arqui- 
tetura pode mudar sua ordem de funcionamento mais rapidamente se preciso, apenas alterando o microsserviço que está no comando. Porém, esse microsserviço comandante pode se tornar um gargalo no sistema se todas as ações precisarem de sua intervenção. Além disso, por ser essencial ao funcionamento do sistema inteiro, torna-se um ponto fraco, de forma que uma falha nele pode deixar o sistema sem funcionar por inteiro. Esse tipo de arquitetura permite o uso dos dois estilos de comunicação mencionados previamente na Seção 2.3.1, sendo que o uso da comunicação síncrona no estilo pedido/resposta pode ser facilmente implementado quando se quer garantir que uma resposta seja recebida.

\section{Coreografia}

Microsserviços em uma arquitetura coreografada sabem o que fazer por conta própria, de forma que o uso de uma comunicação baseada em eventos se encaixa melhor do que uma do tipo pedido/resposta. O uso de microsserviços coreografados pode reduzir a latência do sistema, pois não há a necessidade de se conectar para receber instruções ou responder todas as chamadas. Entretanto, como a lógica de ordem de processos está inserida dentro de cada microsserviço, o custo de trocar essa lógica aumenta em relação a uma arquitetura orquestrada, pois é necessário modificar todos os microsserviços do sistema. A verificação de que o sistema está funcionando corretamente também se torna mais difícil, visto que não há uma autoridade central à qual os microsserviços podem reportar. Uma consequência do uso de coreografia em microsserviços é a resiliência proporcionada. A independência das partes resulta na contenção de falhas pontuais a microsserviços específicos, diminuindo a interferência no uso do restante do sistema.

\subsection{Escalabilidade}

Bondi (2000) define escalabilidade como a habilidade de um sistema acomodar um número crescente de processos ou processar um volume crescente de carga com um mínimo aumento de uso de recursos computacionais. Existem diferentes razões para um sistema ter a escalabilidade como um de seus requisitos. Newman (2015) observa que ela é usada principalmente para conseguir duas coisas: lidar com falhas ou lidar com problemas de desempenho, sejam eles aumentar a carga que um sistema suporta, diminuir a latência ou ambos ao mesmo tempo.

Michael et al. (2007) distinguem a escalabilidade entre vertical e horizontal. A escalabilidade vertical consiste em alocar mais recursos computacionais, sejam eles poder de processamento, memória, largura de banda ou qualquer outro, para o sistema. Esse tipo de escalabilidade pode ser uma solução fácil e rápida para diminuir a latência e aumentar a vazão de um sistema, mas caso a demanda por recursos continue a aumentar, o custo financeiro desses recursos aumenta em uma proporção maior. Além disso, nem todos os tipos de sistemas se beneficiam do aumento de certos recursos: um sistema que não consegue paralelizar seus processos internos possui um limite de quantidade de CPU que ele consegue usar por vez.

A escalabilidade horizontal consiste em distribuir o processamento de um sistema em ambientes distintos, de modo que cada instância do sistema seja executada paralelamente a outra. Um sistema baseado em microsserviços se beneficia mais desse tipo de escalabilidade que um monolítico, pois é possível instanciar conjuntos de microsserviços distintos em diferentes máquinas, sem a necessidade de executar o sistema inteiro em cada máquina.

O propósito de escalar um sistema para aumentar sua tolerância a falhas é alcançar um outro requisito não funcional, a disponibilidade. O intuito é replicar o processamento usando o mínimo de recursos adicionais para manter o sistema disponível pelo maior tempo possível. Porém, isso só é possível com o uso da escalabilidade horizontal, pois a escalabilidade vertical não modifica o número de instâncias do sistema sendo executadas, mantendo o processamento concentrado. 


\subsubsection{Escalabilidade para Microsserviços sem Estado}

Microsserviços que não precisam manter um estado de funcionamento enquanto estão em execução são mais fáceis de serem escalados, pois suas operações são idempotentes, ou seja, qualquer operação feita por uma instância pode ser feita por qualquer outra. O aumento do número de instâncias do mesmo microsserviço pode resolver problemas de desempenho, como alta latência ou baixa vazão. Além disso, caso a carga de trabalho diminua, é possível simplesmente remover as instâncias ociosas. O uso de balanceadores de carga para escalar aplicações baseadas em microsserviços sem estado já foi estudado em alguns trabalhos, inclusive na plataforma de cidades inteligentes InterSCity (Esposte et al., 2017; Francesco, 2017; Villamizar et al., 2015).

\subsubsection{Escalabilidade para Microsserviços com Estado}

Quando o microsserviço precisa guardar estado para realizar suas operações, criar uma nova instância não é suficiente, é preciso também replicar o estado se o objetivo for realizar a mesma operação e obter o mesmo resultado. A viabilidade de distribuir o processamento de sistemas que guardam estado é bastante estudada no contexto de bancos de dados distribuídos, nos quais cada operação deve poder alterar o estado do banco.

Sistemas gerenciadores de bancos de dados distribuídos precisam utilizar técnicas para manter a consistência de seus dados. O teorema CAP, definido por Eric Brewer (Gilbert e Lynch, 2002), descreve que qualquer sistema distribuído que lida com dados só consegue garantir simultaneamente duas das seguintes características: consistência, disponibilidade e tolerância a particionamento.

- Consistência significa que todos os dados no sistema estão sincronizados e não há chance de se fazer uma leitura de um dado desatualizado.

- Disponibilidade significa que o sistema está sempre pronto para receber novas requisições e respondê-las.

- Tolerância a particionamento significa que sempre que houver uma falha de comunicação entre duas partes separadas do sistema, este continuará operando.

Todo sistema distribuído é por natureza tolerante a particionamento, caso contrário ele não poderia ser executado de forma distribuída em um ambiente no qual falhas podem ocorrer. Logo, sistemas distribuídos devem escolher entre manter a disponibilidade e aceitar lidar com dados antigos ou manter a consistência e aceitar que, em certos períodos, o sistema estará indisponível.

Um sistema baseado em uma arquitetura de microsserviços é por natureza distribuído. Portanto, o teorema CAP se aplica a todos os microsserviços que mantêm estado, resultando em uma escolha entre consistência e disponibilidade por parte do sistema. No entanto, esta não precisa ser uma escolha binária, visto que certos dados têm mais valor se forem consistentes e alguns serviços são importantes demais para ficarem indisponíveis. Sistemas Gerenciadores de Bancos de Dados são exemplos de serviços que precisam guardar estado. A partir do teorema CAP, duas maneiras de se distribuir um banco de dados foram desenvolvidas: utilizando escalabilidade para leituras ou escalabilidade para escritas (S. Mullins, 2018).

\section{Escalabilidade para Leituras}

Consiste em manter réplicas do banco de dados para fácil acesso. Esta opção é vantajosa quando vários serviços não escrevem no $\mathrm{BD}$ e só o utilizam para consultar informações. Se o número de serviços que escrevem no banco de dados é pequeno e as escritas são feitas em períodos específicos, o modo mais indicado de conseguir aumentar a escala (neste caso, o número de consultas que o BD realiza) é criar várias réplicas. As escritas devem ser feitas apenas no BD principal e eventualmente passadas para as réplicas, enquanto que as consultas podem ser direcionadas a qualquer uma das réplicas. Como o propósito da escalabilidade é aumentar o desempenho e garantir a disponibilidade, a consistência só ocorrerá eventualmente. 


\section{Escalabilidade para Escritas}

Outra forma de distribuir o BD é chamada de sharding, na qual o conjunto total dos dados armazenados no BD é fisicamente separado. Vários algoritmos podem ser utilizados para decidir em qual local cada dado será armazenado, incluindo o uso de hashing no dado ou a inserção de dados do tipo chave-valor, com chaves no mesmo intervalo da mesma partição. Esta distribuição é vantajosa em sistemas que recebem escritas frequentes de vários serviços e nos quais consultas gerais são raras e normalmente feitas de modo a recuperar entradas específicas. O uso de sharding é oneroso nos casos de consultas que precisam varrer todo o banco de dados, o que requer que todos os nós estejam disponíveis, ou quando é preciso adicionar ou remover nós, o que demanda um rebalanceamento dos dados armazenados. O uso de sharding por si só consegue abrir mão de um pouco de disponibilidade para atingir a consistência, pois na ocorrência de uma escrita, apenas a partição que guarda o dado fica indisponível, enquanto dados de outras partições podem ser acessados concomitantemente.

\subsection{Considerações do Capítulo}

A maioria das ferramentas de CEP de software livre não oferecem escalabilidade horizontal dinâmica sem perda de estado. O uso de ferramentas de processamento de fluxo de dados para a distribuição do processamento, como descrito na Seção 2.1.4, não permite que a topologia de transferência de dados seja alterada em tempo de execução, de forma que qualquer alteração faz com que a execução de todo o sistema seja parada. Além disso, todas as abordagens pesquisadas utilizam arquiteturas orquestradas, que podem não ser tão resilientes a falhas quanto arquiteturas coreografadas, como descrito na Seção 2.3.2, e a maioria não leva em consideração a execução do sistema em um ambiente de nuvem, nem implementa mecanismos de auto-escalabilidade.

A Seção 2.3 mostra como uma arquitetura de microsserviços pode trazer várias vantagens, sendo a principal delas a flexibilidade de execução que ela proporciona. Pelo fato de serem executados separadamente, o uso de microsserviços para a distribuição de processamento de eventos pode resultar em uma economia de uso de recursos pelo sistema. Aliás, a adoção de uma comunicação assíncrona baseada em eventos é uma característica comum ao CEP e aos microsserviços. Porém, a distribuição dos processamento dos eventos complexos utilizando microsserviços depende fortemente do uso de recursos e estado por cada tipo de evento, como dito na Seção 2.1.3.

Como vários eventos precisam usar estado para serem processados, a distribuição do processamento desses eventos precisa ser bem balanceada, similarmente ao que acontece em SGBDs que distribuem seus dados por sharding, como visto na Seção 2.4.2. 


\section{Capítulo 3}

\section{Trabalhos Relacionados}

Neste capítulo, são apresentados trabalhos relacionados a distribuição de processamento de eventos complexos e abordagens adotadas para a execução de processamento de eventos complexos nativo de nuvem. Ao final do capítulo, são feitas considerações sobre as principais características e limitações identificadas nesses trabalhos.

\subsection{Distribuição de Processamento de Eventos}

Vários trabalhos se propuseram a pesquisar como melhorar a escalabilidade em CEP, estudando o balanceamento de carga do processamento de eventos. Diferentes estratégias são adotadas para a distribuição de tipos de evento, tais como a distribuição de acordo com a similaridade das dependências dos tipos de evento, a distribuição da deteç̧ão de um único tipo de evento e a distribuição dos tipos de evento baseada no uso de recursos computacionais. A seguir, cada uma dessas estratégias é apresentada e discutida.

\subsubsection{Distribuição de Tipos de Eventos com Dependências Similares}

Isoyama et al. (2012) propuseram uma abordagem para agrupar o processamento de tipos de evento que dependem dos mesmos tipos de evento de entrada de forma a procurar diminuir a transmissão de eventos entre nós. Algoritmos específicos de balanceamento de carga são usados para selecionar quais tipos de eventos devem ser realocados de nós em sobrecarga para manter a quantidade de eventos sendo transmitidas entre nós a mínima possível. Os autores compararam três modos de alocação de tipos de eventos entre os nós de processamento: (i) por round-robin, (ii) alocando todos os tipos em todas as máquinas com um compartilhamento de estado para evitar deteç̧ão duplicada e (iii) pelo algoritmo proposto por eles. Os resultados mostraram que o algoritmo proposto tem a melhor vazão entre os três, porém não foi feita uma comparação de latências.

Kobayashi et al. (2015) deram continuação ao trabalho de Isoyama et al. (2012) e sugeriram um sistema para lidar com comunicação M2M (Machine-to-Machine), com um foco em detecção de eventos com contexto para plataformas de comunicação de serviços de domínios distintos. O trabalho sugere a separação do processamento de cada tipo de evento com base nos seus atributos, agrupando o processamento de tipos que eventos no mesmo nó de acordo com os atributos que possuem em comum, ou seja, de acordo com os atributos de eventos distintos que representam as mesmas quantidades e que são gerados da mesma maneira. A partir da determinação de atributos principais, os quais são compartilhados pela maioria das definições dos tipos de evento em processamento, a distribuição é feita agrupando o processamento dos tipos de evento que possuem atributos similares. 
Já Pathak e Vaidehi (2015) utilizaram um mecanismo no qual é fixado um limite de número de eventos processados por cada instância de CEP. Cada definição de tipo de evento $X$ é associada a um metadado que contém todos os tipos de eventos de entrada necessários para a detecção de $X$ e os tipos de evento que utilizam $X$ como entrada para seus próprios processamentos. No final, o metadado de cada tipo de evento é utilizado para definir em qual nó ele será processado, agrupando o processamento de tipos de evento que utilizam os mesmos tipos de entrada. Os resultados da comparação da vazão desse algoritmo com o trabalho de Isoyama et al. (2012) mostraram que esse mecanismo atinge um nível mais alto de vazão, especialmente para uma maior quantidade de nós de processamento.

\subsubsection{Distribuição da Detecção de um Único Tipo de Evento}

Um novo modelo de paralelização foi proposto por Xiao et al. (2017), no qual a detecção de um tipo de evento que precisa de dois tipos diferentes de eventos de entrada, $X$ e $Y$, é separada entre EPAs distintos. O fluxo de $X$ é seccionado em subfluxos que são enviados a EPAs paralelos e o fluxo de $Y$ é replicado para todos os mesmos EPAs. Essa técnica pode ser utilizada para mais de dois tipos de eventos de entrada, aplicando-a primeiramente em dois tipos e encaminhando o resultado para ser pareado com outros tipos de eventos sucessivamente. Apenas os operadores Composição e Deteç̧ão de Padrão podem utilizá-la, e somente para operações que não dependam de uma agregação de algum atributo do fluxo de eventos seccionado.

Jayasekara et al. (2015) desenvolveram diferentes operadores para que o usuário defina a paralelização e distribuição dos tipos de evento no sistema de CEP. Cada novo tipo de evento definido que utiliza vários operadores é reescrito de forma a separar o processamento de cada operador. São apresentadas três técnicas para a distribuição do processamento, sendo a primeira por particionamento do processamento dos eventos de entrada, desde que a junção dos eventos detectados assim seja equivalente ao processamento de todos os eventos de entrada pelo mesmo operador em um único nó. A segunda por encaminhamento, quando os eventos processados por um operador são encaminhados para outro operador para que o resultado do processamento dos dois operadores seja igual ao da definição do tipo de evento. A terceira maneira é por uso de operadores distribuídos entre nós. Os operadores são alocados de forma a reduzir a transmissão de eventos entre os nós de processamento disponíveis, com operadores que sempre usam um mesmo fluxo de entrada sendo alocados no mesmo nó.

Schultz-Møller et al. (2009) implementaram um sistema que não utiliza as definições diretas dos tipos de eventos para detectá-los, mas que reescreve a definição dos tipos de eventos, utilizando autômatos para dividir o processamento em diferentes operadores de forma que o processamento de um operador possa ser reutilizado em mais de um tipo de evento. São definidos seis operadores principais: filter, union, next, iteration, exception, time, com os quais os autores dizem ser possível reescrever qualquer definição de tipo de evento. O principal objetivo do trabalho é minimizar o uso de CPU no processamento de eventos e a latência de detecção por meio da reutilização de operadores. São calculados os custos de deteç̧ão de cada operador de cada tipo de evento para determinar em qual nó ele será alocado.

Balkesen et al. (2013) usaram máquinas de estados finitos para estudar as diferenças entre dividir o processamento de tipos de evento por etapa de detecção ou por conjunto de eventos participantes na detecção de um padrão. Na divisão por etapa de detecção, cada nó detecta se os eventos de entrada respeitam uma parte da condição e apenas passa adiante para outros nós as detecções que respeitam a condição anterior. Já na divisão por conjunto de eventos participantes na detecção de um padrão, cada conjunto formado por uma combinação diferente de eventos de entrada é enviado para um nó diferente. Os resultados dos experimentos realizados pelos autores mostraram que a paralelização por separação de conjuntos de eventos de entrada é mais robusta e tem um desempenho melhor na detecção de diferentes eventos. 


\subsubsection{Distribuição de Tipos de Evento Baseada em Desempenho}

O monitoramento da sobrecarga da consulta e a relação com dados históricos em sistemas de CEP, como no operador de Enriquecimento, foram estudados por Martins et al. (2014). Os autores apresentaram uma arquitetura de balanceamento de carga, chamada Audy, que distribui o processamento de tipos de eventos baseando-se no uso de recursos por cada nó e introduz medidas de descarte de eventos se a sobrecarga for muito alta. Ela usa filas de eventos de entrada e saída para monitorar o desempenho dos nós de processamento. O próprio nó requisita a realocação da detecção de tipos de eventos se a fila atinge um limite $n$, definido pelo usuário, e termina a detecção de algum tipo se atinge um outro limite superior $m$, também definido pelo usuário. Além disso, se a deteç̧ão de um tipo de evento, mesmo depois de alocada para um nó que estava ocioso, levou o nó a atingir o limite $m$ da fila de eventos de entrada, a detecção do tipo de evento em questão é descartada. Isso é feito para tentar manter o sistema disponível pelo maior tempo possível, mesmo que nem todos os eventos inseridos possam ser processados.

Shin et al. (2019) criaram um sistema de distribuição independente das ferramentas de detecção de CEP, chamado CEP-Wizard, onde o usuário passa informações sobre o uso de recursosdo sistema e sobre o tipo de evento a ser detectado e o sistema define em qual nó esse tipo de evento será alocado. $\mathrm{O}$ uso de informações como o tipo e a taxa de fluxo dos eventos de entrada permite que o sistema consiga distribuir a alocação para que o uso de recursos seja igualmente distribuído. Porém, o CEPWizard não possui nenhum mecanismo de realocação de eventos em tempo de execução e assume que a taxa de fluxo de eventos de entrada é constante, o que não acontece para muitos sistemas em tempo real. O CEP-Wizard utiliza o Apache Storm para a distribuição de CEP e, como descrito em 2.1.5, o Apache Storm não permite a remoção de nós em tempo de execução, dificultando a administração do uso de recursos.

Randika e Ranathunga (2018) propuseram um mecanismo, chamado Gathika, para a distribuição dinâmica de CEP, levando em conta o número de nós e uso de recursos pelo sistema. No entanto, o Gathika não automatiza a instanciação de novos nós de processamento, só reage a inclusão ou exclusão externa de nós, de forma que não pode ser classificado como auto-escalável. Além disso, a arquitetura do sistema é orquestrada, portanto a distribuição de eventos depende de uma parte específica do sistema, o que diminui sua tolerância a falhas, pois uma falha de execução em um só nó pode impactar todas as realocações de eventos.

\subsection{Tolerância a Falhas}

Os trabalhos encontrados sobre distribuição de processamento de eventos que mais focam no aspecto de tolerância a falhas do sistema são os de Randika et al. (2010), Carbone et al. (2013) e Martins et al. (2014). Visando a manter o sistema de processamento de eventos em funcionamento por maior tempo possível, Martins et al. (2014) propuseram técnicas para realocar ou até remover por um tempo o processamento de certos tipos de eventos, para que o sistema seja tolerante a sobrecarga de uso de recursos e mantenha uma disponibilidade mínima durante sua execução.

Carbone et al. (2013) focaram no processamento monolítico de CEP e introduziram como mecanismo de tolerância a falhas a execução duplicada do processamento de cada tipo de evento. É feito um log distribuído de todos os eventos, pelo qual cada EPA pode recuperar seu estado a partir da retransmissão dos eventos de entrada.

Já Randika et al. (2010) descreveram o uso de uma arquitetura orquestrada para a distribuição de processamento de eventos chamada de epZilla. O sistema cria módulos distintos, cada um responsável por ser o produtor de eventos, consumidor de eventos e um outro módulo, composto por vários nós de processamento, responsável por ser o processador de eventos. A tolerância a falhas é atingida a partir da replicação inteira de cada nó de processamento, sendo que cada nó pode processar múltiplos tipos de eventos. 


\subsection{CEP em Nuvem e Borda}

São poucos os trabalhos que citam CEP na pesquisa de sistemas nativos de nuvem (Kritikos et al., 2019; López et al., 2020; Metsch et al., 2015; Moldovan et al., 2014). Porém a pesquisa em sistemas de CEP distribuídos que são simplesmente executados em ambientes de nuvem é mais extensa.

Higashino et al. (2016) desenvolveram um sistema distribuído de simulação de CEP para execução em nuvem. Ele utiliza grafos dirigidos acíclicos para modelar a rede de processamento de eventos. Os resultados dos experimentos realizados pelos autores mostram que o sistema é eficaz em simular cargas de Big Data em tempo real.

Além disso, várias pesquisas (Dhillon et al., 2018; Guo e Huang, 2015; Power e Kotonya, 2020; Zhao e Yang, 2015) enfocam a execução distribuída de CEP em dispositivos de Internet da Coisas (IoT, do inglês Internet of Things), onde somente eventos de alta importância são enviados para um centro de processamento. Meslin et al. (2020) apresentaram a implementação de uma abordagem desse tipo, na qual é proposta uma arquitetura de três camadas (borda, névoa e nuvem) para o processamento de dados em cidades inteligentes e só os eventos mais relevantes são enviados da borda para a névoa e da névoa para a nuvem.

O uso de CEP em dispositivos IoT, não só para sensoreamento mas também para processamento de eventos, é uma abordagem com vantagens e desvantagens. As principais vantagens são a redução do tráfego de mensagens a partir dos dispositivos e o envio de notificações mais rápido para as localidades mais próximas à detecção. Algumas das desvantagens são a perda inerente de informação a ser armazenada e a menor tolerância a falhas nos casos em que um dispositivo processa dados de vários sensores. Caso ocorra uma falha nesse dispositivo, seu reparo ou reposição depende de intervenção manual e os dados dos sensores associados a ele são perdidos, descartados ou sobrecarregam o processamento de outros dispositivos. Utilizando processamento em nuvem com gerenciamento dinâmico de recursos, a instanciação de um novo ambiente de processamento pode ser feita automaticamente, diminuindo o tempo em que parte do sistema está indisponível. Além disso, com a adoção e maior uso de tecnologias de internet sem fio, como $5 \mathrm{G}$, é esperado que o preço da transmissão de dados seja reduzido (Luong et al., 2019; Maeng et al., 2020).

\subsubsection{Comparação de CEP com Funções-como-Serviço}

López et al. (2020) discutiram a criação de um sistema de orquestração de Funções-como-Serviço (FaaS, do inglês Function-as-a-Service) que atenda as demandas da comunidade de CEP e de outras comunidades que lidam com processamento de dados contínuos. Apesar de um grande esforço ter sido feito para criar sistemas usando as tecnologias de código aberto mais atuais de FaaS, não foi discutida a implementação ou suporte aos operadores de CEP.

Funções-como-Serviço são um tipo de serviço oferecido pela maioria dos provedores de nuvem. Em FaaS, o desenvolvedor escreve o código e especifica suas dependências e é responsabilidade do provedor instanciar e administrar a infraestrutura para a execução do código e expor os serviços oferecidos, ou seja, toda a infraestrutura da operação é de responsabilidade do provedor de nuvem (Garrison e Nova, 2017). Esse tipo de serviço permite que desenvolvedores escrevam pequenos trechos de código para serem disparados assim que um web-hook for acionado ou alguma outra situação for detectada. Apesar de conseguir realizar muitas das funções que CEP oferece, os objetivos e principais usos das FaaS são bem distintos. Como o usuário de FaaS utiliza linguagens de programação para definir o processamento a ser feito, a chegada de um novo evento pode servir para o disparo da realização de vários tipos de ações, como a criação ou remoção de outros processamentos de FaaS, o processamento em lote de algum conjunto de dados ou até a instanciação de novos sistemas no provedor de nuvem. Apesar da grande variedade de operações disponíveis, os serviços de FaaS oferecidos nativamente pelo provedores têm um custo mais alto de uso, que é cobrado pelo tempo de execução do trecho de código, e também são limitados em relação ao tempo de processamento que uma função de FaaS pode continuar em execução ${ }^{1}$.

\footnotetext{
${ }^{1}$ AWSLambda : https://aws.amazon.com/pt/lambda, AzureCloudServices : https://azure.microsoft.com/en-us/ services/cloud-services/, GoogleAppEngine: https://cloud.google.com/appengine
} 
Para a deteç̧ão contínua e constante de eventos, o uso da nuvem para a execução de serviços de CEP resulta em uma economia financeira quanto mais eventos são processados. Apesar de existirem serviços de FaaS de código aberto desenvolvidos para prover as mesmas funcionalidades que os serviços proprietários dos provedores de nuvens ${ }^{2}$, eles não oferecem uma linguagem de CEP, com operadores próprios para a definição de tipos de evento desenvolvidos especificamente para o processamento de dados em tempo real.

\subsection{Considerações}

Os trabalhos apresentam diferentes técnicas para distribuir o processamento de eventos, que nem sempre têm resultados comparáveis, seja pela escala na qual os experimentos foram realizados, seja pelo foco do estudo. Dos trabalhos investigados, todos utilizam um sistema com organização orquestrada, portanto os nós de CEP têm pouca ou nenhuma autonomia em relação a quais eventos são designados a eles.

A pesquisa de Kobayashi et al. (2015) é uma continuação da pesquisa de Isoyama et al. (2012), e ambas mostram ótimos resultados em uma escala de milhares de eventos por segundo, mas não levam em conta as definições de tipos de evento que podem causar sobrecarga no sistema, como fazem Martins et al. (2014), de forma que o sistema fica vulnerável a variações do fluxo de tipos de eventos que podem consumir muitos eventos, e consequentemente recursos disponíveis durante a execução.

O trabalho de Xiao et al. (2017) é o único que tenta paralelizar a detecção de um mesmo tipo de evento sem alterar sua definição. A técnica pode ser utilizada somente por operadores de Composição e Deteç̧ão de Padrões, como visto na Seção 2.1.1, pois são os únicos que lidam com mais de um tipo de evento de entrada. Para todos os casos em que um atributo de um evento precisa ser agregado, há duas possibilidades: ou ele terá o mesmo valor em todos os EPAs - detectando o mesmo evento, pois seus eventos de entrada são encaminhados para todos os EPAs, desperdiçando recursos - ou terá um valor diferente para cada um dos EPAs - se for calculado a partir dos eventos cujo fluxo é seccionado, o que o torna inútil, pois nenhum dos diferentes valores é correto, já que ele não usou todos os eventos de entrada. Ou seja, o uso dessa abordagem só traz benefícios a composições e deteç̧ão de padrões que não usem agregação de nenhum atributo.

Jayasekara et al. (2015), Schultz-Møller et al. (2009) e Balkesen et al. (2013) utilizam técnicas diferentes para reescrever a definição dos eventos, usando pipelining e particionamento de eventos de entrada para melhorar o desempenho da detecção. As ferramentas apresentadas nesses trabalhos foram desenvolvidas para serem utilizadas dentro de uma mesma instância de suas respectivas ferramentas de CEP, alterando como a definição do evento é interpretada ou como ele é processado internamente, enquanto este trabalho de mestrado se relaciona com a distribuição do processamento em diferentes instâncias de CEP.

Algumas dessas técnicas estão estreitamente ligadas à linguagem usada para a definição de eventos, de modo que o reuso delas requer um trabalho tão grande quanto a criação de uma nova ferramenta de CEP. Além disso, as deteç̧ões apresentam melhores resultados quanto mais operadores forem usados na definição do mesmo tipo de evento. Um sistema distribuído de CEP em que os tipos de eventos definidos utilizam o menor número de operadores por tipo possível pode naturalmente realizar o encadeamento de definições de tipos de eventos distintos.

O principal diferencial do trabalho de Pathak e Vaidehi (2015) em relação aos demais trabalhos aqui discutidos é o seu foco em não repetir o processamento de um mesmo evento, o que certamente economiza recursos do sistema. Os resultados apresentados pelos autores mostram um desempenho melhor do que o do trabalho de Isoyama et al. (2012), com menor latência e maior vazão, mas os testes foram realizados em uma escala muito menor e não incluíram definições de eventos mais complicadas, que podem levar a um maior tempo de processamento e maior uso de recursos.

\footnotetext{
${ }^{2}$ Knative: https://knative.dev/, Kubeless: https://kubeless.io/, OpenFaaS: https://www.openfaas.com, Serverless: https://www.serverless.com
} 
A arquitetura apresentada por Martins et al. (2014) usa uma abordagem para escalar a detecção de eventos que prioriza deixar o sistema em funcionamento pelo maior tempo possível, porém os resultados dela não são comparáveis aos de outros trabalhos exatamente por isso. O trabalho de Isoyama et al. (2012) apresenta o melhor resultado em relação ao número de eventos processados por segundo. Contudo é importante levar em consideração que o trabalho de Martins et al. (2014) não tem como objetivo a escalabilidade e sim a resiliência de funcionamento do sistema em situações de sobrecarga de eventos de entrada.

A pesquisa em desenvolvimento de sistemas de CEP que escalam horizontalmente e são nativos de nuvem ainda foi pouco explorada. Atualmente, com o aumento do uso de computação em nuvem, esta deveria ser uma das considerações mais importantes no projeto de sistemas distribuídos, visto que a grande maioria dos sistemas que lidam com Big Data em tempo real estão migrando para nuvem. Sistemas que são construídos a partir do conhecimento de como a nuvem funciona e levando em conta as falhas e os métodos padronizados de recuperação automática, além da auto-escalabilidade, são reconhecidos como exemplos a serem seguidos, não só pela comunidade de sistemas nativos de nuvem, como por administradores e pesquisadores em geral (Davis, 2019; Fregly e Barth, 2021; Garrison e Nova, 2017; Gilbert, 2018; Grant et al., 2020; Richardson, 2018). Este trabalho de mestrado desenvolveu uma arquitetura de CEP que leva em consideração esses requisitos para a distribuição de processamento de eventos. 


\section{Capítulo 4}

\section{Arquitetura para a Distribuição do Processamento de Eventos Complexos}

Com o objetivo de criar um sistema auto-escalável para o processamento de dados de cidades inteligentes em tempo real, este trabalho de mestrado propõe uma arquitetura de microsserviços para a execução e distribuição do processamento de eventos complexos.

As seções a seguir descrevem os componentes da arquitetura e os mecanismos de distribuição.

\subsection{Arquitetura CEP Handler}

Essa arquitetura, chamada CEP Handler, consiste em quatro microsserviços-CEP Cataloger, Event Composer, Event Sender e CEP Worker - e utiliza mais dois microsserviços prontos para realizar sua funções: um sistema gerenciador de bancos de dados chave-valor e um sistema de mensageria. Todos esses microsserviços operam sob um serviço de gerenciamento dinâmico de recursos na nuvem. A Figura 4.1 mostra os componentes da arquitetura CEP Handler. A arquitetura foi desenhada com o intuito de estender a plataforma InterSCity de cidades inteligentes, recebendo dados em tempo real dela.

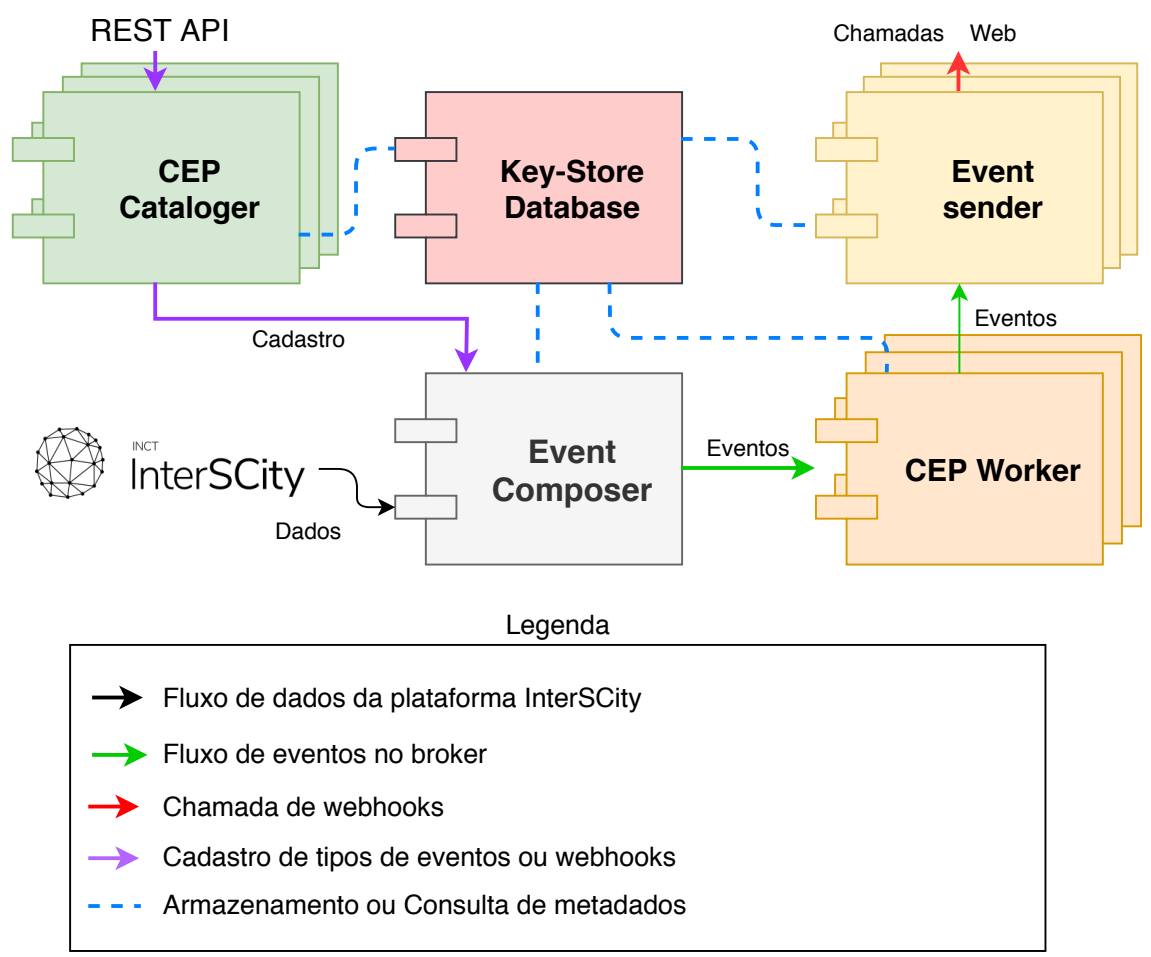

Figura 4.1: Arquitetura CEP Handler para processamento distribuído de eventos complexos. 


\subsubsection{Microsserviço CEP Cataloger}

O microsserviço CEP Cataloger é responsável por prover uma API RESTful para o usuário cadastrar novos tipos de eventos para serem detectados e webhooks, que são URLs a serem chamadas pelo sistema por REST quando eventos de tipos cadastrados forem detectados. Ele disponibiliza seis funcionalidades principais para o usuário:

- Cadastrar um novo tipo de evento: o usuário pode cadastrar novos tipos de eventos no sistema para que sejam detectados. Como a fonte de dados é a plataforma InterSCity, o usuário deve fornecer os identificadores dos recursos e capacidades cadastrados na plataforma ou os identificadores de outros tipos de eventos já cadastrados para servirem como origem dos eventos de entrada, além de um nome e uma definição para o novo tipo de evento, descrevendo que processamento deve ser feito.

- Listar eventos cadastrados: o usuário pode verificar quais tipos de eventos já estão cadastrados, para poder utilizá-los como tipos de entrada ou associar webhooks a eles.

- Cadastrar webhooks: o usuário pode cadastrar endereços URL para servirem como webhooks, fornecendo o identificador de um tipo de evento e o endereço URL associado a ele. Cada vez que o evento desse tipo for detectado, uma chamada será feita para o URL, pelo Event Sender, passando os dados do evento detectado.

- Listar webhooks: o usuário pode ver todos os webhooks associados a cada um dos tipos de eventos.

- Remover webhooks: o usuário pode remover um webhook associado a qualquer um dos tipos de eventos.

\subsubsection{Microsserviço Event Composer}

O microsserviço Event Composer é responsável por transformar os dados em tempo real vindos da plataforma InterSCity em eventos de entrada primários, além de ser responsável por cadastrar tipos de eventos de entrada primários. A plataforma InterSCity utiliza o conceito de Recurso para definir objetos espalhados pela cidade que funcionam como sensores ou atuadores e o conceito de Capacidade como os tipos de medições que os Recursos com capacidades sensoriais podem coletar. Quando um usuário cadastra um novo tipo de evento no CEP Handler que utiliza diretamente os dados da plataforma como fonte, ele precisa informar quais Recursos e quais Capacidades desses recursos medem os dados em tempo real. O Event Composer cria um tipo de evento primário, que contém como campos de atributos todos os dados da capacidade e recursos especificados. Como a plataforma InterSCity transmite internamente os dados em tempo real por meio de um broker de mensagens, o Event Composer se inscreve para receber os dados das capacidades em tempo real na plataforma. Quando esses dados chegam, ele adiciona as informações dos recursos que originaram os dados e converte-os em formato de evento para que o CEP Worker consiga reconhecer e processar.

\section{Sistema de Mensageria}

Para o envio de dados em tempo real entre os microsserviços do sistema CEP Handler, escolheu-se um sistema de mensageria do tipo broker de mensagens. Um broker de mensagens é definido como um sistema que centraliza o envio e recebimento de mensagens entre serviços, permitindo que qualquer serviço se inscreva para receber mensagens de qualquer outro serviço, no estilo de comunicação assíncrona , como descrito na Seção 2.3.1. Todas os envios de eventos entre os microsserviços desenvolvidos para o sistema CEP Handler são feitos de forma assíncrona por meio do broker. Os Sistemas de mensageria podem utilizar três tipos de configurações para o número de tentativas de envio de mensagens: no máximo uma vez, no mínimo uma vez ou exatamente uma vez. O sistema CEP Handler pode ser utilizado com qualquer uma das três configurações. 


\subsubsection{Sistema Gerenciador de Banco de Dados Chave-Valor}

Para o armazenamento de metadados dos tipos de eventos, como nome, definição em EPL, tipos de eventos de entrada e armazenamento dos webhooks associados a cada tipo de evento, optou-se pelo uso de um sistema gerenciador de banco de dados chave-valor. Esta escolha se deve principalmente a esse tipo de SGBD oferecer as menores latência de consulta e escrita em comparação a outros tipos de SGBDs NoSQL ou relacionais.

\subsubsection{Microsserviço Event Sender}

O Event Sender é responsável por fazer requisições para os webhooks cadastrados. Ele se inscreve com o broker para receber os tipos de eventos que têm webhooks associados e envia uma chamada REST do tipo POST para o endereço, contendo os atributos recebidos em cada evento do tipo associado. Periodicamente, ele consulta o banco de dados chave valor e atualiza a lista de webhooks associados.

\subsubsection{Microsserviço CEP Worker}

O CEP Worker é o microsserviço responsável pela deteç̧ão contínua de eventos, de forma que cada instência dele pode realizar a deteç̧ão de vários tipos de eventos concomitantemente. Em contraste com os outros microsserviços do CEP Handler, o CEP Worker precisa manter um estado de execução para a deteç̧ão de eventos, pois provê a execução de operadores de CEP como Agregação, Composição e Detecção de Padrão, que utilizam dados de vários eventos, como visto na Seção 2.1.3. Para que a detecção de eventos ocorra da maneira esperada, é necessário que o próprio CEP Worker administre seu uso de recursos computacionais, caso contrário uma sobrecarga levaria a terminação do processo de eventos e a perda do estado de agregação dos tipos de eventos em deteç̧ão.

Diferentemente do CEP Worker, os outros três microsserviços do sistema CEP Handler não armazenam estado durante seu funcionamento, podendo ser escalados horizontalmente a partir da instanciação de réplicas.

\section{Cadastro de novos tipos de evento}

Os passos para o cadastro de novos tipos de eventos podem ser descritos na seguinte ordem:

1. O usuário registra os metados do tipos de evento no CEP Cataloger, que por sua vez armazena-os no Banco de Dados.

2. Caso o tipo de evento cadastrado use os dados da plataforma InterSCity diretamente, o CEP Cataloger envia uma chamada para o Event Composer criar o tipo de evento de entrada, armazená-lo no banco de dados chave-valor do sistema.

3. o Event Composer realiza a ação anterior e começa a receber os dados da plataforma em tempo real, convertendo-os em eventos de entrada para o novo tipo de evento cadastrado pelo usuário.

4. Periodicamente, os CEP Workers verificam o banco de dados para o cadastro e início de detecção de novos tipos de eventos. Quando o novo tipo de evento é cadastrado, o CEP Worker se inscreve no broker para receber os eventos de entrada gerados pelo Event Composer.

5. Periodicamente, o Event Sender atualiza sua lista interna de webhooks a serem chamados na detecção de cada tipo de evento e se inscreve no broker para receber os tipos de evento com webhooks associados.

6. Quando o CEP Worker detecta um evento do novo tipo de evento, o evento é enviado ao broker e chega ao Event Sender que o converte em chamada POST e o envia para os endereços URL associados. 


\section{Funcionamento do CEP Worker}

O CEP Worker é o principal microsserviço do sistema CEP Handler. Além de ser responsável pelo processamento dos tipos de eventos, ele tem a capacidade de auto-escalabilidade horizontal, a partir da criação de novas instâncias de si próprio. Para distribuir o processamento de eventos entre as instâncias, o CEP Worker utiliza uma série de técnicas para selecionar qual tipo de evento será realocado, como é feita a realocação do tipo de evento sem perda de detecção a partir dos eventos de entrada e como é feito o monitoramento do uso de recursos. O CEP Worker utiliza o SGBD chave-valor para compartilhar todos os dados que são utilizados por mais de uma instância, como metadados de tipos de eventos, informações sobre a realocação de tipos de eventos, etc.

O disparo da criação de novas instâncias do CEP Worker é feito a partir do monitoramento de recursos (CPU e memória) utilizados por cada instância. São definidos dois limites de sobrecarga, um limite fraco e outro forte. Quando o limite fraco é atingido, a instância pára o cadastramento de novos tipos de eventos para processamento e mantém o processamento dos tipos de eventos já cadastrados. Quando o limite forte é atingido, a instância inicia o processo de realocação dos tipos de evento. A partir do momento em que é iniciada, cada instância nova do CEP Worker recebe um identificador e inicia três threads, cada um com uma responsabilidade distinta:

- O thread de Aceitação (Algoritmo 1) é responsável pelo cadastro de eventos no sistema. Quando é iniciado, ele verifica, a partir do identificador, se a instância de CEP Worker é nova ou foi terminada previamente, por motivo de falha no ambiente de execução. Caso a instância seja nova, o thread procura por tipos de eventos prontos para serem realocados de outras instâncias de CEP Worker e inicia o processo de aceitar a realocação. Esse processo se repete até que o percentual de uso da CPU e memória disponíveis para a instância atinja um limite de sobrecarga fraca. Se não for atingida a sobrecarga fraca depois de aceitar todas as realocações disponíveis, a instância inicia o cadastro de tipos de eventos recém registrados no sistema até atingir o limite de sobrecarga fraca. Caso a instância tenha sido terminada indevidamente previamente, o thread inicia o recadastramento dos tipos de eventos anteriormente cadastrados até atingir o limite de sobrecarga fraca.

Independentemente se a instância está se recuperando de uma falha de execução ou foi recém criada pelo sistema, ao atingir o limite de sobrecarga fraca ela para de cadastrar tipos de eventos. A informação que a instância atingiu o limite de sobrecarga fraca é armazenada no SBGD chave valor. A instância verifica se ainda existem tipos de eventos recém registrados que ainda não foram cadastrados em nenhuma instância e se todas as instâncias também estão em sobrecarga fraca. Se for esse o caso, ela requisita a criação de uma nova instância de CEP Worker. A especificação para a quantidade de cada recurso computacional a ser usado por uma nova instância é fixada no mecanismo de requisição de novas instâncias ao serviço de gerenciamento dinâmico de recursos da nuvem. Depois disso, o thread dorme por um período de tempo fixo (definido por variável de ambiente). O thread verifica periodicamente a sobrecarga e, caso ela esteja abaixo do limite de sobrecarga fraca, ele repete os passos descritos anteriormente até atingir a sobrecarga fraca ou até atingir o ponto de dormir novamente. $\mathrm{O}$ período fixo de tempo durante o qual o thread dorme deve ser ajustado de acordo com o funcionamento do sistema. Esse ajuste é necessário pois, na ausência de novos eventos a serem cadastrados, o funcionamento constante do thread de aceitação pode acarretar desperdício de recursos. Quando um tipo de evento é cadastrado em uma instância do CEP Worker pelo thread de Aceitação, a instância se inscreve automaticamente para receber os eventos dos tipos de eventos de entrada desse tipo de evento no broker de mensagens.

- O thread de Sobrecarga (Algoritmo 2) monitora periodicamente o uso de recursos do sistema. Ele inicia a realocação de tipos de eventos cadastrados na instância caso o uso atinja um limite de sobrecarga forte, ou dorme por um período de tempo pré-definido no caso contrário. A duração desse período e o limite de sobrecarga forte podem ser definidos ao iniciar a execução do sistema. Caso esteja em sobrecarga forte, a instância escolhe o tipo de evento que será 


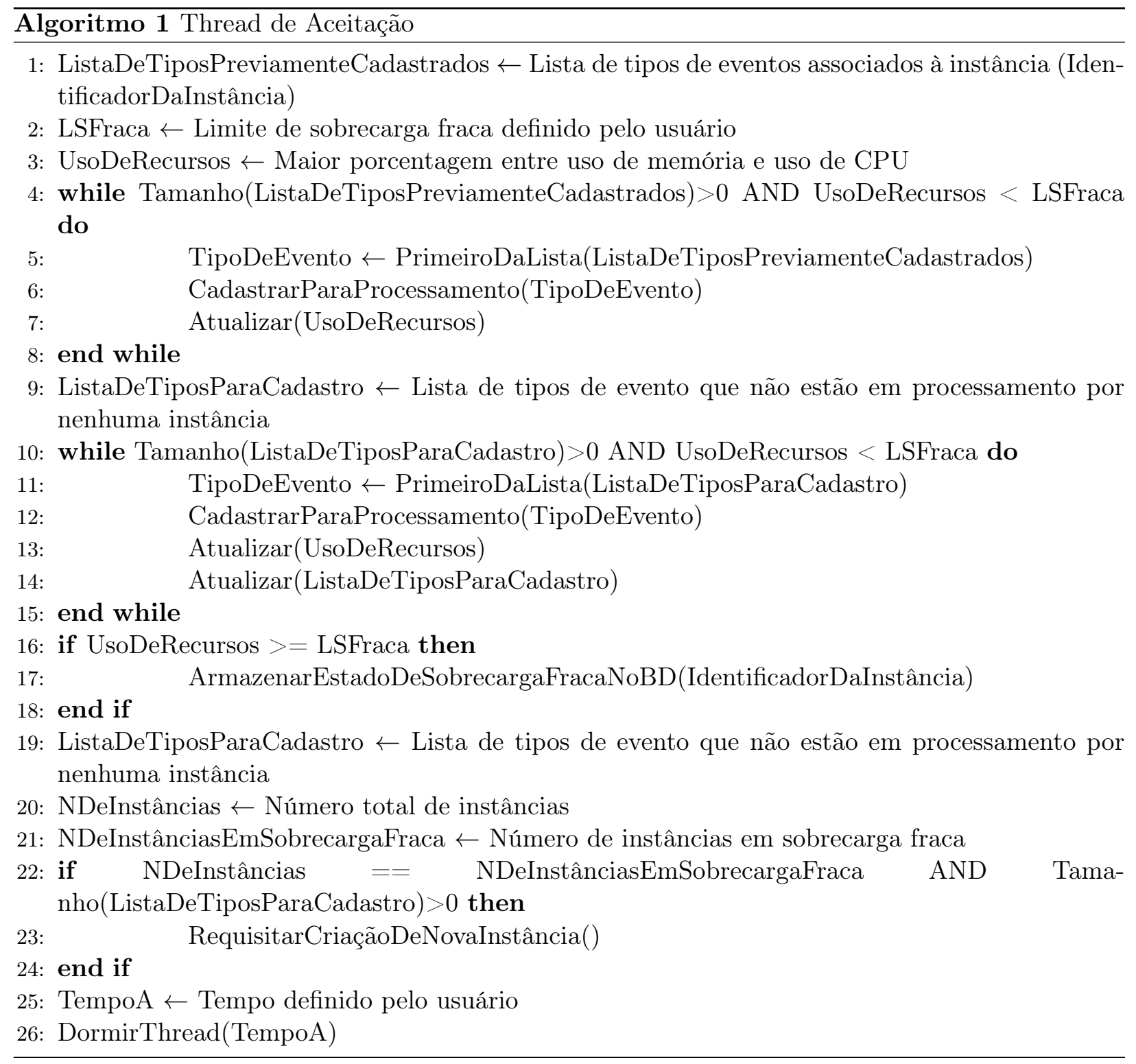

realocado a partir de dois algoritmos de balanceamento de carga, que serão descritos na Seção 4.3. Além disso, esse thread também monitora se o número de instâncias em sobrecarga forte é maior que o número de instâncias que não estão em nenhuma sobrecarga. Se esse for o caso, ele requisita e criação de uma nova instância de CEP Worker para o serviço de gerenciamento dinâmico de recursos na nuvem, utilizando a especificação fixada de recursos computacionais de cada instância.

- O thread de Subcarga (Algoritmo 3) também monitora periodicamente o uso de recursos do sistema e armazena no banco de dados quando o limite de subcarga é atingido. Caso a instância seja a com menor uso de recursos entre todas em subcarga, o thread inicia a realocação de todos os tipos de eventos cadastrados na instância. Caso todos os tipos de eventos forem realocados, a instância requisita sua remoção ao serviço de gerenciamento dinâmico de recursos na nuvem. O intervalo de tempo entre uma verificação e a próxima e o limite de subcarga podem ser definidos por variáveis de ambiente ao iniciar o sistema. Isso garante que instâncias que estão subutilizadas possam ser removidas.

A sobrecarga, fraca ou forte, é atingida quando a porcentagem de uso de CPU ou de memória RAM são superiores ao valor de porcentagem estabelecido como limite. A subcarga é atingida quando a porcentagem de uso de CPU e de memória são inferiores ao valor estabelecido como limite. 

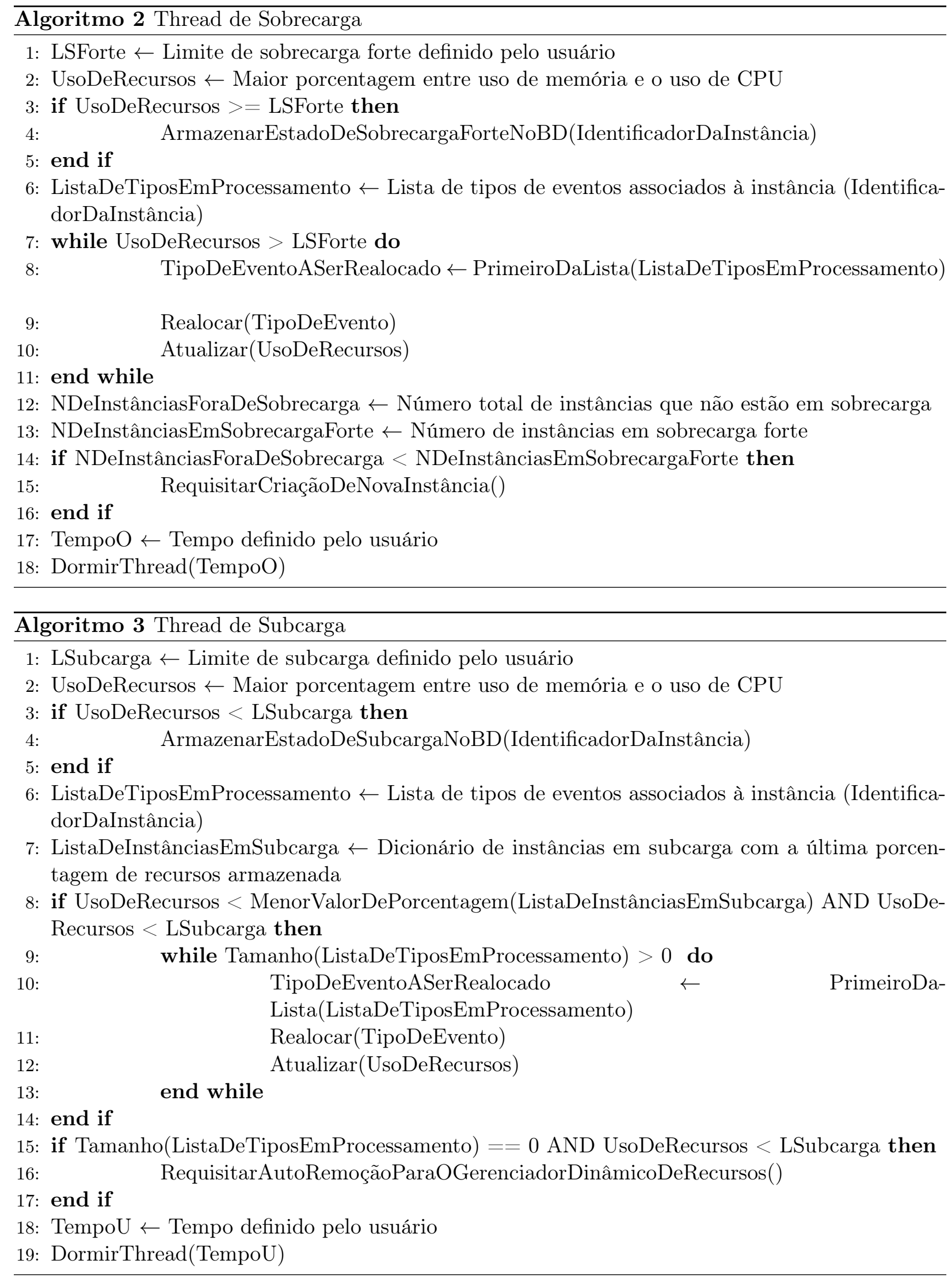

\subsection{Método de Realocação}

Quando uma instância está em subcarga ou em sobrecarga forte, ela inicia o método de realocação de tipos de eventos. A duração da realocação depende do contexto e estado do tipo de evento 
realocado, de acordo com os operadores utilizados, como visto nas seções 2.1.3 e 2.1.2.

Como exemplo, considere um cenário no qual há uma instância $A$ que precisa realocar um tipo de evento $T$ e uma instância $B$ que não está em sobrecarga e que poderia, portanto, receber $T$. A realocação, nesse caso, se dá da seguinte forma:

1. A instância $A$ sinaliza, armazenando um pedido de realocação no SGBD chave-valor, que quer realocar o tipo de evento $T$, iniciando o processo de realocação.

2. A instância $B$ verifica quais tipos de eventos estão prontos para realocação e sinaliza, armazenando uma confirmação de aceitação de realocação no SGBD chave-valor, que irá alocar o tipo de evento $T$ da instância $A$. O processo de sinalização é atômico, de forma que outra instância $C$ não consegue sinalizar ao mesmo tempo que vai alocar o tipo de evento $T$.

3. A instância $A$ verifica no SGBD que a instância $B$ se prontificou a aceitar a realocação do tipo de evento $T$.

4. A instância $B$ inicia a deteç̧ão do tipo de evento $T$, se inscrevendo para receber seus tipos de eventos de entrada, porém sem enviar os eventos detectados para o broker, já que a instância $A$ ainda está os enviando e isso causaria detecção duplicada.

5. Ambas instâncias esperam um período de tempo para que o estado do tipo de evento $T$ seja reconstruído na instância $B$. Esse período é determinado pela janela de eventos utilizada na definição de $T$. Caso seja uma janela temporal, o tempo da janela é esperado. Caso seja uma janela por número de eventos, a espera continua até que o número de eventos de entrada que chegaram na instância $B$ seja igual ou maior ao número especificado na definição.

6. A instância $B$ avisa a instância $A$ de que o estado foi reconstruído.

7. A instância $A$ confirma que a instância $B$ pode começar a enviar eventos do tipo $T$ realocado, pára de enviar eventos desse tipo e inicia o processo de remoção da detecção dele.

8. A instância $B$ inicia o envio de eventos do tipo $T$ assim que recebe confirmação da instância A.

Além desses passos, algumas limitações são impostas no processo para o funcionamento correto do sistema:

- Como são threads separados que cuidam da aceitação de realocação e da realocação dos tipos de eventos para outras instâncias, cada início de processo de realocação verifica se o tipo de evento a ser aceito para alocação não está atualmente sendo processado na instância que iniciou o processo de aceitação de realocação.

- O processo de realocação de tipos de eventos ou de aceitação de realocação de tipos de eventos é sequencial, pois só um thread administra o processo de aceitação de realocação.

- O sistema pressupõe que os eventos de entrada estão chegando concomitantemente nas instâncias $A$ e $B$. Não são feitas verificações para saber se os eventos de entrada não estão chegando nos dois nós concomitantemente, pois esse seria um problema do ambiente de execução.

A partir disso, é possível dizer que, durante a realocação dos tipos de eventos, especialmente entre os passos 7 e 8, o CEP Worker garante que cada evento detectado é enviado no máximo uma vez. Quanto menor o tempo entre os passos 7 e 8 pode ser minimizado, menor a possibilidade da chegada de eventos de entrada e a consequente detecção de novos eventos nesse período. Entretanto, esse tempo depende das condições do ambiente de execução e da latência de comunicação com o SGBD chave-valor. Fora do processo de realocação, todos os eventos são detectados de acordo com a garantia de entrega dos eventos de entrada pelo sistema de mensageria, que pode ter configurações distintas dependendo do usuário. 


\subsection{Algoritmos de Distribuição de Carga}

Duas estratégias distintas podem ser usadas por uma instância de CEP Worker para escolher tipos de eventos para realocação em outras instâncias num caso de sobrecarga:

- Considerar na escolha os tipos e tamanhos de estados usados na detecção dos tipos de eventos alocados na instância sobrecarregada, como feito por Martins et al. (2014). Essa estratégia (descrita no Algoritmo 4) separa os tipos de eventos entre aqueles que não necessitam de estado para detecção, aqueles cuja estado é baseado em janela temporal e aqueles cujo estado depende do fluxo de eventos de entrada. Os tipos de eventos que utilizam nenhum estado ou que usam menos estado são os primeiros a serem selecionados para realocação. O ranqueamento é baseado no tempo que se leva para construir o estado de cada tipo de evento, de acordo com seus eventos de entrada. Tipos de evento baseados em janelas temporais são avaliados a partir do intervalo de tempo de suas janelas. Tipos de eventos baseados em janelas de eventos são avaliados a partir da medição do seu fluxo de eventos de entrada, mais especificamente do menor fluxo entre os eventos de entrada. Isso garante que as realocações de tipos de evento possam ocorrer mais rapidamente.

- Considerar na escolha a similaridade entre tipos de eventos de entrada dos tipos de eventos alocados na instância sobrecarregada, como proposto por Isoyama et al. (2012). Nessa segunda estratégia (descrita no Algoritmo 5), os tipos de eventos sendo detectados cujos tipos de evento de entrada diferem mais dos de outros tipos de eventos processados na instância são selecionados primeiro para realocação. Quando todos os tipos de evento processados utilizam os mesmos tipos de evento de entrada, os tipos de eventos para realocação são selecionados de acordo com o Algoritmo 4.

A partir dessas duas estratégias, foram criados dois algoritmos de balanceamento de carga para a seleção de tipos de eventos a serem realocados no sistema CEP Handler:

\subsubsection{Algoritmo de Balanceamento de Carga por Uso de Estado}

O Algoritmo 4 (Balanceamento de Carga por Uso de Estado) cria duas estruturas de dicionário ordenadas: um ranking de tipos de eventos que utilizam janelas temporais e um ranking de tipos de eventos que utilizam janelas de número de eventos (chamadas doravante de janelas de tamanho). Essas estruturas são listas de pares entre o identificador do tipo de evento e um outro valor.

No ranking de tipos de eventos que utilizam janelas temporais, o outro valor é o intervalo de tempo da janela de agregação utilizada. A janela de tempo é obtida da definição do tipo de evento. Os tipos que eventos que não utilizam janelas de agregação são adicionados ao ranking de tipos de eventos com janela temporal, com zero como valor de intervalo de tempo da janela.

No ranking de tipos de eventos que utilizam janelas de tamanho de eventos, o outro valor é a divisão do tamanho da janela de eventos pela taxa de consumo de eventos de entrada. A taxa de consumo de cada evento de entrada é calculada pela divisão do número de eventos de cada tipo entrando no sistema por intervalo de tempo. A taxa de consumo de eventos de entrada é recalculada a cada inclusão ou remoção de tipos de evento para processamento na instância. O disparo do recálculo é feito dessa maneira pois uma mudança do número de tipos de eventos processados pela instância significa que houve alguma mudança no uso de recursos do sistema e, possivelmente, nos fluxos dos eventos de entrada que impactam o uso de recursos pela instância.

A Figura 4.2 representa uma instância de CEP Worker processando dois tipos de eventos. Os triângulos representam eventos distintos e as caixas que se estendem para fora da instância representam as janelas de eventos dos tipos de eventos de entrada. Caso precisasse realocar um de seus tipos de de eventos, o algoritmo de balanceamento de carga por uso de estado selecionaria primeiro o tipo de evento no EPA 2 para realocação, por ter a menor janela de eventos de entrada.

A cada novo cadastro ou remoção do processamento de algum tipo de evento, todos os valores da estrutura de ranking de tipos de eventos que utilizam janelas de tamanho são atualizados. A 


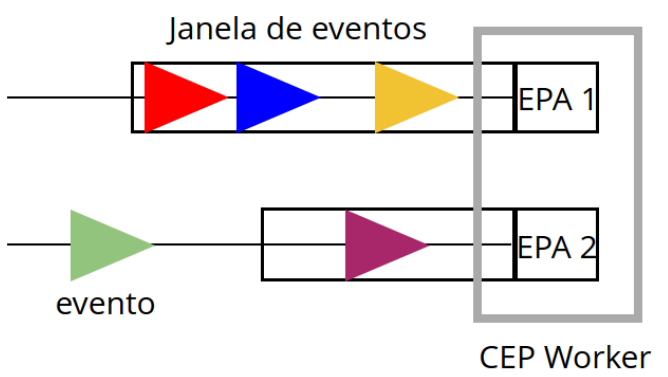

Figura 4.2: Diagrama de representação do algoritmo de balanceamento de carga por Uso de Estado.

estrutura utilizada para o ranking de tipos de eventos que utilizam janelas temporais é reordenada para cada inserção ou remoção de tipo de evento, porém o valor associado a cada tipo é constante. O valor colocado como rank nas duas estruturas ordenadas para cada tipo de evento é semelhante ao tempo necessário para a construção do estado interno da janela de agregação. Quando a função de selecionar o próximo tipo de evento a ser realocado é chamada, ela compara qual das duas listas ordenadas oferece o menor tempo de realocação e retorna o tipo de evento, dentre as duas estruturas, que possui o menor valor de rank.

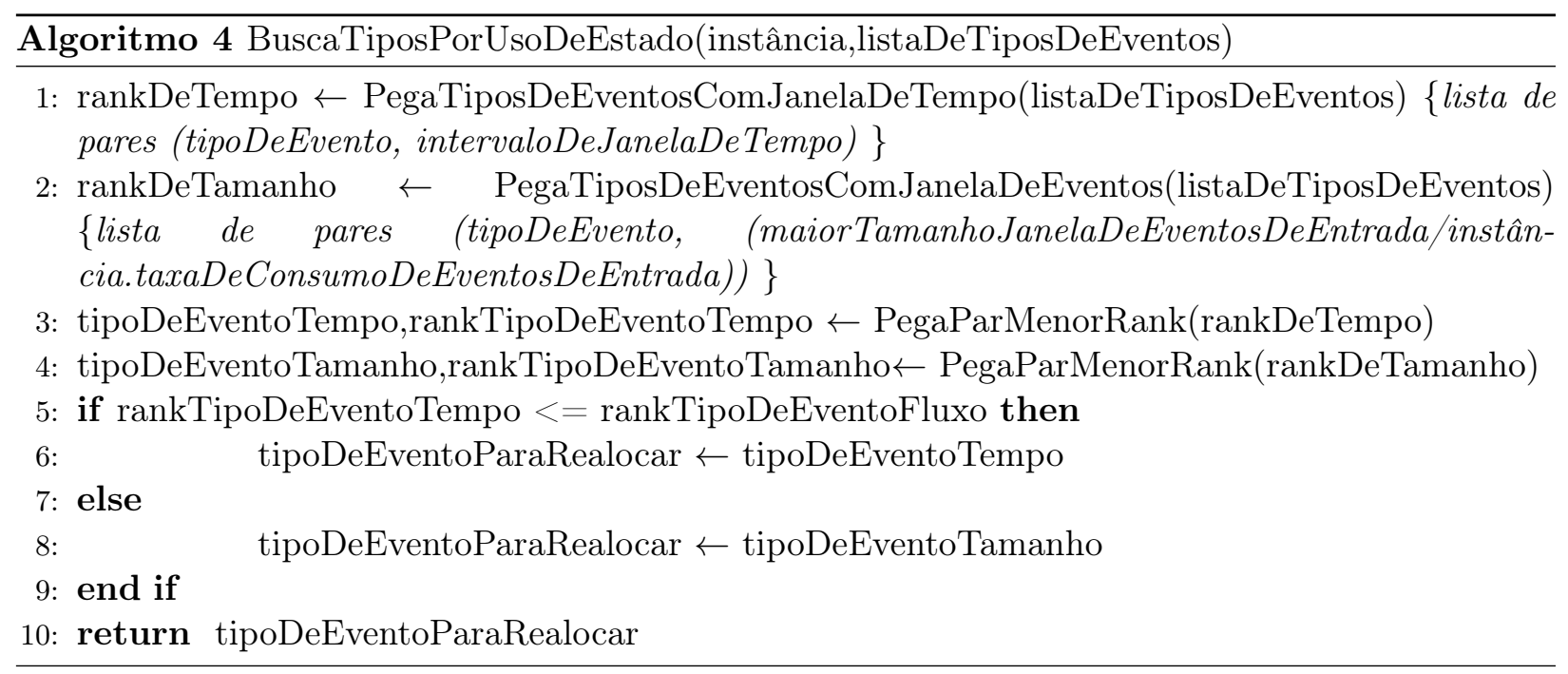

\subsubsection{Algoritmo de Balanceamento de Carga por Similaridade de Entrada}

O Algoritmo 5 (Balanceamento de Carga por Similaridade de Entrada) utiliza duas estruturas principais para organizar a seleção dos tipos de evento. A primeira (o indiceInvertidoDeEntrada) é um índice invertido de tipos de eventos, que armazena, para cada tipo de evento, uma lista dos tipos de evento que o têm como entrada. A segunda (TiposDeEventoPorRank), é um dicionário de tipos de evento por rank, que utiliza um valor numérico (o rank) como chave e possui uma lista de tipos de evento como valor por cada chave.

O algoritmo utiliza os metadados dos tipos de evento para saber qual tipo de evento usa um dado outro tipo de evento como entrada e popular a estrutura indiceInvertidoDeEntrada. Depois que essa estrutura está devidamente populada, para cada tipo de evento $T$, o algoritmo seleciona o tipo de evento de entrada $P$ de $T$ menos utilizado por outros tipos de eventos, utilizando o tamanho da lista de tipos de eventos associada ao tipo de evento de entrada $P$ em indiceInvertidoDeEntrada. A partir da seleção de $P$ é selecionado o valor $a$ da quantidade de vezes que $P$ é usado como entrada por todos os tipos de eventos. O valor $a$ é utilizado como o rank de $T$ em TiposDeEventoPorRank.

Para selecionar qual tipo de evento deve ser realocado, busca-se o menor rank dentre aqueles presentes como chave em TiposDeEventoPorRank e a seleção entre os tipos de evento que estão associados ao mesmo rank é feita utilizando o Algoritmo 4. 

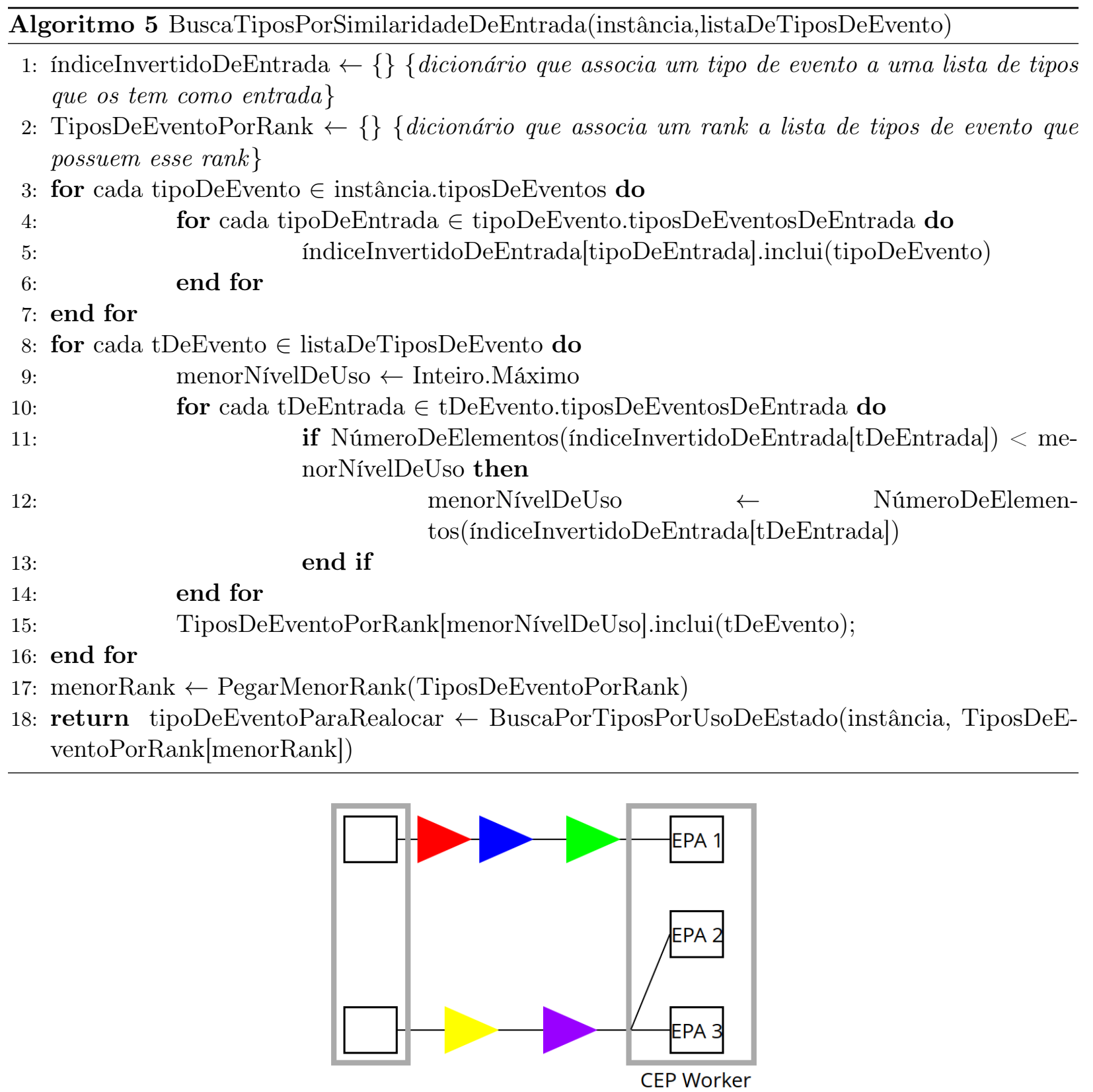

Figura 4.3: Diagrama de representação do algoritmo de balanceamento de carga por Similaridade de Entrada.

A Figura 4.3 representa uma instância de CEP Worker processando três tipos de eventos. Dois destes usam o mesmo tipo de evento de entrada, enquanto o tipo de evento no EPA 1 uso um tipo de evento de entrada distinto. Caso a instância utilizasse o algoritmo de balanceamento por similaridade de entrada para selecionar qual tipo de evento será realocado, o tipo de evento processado pelo EPA 1 seria selecionado primeiro pois usa o tipo de evento de entrada menos usado.

\subsection{Escalabilidade e Tolerância a Falhas}

A arquitetura descrita neste capítulo pode ser considerada como nativa de nuvem pois cumpre os principais requisitos não funcionais desse tipo de sistema que, conforme explicado no 2, são: auto-escalabilidade e tolerância a falhas.

Dos seis microsserviços que compõe o sistema, quatro não armazenam estado durante seu processamento: CEP Cataloger, Event Composer, Event Sender e o broker de mensagens. Como 
visto na Seção 2.4.1, esse tipo de microsserviço pode ser replicado para tratar um aumento na carga a ser processada sem maiores complicações. O aumento ou diminuição do número de instâncias de microsserviços sem estado é normalmente gerido pelo serviço de gerenciamento dinâmico de recursos na nuvem escolhido. Além disso, vários SGBDs chave-valor oferecem mecanismos de escalabilidade horizontal para leitura rápida, como os mencionados na Seção 2.4.2. Na Seção 4.1.5, foram discutidos os métodos de deteç̧ão de sobrecarga e requisição de novas instâncias para o serviço de gerenciamento dinâmico de recursos quando a sobrecarga forte é detectada.

No caso de microsserviços que não armazenam estado, caso sofram falhas de execução, o próprio serviço de gerenciamento dinâmico de recursos na nuvem se responsabiliza por remover a instância com falha e iniciar uma nova instância. Os outros dois serviços, o SBGD chave-valor e o CEP Worker, mantêm um estado em memória durante seu funcionamento. Os SBGDs chave-valor atualmente mais utilizados pela comunidade normalmente oferecem métodos de armazenamento em disco em segundo plano a partir de comandos ou periodicamente. Caso ocorra uma falha na execução do SGBD, apesar do microsserviço perder sua instância de processamento, ele pode ser re-instanciado e consultar os dados que estavam em disco. Normalmente, a frequência de gravação em disco em segundo plano é de um minuto ou menos, podendo ser configurada pelo usuário. O CEP Worker, como visto na Seção 4.1.5, tem implementado um mecanismo para verificar, a cada novo início de instância, se ela foi previamente terminada por falhas e, se for esse o caso, recadastrar os tipos de eventos que estavam previamente cadastrados na instância.

Logo, todos os microsserviços do CEP Handler possuem mecanismos para se recuperarem de falhas de execução e retornarem a um estado de processamento usual. Também cumprem o requisito de auto-escalabilidade, ou por mecanismos internos ou por configuração do serviço de gerenciamento dinâmico de recursos na nuvem utilizado. 


\section{Capítulo 5}

\section{Protótipo e Ferramentas Selecionadas}

Neste trabalho, um protótipo da arquitetura para sistema de CEP distribuído apresentada no Capítulo 4 foi implementado e avaliado. A escolha das ferramentas para a implementação do protótipo levou em conta vários fatores que dependem da função de cada ferramenta no sistema. Mas um dos critérios de seleção aplicado foi o de que os softwares utilizados na implementação deveriam ser livres, com uma licença que garantisse a visualização, alteração e distribuição do código da ferramenta. O código desenvolvido pode ser encontrado no repositório online GitLab ${ }^{1}$

A Figura 5.1 representa a arquitetura do sistema com as ferramentas selecionadas. As seções a seguir apresentam detalhes sobre a escolha das ferramentas e a implementação do protótipo.

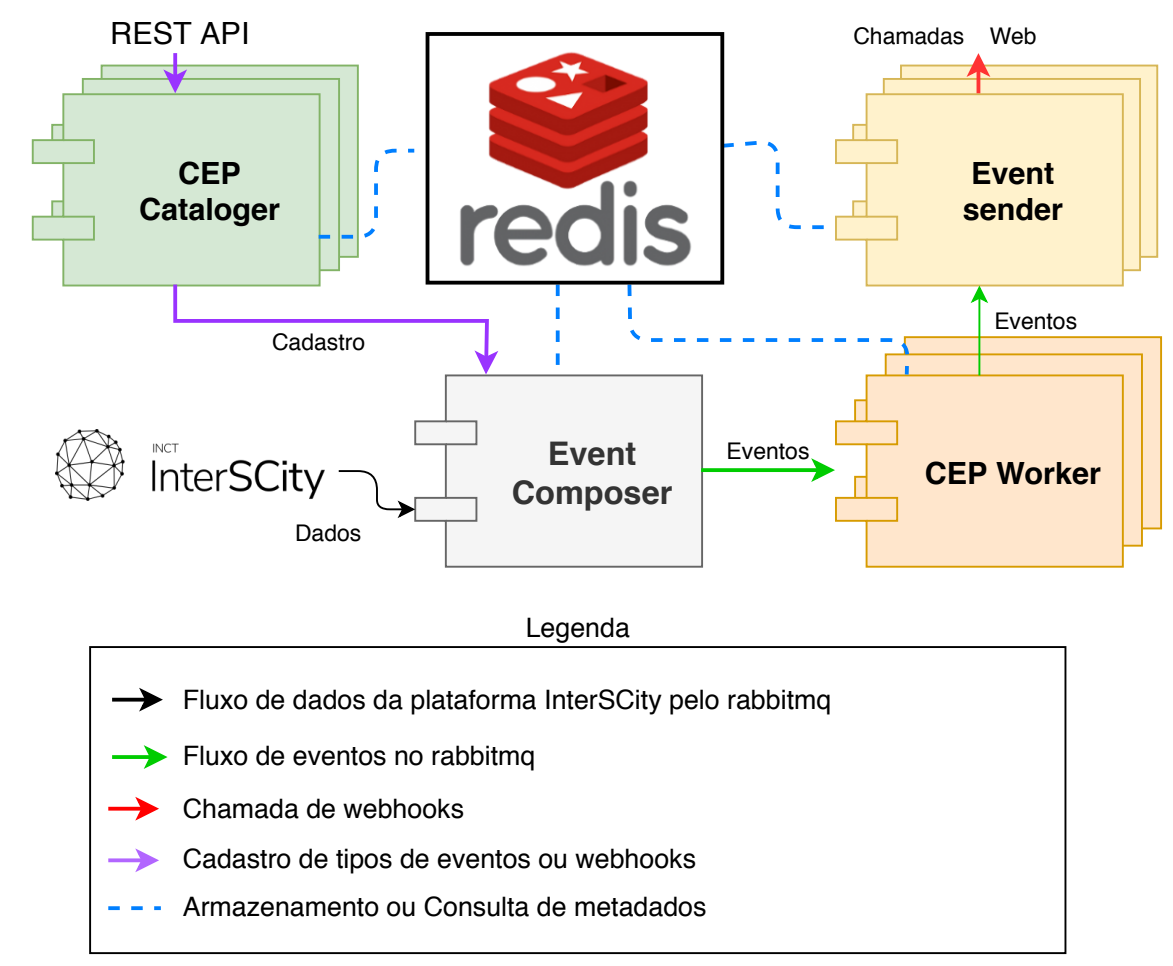

Figura 5.1: Protótipo da arquitetura do CEP Handler.

\section{A Plataforma InterSCity}

A plataforma de cidades inteligentes InterSCity foi projetada e desenvolvida pelo Instituto Nacional de Ciência e Tecnologia da Internet do Futuro para Cidades Inteligentes (Esposte et al., 2019), sediado no IME-USP, para o desenvolvimento e suporte a projetos de Cidades Inteligentes. O principal propósito da plataforma é prover serviços de alto nível e APIs RESTful para suporte

\footnotetext{
${ }^{1}$ https://gitlab.com/interscity/interscity-platform
} 
no desenvolvimento de novos serviços para as cidades. A plataforma adota uma arquitetura de microsserviços para possibilitar a integração de uma grande quantidade de recursos e dados e prover serviços de qualidade para a cidade. Na plataforma, os sensores ou atuadores na cidade são considerados Recursos, que podem enviar diferentes tipos de dados. Cada Recurso está associado a uma ou mais Capacidades, que descrevem quais tipos de dados os sensores podem coletar ou quais ações os atuadores podem realizar. A seguir, são descritos os principais microsserviços da plataforma:

- Resource Adaptor: responsável por coletar dados enviados em tempo real por sensores espalhados pela cidade.

- Actuator Controller: responsável por enviar comandos para atuadores na cidade.

- Resource Cataloger: responsável por manter um registro de todos os sensores e atuadores na cidade, além dos tipos de Capacidades que cada Recurso possui e do esquema dos dados que cada Capacidade envia.

- Data-Collector: responsável por manter uma cópia de todos os dados coletados para análises em lotes.

- Resource-Viewer: responsável por fazer a interação da plataforma com usuários por interface gráfica.

A plataforma InterSCity possibilita o cadastro de novos Recursos e Capacidades por uma API RESTful, além da visualização dos dados já coletados. O microsserviço Event Composer da ferramenta CEP Handler, descrito na Seção 4.1.2, se conecta com o Resource Adaptor, para receber os dados em tempo real, e com o Resource Cataloger, para saber o esquema dos dados recebidos e convertê-los em eventos. Todos os dados enviados em tempo real para o sistema podem ser convertidos em eventos e ser utilizados na definição de outros eventos. Como o sistema de processamento de eventos desenvolvido neste trabalho foi implementado de forma integrada à plataforma do InterSCity, escolheu-se um nome em inglês para ele (CEP Handler), para manter o mesmo estilo de nomenclatura já usado nos microsserviços da plataforma.

\subsection{Ferramenta de Processamento de Eventos}

Para o processamento de eventos nos nós do sistema distribuído (ou seja, nas instâncias de CEP Worker), foi escolhida a ferramenta mais utilizada pela comunidade de CEP e que possui a interface mais conhecida - a Esper ${ }^{2}$. As vastas documentação e comunidade de apoio dessa ferramenta facilitaram o seu uso na implementação do sistema CEP Handler. A Esper permite representar eventos em alguns formatos diferentes, porém somente três deles apresentam ocupam o mínimo de memória durante o processamento (EsperEventRepresentation, 2020):

- Java Object Array: possibilita trabalhar com eventos representados por vetores de objetos, em que cada campo do objeto representa um campo do evento. Essa abordagem permite trabalhar com qualquer evento, mesmo quando não se sabe quais medidas ou campos ele contém, mas tem a desvantagem de ser uma representação específica da linguagem Java.

- Classe Java - POJO: possibilita representar cada evento como uma definição de classe em um arquivo Java. Esse formato só pode ser utilizado para tratar eventos em um contexto no qual os campos já são previamente conhecidos, o que não condiz com a proposta deste trabalho, ou utilizando geração automática de código Java, o que tornaria necessário recompilar o CEP Worker e instanciá-lo novamente toda vez que um novo evento fosse cadastrado em uma instância dele ativa, forçando o sistema a parar o processamento para isso.

\footnotetext{
${ }^{2}$ https://www.espertech.com/esper/
} 
- Apache Avro: Apache Avro ${ }^{3}$ é um protocolo de seriação de dados implementado em várias linguagens. Ele apresenta um uso de memória interno tão pequeno quanto um vetor de objetos Java, com a vantagem de poder ser lido por outros softwares em outras linguagens. Feito inicialmente para o Apache Hadoop ${ }^{4}$, atualmente ele é aceito em vários sistemas de processamento em tempo real além do Esper, como o Apache $\operatorname{Spark}^{5}$, o que diminui o custo de integração com outros serviços no futuro.

Optou-se pelo uso do Apache Avro para a representação de eventos neste trabalho, por ele ser independente do Java, deixando, dessa forma, o sistema mais desacoplado de qualquer linguagem de programação. Durante o desenvolvimento deste trabalho, foi adicionada à ferramenta Esper suporte à representação de eventos com o formato JSON (JavaScript Object Notation). A representação de eventos por JSON tem um uso de memória tão pequeno quanto o dos outros formatos apresentados aqui, mas não foi considerada pois o sistema e os experimentos já estavam desenvolvidos para o uso do formato Avro quando ela ficou disponível no Esper.

Um fator limitante no desenvolvimento do protótipo foi o suporte aos tipos de janelas de agregação. Como discutido na Seção 4.3, para o balanceamento da carga entre as instâncias de processamento, é necessário determinar o tamanho das janelas de dados a partir da definição dos tipos de eventos. De todos os tipos de janelas de dados oferecidas pelo Esper (ESPERDataWindows, 2020), só foi implementado o suporte a quatro: ext_timed, ext_time_batch, length e length_batch. Os dois primeiro foram selecionados por serem exemplos de janelas temporais nos quais o tempo utilizado é externo e não necessita da coordenação dos relógios internos dos nós de processamento de eventos. Os dois últimos foram selecionados como exemplos de janelas de agregação por número de eventos, por serem um dos tipos mais comuns de janelas de dados utilizados.

\subsubsection{Limitações}

O suporte a tabelas de nomes ou conexões com SGBDs por SQL não foi implementado, o que limita o número de operadores que podem ser usados. Além disso, durante a recriação das instâncias que sofreram falhas de execução, todos os eventos em estado de EPAs se perdem, independentemente do tamanho da janela de eventos de entrada de cada tipo de evento em processamento. Uma possível solução para esse problema da perda seria a implementação de um mecanismo de reenvio dos eventos de entrada em caso de falha, de acordo com a janela de eventos de entrada de cada tipo de evento.

\subsection{Microsserviços sem Estado}

O CEP Cataloger, Event Composer e Event Sender são microsserviços que só oferecem métodos que não guardam estado. A implementação dos três microsserviços foi feita usando Docker para o isolamento de ambiente de execução, de forma que poderia ser escrita em qualquer linguagem de programação com suporte a clientes dos outros serviços. Pelo conhecimento prévio de Java do autor do trabalho, essa foi a linguagem escolhida para o desenvolvimento dos três microsserviços.

\subsection{Gerenciamento Dinâmico de Recursos}

Para executar os contêineres em ambientes de nuvem, existem várias alternativas, entre elas: executá-los diretamente em máquinas virtuais, utilizar orquestradores de contêineres proprietários, como o Elastic Container Service - ECS ${ }^{6}$ da AWS, ou utilizar orquestradores de recursos de software livre.

Entre os orquestradores de software livre, três se destacam:

\footnotetext{
${ }^{3}$ https://avro.apache.org

${ }^{4}$ https://hadoop.apache.org

${ }^{5}$ https://spark.apache.org

${ }^{6}$ https://aws.amazon.com/pt/ecs/
} 
- Apache Mesos ${ }^{7}$ : Desenvolvido inicialmente pela universidade de Berkeley, depois passou a ser mantido pela Apache Foundation. Foi desenvolvido com foco em coordenação de clusters de computadores e depois passou a receber suporte a administração de contêineres.

- Docker Swarm ${ }^{8}$ : Desenvolvido pela mesma empresa que mantém a ferramenta Docker, o Docker Swarm tem compatibilidade nativa com o sistema de isolamento de ambientes Docker.

- Kubernetes ${ }^{9}$ : Desenvolvido pela Google com o codinome Borg internamente, teve seu código aberto em e passou a ser mantido pela Cloud Native Computing Foundation - CNFC ${ }^{10}$. A CNCF é uma fundação voltada ao desenvolvimento de ferramentas para sistemas feitos nativamente para execução em nuvem.

Truyen et al. (2019) fizeram uma comparação dos três orquestradores de contêineres e concluíram que o Kubernetes oferece o maior número de opções de configuração entre os três. Além disso, é o único que possui suporte nativo pelas três maiores provedoras de computação em nuvem (AWS, GCP e Azure). Por esses motivos, o Kubernetes foi escolhido para a implementação do protótipo aqui apresentado.

\subsection{Transmissão Assíncrona}

Para a transmissão de eventos em tempo real, foi escolhido o broker de mensagens RabbitMQ ${ }^{11}$. RabbitMQ é um dos brokers mais usados atualmente, pois implementa vários protocolos de comunicação assíncrona (Dobbelaere e Esmaili, 2017). O principal fator para a escolha do RabbitMQ como broker foi a compatibilidade com a plataforma InterSCity, cuja implementação já utiliza o RabbitMQ como mensageiro assíncrono. Já que o sistema proposto neste trabalho foi desenvolvido como uma extensão da plataforma InterSCity, é interessante utilizar em sua implementação as mesmas ferramentas usadas na plataforma, para permitir uma maior integração entre eles.

No protótipo do sistema aqui apresentado, o RabbitMQ opera dentro de um contêiner Docker, cuja imagem é disponibilizada oficialmente pelo repositório de imagens Docker Hub ${ }^{12}$. Todos os eventos, primários ou detectados pelo sistema, passam pelo RabbitMQ, mesmo que o tipo de evento que vai utilizar o evento esteja sendo detectado na mesma instância de CEP Worker que o produz. Desta forma, é mais fácil conectar webhooks a qualquer tipo de evento. Um webhook começa a receber eventos assim que é cadastrado e começa a ser verificado pelo Event Sender, sem a necessidade de modificação interna no CEP Worker.

\subsection{Sistema Gerenciador de Banco de Dados}

Como sistema gerenciador de banco de dados, para guardar a definição dos eventos e seus metadados, foi escolhido o Redis ${ }^{13}$, um sistema NoSQL baseado no modelo de dados chave-valor. O Redis foi escolhido por ser um software livre, ter uma grande comunidade de usuários e apresentar uma das menores latências entre sistemas gerenciadores de bancos de dados (Rabl et al., 2012). No protótipo do sistema CEP Handler desenvolvido, o Redis opera dentro de um único contêiner Docker, cuja imagem é disponibilizada oficialmente pelo repositório de imagens Docker Hub.

Para o armazenamento segundo o modelo de dados chave-valor, identificadores do tipo UUID (universally unique identifier) são usados como chaves para os tipos de evento. A unicidade desse tipo de identificador não depende de um registro central ou de coordenação entre diferentes partes

\footnotetext{
${ }^{7}$ https://mesos.apache.org

${ }^{8}$ https://docs.docker.com/engine/swarm/

${ }^{9}$ https://kubernetes.io

${ }^{10}$ https://cnfc.io

${ }^{11}$ https://www.rabbitmq.com/

${ }^{12}$ https://hub.docker.com/

${ }^{13}$ https://redis.io/
} 
do sistema distribuído, em contraste com a maioria dos demais tipos de identificadores. A probabilidade que um UUID seja duplicado é negligenciável. O método para a geração desse tipo de identificador é reconhecido pela Open Software Foundation (OSF, 2020), pela Internet Engineering Task Force (IETF, 2020), como parte do ISO/IEC 11578:1996 "Information technology - Open Systems Interconnection - Remote Procedure Call (RPC)" e mais recentemente em ITU-T Rec. X.667 | ISO/IEC 9834-8:2005 (11578:1996, 2020).

No sistema CEP Handler, estão associados a uma chave UUID de tipo de evento: os tipos de eventos que lhe servem de entrada, o nome do tipo de evento, a sua definição em EPL e os endereços de webhooks a serem chamados no caso da deteç̧ão de eventos desse tipo. 


\section{Capítulo 6}

\section{Experimentos de Avaliação de Desempenho do CEP Handler}

O desempenho do sistema de processamento de eventos desenvolvido neste trabalho foi avaliado por meio de experimentos executados em uma plataforma de nuvem pública, com uma rede e processamento de eventos para o monitoramento de tráfego de ônibus do sistema de transporte público da cidade de São Paulo, SP. Os detalhes sobre os experimentos são descritos nas seções a seguir.

\subsection{Caracterização dos Dados de Posição de Ônibus}

Os experimentos usam como entrada dados das posições de ônibus do sistema de transporte público de São Paulo coletados durante três horas contínuas. Os dados foram obtidos por meio da API do sistema Olhovivo ${ }^{1}$ da São Paulo Transporte S/A (SPTrans), empresa que faz a gestão do sistema de transporte público por ônibus na cidade.

Os dados foram coletados no dia quatro de novembro de 2019, segunda-feira, das 7h57 até às 11h02. Eles se referem a 2.360 linhas de ônibus e 26.624 veículos. O intervalo de tempo médio entre dois envios de dados em cada ônibus é de quinze a vinte segundos. Os dados coletados foram pré-processados, pois estavam organizados de acordo com as linhas, com um dado em JSON para cada linha de ônibus e um campo com um JSON Array contendo os dados de cada ônibus servindo a linha. A partir do pré-processamento, os atributos específicos das linhas foram replicados para cada dado de ônibus. Depois do pré-processamento, os dados ficaram com os campos descritos no Exemplo 12.

\subsection{Tipos de Evento Detectados}

A rede de processamento de eventos criada para o experimento contém cinco categorias de tipos de evento, que detectam problemas de tráfego de ônibus comuns em grandes cidades, tais como lentidão em corredores e agrupamentos de ônibus. Cada categoria foi implementada em um dos seguintes níveis de granularidade:

- um tipo de evento para cada linha de ônibus;

- um tipo de evento para cada corredor de ônibus da cidade;

- um tipo de evento para cada ônibus.

A Figura 6.1 mostra o diagrama da rede de processamento, com as origens e destinos de cada categoria de tipo de evento. Cada tipo de evento teve seu identificador e seu nome criados a partir de

\footnotetext{
${ }^{1}$ http://olhovivo.sptrans.com.br
} 


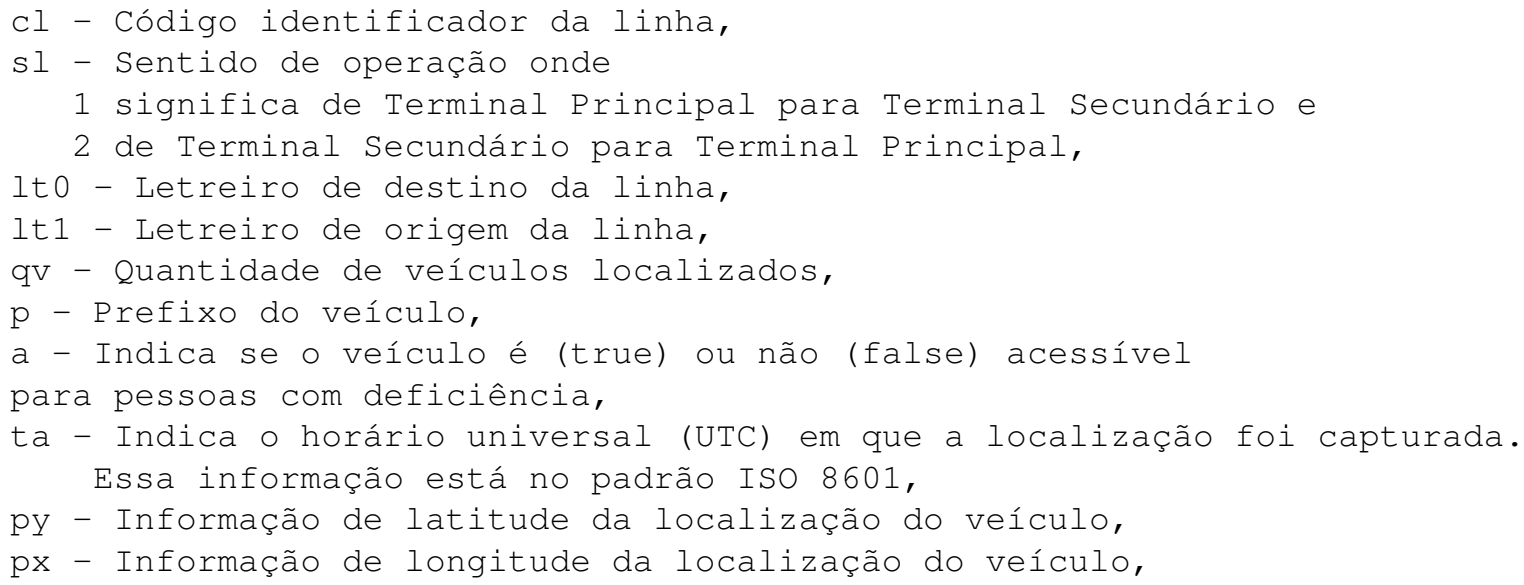

Exemplo 12: Descrição dos dados da SPTrans após o pré-processamento.

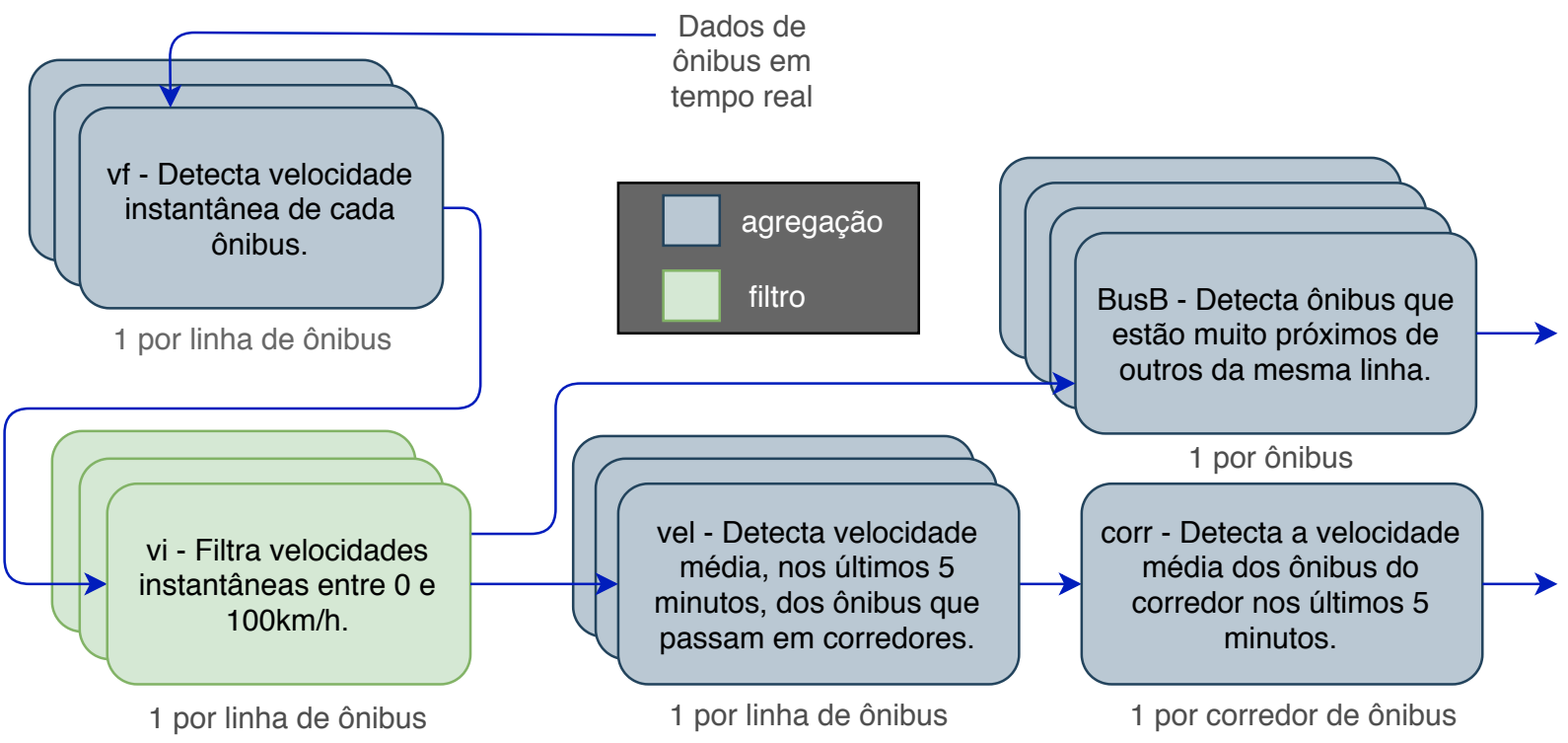

Figura 6.1: Rede de processamento de eventos de localização de ônibus.

prefixos específicos para cada categoria, concatenados ao identificador de linha, ônibus ou corredor. A definição dos tipos de evento foi feita na linguagem EPL do Esper. Para o experimento, foram utilizados dois tipos de janelas:

- ext_timed: utiliza um timestamp do próprio tipo de evento para realizar a agregação em janelas temporais deslizantes;

- lenght: utiliza um número de eventos fixo para a agregação por janelas de eventos deslizantes.

As definições de janelas de eventos deslizantes e janelas de tempo deslizantes podem ser encontradas na Seção 2.1.2. Para cada categoria de tipo de evento, além dos tipos de evento de entrada, é necessário definir o identificador (Id) do tipo de evento, o nome e a definição em EPL, como descrito na Seção 5.5. As cinco categorias de tipos de eventos da rede dos experimentos são:

- Velocidade Instantânea de Ônibus (vf) - nível: um por linha de ônibus

- Id do tipo de evento: $v f+c l$

- Nome do tipo de evento: velf $+\mathrm{cl}$ 
Cada tipo de evento nessa categoria calcula a velocidade instantânea de cada ônibus de uma linha, usando a posição recebida e a posição anterior do ônibus.

A definição de vf na linguagem EPL é:

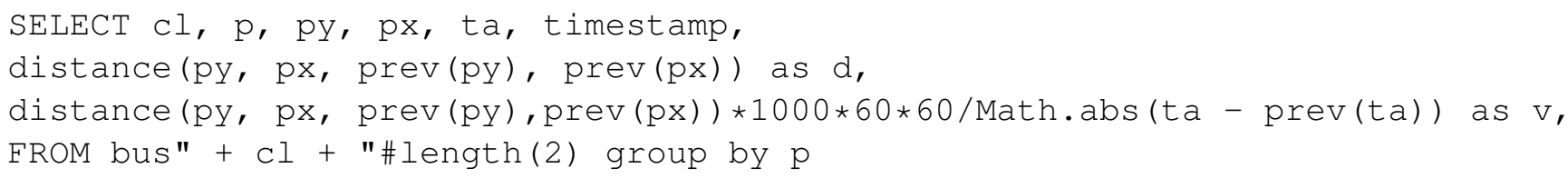

Os campos do tipo de evento são:

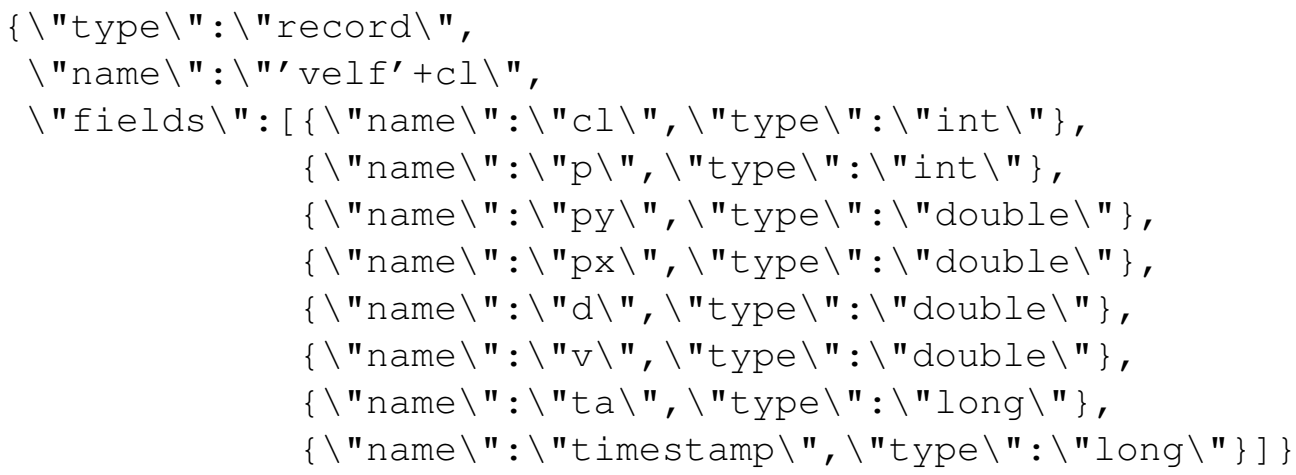

Nos experimentos, criou-se um tipo de evento da categoria vf para cada linha de ônibus. Na definição dele, foi utilizado o operador group by para separar os eventos por ônibus, já que a função de vf é detectar a velocidade de ônibus (e não de linhas). Na cláusula FROM, pode-se notar que a fonte dos eventos é fixada com o nome de bus $+\mathrm{cl}$, sendo cl iterado sobre o conjunto de linhas da cidade.

A função distance utilizada na definição foi adicionada ao código do protótipo, para o cálculo de distancias geodésicas entre coordenadas de latitude e longitude de dois pontos na superfície terrestre em quilômetros. Ela se baseia na fórmula de Haversine para realizar o cálculo (Haversine, 2020). A velocidade em $\mathrm{km} / \mathrm{h}$ é calculada pela divisão da distância pela diferença dos timestamps ta, convertida para horas.

- Velocidade Instantânea de Ônibus Filtrada (vi) - nível: um por linha de ônibus

- Id do tipo de evento: vi+cl

- Nome do tipo de evento: veli+cl

Cada tipo de evento nessa categoria filtra os eventos de vf, selecionando aqueles que apresentam velocidades entre $0 \mathrm{~km} / \mathrm{h}$ e $100 \mathrm{~km} / \mathrm{h}$. Essa categoria é importante para filtrar possíveis eventos com dados de posição irregulares vindos da SPtrans.

Em EPL, a definição de vi fica:

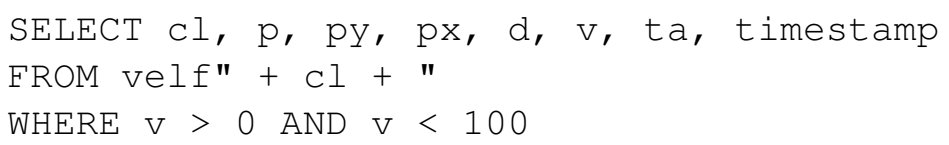

Os campos do tipo de evento são:

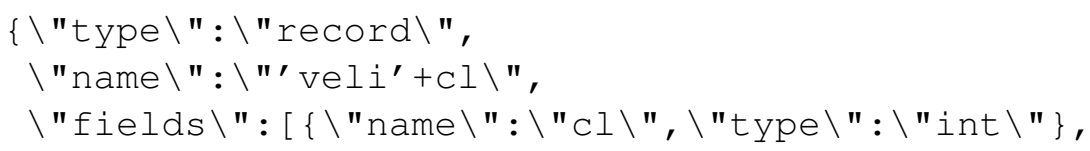




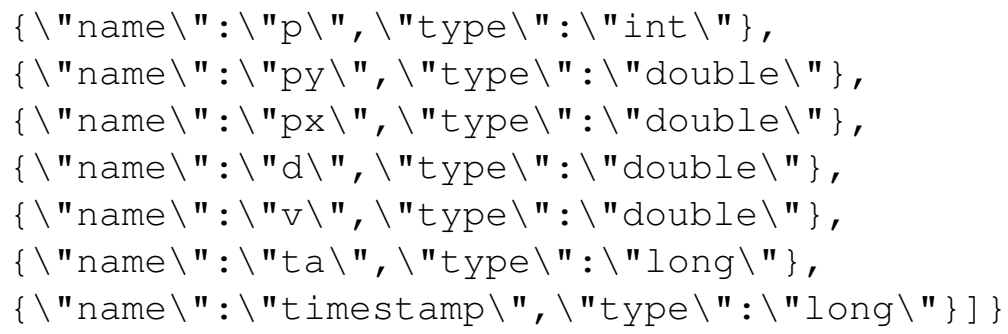

- Velocidade Média de Ônibus (vel) - nível: um por linha de ônibus que passa em corredores

- Id do tipo de evento: vel+cl+(nome do corredor)

- Nome do tipo de evento: speedbus+(nome do corredor)

Cada tipo de evento nessa categoria calcula a velocidade média de cada ônibus de uma linha, considerando as velocidades instantâneas do ônibus acumuladas nos últimos 5 minutos.

Os tipos de evento da categoria vel foram criados somente para as linhas que passam em corredores de ônibus.

A definição em EPL dos tipos da categoria vel é:

SELECT cl,p, py, px, ta, avg(v) as speed, timestamp

FROM veli" + cl + "\#ext_timed(ta,300) group by p

Os campos do tipo de evento são:

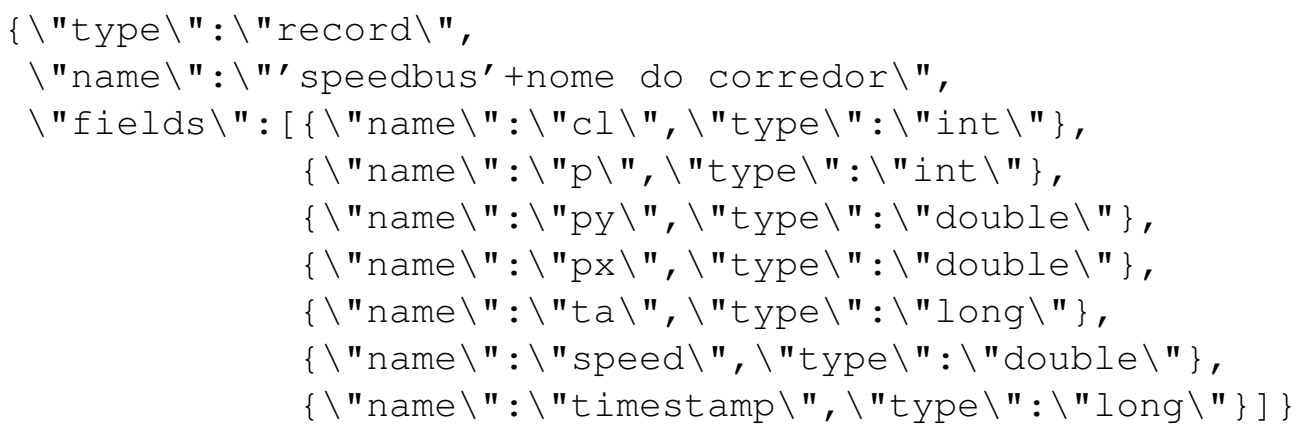

- Velocidade Média em Corredor (corr) - nível: um por corredor principal da cidade

- Id do tipo de evento: corr+(identificador do corredor)

- Nome do tipo de evento: corridor+(identificador do corredor)

Essa categoria de tipos de evento tem como objetivo calcular a velocidade média em cada corredor principal da cidade, a partir das velocidades médias dos ônibus que passam por ele registradas nos últimos 5 minutos.

No experimento, foram criados 12 tipos de evento dessa categoria, um para cada um dos principais corredores de ônibus de São Paulo.

A definição desses tipos de eventos corr em EPL é:

SELECT avg (speed) as avg_speed, ta, timestamp

FROM speedbus" + corredor + "\#ext_timed(ta, 300) 
No experimento, para facilitar a definição em EPL dos tipos de evento de vel, registrou-se com um mesmo nome (speedbus+corredor) todos os tipos de eventos das linhas que passam num mesmo corredor de ônibus. Dessa forma, não foi preciso especificar explicitamente na cláusula FROM a grande lista de tipos de evento de entrada (referentes às várias linhas de ônibus que passam pelo corredor).

Os campos to tipo de evento são:

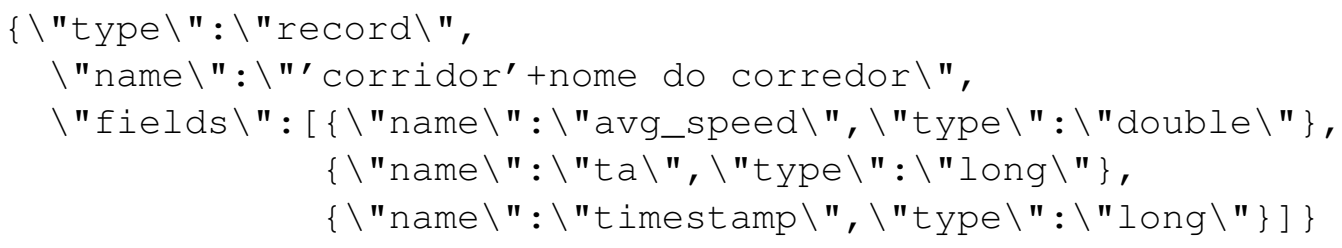

- Aglomeração em Linha de Ônibus (BusB) - nível: um por ônibus

- Id do tipo de evento: BusB $+\mathrm{p}+\mathrm{cl}$

- Nome do tipo de Evento: $\mathrm{BB}+\mathrm{p}+\mathrm{cl}$

Nessa categoria, um tipo de evento é criado para cada ônibus em circulação, para detectar se existem ônibus da mesma linha circulando muito próximos um do outro. Esse é um problema comum em engenharia de transporte público, algo que ocorre com frequência na cidade, e que leva a um tempo desigual de espera entre ônibus da mesma linha.

A definição em EPL dos tipos de eventos da categoria BusB fica:

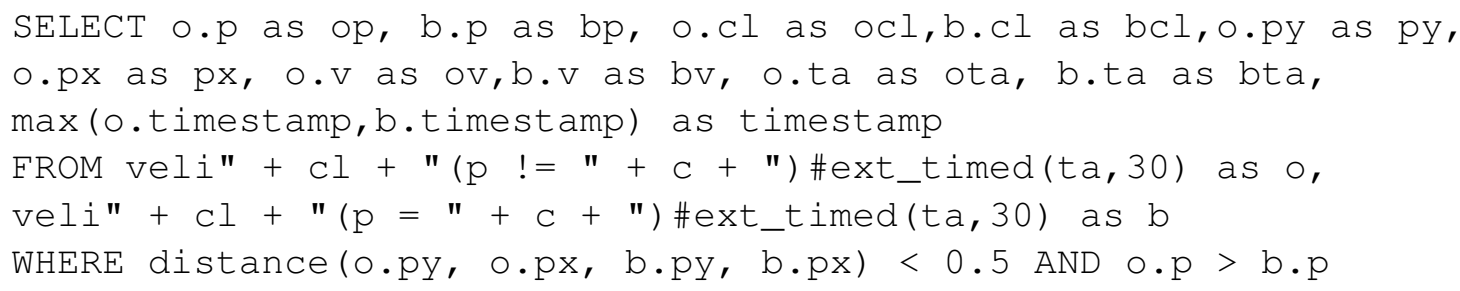

Os tipos de evento de BusB utilizam como entrada os eventos do tipo vi, com duas fontes separadas - uma só para eventos do ônibus selecionado $(p=c)$ e uma para todos os outros ônibus da mesma linha ( $\mathrm{p} !=\mathrm{c})$ - e disparam toda vez que dois eventos, um de cada fonte, apresentam uma distância de menos de 500 metros entre si dentro de um intervalo de 30 segundos. A condição o.p > b.p foi adicionada pois, como um tipo de evento de BusB é criado para cada ônibus, na ocorrência de um agrupamento de ônibus seriam detectados eventos para ambos os ônibus participantes do agrupamento. Com essa condição, somente o tipo de evento do ônibus com o identificador de maior número é disparado.

Os campos do tipo de evento são:

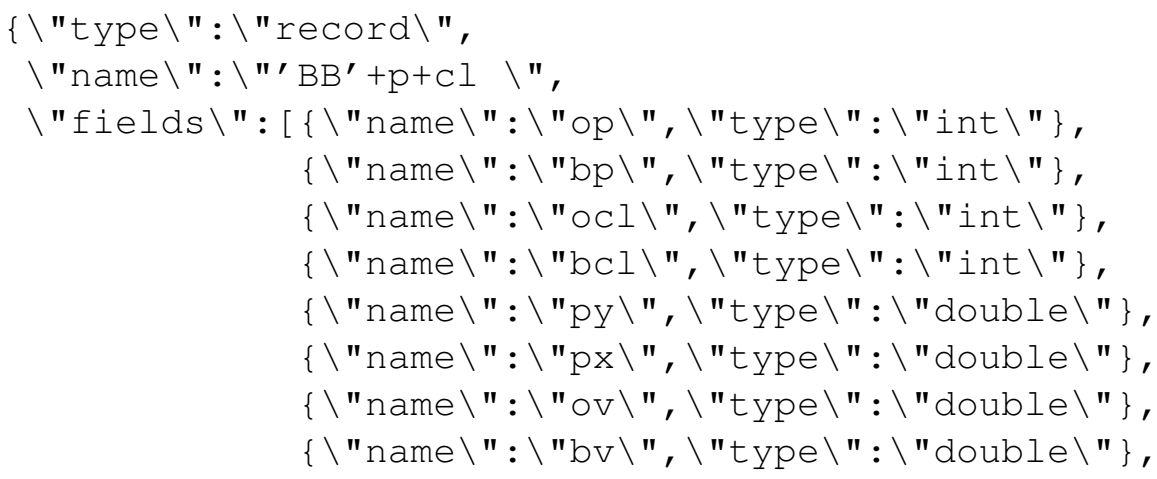




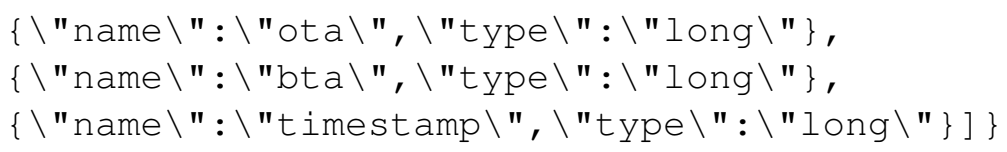

Para os experimentos, foram usados dados de apenas 708 linhas de ônibus (30\% do total de linhas da cidade), devido a limitações de uso de recursos no cadastro de filas e canais no RabbitMQ. Cada experimento utiliza uma só instância do RabbitMQ e, para cada tipo de evento registrado, é necessária a inscrição da instância no RabbitMQ para receber os novos tipos de entrada e enviar os eventos detectados pelo novo tipo cadastrado. Optou-se pelo uso de uma única instância de broker para minimizar a variação de latência que a transmissão de dados poderia atingir caso os dados fossem transmitidos para instâncias distintas, em máquinas virtuais distintas. As 708 linhas foram escolhidas porque passam pelos corredores de ônibus da cidade e têm a maior quantidade de dados coletados. No total, a rede de processamento para o monitoramento dessas linhas contém 15.729 tipos de eventos, sendo:

- 708 tipos para detecção de velocidades instantâneas de ônibus (vf), um por linha;

- 708 tipos para filtragem de velocidades entre 0 e $100 \mathrm{~km} / \mathrm{h}$ (vi), um por linha;

- 180 tipos para cálculo de velocidade média de ônibus (vel), um por linha que passa em corredores;

- 12 tipos para cálculo de velocidade média em corredor (corr), um para cada corredor principal;

- 14.121 tipos para detecção de aglomeração em linha de ônibus (busB), um para cada ônibus.

O experimento foi desenhado de modo a ter uma grande quantidade de tipos de evento, para testar o uso de recursos associado tanto ao cadastro dos tipos de evento quanto ao volume de eventos entrando no sistema.

\subsection{Arquitetura dos Experimentos}

Para simular um ambiente de execução do sistema CEP Handler de forma automatizada, foi projetado um microsserviço adicional, o Experiment-Repository ${ }^{2}$, cuja função é o envio dos eventos primários e a coleta e armazenamento de todos os eventos detectados. A arquitetura do ambiente dos experimentos é representada na Figura 6.2. O banco de dados chave-valor que é consultado pelo CEP Worker para o cadastro e verificação dos metadados dos tipos de eventos é instanciado já com todos os metadados dos tipos de eventos da rede de processamento dos experimentos pré-registrados. A plataforma InterSCity não foi integrada à execução dos experimentos, pois seu desempenho já foi analisado em outros trabalhos Esposte et al. (2019). Além disso, não foi realizada injeção de falhas durante a execução dos experimentos.

O microsserviço de experimento carrega todos os dados dos eventos primários de um arquivo para a memória RAM antes do início do experimento e depois os ordena pela marca temporal ta (do horário em que a posição do ônibus foi capturada no sistema da SPTrans), para enviá-los um por vez ao CEP Handler. Um evento primário $E_{t}$ só é enviado pelo Experiment-Repository ao CEP Handler quando o intervalo de tempo transcorrido desde o envio do evento anterior $E_{t-1}$ for igual ao intervalo entre os tempos $E_{t}$.ta e $E_{t-1} . t a$. Dessa forma, o microsserviço de experimento simula o envio de eventos na mesma taxa provida pela SPTrans. Além disso, no envio dos eventos primários, é adicionado um atributo novo, chamado timestamp, que contém a marca temporal do envio do evento pelo microsserviço. Quando o microsserviço coleta os eventos detectados, ele armazena a marca temporal de saída do evento do sistema. Com as duas marcas temporais, é possível calcular a latência da deteç̧ão dos eventos no sistema CEP Handler posteriormente.

\footnotetext{
${ }^{2}$ https://gitlab.com/fernandofreire/experiment-microservice.
} 


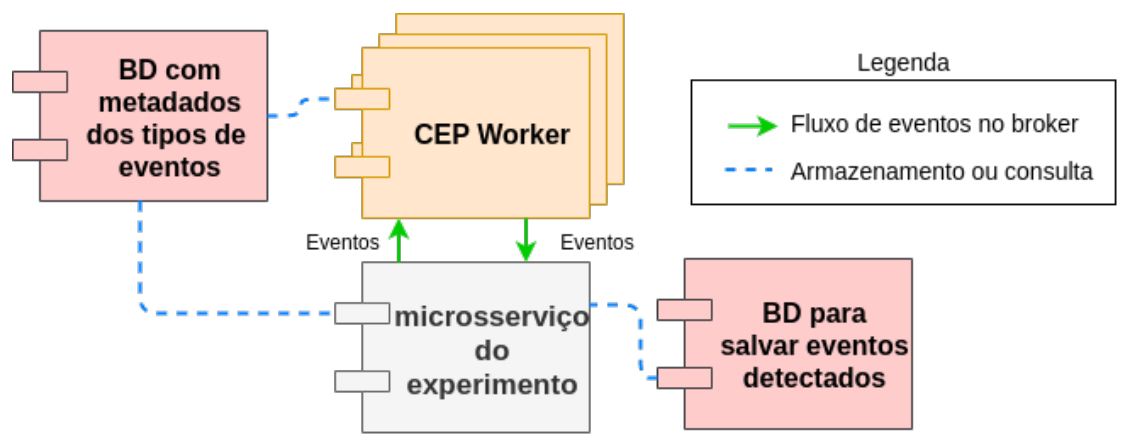

Figura 6.2: Arquitetura de processamento dos experimentos.

\subsection{Execução}

A execução dos experimentos foi feita na plataforma de nuvem Amazon Web Services (AWS), com créditos concedidos ao projeto CNPq/AWS № 032/2019, intitulado "Computação em nuvem para big-data em cidades inteligentes". A ferramenta eksctl ${ }^{3}$ foi usada para fazer a interface entre o orquestrador de contêineres Kubernetes, utilizado pelo CEP Handler, e os recursos providos pela AWS.

Cada um dos microsserviços foi alocado em uma máquina virtual do tipo t3a.medium da AWS, com 2 vCPU, 4 GB de memória RAM e até 5 Gbps de desempenho na rede (AWS-Instances, 2020). Esse tipo de máquina virtual foi escolhido por representar uma máquina virtual comum, que poderia ser encontrada em qualquer provedor de nuvem. Para o cenário experimental descrito neste capítulo, uma máquina virtual com uma quantidade maior de CPU e memória dificultaria a visualização da escalabilidade horizontal, pois aconteceria a escalabilidade vertical primeiro. Não foram feitas execuções dos experimentos com máquinas virtuais com menos recursos, ou com diferentes tipos de máquinas virtuais para cada microsserviço. Também não foi foi feita a deteç̧ão dos mesmos eventos utilizando outro tipo de processamento contínuo, como processamento em stream ou em batch, para validar a veracidade dos dados detectados. Como a latência de transmissão de eventos influencia diretamente a deteç̧ão dos tipos de evento com janelas temporais, o número de eventos e os valores detectados por categorias de tipos de eventos que usam janelas temporais variam de uma execução para outra do mesmo experimento e ainda mais com execuções em batch.

O experimento foi executado dez vezes, cinco para cada um dos algoritmos de balanceamento de carga apresentados no Capítulo 4. A cada nova execução, todos os recursos do ambiente de nuvem eram removidos e requisitados novamente.

\footnotetext{
${ }^{3}$ https://eksctl.io/
} 


\section{Capítulo 7}

\section{Resultados}

Neste capítulo, são apresentados os resultados dos experimentos de avaliação do CEP Handler descritos no Capítulo 6. Foram executados dez experimentos no total, cinco repetições para cada um dos dois algoritmos de balanceamento de carga apresentados na Seção 4.3.

As seções a seguir discutem os dados detectados relevantes no contexto de monitoramento de tráfego de ônibus na cidade de São Paulo, bem como medidas de desempenho (tais como número total, vazão e latência de eventos detectados) por execução do experimento. Ao final do capítulo, são apresentadas as conclusões dos resultados e uma discussão sobre os efeitos do uso de cada um dos algoritmos de balanceamento de carga.

\subsection{Dados Detectados}

Como discutido no Capítulo 6, os tipos de eventos do cenário do experimento foram escolhidos com o propósito de criar uma rede de processamento de eventos grande o suficiente para avaliar o funcionamento da auto-escalabilidade do CEP Handler, como é o caso da rede de detecção de problemas de tráfego de ônibus do transporte público de São Paulo. Os tipos de eventos nas pontas da rede da Figura 6.1, especificamente a detecção de agrupamento de ônibus e a deteç̧ão de velocidade média em corredor de ônibus principal, servem o propósito de verificar se a frota de ônibus está circulando como o determinado pelo planejamento da SPTrans.

Os gráficos das figuras 7.1 e 7.2 foram criados a partir dos dados das detecções desses tipos de evento em uma das execuções do experimento. A Figura 7.1 mostra as velocidades médias detectadas no corredor de ônibus Guarapiranga. Os gráficos das velocidades médias dos outros 11 corredores de ônibus principais da cidade podem ser encontrados no Apêndice A. A Figura 7.2 mostra o número de ocorrências de agrupamentos de ônibus dentro de intervalos de 15 minutos, ao longo de todo o período de circulação de ônibus coberto pelo experimento. De uma execução para outra do experimento, não houve variação significativa nos eventos detectados pelo sistema CEP Handler, como era esperado. 


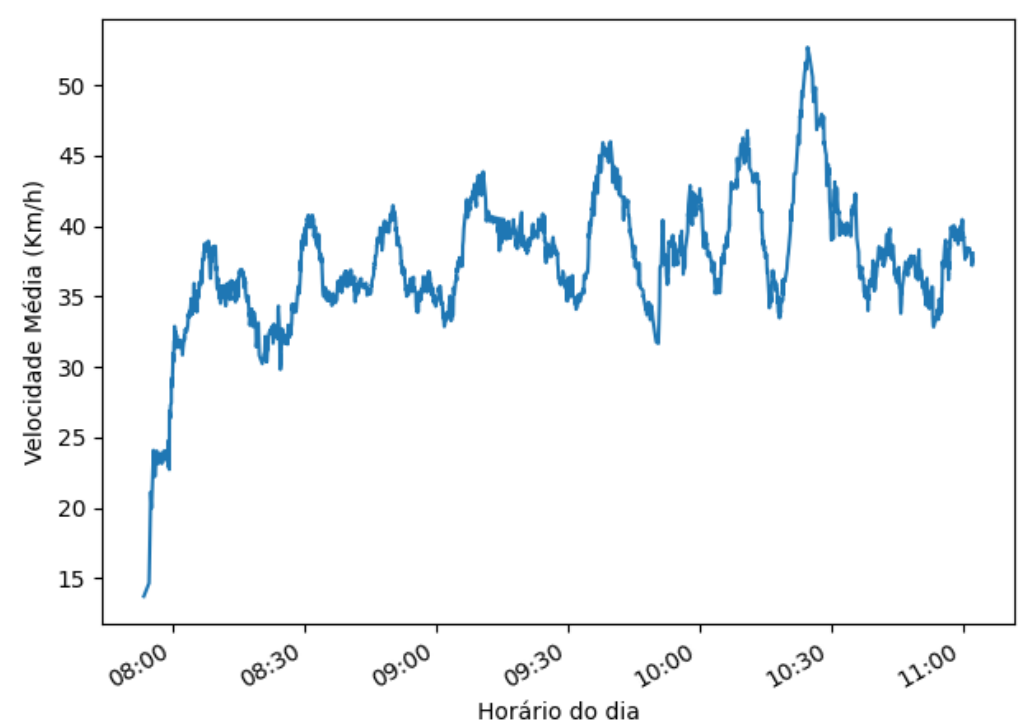

Figura 7.1: Velocidades médias no corredor de ônibus Guarapiranga para uma execução do experimento.

O gráfico da Figura 7.1 mostra a velocidade pelo horário de coleta do dado. Como explicado na Seção 6.2, a velocidade média de um corredor é calculada pelos tipos de evento da categoria corr, a partir das velocidades médias dos ônibus que passam no corredor nos últimos cinco minutos. O gráfico mostra uma discrepância entre as velocidades detectadas nos minutos iniciais e as velocidades detectadas posteriormente. Isso se deve ao fato de que, nos primeiros minutos, as janelas de agregação para o cálculo das velocidades médias não agregam dados suficientes, pois ainda não se passaram os cinco minutos necessários para o cálculo. Ao longo de todo o período do experimento, a velocidade média móvel do corredor Guarapiranga se manteve majoritariamente entre os $30 \mathrm{~km} / \mathrm{h}$ e $50 \mathrm{~km} / \mathrm{h}$, um intervalo que deve representar o tráfego comum do corredor. Com esse tipo de evento em atuação, poderia-se detectar em tempo real acidentes nos quais os veículos envolvidos bloqueassem a circulação no corredor.

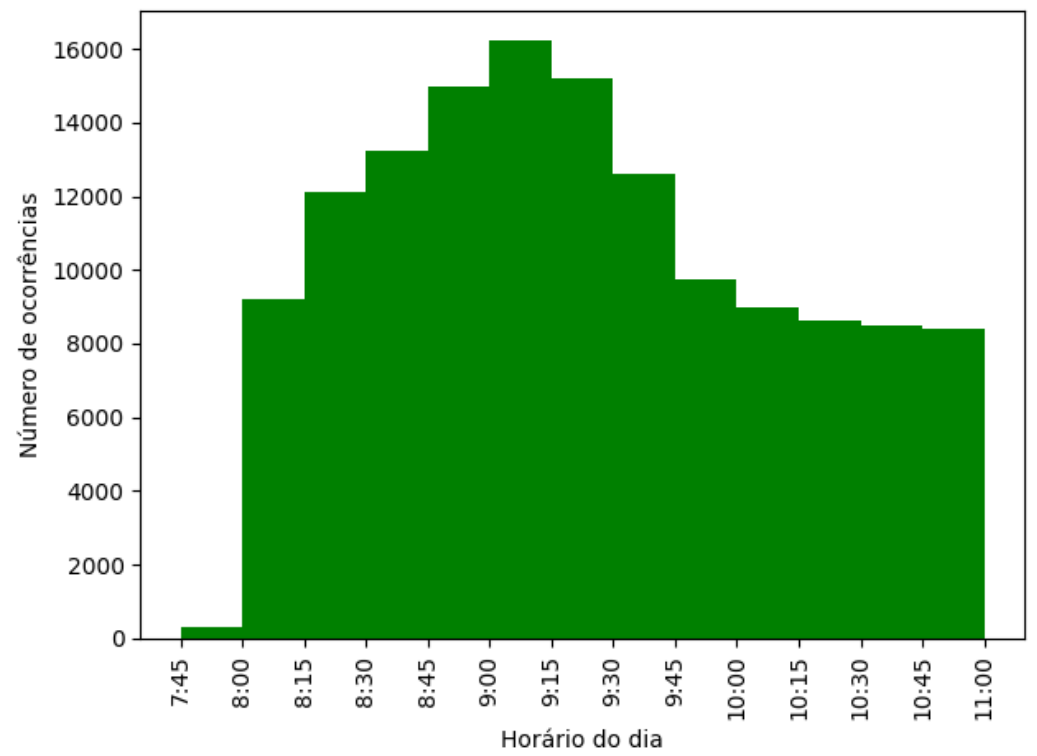

Figura 7.2: Histograma do número de ocorrências de agrupamento de ônibus para uma execução do experimento.

O histograma dos eventos de agrupamento de ônibus (Figura 7.2) apresenta o número de ocor- 
rências desse tipo a cada intervalo de quinze minutos, utilizando o horário de coleta do dado. Os primeiros dados foram enviados ao sistema às 07h57. Por isso, o intervalo inicial do histograma, que vai das $7 \mathrm{~h} 45$ às $8 \mathrm{~h} 00$, contém um número de ocorrências bem menor do que o dos intervalos seguintes. É possível observar um crescimento do número de ocorrências até atingir um pico entre às $9 \mathrm{~h} 00$ e $9 \mathrm{~h} 15$, sendo que essa faixa de tempo coincide com o maior crescimento do número de dados entrando no sistema (mostrado na Figura 7.5). Uma possível explicação é que, ao longo da manhã, o número de ônibus ativos em cada linha aumenta. Quando esses ônibus iniciam sua circulação e começam a enviar suas posições para a SPTrans, eles estão localizados em terminais ou garagens, junto com outros ônibus da mesma linha. Depois das 9h15, há uma diminuição do número de ocorrências de aglomeração, pois a maioria dos ônibus está em circulação nas vias, longe de outros ônibus da sua própria linha. A partir das 10h00, a maioria das ocorrências de agrupamento de ônibus detectadas podem ser em terminais de ônibus, onde os veículos ficam estacionados entre uma viagem e outra.

\subsection{Auto-Escalabilidade do Sistema}

A partir dos dados coletados de cada repetição do experimento, para os dois algoritmos de balanceamento de carga, foi possível observar que o sistema se auto-escala conforme o número de eventos de entrada aumenta. As figuras 7.3 e 7.4 mostram o número de instâncias de CEP Workers no sistema ao longo do tempo para todas as execuções do experimento com o algoritmo de balanceamento por Uso de Estado e com o algoritmo de balanceamento por Similaridade de Entrada, respectivamente. Em todas, observa-se que o número de instâncias aumenta mesmo antes do início do envio de eventos, enquanto o sistema ainda está cadastrando os tipos de eventos. Cada cadastro já ocupa um espaço na memória RAM, que cumulativamente gera o disparo da instanciação de novos CEP Workers.

No experimento, escolheu-se fazer o cadastro de todos os tipos de eventos antes do início dos envios para que se pudesse distinguir melhor os efeitos, em relação ao uso de memória e CPU, do cadastro de novos tipos de eventos e os efeitos do aumento do número de eventos de entrada. As figuras 7.3 e 7.4 mostram o crescimento do número de instâncias de CEP Worker desde o início da execução. O número de instâncias cresce antes do início do envio de eventos de entrada pois só o cadastro dos tipos de eventos já ocupa toda a memória disponível em algumas instâncias. Pode-se observar que são necessárias, no mínimo, três instâncias para o cadastro de todos os tipos de evento. Como cada instância tem 4 GB de memória e são 15.729 tipos de evento, foram aproximadamente 1.300 cadastros de tipos de evento por cada GB de memória disponível. As figuras 7.5 e 7.6 mostram o crescimento do número de instâncias de CEP Worker a partir do início de envio de eventos, pelo horário do dia da coleta do evento para todas as execuções. Elas melhor evidenciam a relação entre o crescimento do número de instâncias e o aumento da carga de entrada no sistema.

Como mostra a Figura 7.3, em todas as cinco repetições do experimento usando o algoritmo de balanceamento por Uso de Estado, o número máximo de instâncias de CEP Worker em uso para lidar com a carga de eventos de entrada foi cinco. Já com o algoritmo de balanceamento por Similaridade de Entrada, duas das cinco repetições chegaram ao disparo de seis instâncias de CEP Worker, como mostrado na Figura 7.4. Em uma delas, a criação da sexta instância de CEP Worker ocorreu depois do final do envio de eventos de entrada. 


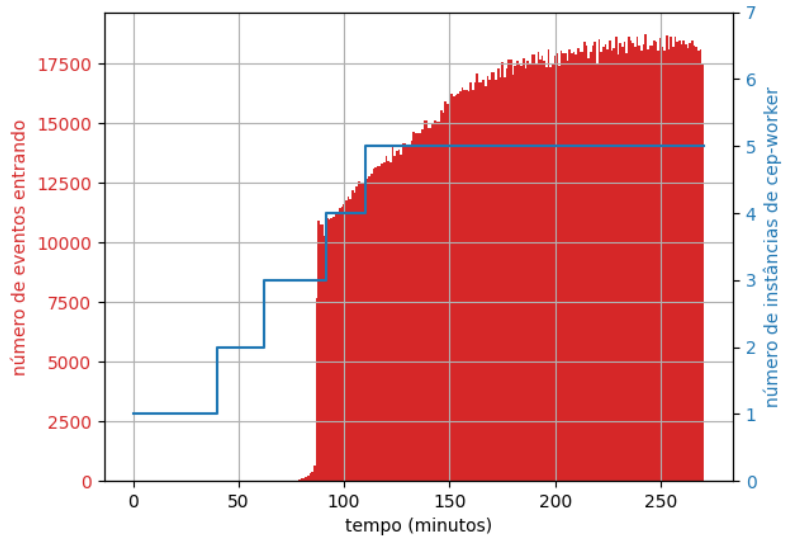

(a) Execução 1

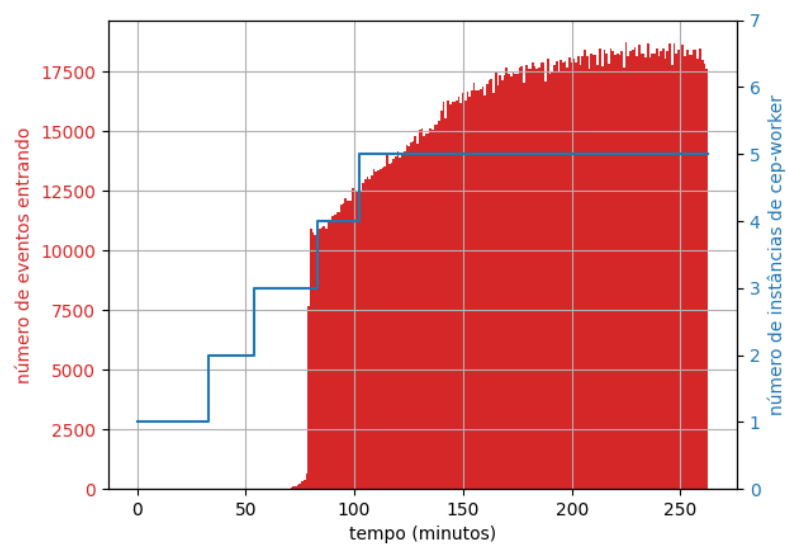

(c) Execução 3

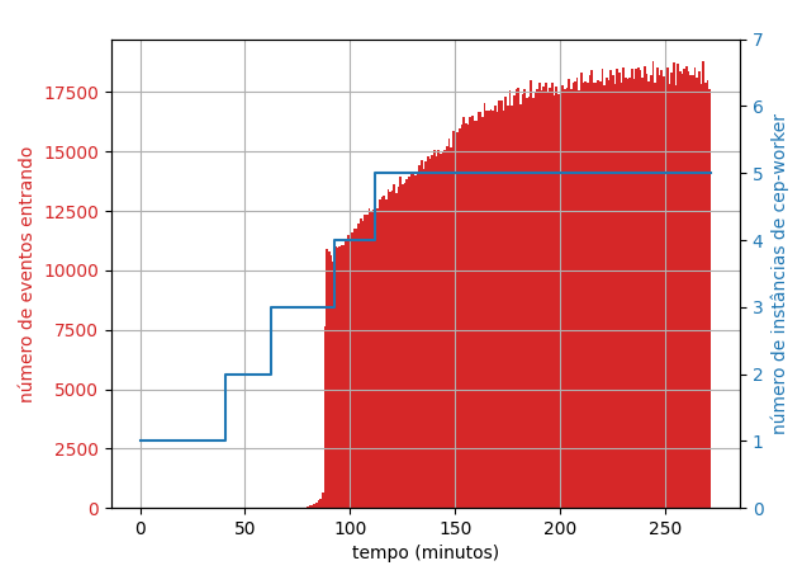

(e) Execução 5

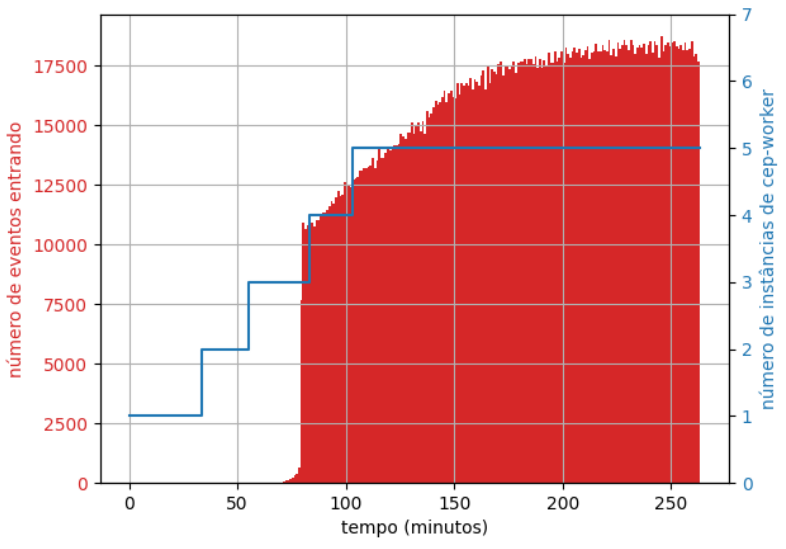

(b) Execução 2

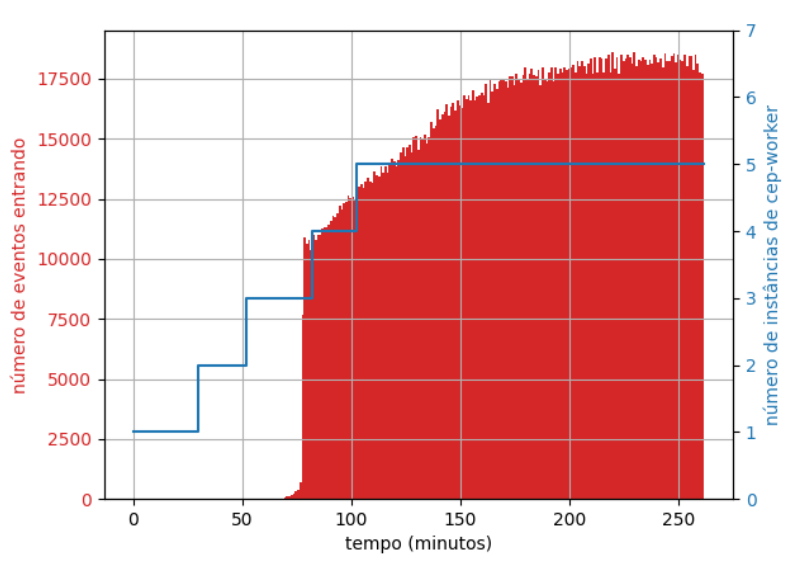

(d) Execução 4

Figura 7.3: Número de eventos entrando no sistema (em vermelho) e número de instâncias de CEP Worker (em azul) em função do tempo nas execuções do experimento utilizando o algoritmo de balanceamento de carga por Uso de Estado. Algumas instâncias são iniciadas antes do início do envio de eventos pois nesse período o cadastro de tipos de eventos já ocupa toda a memória disponível de algumas instâncias. A criação de novas instâncias depende de vários fatores que são descritos no Capítulo 4.1.5. 


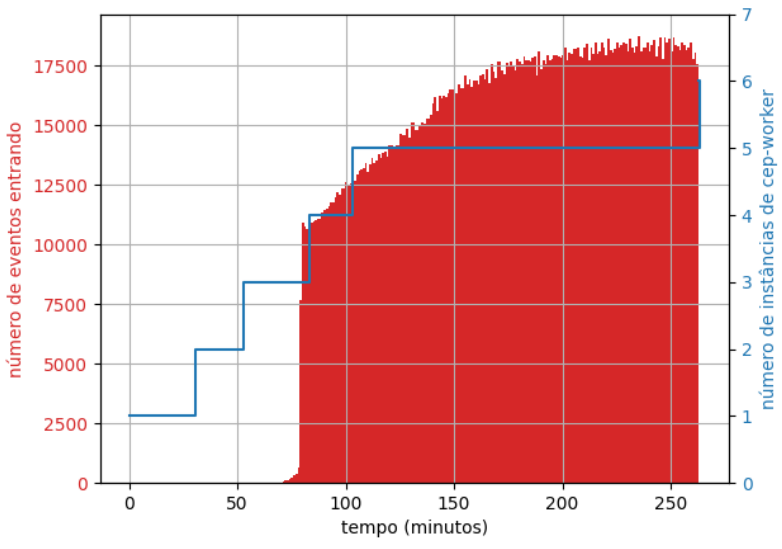

(a) Execução 1

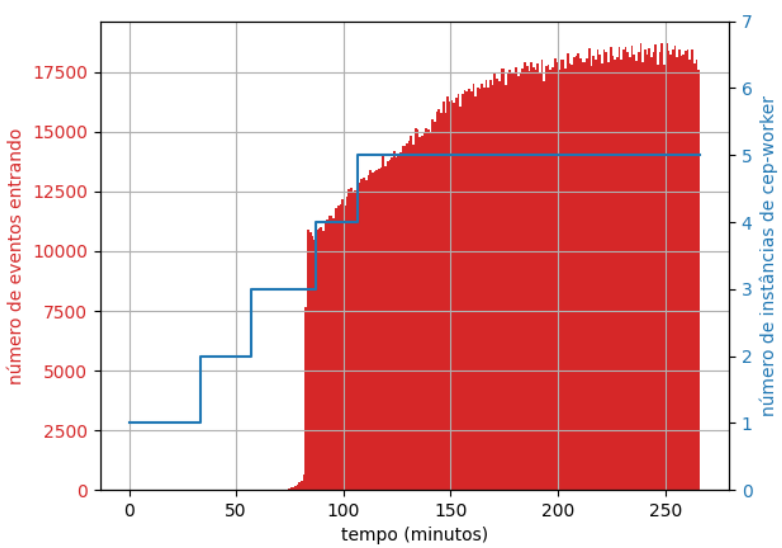

(c) Execução 3

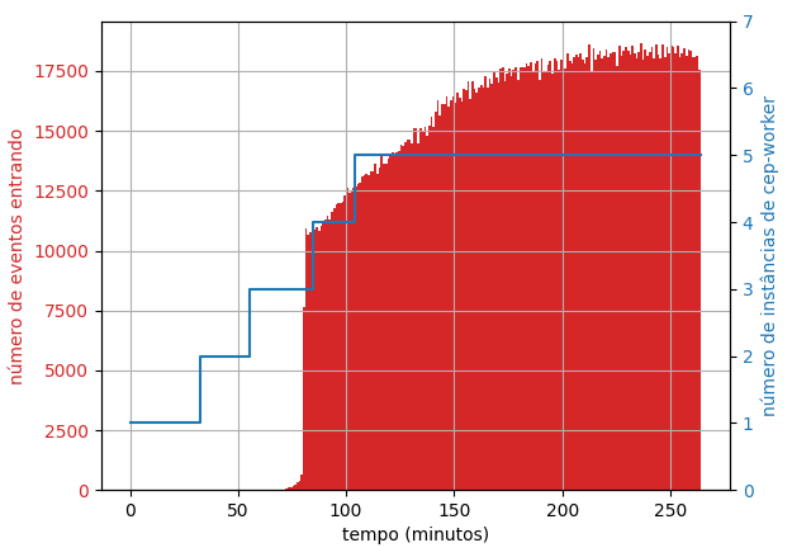

(e) Execução 5

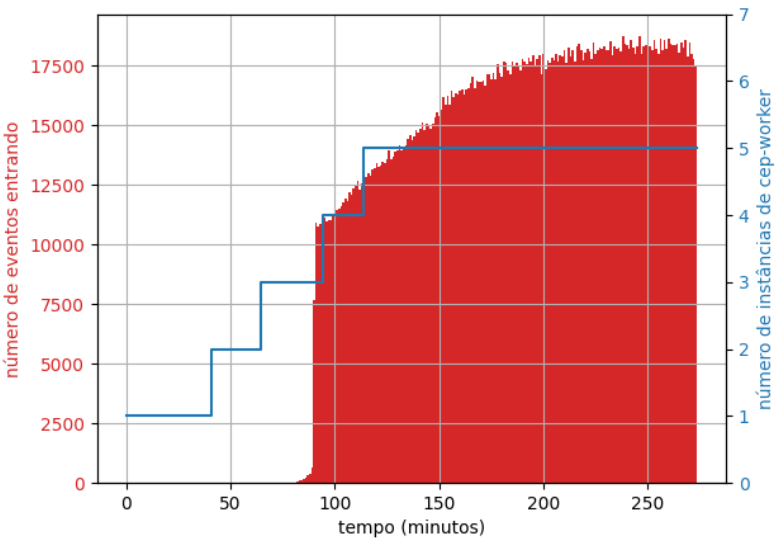

(b) Execução 2

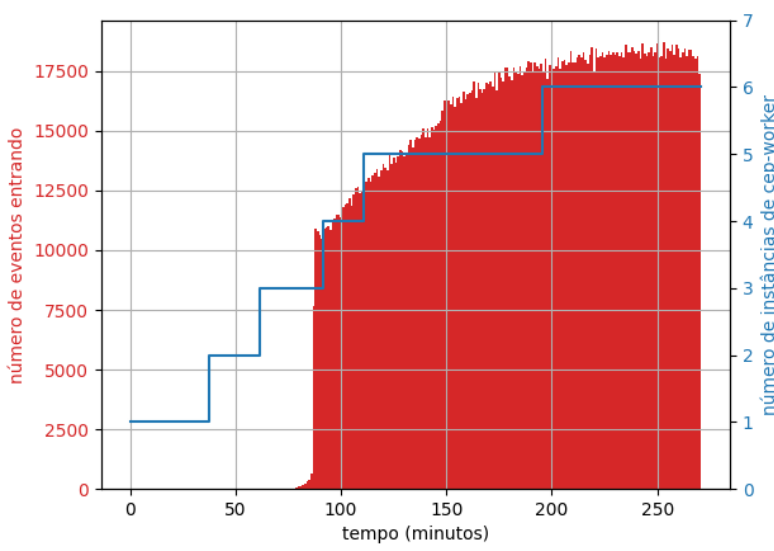

(d) Execução 4

Figura 7.4: Número de eventos entrando no sistema (em vermelho) e número de instâncias de CEP Worker (em azul) em função do tempo nas execuções do experimento utilizando o algoritmo de balanceamento de carga por Similaridade de Entrada. Algumas instâncias são iniciadas antes do início do envio de eventos pois nesse periodo o cadastro de tipos de eventos já ocupa toda a memória disponivel de algumas instâncias. A criação de novas instâncias depende de vários fatores que são descritos no Capítulo 4.1.5. 


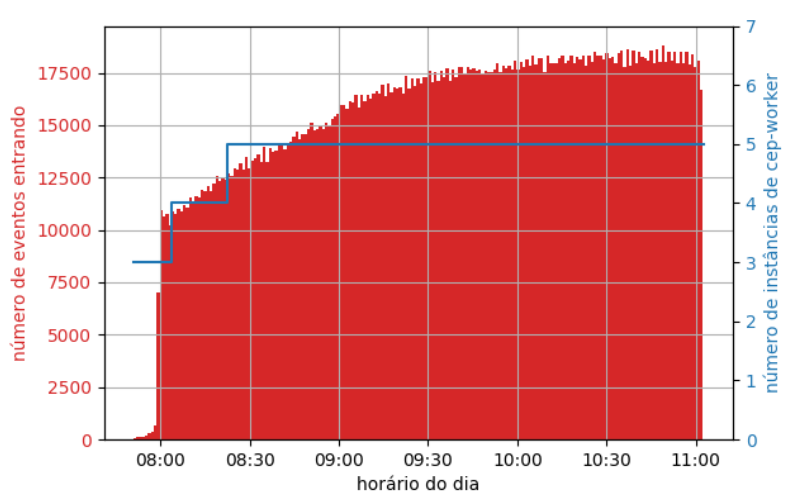

(a) Execução 1

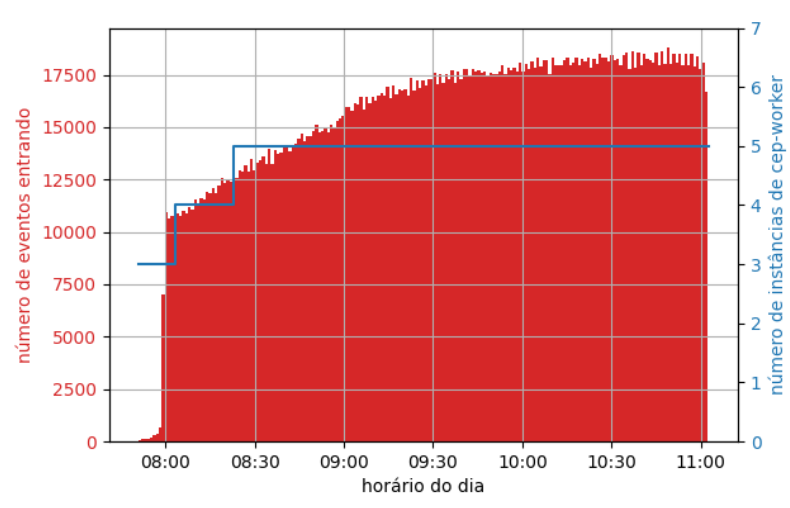

(c) Execução 3

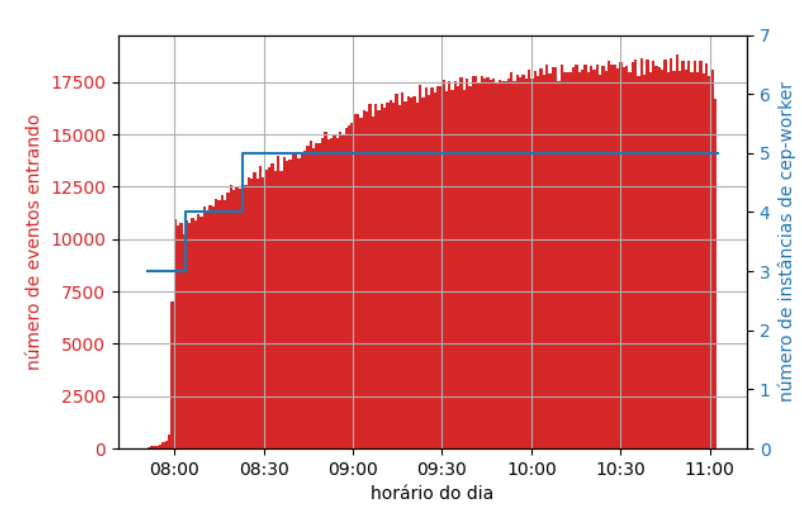

(e) Execução 5

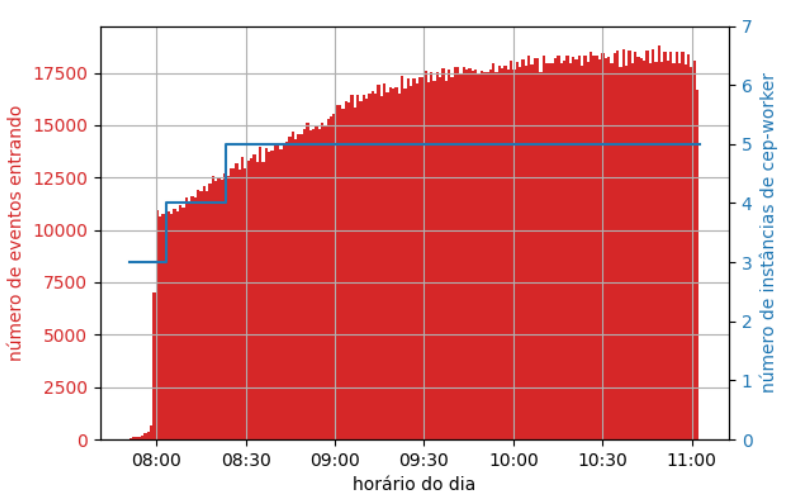

(b) Execução 2

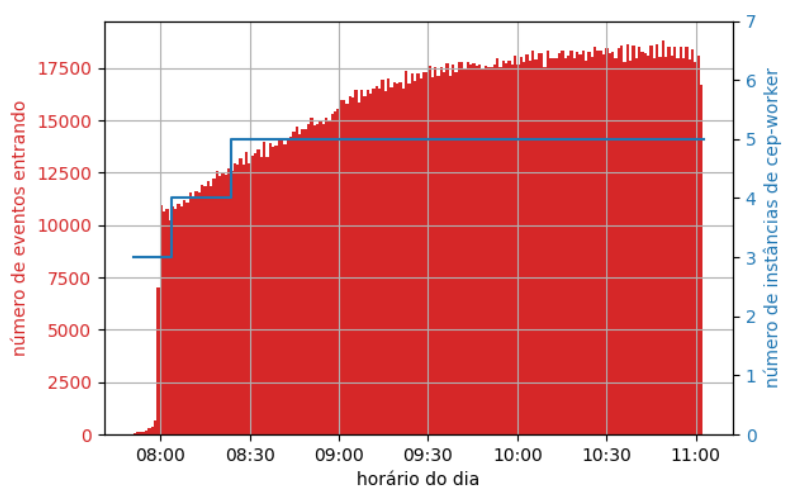

(d) Execução 4

Figura 7.5: Número de eventos entrando no sistema (em vermelho) e número de instâncias de CEP Worker (em azul) em função do horário do dia nas execuções do experimento utilizando o algoritmo de balanceamento de carga por Uso de Estado. 


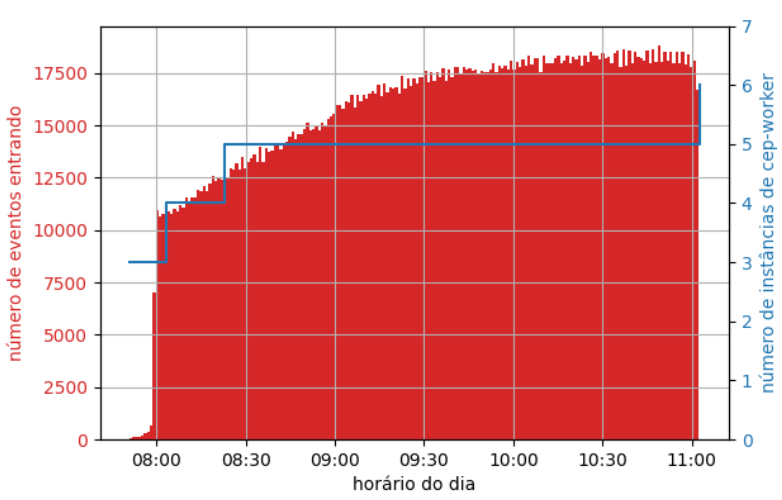

(a) Execução 1

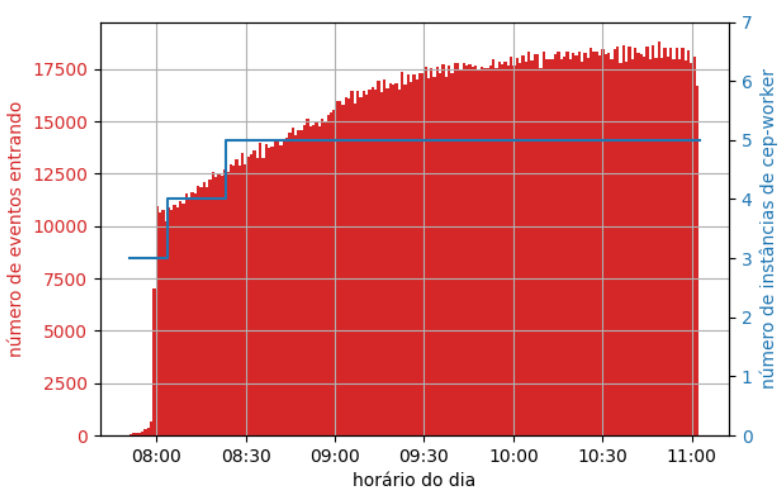

(c) Execução 3

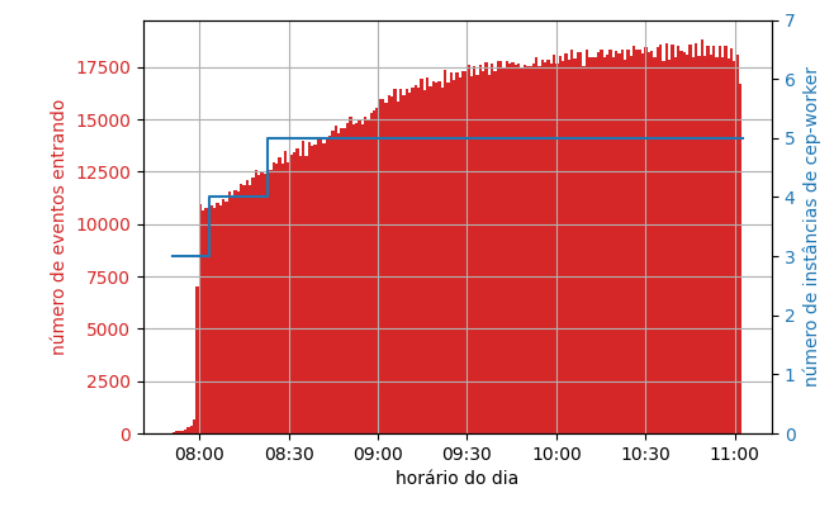

(e) Execução 5

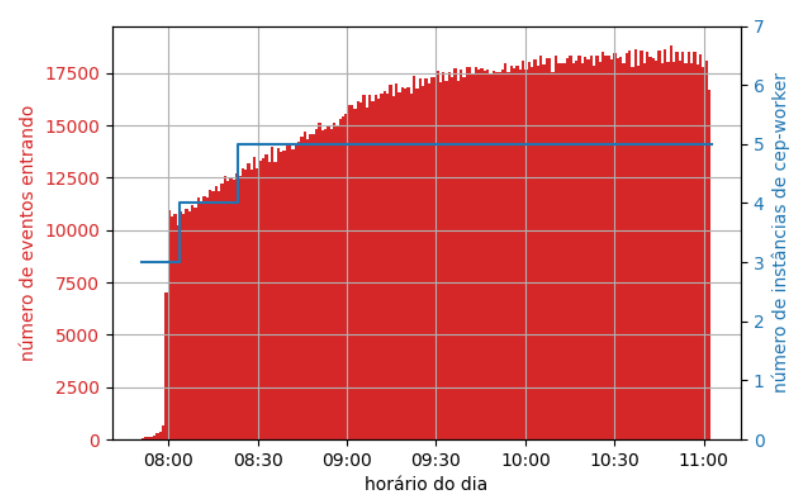

(b) Execução 2

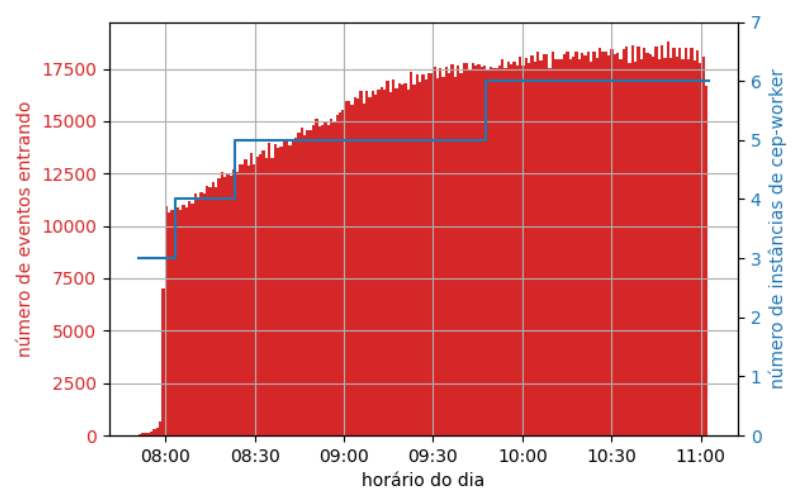

(d) Execução 4

Figura 7.6: Número de eventos entrando no sistema (vermelho) e número de instâncias de CEP Worker (em azul) em função do horário do dia nas execuções do experimento utilizando o algoritmo de balanceamento de carga por Similaridade de Entrada. 


\subsection{Tempo de Uso de Recursos}

Nas execuções do experimento de avaliação do desempenho do CEP Handler na AWS, usou-se um só tipo de máquina virtual, o t3a.medium. Todos os microsserviços do experimento, listados no Capítulo 6, foram instanciados nesse tipo de máquina virtual. Exceto pelo CEP Worker, utilizouse somente uma instância para cada microsserviço. Portanto, a variação da quantidade de uso de recursos depende exclusivamente da instanciação de CEP Workers feita em cada execução.

A quantidade de máquinas virtuais alocadas dinamicamente para as instâncias de CEP Workers e os seus respectivos tempos de uso variaram de uma execução para outra, como mostrado na Seção 7.2. Mas o tempo total de uso de recursos variou relativamente pouco nas execuções. A Tabela 7.1 mostra o tempo de uso de recursos, em minutos, somado de todas as instâncias de CEP Workers para cada execução do experimento.

Tabela 7.1: Tempo de uso de recursos em minutos de cada execução do experimento.

\begin{tabular}{lrrr}
$\begin{array}{l}\text { Balanceamento de Carga por } \\
\text { Uso de Estado }\end{array}$ & \multicolumn{2}{c}{$\begin{array}{c}\text { Balanceamento de Carga por } \\
\text { Similaridade de Entrada }\end{array}$} \\
& $1.049,94$ & \\
& $1.041,69$ & & $1.045,14$ \\
& $1.041,86$ & & $1.054,98$ \\
& $1.042,23$ & & $1.052,84$ \\
& $1.052,08$ & & $1.045,12$ \\
Média & & Média & $1.049,2$ \\
Desvio Padrão & $1.045,56$ & & \\
& & Desvio Padrão & 4,51
\end{tabular}

As médias de tempo de uso de recursos dos dois algoritmos de balanceamento não apresentaram uma diferença expressiva. Uma possível explicação para isso é que a alta velocidade de realocação dos tipos de eventos é um fator importante para minimizar o intervalo de tempo que cada instância se mantêm em sobrecarga forte. Como todas as execuções do experimento que utilizaram o algoritmo de balanceamento de carga por Uso de Estado chegaram a um máximo de cinco instâncias ativas ao mesmo tempo, de acordo com o mecanismo de requisição de novas instâncias descrito na Seção 4.1.5, em nenhum momento três das cinco instâncias estavam em sobrecarga forte ao mesmo tempo, ou seja, o uso do algoritmo propiciou um máximo de duas instâncias em sobrecarga forte em qualquer momento ao longo do experimento. É importante lembrar que uma instância nova só é requisitada por sobrecarga forte quando o número de instâncias em sobrecarga forte é maior que o número de instâncias que não atingiram nenhum tipo de sobrecarga. Essa solução é adotada pois a realocação de efeitos é realizada de forma sequencial, sendo que uma instância não pode aceitar a realocação de tipos de eventos de duas instâncias distintas ao mesmo tempo, como descrito na Seção 4.1.5.

Em comparação, o algoritmo de balanceamento de carga por Similaridade de Entrada buscou selecionar os tipos de eventos para realocação de modo a reduzir a duplicação de envio de eventos para instâncias distintas. As execuções do experimento com esse algoritmo não buscaram necessariamente selecionar os tipos de eventos que seriam mais rapidamente realocados e levaram a um máximo de seis instâncias de CEP Worker ativas em alguns casos. Como os intervalos de tempo em que cada instância ficou em sobrecarga forte foram maiores, usando o algoritmo de balanceamento de carga por Similaridade de Entrada, em algumas execuções haviam três instâncias de CEP Worker em sobrecarga ao mesmo tempo, levando a criação de três instâncias adicionais. No entanto, a média do tempo de uso de recursos somado de todas as instâncias foi similar para os dois algoritmos de balanceamento. 


\subsection{Número de Eventos Detectados}

A Tabela 7.2 mostra o número de eventos detectados para cada uma das execuções do experimento, bem como a média e o desvio padrão para as execuções de cada um dos algoritmos de balanceamento de carga. A média do número de eventos detectados com o uso do algoritmo de balanceamento por Uso de Estado não foi expressivamente diferente da média de eventos detectados com o uso do algoritmo de balanceamento por Similaridade de Entrada.

Tabela 7.2: Número de eventos detectados em cada execução do experimento.

\begin{tabular}{lrlr}
$\begin{array}{l}\text { Balanceamento de Carga por } \\
\text { Uso de Estado }\end{array}$ & \multicolumn{2}{c}{$\begin{array}{l}\text { Balanceamento de Carga por } \\
\text { Similaridade de Entrada }\end{array}$} \\
& 1.703 .200 & & 1.706 .853 \\
& 1.705 .963 & & 1.707 .100 \\
& 1.704 .298 & & 1.703 .770 \\
& 1.709 .012 & & 1.703 .887 \\
& 1.707 .569 & & 1.704 .115 \\
Média & & Média & 1.705 .145 \\
Desvio Padrão & $1.706 .008,4$ & & \\
& & Desvio Padrão & $1.678,79$
\end{tabular}

A principal causa das diferenças no número de eventos detectados fica mais clara ao olhar para os resultados separados por categoria de tipo de evento para cada execução do experimento. As tabelas 7.3 e 7.4 mostram que não há diferença no número de eventos coletados para tipos de evento de cálculo de velocidade instantânea e de filtro de velocidade. Isso sugere que as diferenças no número de eventos detectados mostradas na Tabela 7.2 não são devido a problemas de conexão.

A diferença só é expressa nos eventos obtidos a partir de tipos de evento que utilizam janelas temporais. O uso de janelas temporais para os operadores de agregação nesses tipos de evento faz com que o número total de eventos gerados por eles seja impactado pela variação de latência dos seus eventos de entrada. Como a distribuição das latências ao longo do tempo muda de uma execução do experimento para outra (como será mostrado na Seção 7.6), isso causa as discrepâncias no número de eventos gerados por esses tipos de evento em diferentes execuções.

Tabela 7.3: Número de eventos detectados por categoria de tipo de evento em cada execução do experimento com o algoritmo de balanceamento por Uso de Estado.

\begin{tabular}{llrrrr} 
& vf & vi & vel & \multicolumn{1}{c}{ BusB } & \multicolumn{1}{c}{ corr } \\
& 1.434 .615 & 80.528 & 26.613 & 138.452 & 26.645 \\
& 1.434 .615 & 80.530 & 26.608 & 138.667 & 26.680 \\
& 1.434 .615 & 80.529 & 26.541 & 135.752 & 26.333 \\
& 1.434 .615 & 80.529 & 26.534 & 135.860 & 26.349 \\
Média & 1.434 .615 & 80.528 & 26.563 & 136.007 & 26.402 \\
Desvio Padrão & 1.434 .615 & $80.528,8$ & $26.571,8$ & $136.947,6$ & $26.481,8$ \\
& 0 & 0,8367 & 36,95 & 1476,19 & 167,38
\end{tabular}

Ao observar, como exemplo de tipo de evento que não utiliza janela temporal, a diferença entre o valor máximo e mínimo do número de eventos dos tipos de filtro de velocidade (vi), verifica-se que foram coletados no máximo 80.530 e no mínimo 80.528 eventos, sendo a diferença de apenas 2 eventos, ou seja, de $0,00002 \%$. Isso é um indício de que não houve perda significativa de eventos no sistema por parte de transmissão entre instâncias de CEP Worker ou por outros mecanismos do experimento. 
Tabela 7.4: Número de eventos detectados por categoria de tipo de evento em cada execução do experimento com o algoritmo de balanceamento por Similaridade de Entrada.

$\begin{array}{llrrrl} & \text { vf } & \text { vi } & \text { vel } & \text { BusB } & \text { corr } \\ & 1.434 .615 & 80.529 & 26.522 & 135.246 & 26.288 \\ & 1.434 .615 & 80.528 & 26.585 & 137.671 & 26.564 \\ & 1.434 .615 & 80.528 & 26.537 & 136.227 & 26.391 \\ & 1.434 .615 & 80.529 & 26.718 & 140.277 & 26.873 \\ & 1.434 .615 & 80.530 & 26.644 & 139.071 & 26.709 \\ \text { Média } & 1.434 .615 & 80.528,8 & 26.601,2 & 137.698,4 & 26.565 \\ \text { Desvio Padrão } & 0 & 0,8367 & 80,83 & 2.044,09 & 235,91\end{array}$

\subsection{Vazão}

A vazão do sistema pode ser definida como a quantidade de dados transmitidos por intervalo de tempo (Jain, 2008). Neste trabalho, a vazão do CEP Handler é definida como a quantidade de eventos por minuto transmitidos pelas instâncias de CEP Worker para o sistema de mensageria, para serem utilizados como entrada na detecção de outros tipos de eventos ou para o consumo do usuário final. As figuras 7.8 e 7.7 mostram a vazão do sistema ao longo de uma execução do experimento para cada algoritmo de balanceamento. Na figuras, pode-se observar que existe um crescimento da vazão ao longo do tempo similar ao da carga de entrada.

As figuras que mostram a variação de vazão de todas as execuções do experimento podem ser encontradas no Apêndice A. Comparando os gráficos das execuções que usam o algoritmo de balanceamento de carga por Uso de Estado com os do algoritmo por Similaridade de Entrada, não é possível notar uma diferença significativa nas vazões do sistema, para qualquer sub-intervalo de tempo do experimento. A pequena variação observada na vazão do sistema pode se originar da variação de latência ao longo do tempo dos eventos de entrada para cada tipo de evento, principalmente para os tipos de eventos que usam janelas de tempo para a detecção. Esse é o caso dos tipos de evento de detecção de agrupamento de ônibus, que são maioria na rede de processamento de eventos do cenário do experimento. 


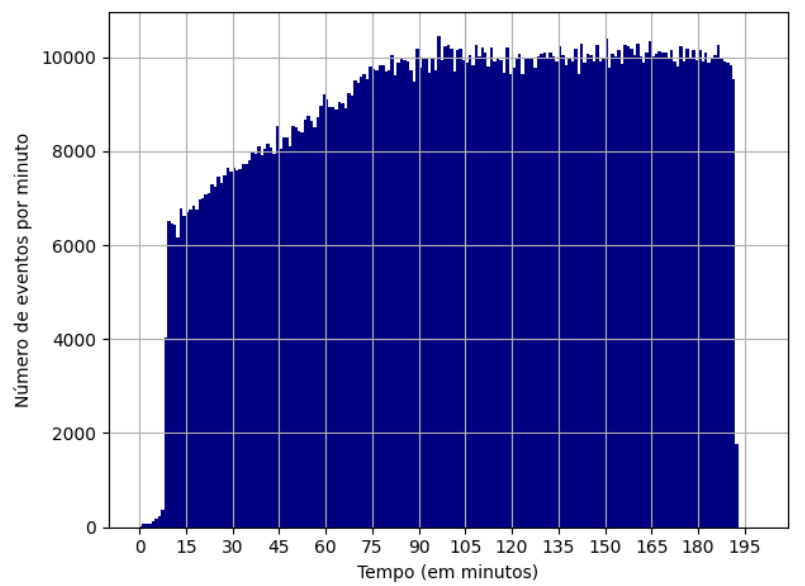

(a) Execução 1

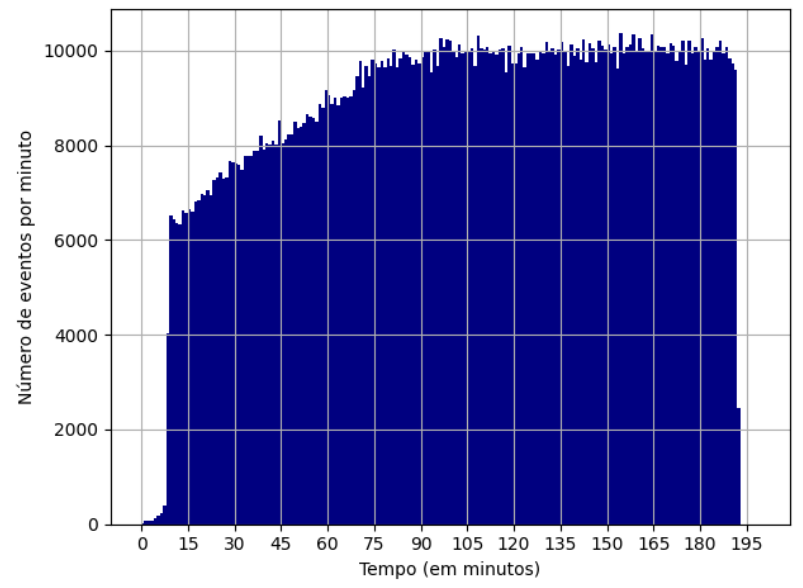

(c) Execução 3

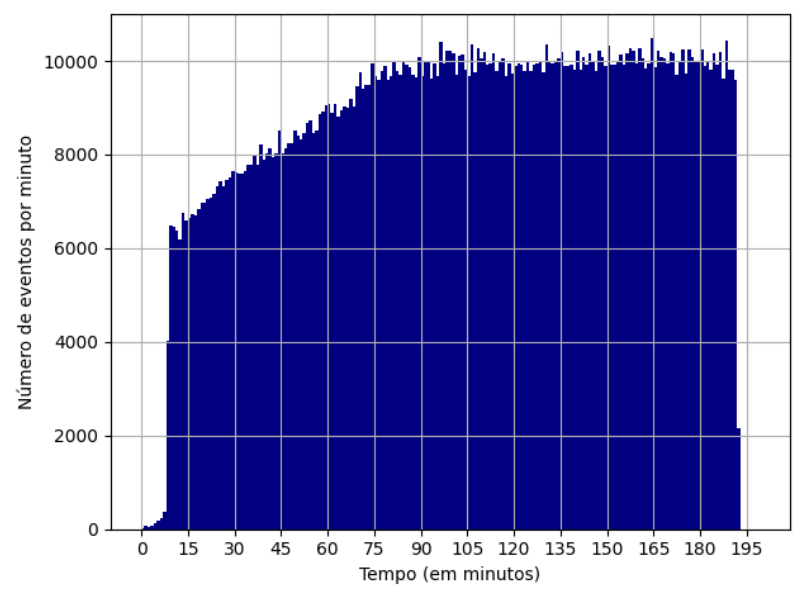

(e) Execução 5

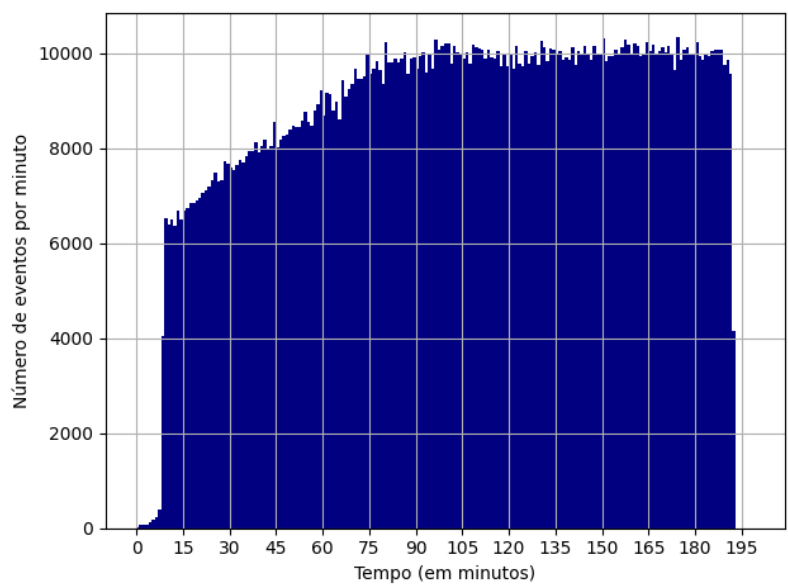

(b) Execução 2

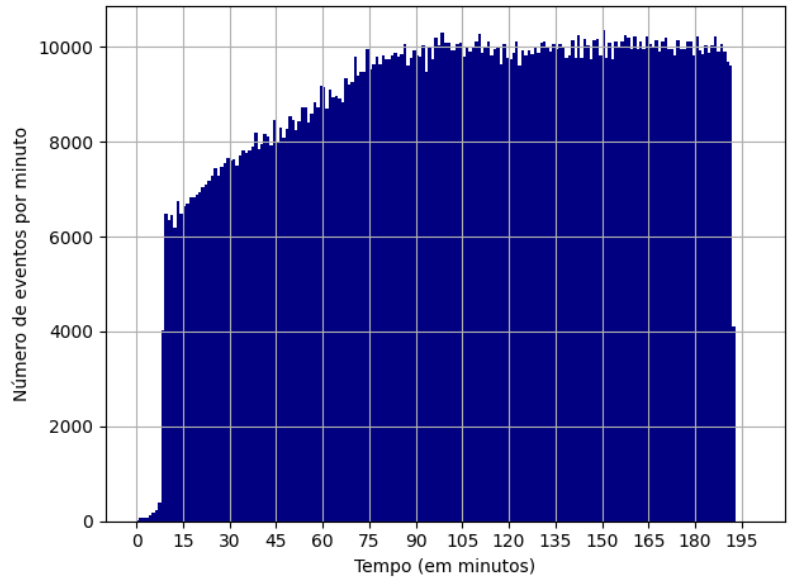

(d) Execução 4

Figura 7.7: Vazão de eventos detectados pelo sistema nas execuções do experimento utilizando o algoritmo de de balanceamento por Uso de Estado. 


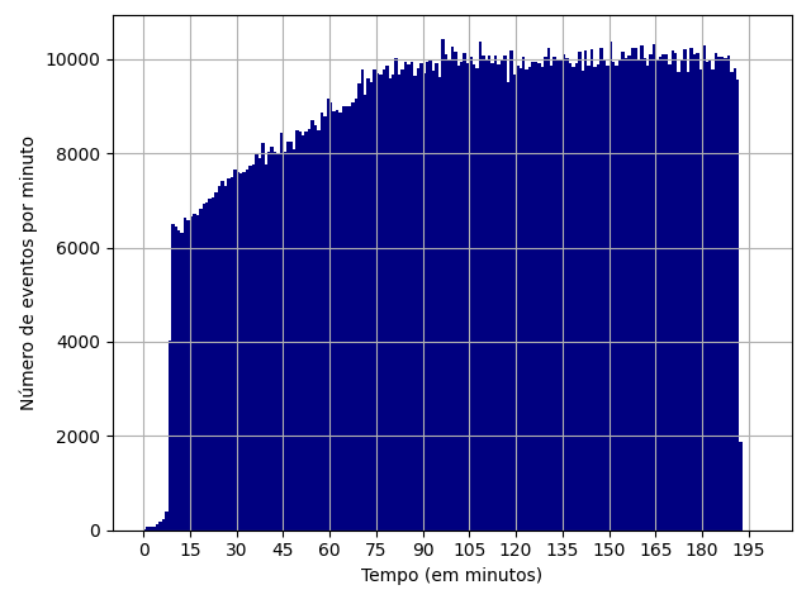

(a) Execução 1

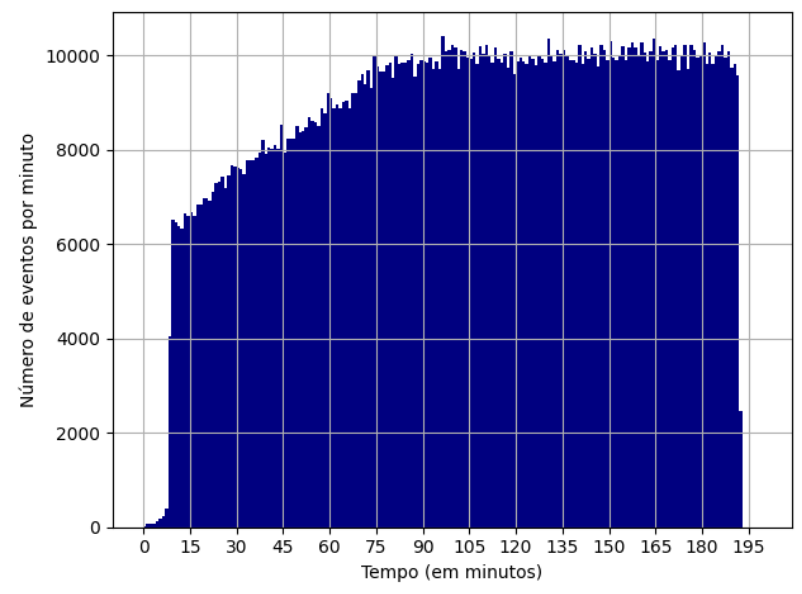

(c) Execução 3

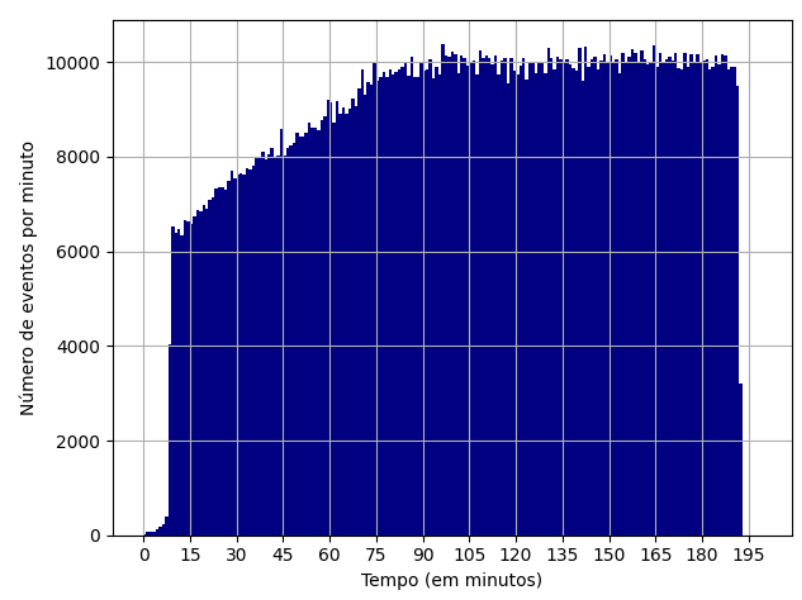

(e) Execução 5

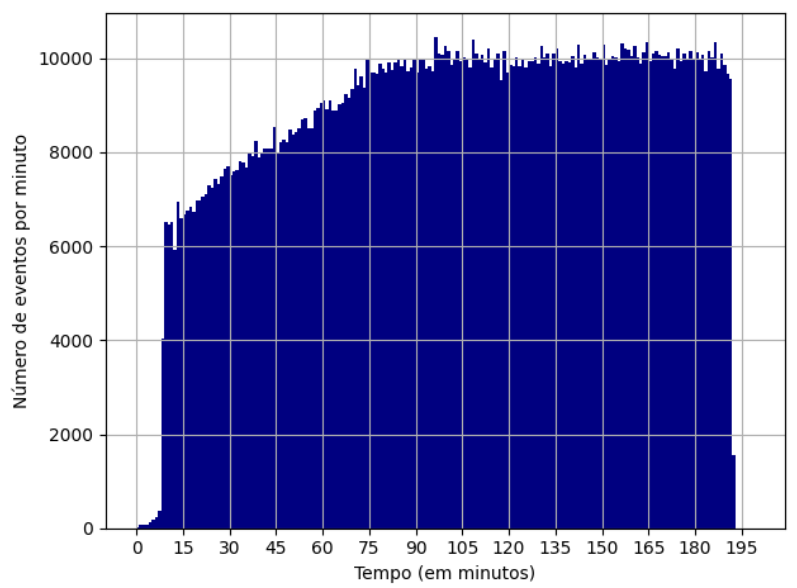

(b) Execução 2

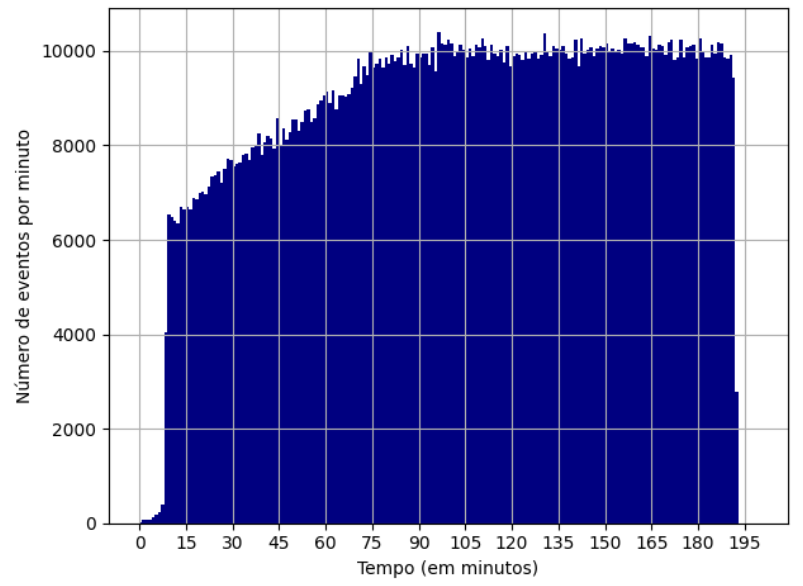

(d) Execução 4 


\subsection{Latência}

Em um sistema que lida com dados em tempo real, a latência da transmissão de eventos pelo sistema é a principal métrica de análise do desempenho. Para medir a latência no CEP Handler, foi usado o método descrito na Seção 6.3. Uma marca temporal foi gerada no momento em que o evento primário foi enviado do microsserviço do experimento para ser consumido pelas instâncias de CEP Workers. Outra marca temporal foi gerada quando o evento foi armazenado no banco de dados chave-valor, depois de sua deteç̧ão pelo sistema. A latência foi tomada como a diferença entre esses dois valores. Os dois valores são coletados no mesmo microsserviço e utilizam o mesmo relógio interno. O tempo utilizado para os intervalos no eixo x dos gráficos de latência vêm da marca temporal de quando o evento foi armazenado, depois da detecção.

Cada uma das figuras de 7.9 a 7.13 mostram as latências das execuções de uma categoria de tipos de evento, separadas por algoritmo de balanceamento de carga. Diagramas de caixa foram usados para representar a variação de latência das execuções. Cada caixa mostra o primeiro quartil, a mediana e o terceiro quartil das latências de uma execução. As linhas que se estendem a partir de uma caixa indicam a variabilidade fora do quartil superior e do quartil inferior.

Como mostram os diagramas de caixa, o sistema apresentou um bom desempenho em relação à latência para todos os tipos de eventos da rede de processamento. O terceiro quartil das latências medidas durante todas as execuções ficou sempre abaixo de cem milissegundos, para todas as categorias de tipos de eventos e considerando o uso de ambos os algoritmos de balanceamento de carga.
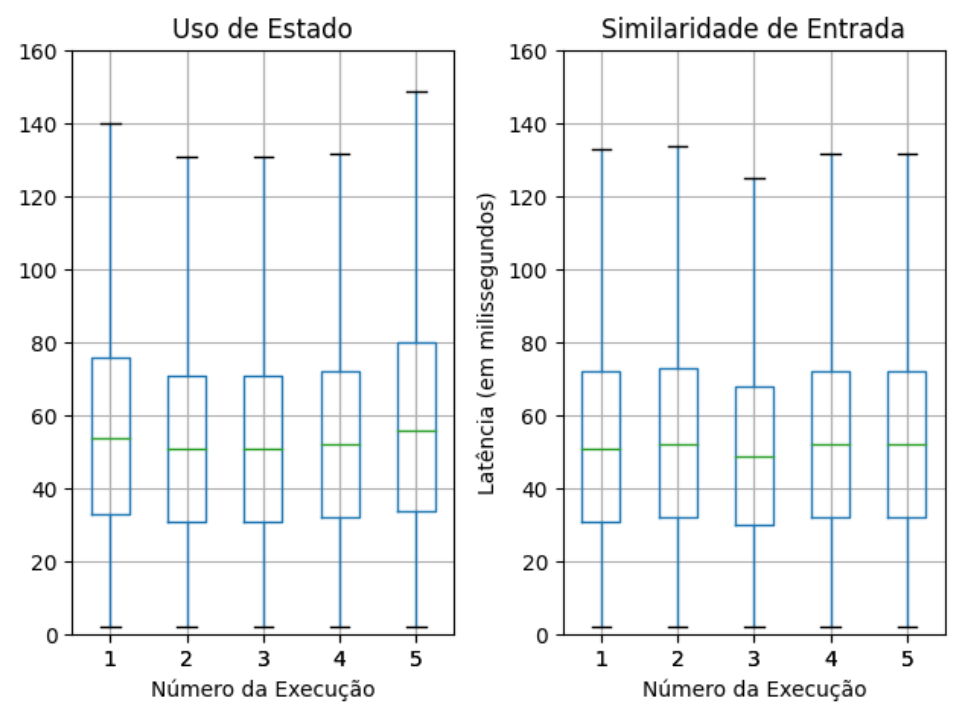

Figura 7.9: Latência para velocidade instantânea nas execuções do experimento para cada algoritmo de balanceamento de carga.

A Figura 7.14 mostra, para cada uma das categorias de eventos, a variação da latência ao longo da execução 2 do experimento com o algoritmo de balanceamento de carga por Similaridade de Entrada. Os gráficos da variação de latência por categoria de evento ao longo das outras execuções podem ser vistos no Apêndice A. As latências foram agrupadas em intervalos de cinco minutos, para facilitar a visualização do dados. Na Figura 7.14, é possível visualizar que o terceiro quartil da latência aumenta ao longo do experimento até atingir um patamar estável, seguindo o aumento da carga de entrada, apresentado na Figura 7.5. As categorias de tipo de evento corr, BusB e vel apresentam um crescimento maior no início do experimento e atingem um patamar um pouco mais elevado. Isso pode ser explicado por utilizarem os tipos de eventos da categoria vi como entrada, o qual utiliza os tipos vf como entrada. Logo, os dados do evento de entrada para os tipos de evento das categorias vel e BusB já foram transmitidos pelo broker duas vezes. 

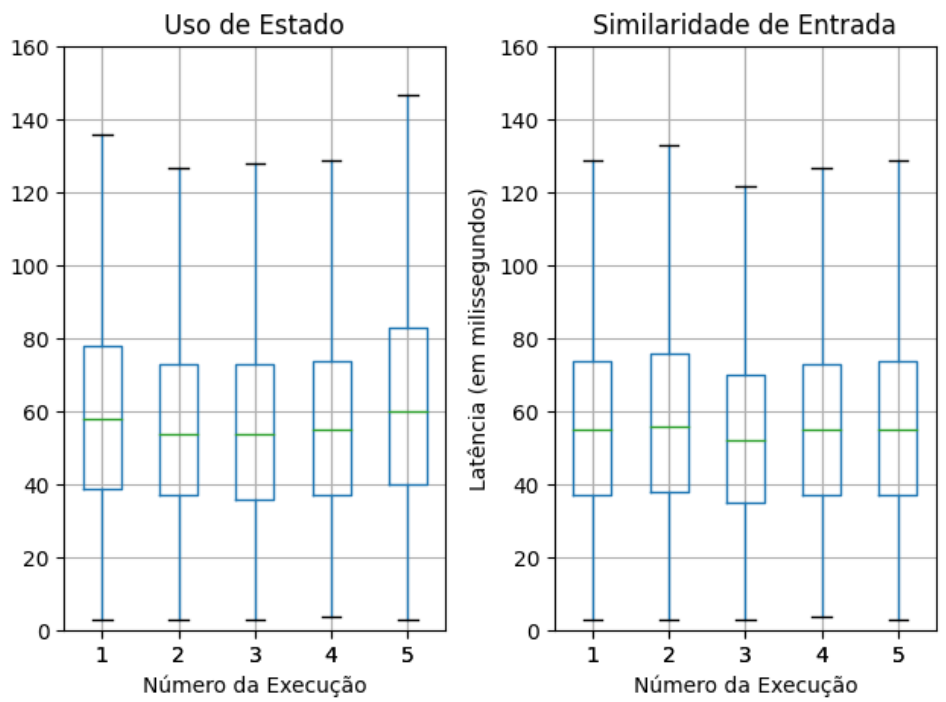

Figura 7.10: Latência para filtro de velocidade nas execuções do experimento para cada algoritmo de balanceamento de carga.
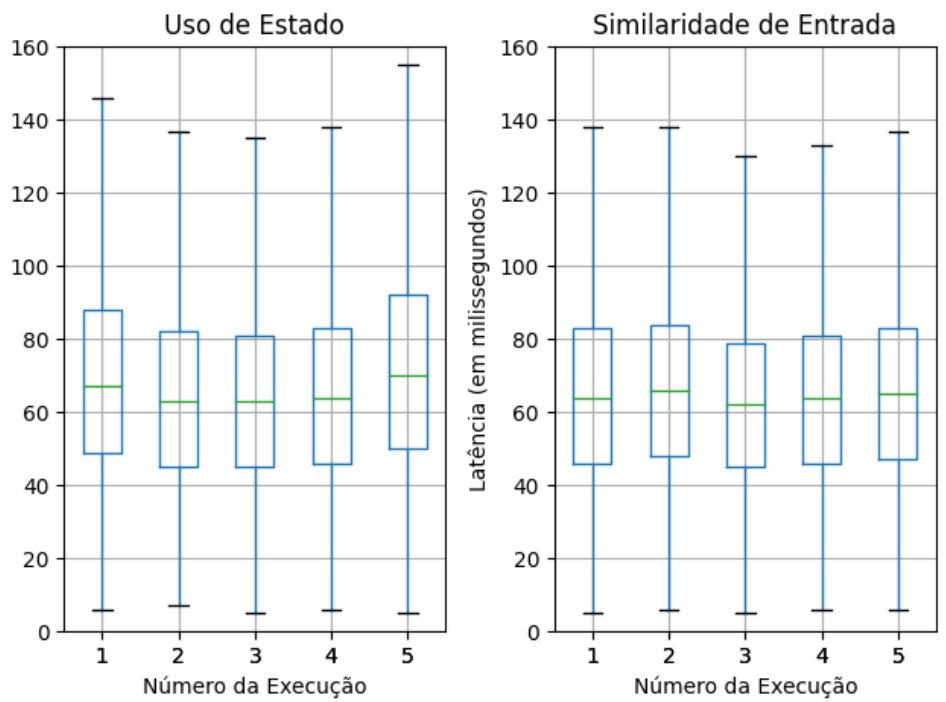

Figura 7.11: Latência para velocidade média de ônibus nos corredores nas execuções do experimento para cada algoritmo de balanceamento de carga. 

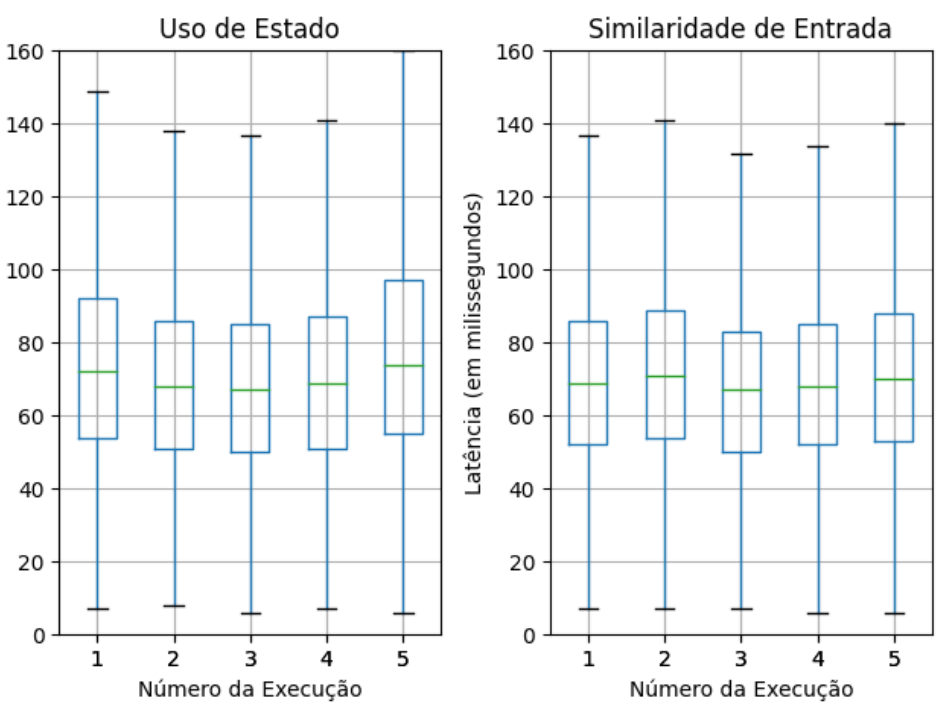

Figura 7.12: Latência para velocidade média de cada corredor nas execuções do experimento para cada algoritmo de balanceamento de carga.
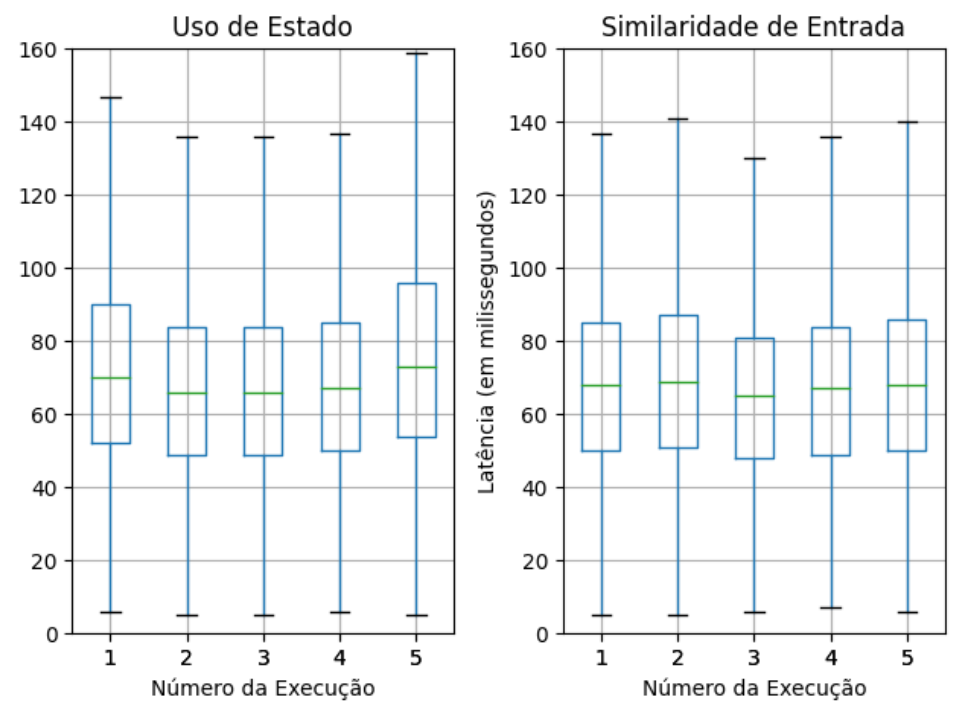

Figura 7.13: Latência para deteç̧̃̃o de agrupamento de ônibus nas execuções do experimento para cada algoritmo de balanceamento de carga. 


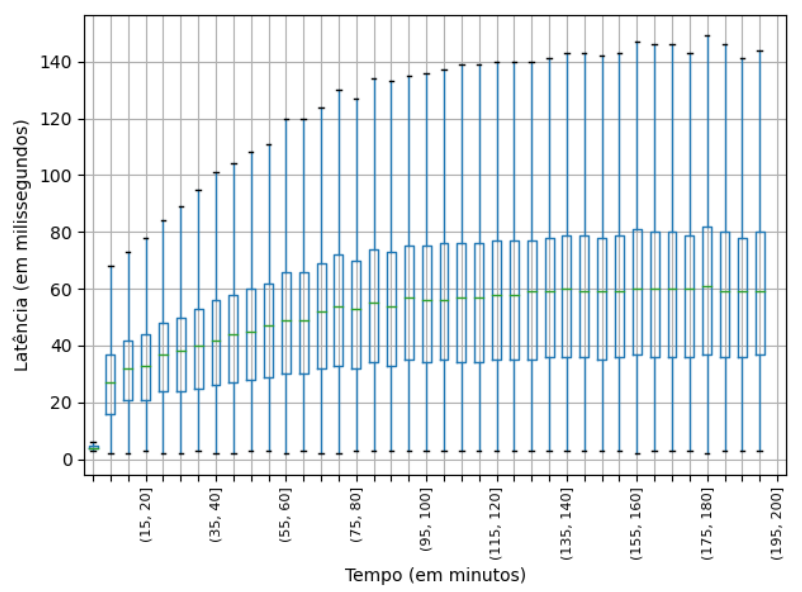

(a) Tipos de evento $\boldsymbol{v f}$

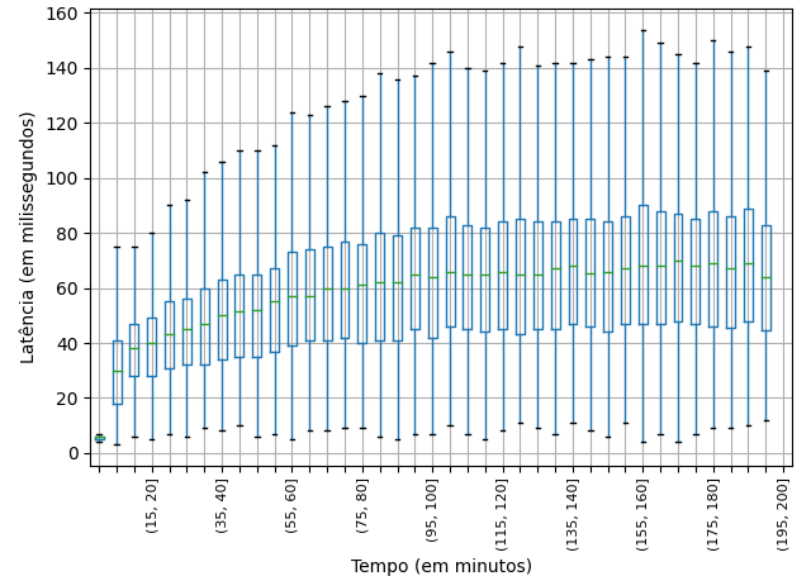

(b) Tipos de evento $\boldsymbol{v i}$

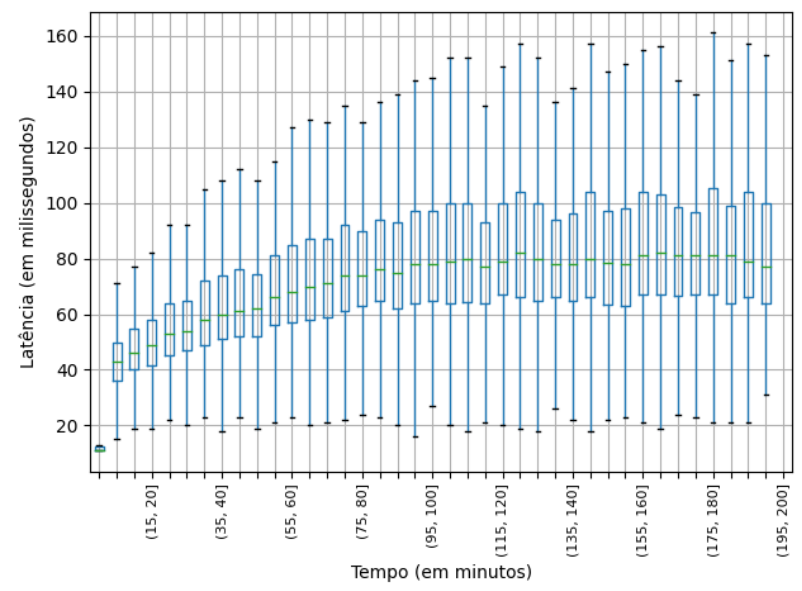

(d) Tipos de evento corr

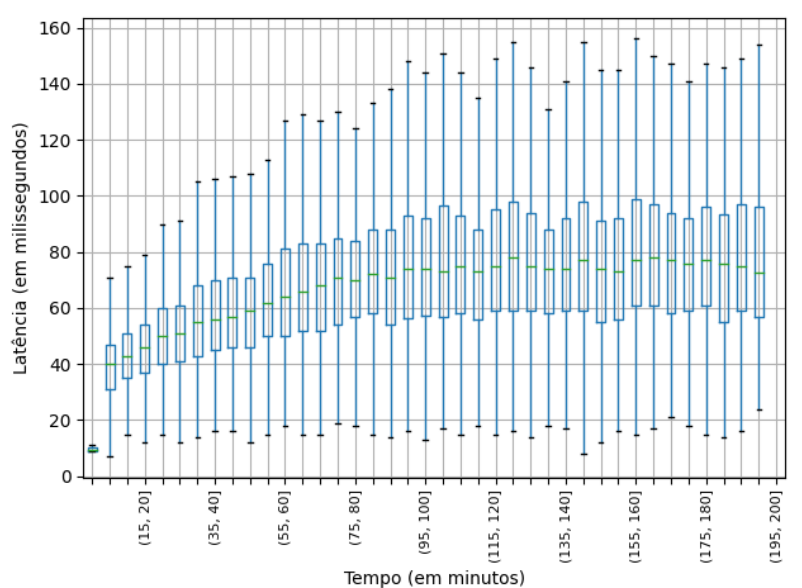

(c) Tipos de evento vel

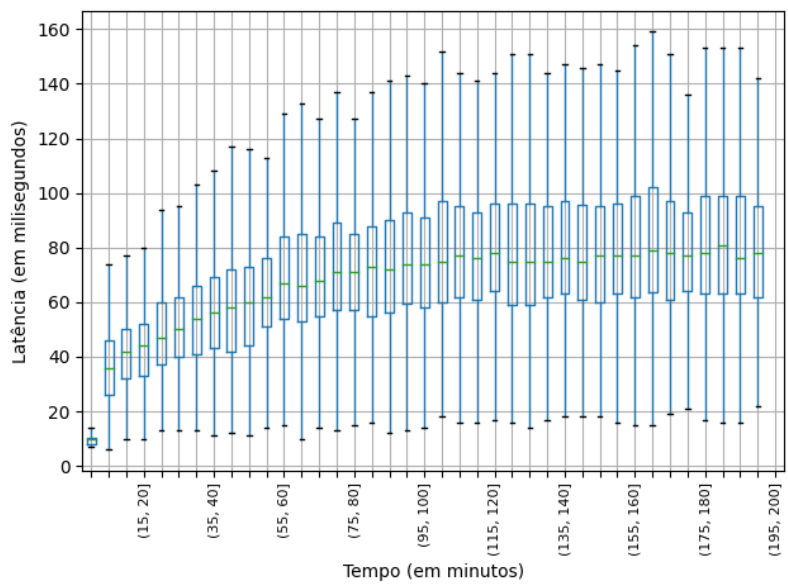

(e) Tipos de evento BusB

Figura 7.14: Latências das categorias de tipos de evento por intervalos de cinco minutos ao longo da execução 2 do experimento utilizando o algoritmo de balanceamento de carga por Similaridade de Entrada. 


\subsection{Conclusão}

A análise dos resultados do experimento em relação a latência, vazão, número de eventos detectados e tempo de uso de recursos indica que os dois algoritmos de balanceamento de carga obtiveram resultados próximos e permitiram o sistema satisfazer o requisito de auto-escalabilidade.

A grande maioria das latências medidas no experimento ficou abaixo de cem milissegundos, mesmo para os eventos que estão no final da rede de processamento e que dependem da detecção de toda uma cadeia de eventos. Essas latências atendem de forma satisfatória os requisitos de processamento em tempo real dos dados da aplicação considerada no experimento - o monitoramento de tráfego de ônibus de uma grande cidade. Essa rapidez na detecção e notificação dos eventos habilita a administração pública e as empresas que cuidam da gestão do transporte por ônibus a tomar ações para a resolução de problemas de tráfego em tempo oportuno.

A vazão e o número de eventos detectados pelo experimento são dependentes da latência no caso de tipos de eventos com janela temporal, como discutido na Seção 7.5, pois para agrupar os eventos em janelas, os horários de chegada dos eventos no CEP Worker são usados. Para os eventos de outros tipos, a vazão e o número de eventos detectados não se alteram de uma execução para outra.

O tempo médio de uso de recursos computacionais pelas instâncias de CEP Worker em cada execução do experimento não foi expressivamente diferente para o dois algoritmos de balanceamento de carga, sendo de 1.049, $2 \pm$ 4, 51 minutos para o Algoritmo de balanceamento por Similaridade de Entrada e 1.045, $56 \pm 5,04$ minutos para o algoritmo de balanceamento por Uso de Estado. Como discutido na Seção 7.3, uma possível explicação é que a alta velocidade de realocação dos tipos de eventos é um fator importante para minimizar o intervalo de tempo que cada instância se mantêm em sobrecarga.

Os dados usados no experimento, durante as três horas contínuas, só apresentaram crescimento de número de dados enviados ao longo do tempo. Consequentemente, a escalabilidade detectada no experimento foi só com o aumento de número de instâncias de CEP Worker. Não foi possível testar a remoção de instâncias de CEP Worker por baixo uso de recursos nesse cenário experimental. 


\section{Capítulo 8}

\section{Conclusões}

As técnicas e ferramentas de Processamento de Eventos Complexos foram desenvolvidas com o propósito explícito de lidar com o processamento de dados em tempo real de forma contínua. A lista de operadores desenvolvidos para a definição de tipos de eventos é extensa, mas necessária para que as linguagens de definição de consultas em tempo real sejam tão abrangentes em sua cobertura de possíveis tipos de eventos quanto as linguagens de consulta a bancos de dados relacionais são no campo de consultas por lote.

Uma dificuldade encontrada em utilizar Processamento de Eventos Complexos para a detecção de eventos em grande escala, como em aplicações para cidades inteligente, é a implementação de um sistema que seja escalável, ou seja, que consiga aumentar sua capacidade de processamento de acordo com a carga atribuída a ele. Se o aumento na capacidade de processamento requer um administrador humano para monitorar o sistema e a carga de entrada constantemente e aplicar as medidas necessárias de acordo com o incremento de carga, o desempenho do sistema fica limitado ao tempo de resposta do administrador.

Para atender requisitos de tempo real no monitoramento contínuo de um ambiente urbano, o próprio sistema de processamento de eventos deve ser capaz de aumentar sua alocação de recursos quando necessário, ou seja, deve ser auto-escalável. As soluções encontradas atualmente na literatura, apesar de apresentar várias técnicas para a distribuição, não exploram o desenvolvimento de sistemas de processamento de eventos complexos que sejam auto-escaláveis, gerenciando dinamicamente o uso de recursos do sistema, e que considerem a tolerância a falhas nos nós de processamento um requisito igualmente importante. De forma geral, esses trabalhos tendem a focar a busca só da escalabilidade ou só da tolerância a falhas.

A partir da combinação de mecanismos de processamento de eventos complexos de código aberto com sistemas de mensageria em tempo real, de isolamento de ambiente de execução, armazenamento de dados em memória RAM e técnicas de gerenciamento dinâmico de recursos na nuvem, foi criada neste trabalho uma arquitetura de microsserviços que traz a pesquisa de Processamento de Eventos Complexos para o ambiente de desenvolvimento nativo de nuvem. Este é um passo importante, visto que o crescimento na popularidade e uso de plataformas de nuvens para o processamento em todas as áreas da Computação está impulsionando a pesquisa de sistemas nativos de nuvem para o melhor aproveitamento dos recursos disponíveis nesse ambiente de execução.

$\mathrm{Na}$ arquitetura desenvolvida neste trabalho, chamada de CEP Handler, a auto-escalabilidade é provida por um mecanismo de detecção de sobrecarga de recursos e de distribuição do processamento de eventos entre múltiplas instâncias de um mesmo microsserviço em execução na nuvem. O sistema detecta automaticamente a necessidade da criação de novas instâncias de processamento de eventos e as requisita utilizando especificações de recursos computacionais iguais aos utilizados pelas instâncias em sobrecarga.

A tolerância a falhas é satisfeita no sistema pelo mecanismo de recriação de instâncias que foram removidas indevidamente, de forma que toda instância verifica no início do processamento se existem tipos de eventos que já estavam previamente cadastrados nela e os recadastra se necessário. A escolha do estilo de organização arquitetural de coreografia também aumenta a tolerância a falhas 
do sistema, pois não há um nó central no qual uma falha de execução impactaria a execução do resto do sistema. Mesmo o SGBD chave-valor pode ser executado com réplicas de leitura e mecanismos automatizados para eleição de instância principal em caso de falhas, para assegurar uma maior disponibilidade de acesso aos metadados. A auto-escalabilidade e a tolerância a falhas proveem o processamento de eventos nativo de nuvem e diminuem a necessidade de intervenção manual durante o funcionamento do sistema.

A partir da pesquisa de trabalhos relacionados a distribuição de processamento de eventos complexos, detalhada no Capítulo 3, dois algoritmos de balanceamento de carga foram criados para o CEP Handler. Esses algoritmos definem a ordem de realocação dos tipos de evento de um nó de processamento para outro. Um dos algoritmos seleciona o tipo de evento a ser realocado a partir do tempo necessário para reconstruir seu estado em outro nó de processamento. O outro algoritmo seleciona o tipo de evento a ser realocado considerando a similaridade entre os seus tipos de entrada e os tipos de entrada dos demais tipos processados no mesmo nó, tentando manter agrupados num mesmo nó os tipos que compartilham os mesmos tipos de entrada, minimizando assim a duplicação na transmissão de eventos para os nós de processamento do sistema.

Para avaliar a arquitetura proposta, foi construído um protótipo dela utilizando somente ferramentas de software livre, como visto no Capítulo 5. O protótipo foi implementado como uma extensão da plataforma de software livre para cidades inteligentes InterSCity (Esposte et al., 2019), do Instituto Nacional de Ciência e Tecnologia (INCT) da Internet do Futuro para Cidades Inteligentes $^{1}$.

O monitoramento de tráfego de ônibus do sistema de transporte público da cidade de São Paulo, SP, foi usado como cenário experimental na avaliação do protótipo. Como apresentado no Capítulo 6, para o experimento, foram utilizados dados de três horas contínuas da localização de ônibus que servem a infraestrutura pública de transportes na capital paulista. Essas três horas compreendem um dos períodos de maior variação no número de ônibus em circulação e, consequentemente, grande variação de número de eventos entrando no sistema. Foram utilizados dados de trinta por cento de todas as linhas da cidade, totalizando 708 linhas e 14.121 veículos.

A partir das 708 linhas, foram criados 15.729 tipos de eventos, de cinco categorias distintas, que utilizam diferentes métodos de agregação de eventos. A rede de processamento de eventos criada para o experimento usou tanto tipos de eventos simples, que não possuem janelas de agregação de eventos de entrada, quanto tipos de eventos que as utilizam. Um dos desafios na implementação do sistema foi a criação de um método para a realocação dos tipos de eventos entre nós de processamento com a garantia de que nenhum evento seria descartado durante o processo de realocação. Isso é feito a partir do cálculo do tempo necessário para reconstruir o estado da janela de agregação do tipo de evento em realocação, com base na própria definição do tipo. Até que o tempo necessário para a reconstrução do estado no novo nó transcorra, o tipo de evento continua sendo detectado pelo seu nó de processamento original.

O experimento foi executado com dez repetições ao total, cinco para cada um dos algoritmos de balanceamento de carga implementados. A partir dos resultados coletados, descritos no Capítulo 7, pode-se verificar que o sistema apresentou latências que normalmente ficaram abaixo de cem milissegundos, satisfazendo os requisitos de processamento em tempo real do cenário considerado. Além disso, o experimento mostrou que o sistema consegue automaticamente identificar uma sobrecarga no uso de recursos computacionais e requisitar recursos adicionais do provedor de nuvem utilizado, se auto-escalando e rebalanceando conforme a variação da carga de trabalho. Não foi observada diferença significativa entre os desempenhos dos dois algoritmos de balanceamento de carga implementados.

\subsection{Considerações Finais}

A partir do estudo das pesquisas e técnicas de processamento em tempo real e de sistemas nativos de nuvem, foi possível desenvolver um sistema de processamento de eventos distribuído que

\footnotetext{
${ }^{1}$ https://interscity.org/
} 
não depende de monitoramento ativo por parte de um administrador para se recuperar de falhas no ambiente de execução e se auto-escalar de acordo com a carga de entrada. A combinação das tecnologias de processamento de eventos complexos e de sistemas nativos de nuvem se provou frutífera no desenvolvimento de uma arquitetura e implementação que cumprem os requisitos mencionados anteriormente.

Para o oferecimento de serviços que tornem as cidades inteligentes, sistemas que cumprem os requisitos para serem nativos de nuvem se fazem necessários para que plataformas de cidades inteligentes servindo a cidade consigam detectar ocorrências e respondê-las em tempo real, ajustando sua distribuição automaticamente à variação de carga entrando no sistema e se recuperando de possíveis falhas sem a necessidade de intervenção manual de operadores do sistema.

\subsection{Sugestões para Pesquisas Futuras}

O desenho do experimento foi limitado por vários fatores, como a escolha do RabbitMQ como broker usado no protótipo e experimento, a coleta de dados para o experimento do sistema da SPTrans que não oferece nativamente um método para baixar todos os dados de posições de um dia inteiro, o uso de dados só dos ônibus municipais, sem levar em conta os outros métodos de transporte urbanos ou mesmo outros fatores de interesse em monitoramento na cidade, entre outros. Esses fatores poderiam ser explorados individualmente para um melhor entendimento de como cada um afeta o desempenho geral do sistema CEP Handler. Como o intuito era criar um cenário experimental de grande porte relacionado a cidades inteligentes, foram utilizados dados do monitoramento de tráfego de ônibus do transporte público. Mas para poder caracterizar o desempenho do sistema de forma mais geral, é necessário analisá-lo com outros tipos de aplicações que se beneficiem do processamento de dados em tempo real.

A seguir, estão algumas das sugestões de como explorar ainda mais a arquitetura e o protótipo desenvolvidos neste trabalho:

- Uso de dados para o experimento com maior variação de fluxo, positiva e negativa, para testar melhor o tempo necessário para aumentar e diminuir o número de instâncias de CEP Worker no sistema.

- Inclusão de suporte para outros tipos de janelas de CEP, além de janelas temporais externas e janelas de eventos.

- Experimentos com tipos de eventos mais diversos, com mais tipos de operadores e uma rede de processadores de eventos mais complexa.

- Paralelização do processo de realocação de eventos em threads, para diminuir o tempo necessário para a redistribuição de tipos de eventos entre instâncias de CEP Worker.

- Comparação do uso de outros sistemas de mensageria além do RabbitMQ, que foi um dos fatores limitantes na definição do experimento.

- Inclusão de um sistema de recuperação de falhas para reconstrução dos estados dos tipos de eventos a partir do reenvio dos eventos de entrada de acordo com as janelas definidas pelos tipos de eventos processados por cada CEP Worker.

- Comparação das métricas coletadas para um mesmo cenário experimental com CEP e outras técnicas de processamento de dados em tempo real, como processamento de stream.

- Inclusão do suporte a representação de eventos pelo formato JSON, o qual é o formato de dados utilizado nativamente na Plataforma InterSCity.

- Estudo de escolha de máquinas virtuais para a execução dos microsserviços, considerando o preço de execução de cada máquina e os limites de sobrecarga usados por execução. 
- Experimento com injeção de falhas durante a execução do experimento, para teste dos mecanismos de tolerância a falhas. 


\section{Apêndice A}

\section{Gráficos das Execuções do Experimento}

Aqui são mostrados gráficos obtidos a partir dos resultados de cada uma das dez execuções do experimento de avaliação de desempenho do CEP Handler, sistema de processamento de eventos complexos nativo de nuvem desenvolvido neste trabalho. A legenda das figuras explicam quais são as métricas de desempenho representadas nos gráficos. A descrição do experimento pode ser encontrada no Capítulo 6 e a análise dos resultados no Capítulo 7.

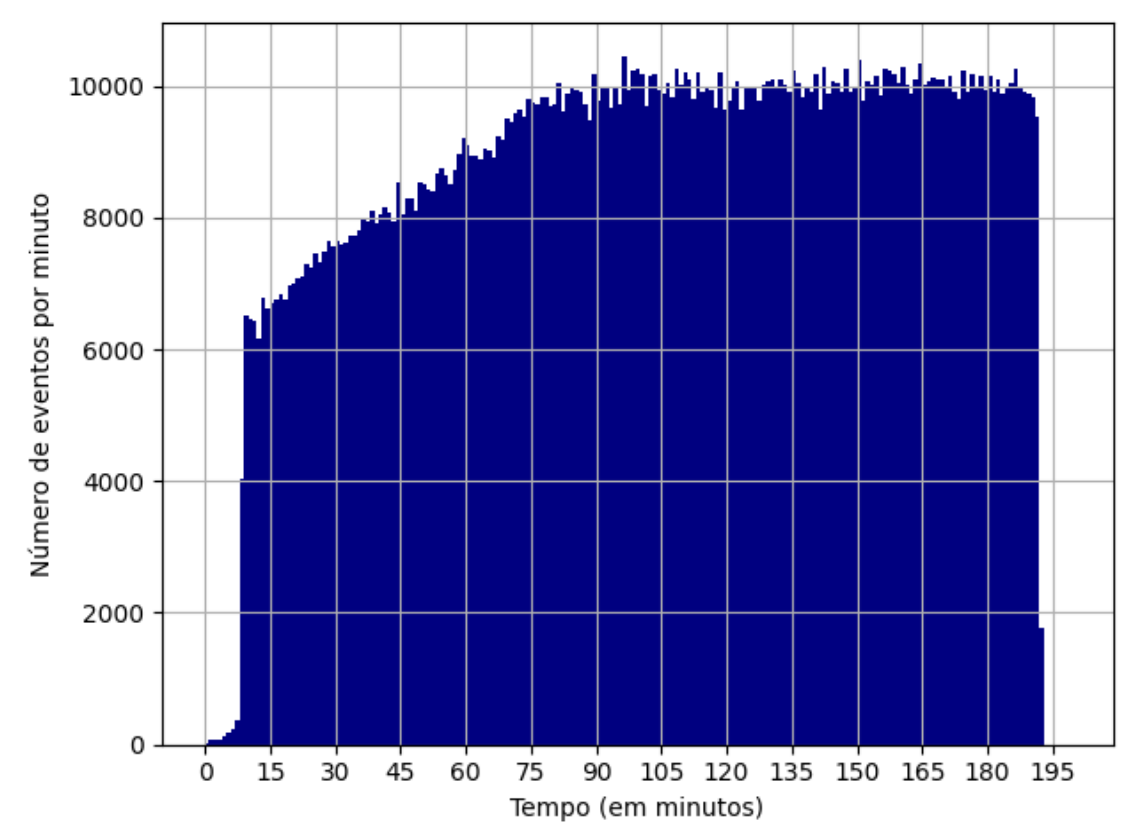

Figura A.1: Vazão de eventos detectados pelo sistema na execução 1 do experimento utilizando o algoritmo de balanceamento por Uso de Estado. 


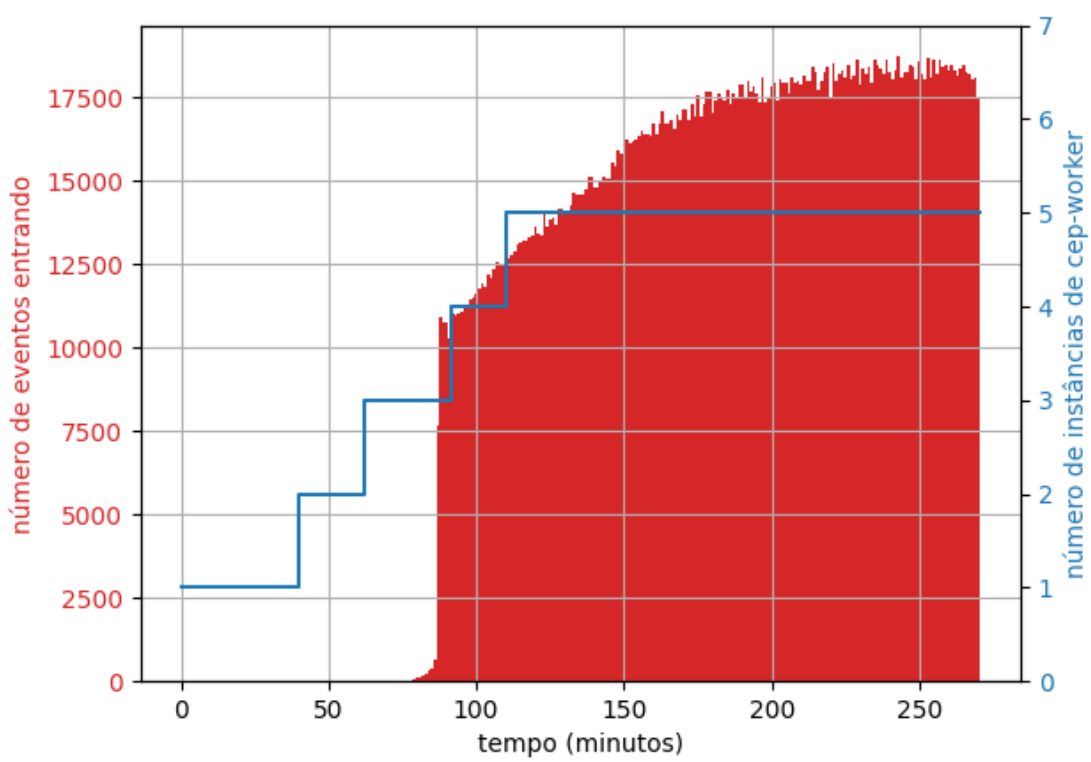

(a) Em função do tempo da execução

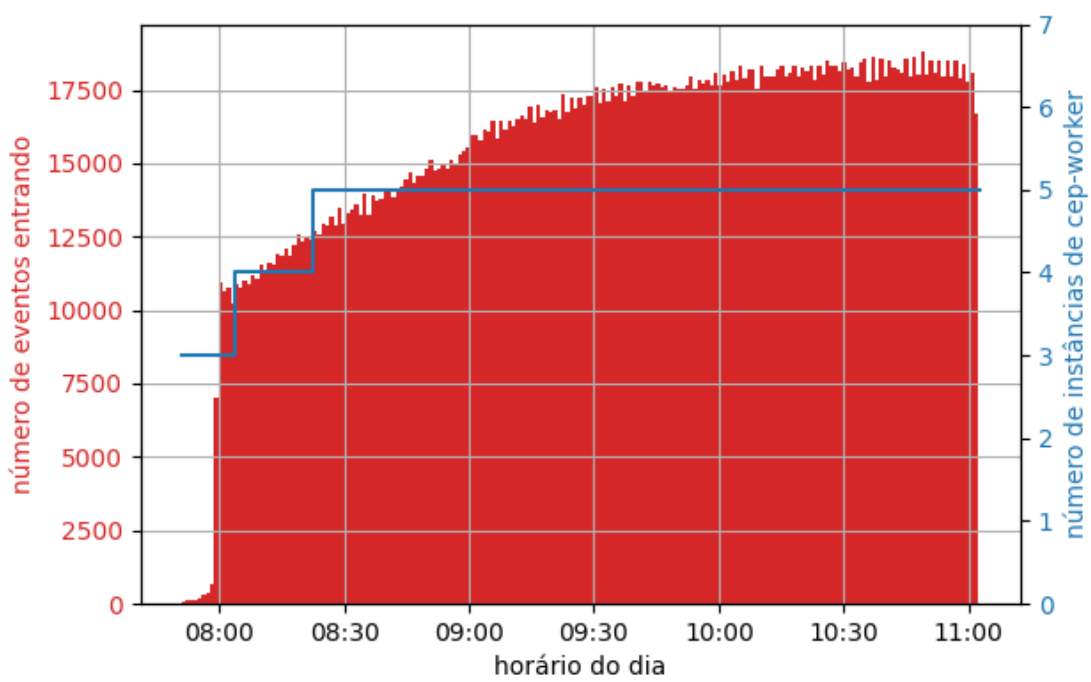

(b) Em função do horário do dia

Figura A.2: Número de eventos entrando no sistema (em vermelho) e número de instâncias de CEP Worker (em azul) na execução 1 do experimento utilizando o algoritmo de balanceamento de carga por Uso de Estado. Algumas instâncias são iniciadas antes do início do envio de eventos pois nesse período o cadastro de tipos de eventos já ocupa toda a memória disponível de algumas instâncias. 


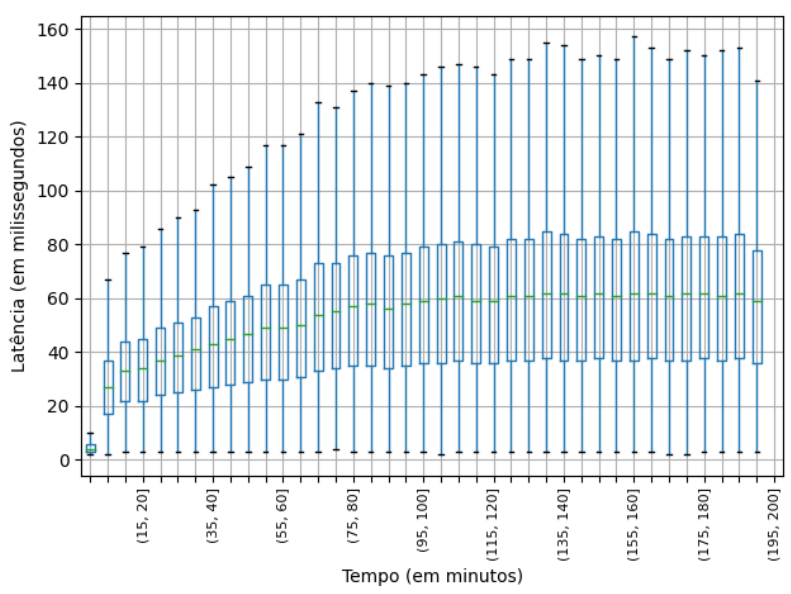

(a) Tipos de evento de $\boldsymbol{v f}$

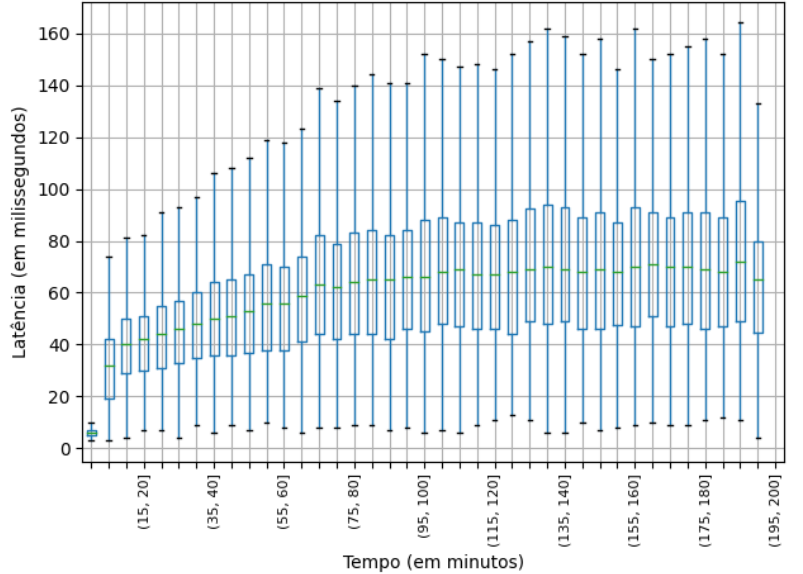

(b) Tipos de evento de $\boldsymbol{v i}$

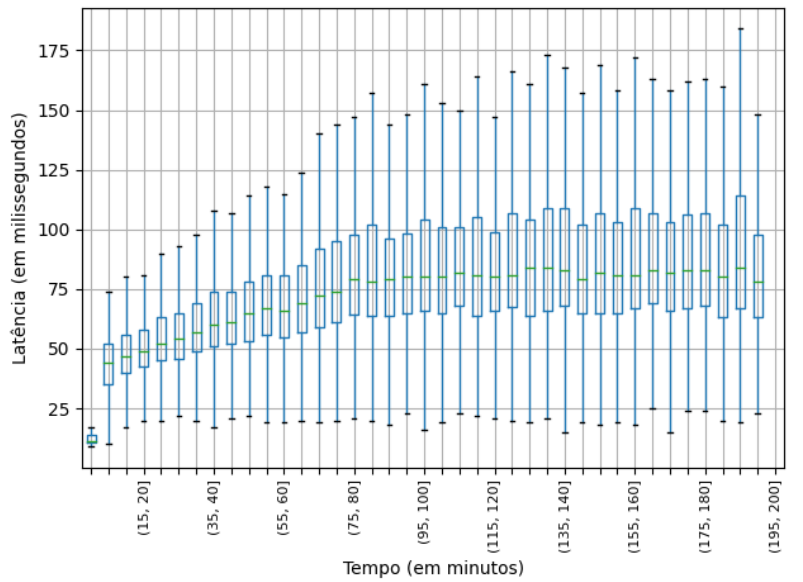

(d) Tipos de evento de corr

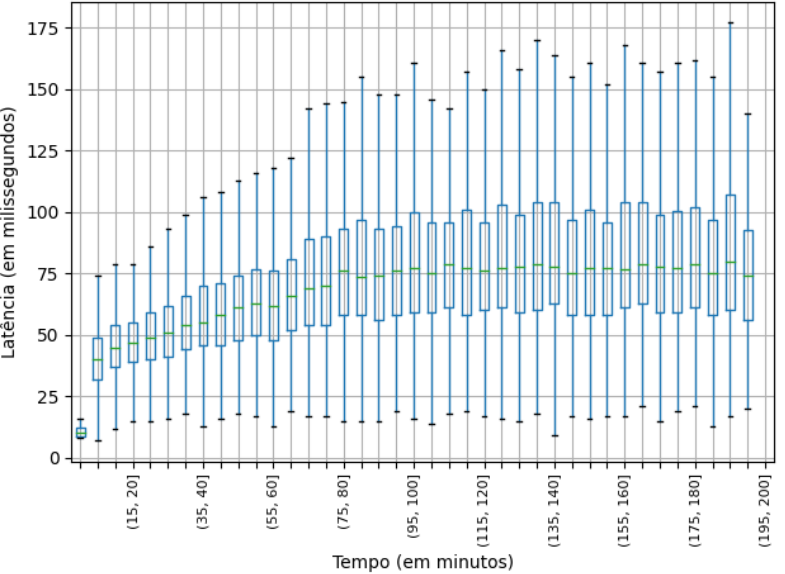

(c) Tipos de evento de vel

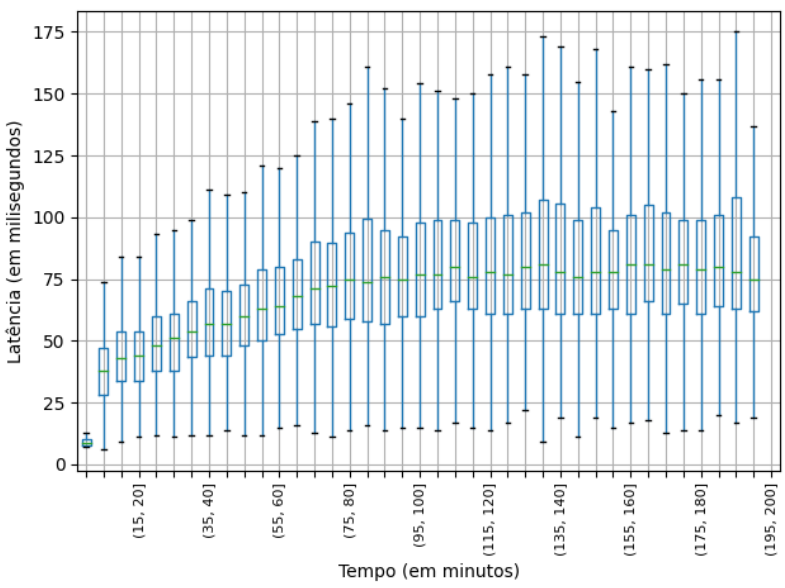

(e) Tipos de evento de $\boldsymbol{B u s B}$

Figura A.3: Diagramas de caixa das latências por intervalos de cinco minutos ao longo da execução 1 do experimento utilizando o algoritmo de balanceamento de carga por Uso de Estado. 


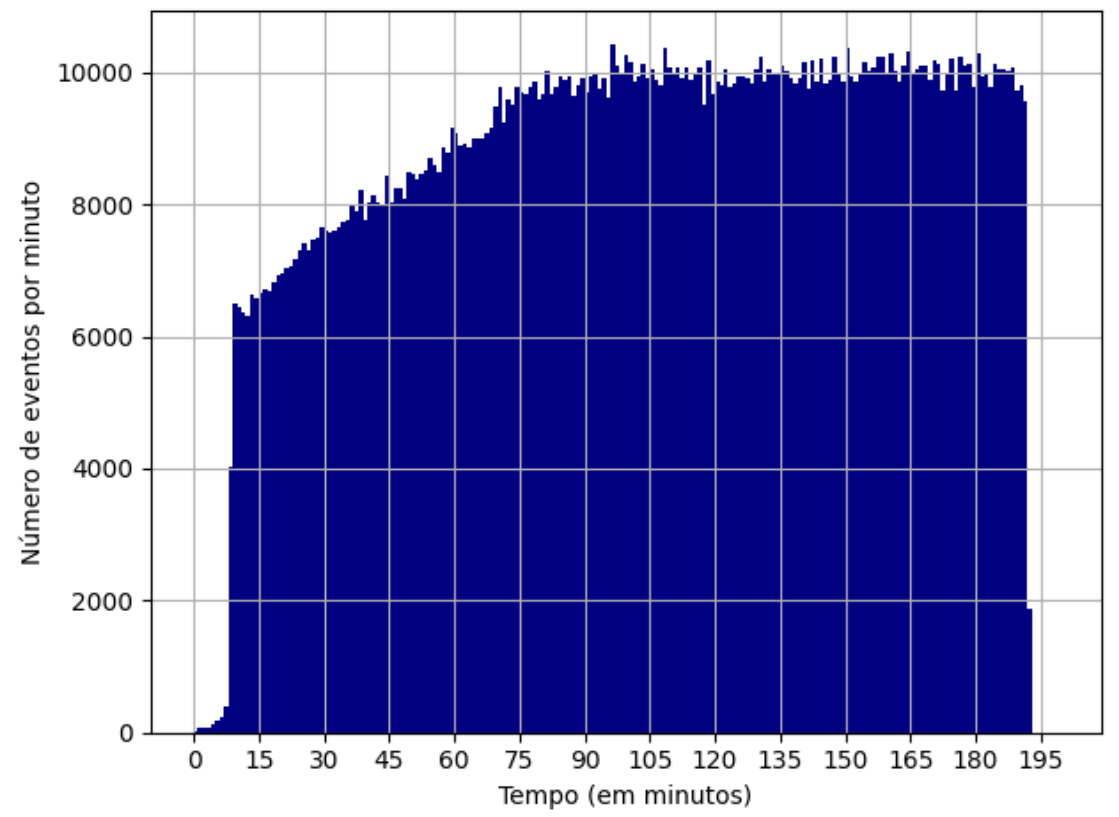

Figura A.4: Vazão de eventos detectados pelo sistema na execução 1 do experimento utilizando o algoritmo de balanceamento por Similaridade de Entrada. 


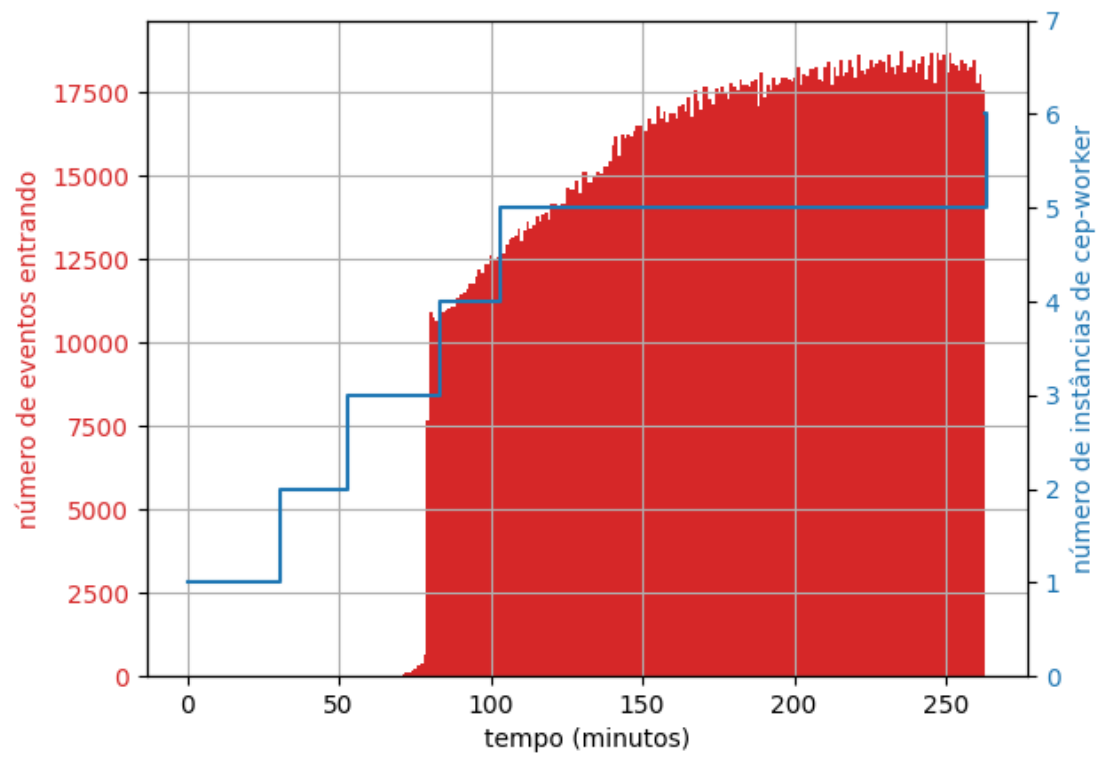

(a) Em função do tempo da execução

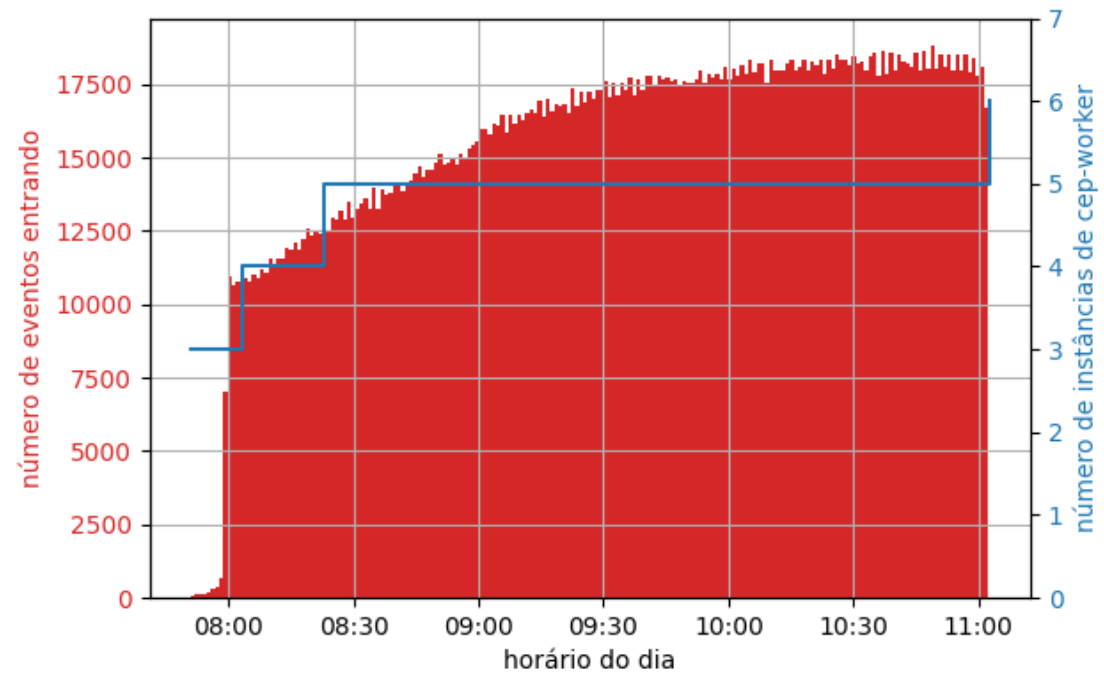

(b) Em função do horário do dia

Figura A.5: Número de eventos entrando no sistema (em vermelho) e número de instâncias de CEP Worker (em azul) na execução 1 do experimento utilizando o algoritmo de balanceamento de carga por Similaridade de Entrada. Algumas instâncias são iniciadas antes do início do envio de eventos pois nesse período o cadastro de tipos de eventos já ocupa toda a memória disponível de algumas instâncias. 


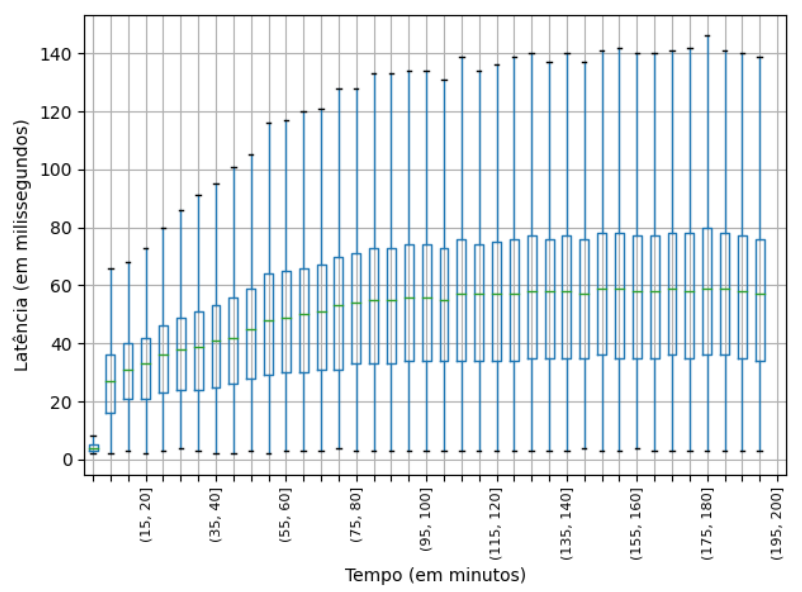

(a) Tipos de evento $\boldsymbol{v f}$

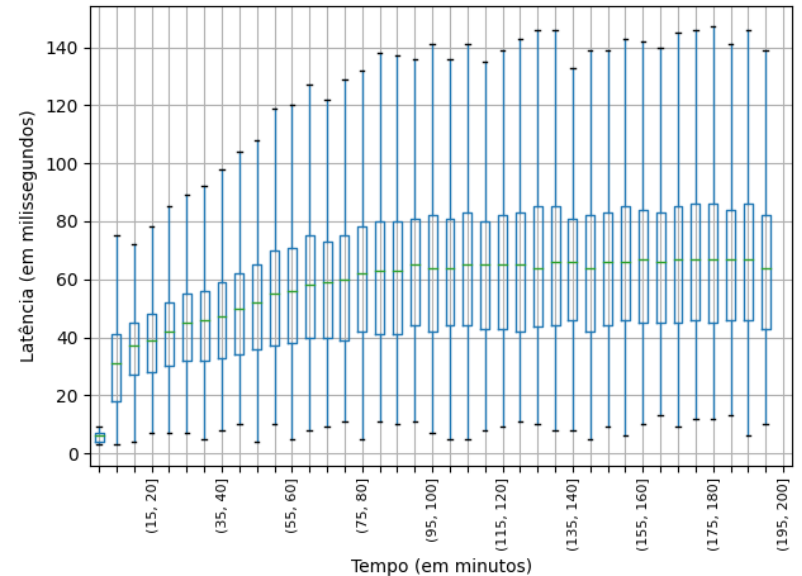

(b) Tipos de evento vi

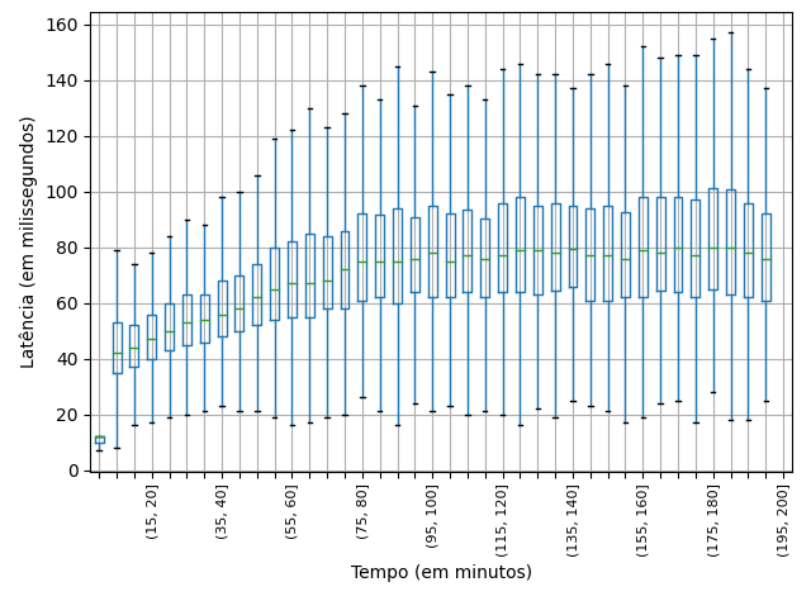

(d) Tipos de evento de corr

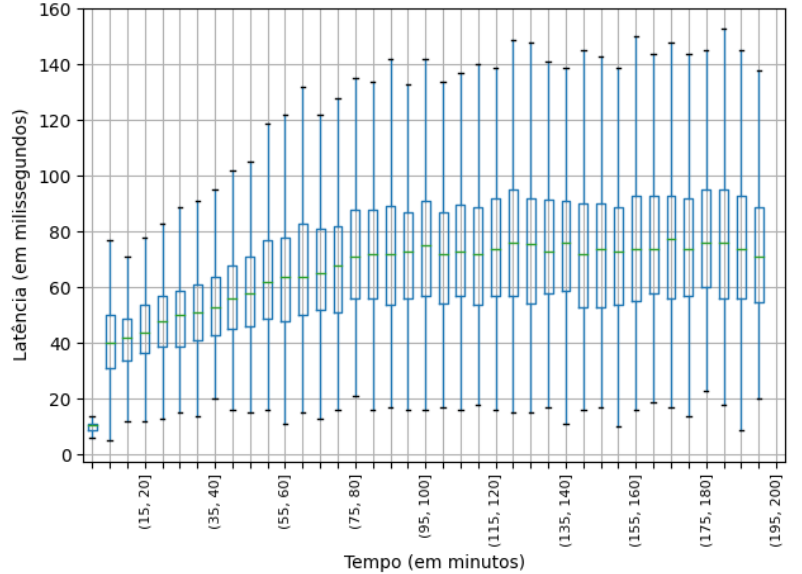

(c) Tipos de evento de vel

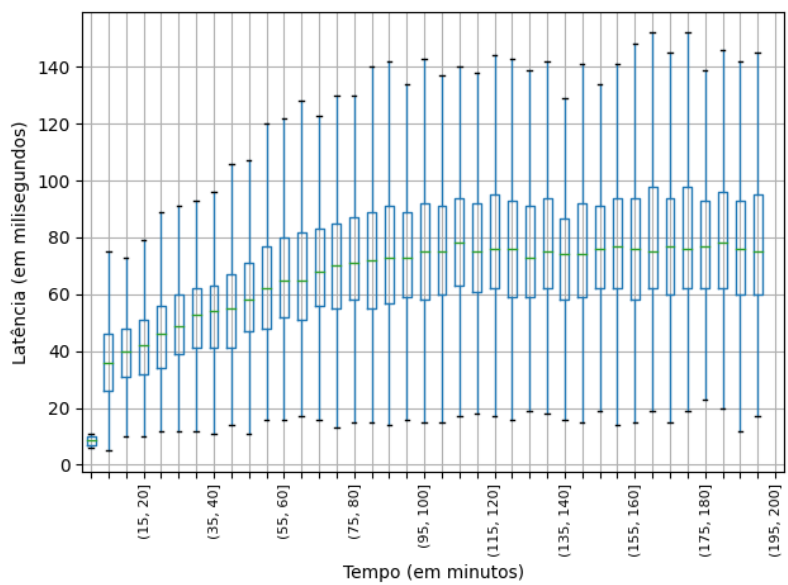

(e) Tipos de evento de BusB

Figura A.6: Diagramas de caixa das latências por intervalos de cinco minutos ao longo da execução 1 do experimento utilizando o algoritmo de balanceamento de carga por Similaridade de Entrada. 


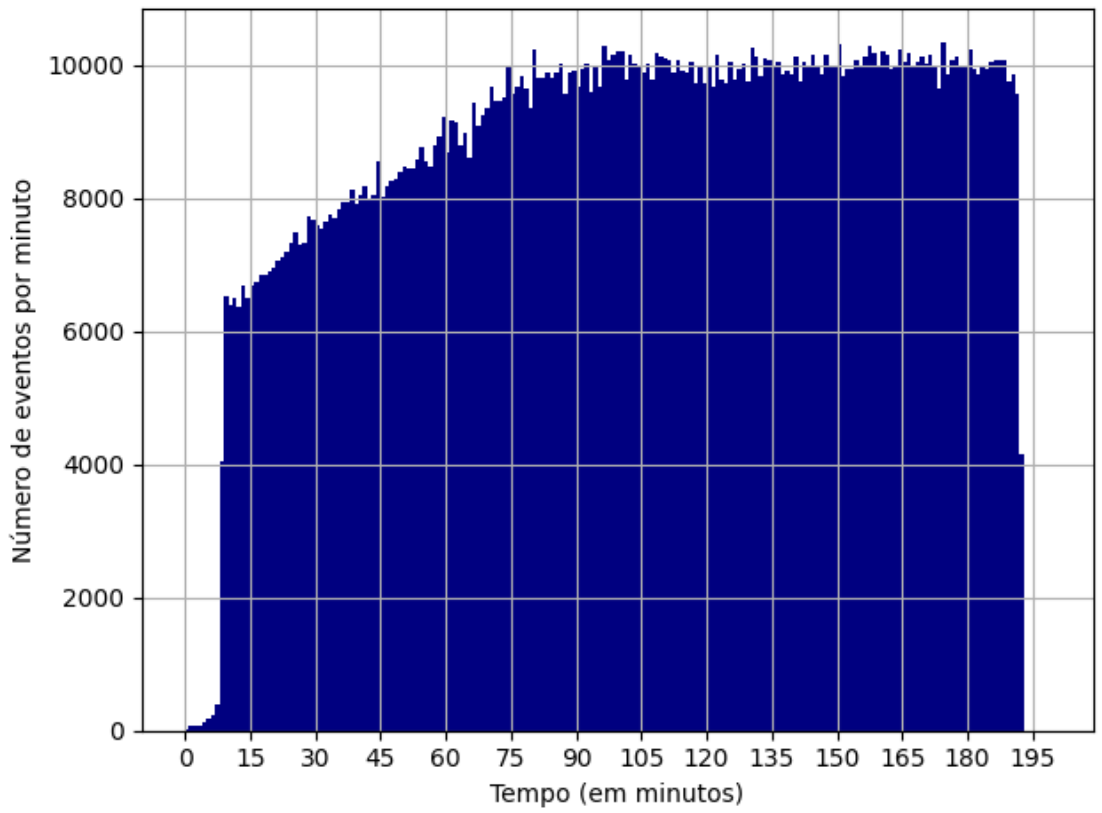

Figura A.7: Vazão de eventos detectados pelo sistema na execução 2 do experimento utilizando o algoritmo de balanceamento por Uso de Estado. 


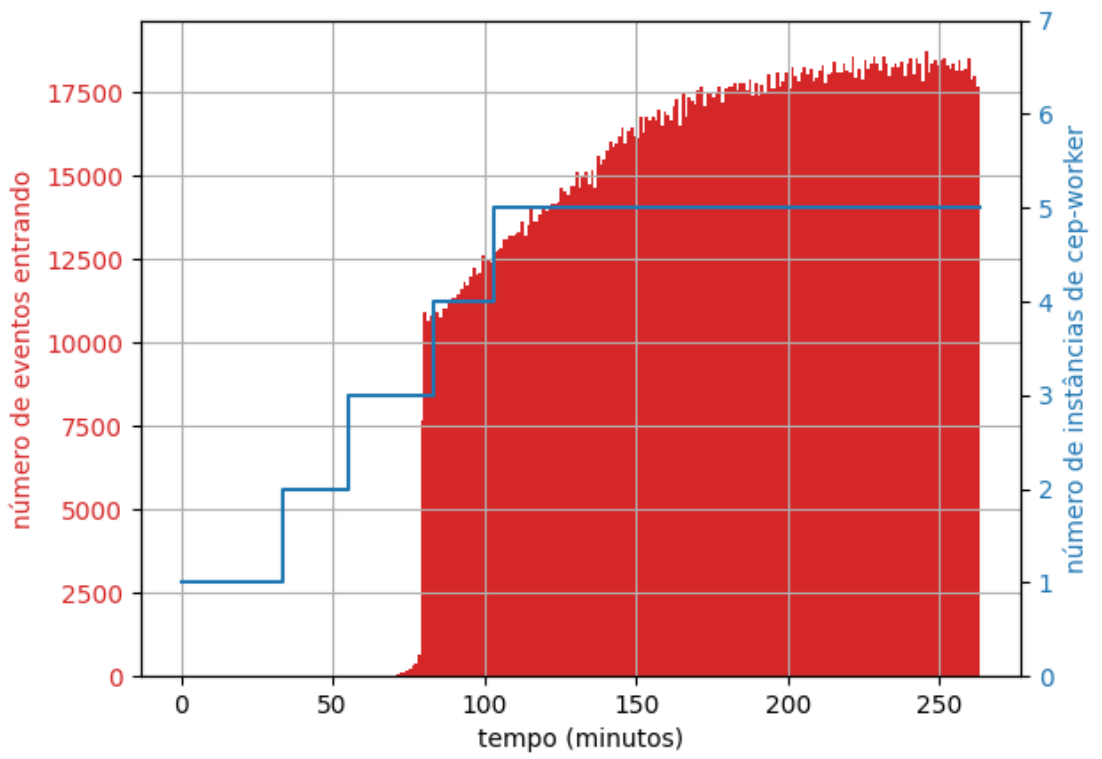

(a) Em função do tempo

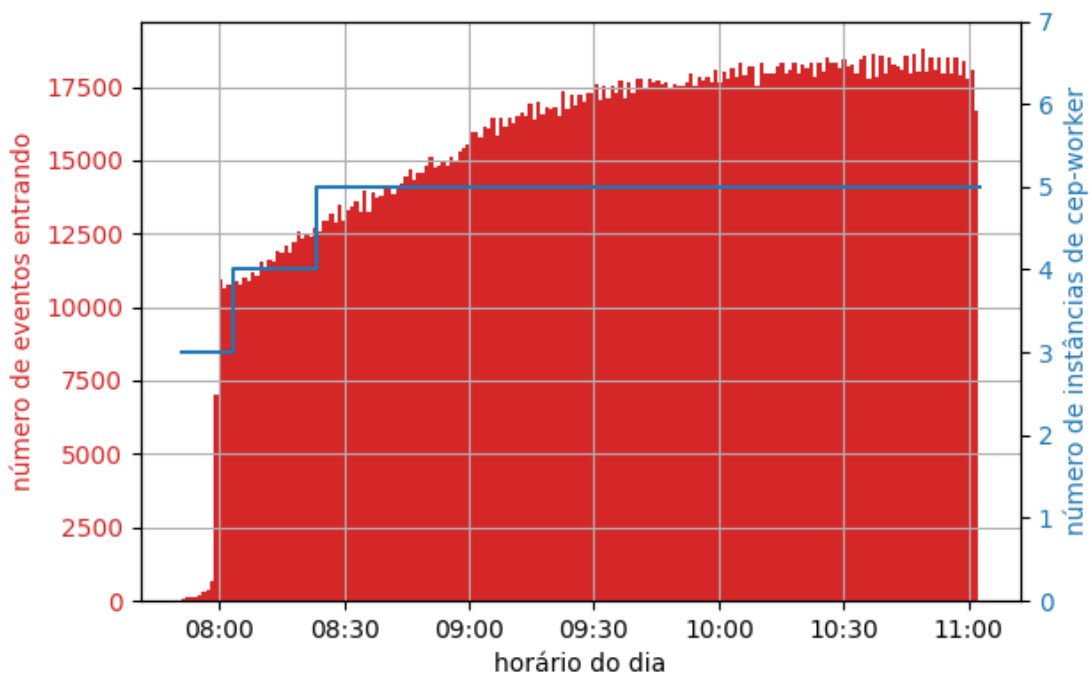

(b) Em função do horário do dia

Figura A.8: Número de eventos entrando no sistema (em vermelho) e número de instâncias de CEP Worker (em azul) na execução 2 do experimento utilizando o algoritmo de balanceamento de carga por Uso de Estado. Algumas instâncias são iniciadas antes do início do envio de eventos pois nesse período o cadastro de tipos de eventos já ocupa toda a memória disponivel de algumas instâncias. 


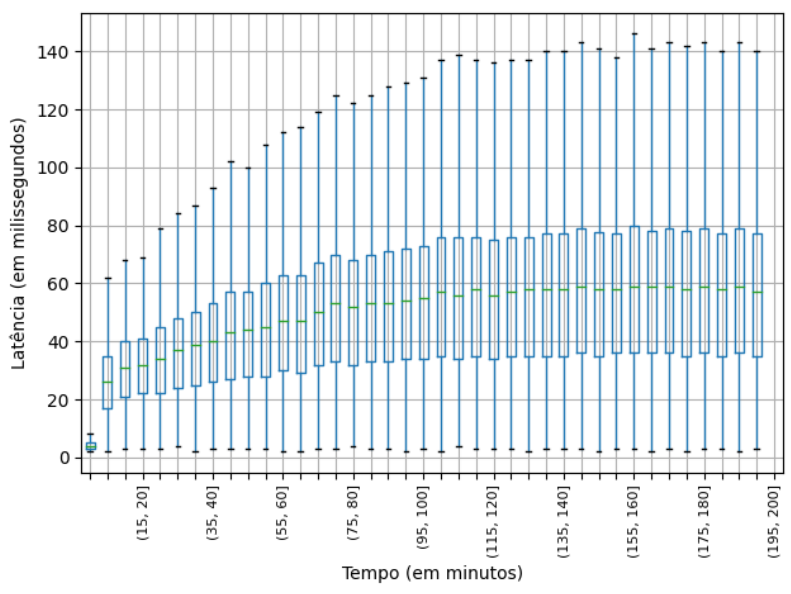

(a) Tipos de evento $v f$

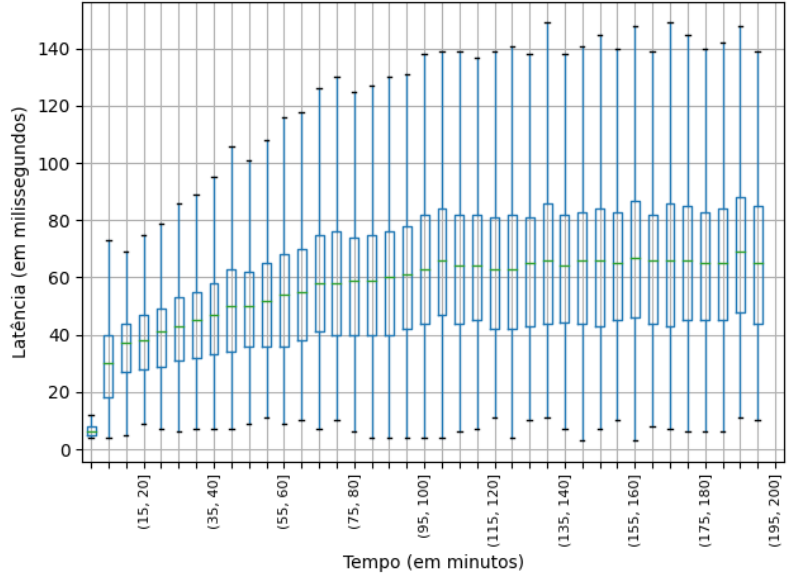

(b) Tipos de evento $\boldsymbol{v i}$

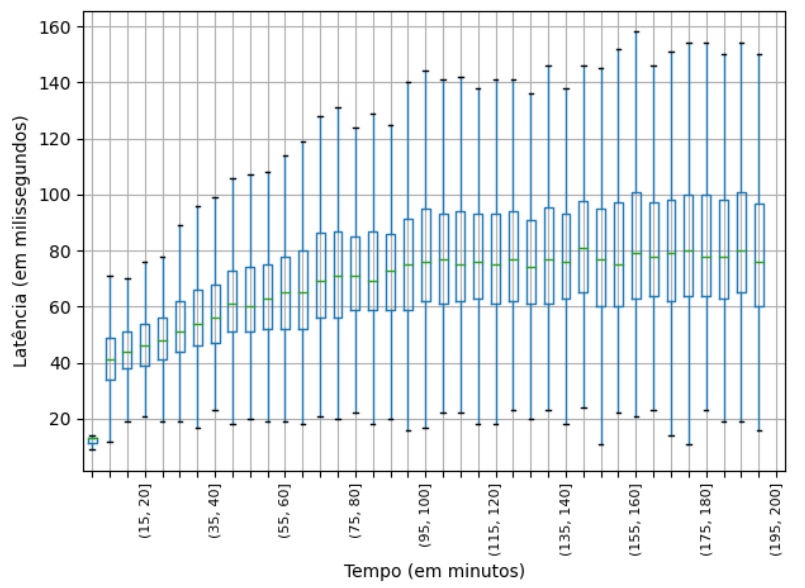

(d) Tipos de evento corr

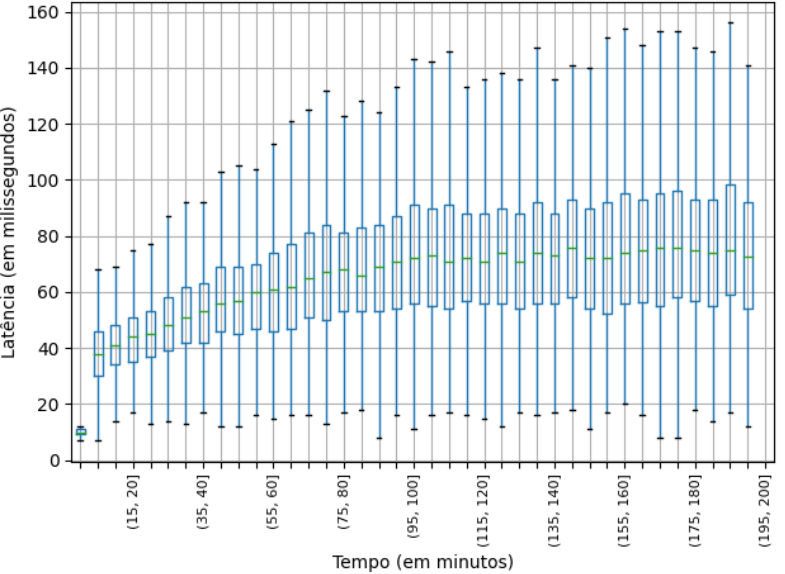

(c) Tipos de evento vel

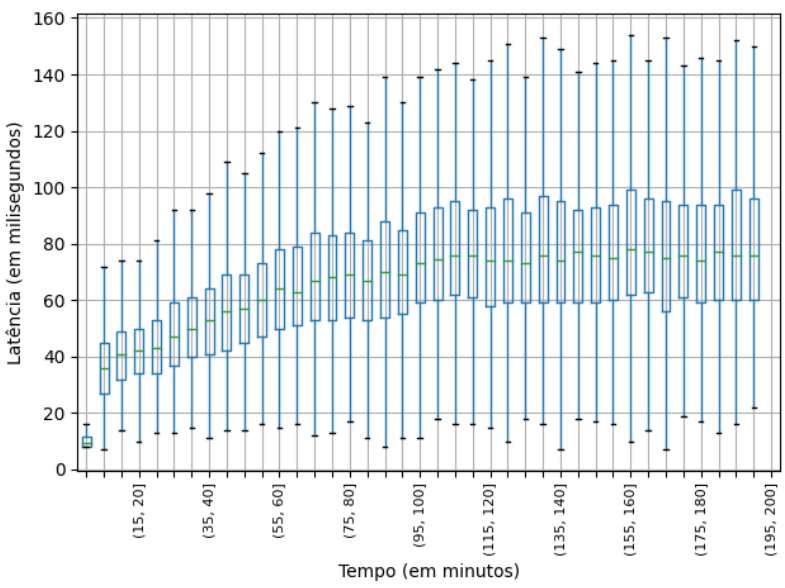

(e) Tipos de evento BusB

Figura A.9: Diagramas de caixa das latências por intervalos de cinco minutos ao longo da execução 2 do experimento utilizando o algoritmo de balanceamento de carga por Uso de Estado. 


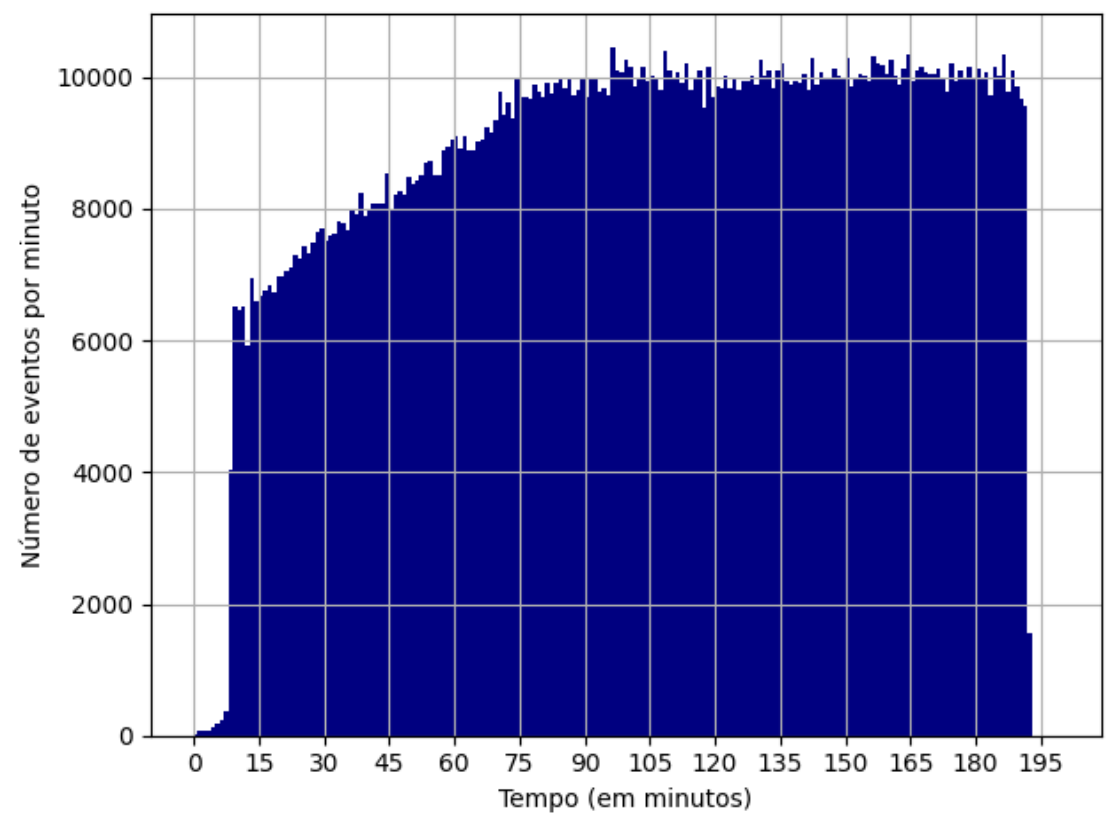

Figura A.10: Vazão de eventos detectados pelo sistema na execução 2 do experimento utilizando o algoritmo de balanceamento por Similaridade de Entrada. 


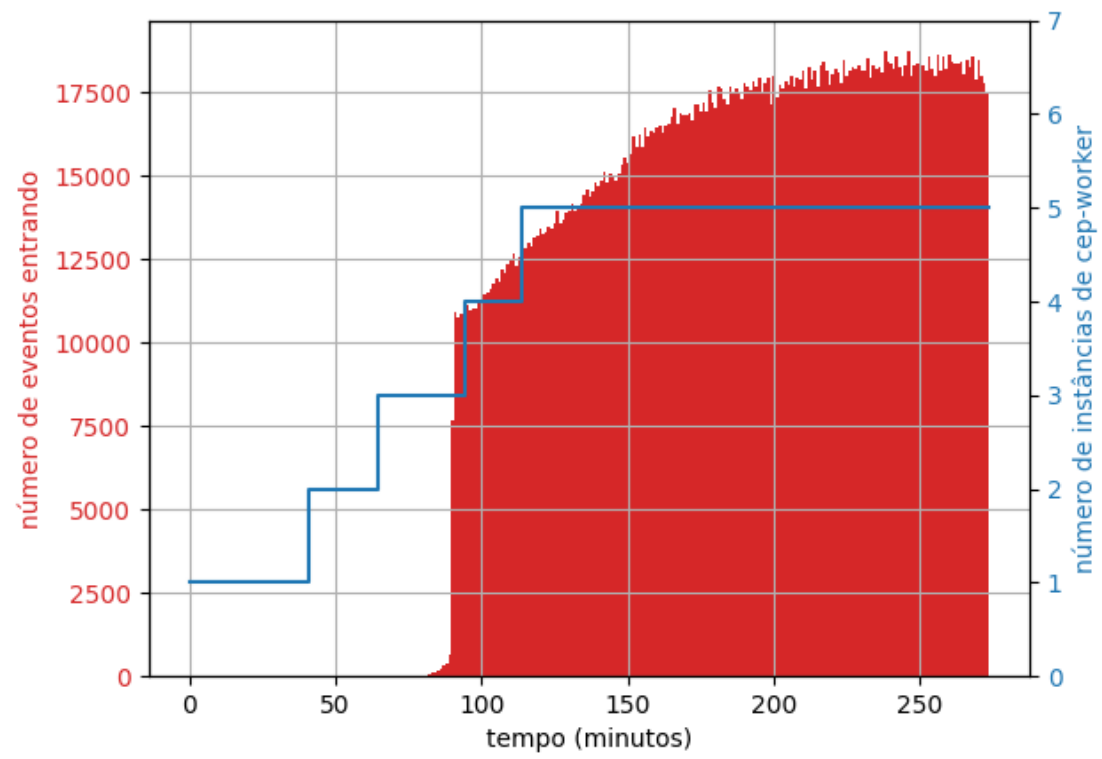

(a) Em função do tempo da execução

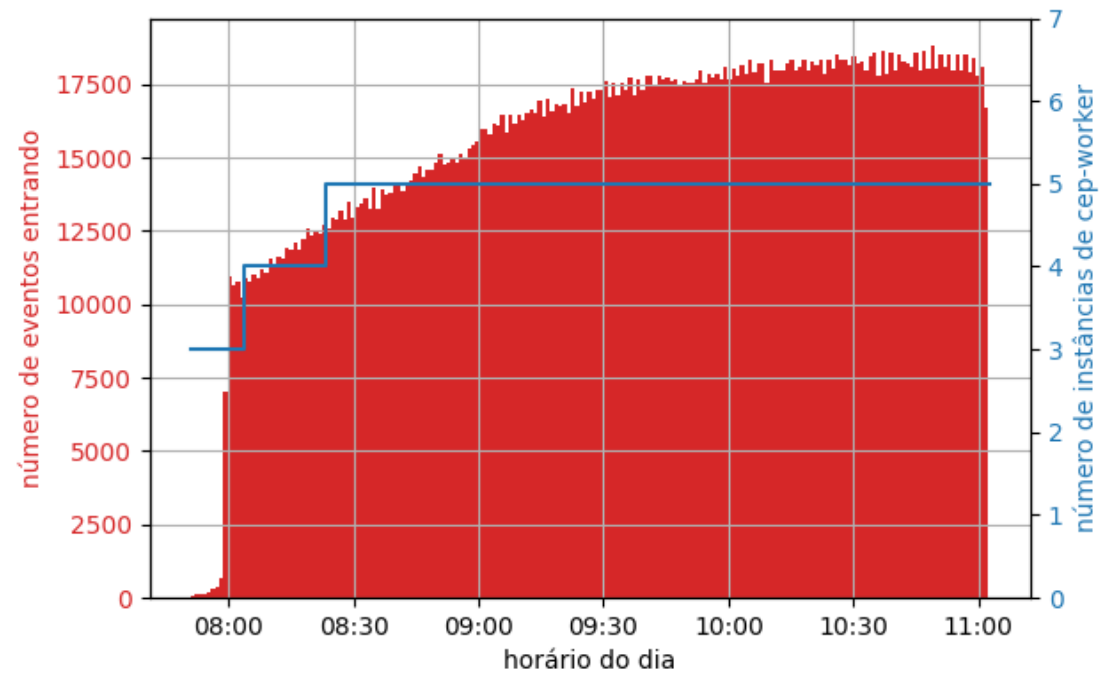

(b) Em função do horário do dia

Figura A.11: Número de eventos entrando no sistema (em vermelho) e número de instâncias de CEP Worker (em azul) na execução 2 do experimento utilizando o algoritmo de balanceamento de carga por Similaridade de Entrada. Algumas instâncias são iniciadas antes do início do envio de eventos pois nesse período o cadastro de tipos de eventos já ocupa toda a memória disponível de algumas instâncias. 


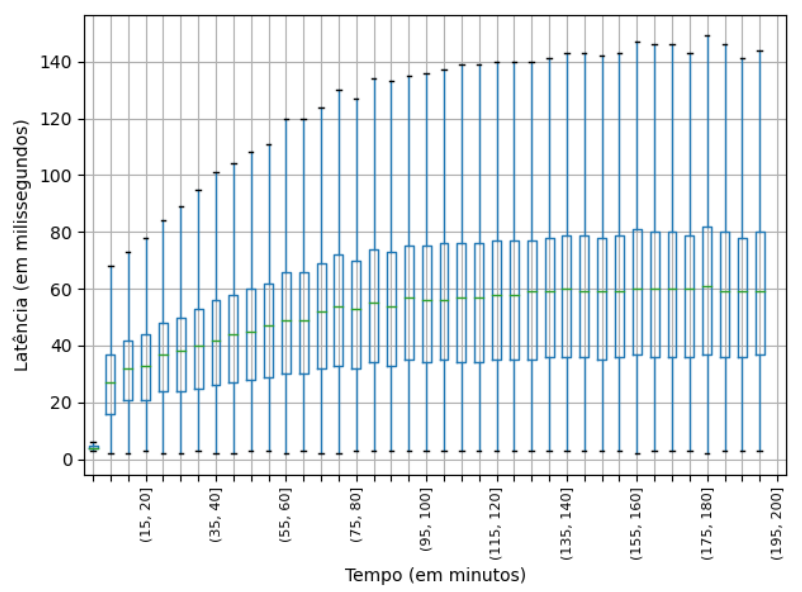

(a) Tipos de evento $\boldsymbol{v f}$

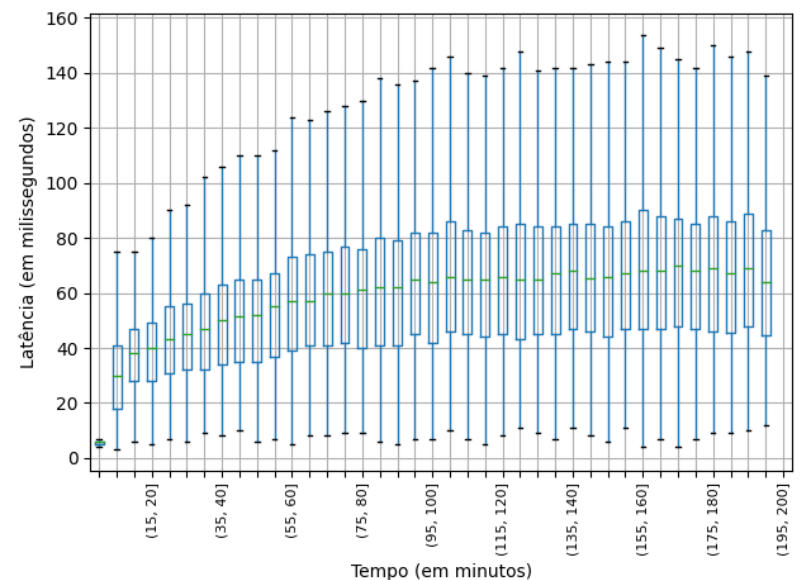

(b) Tipos de evento $\boldsymbol{v i}$

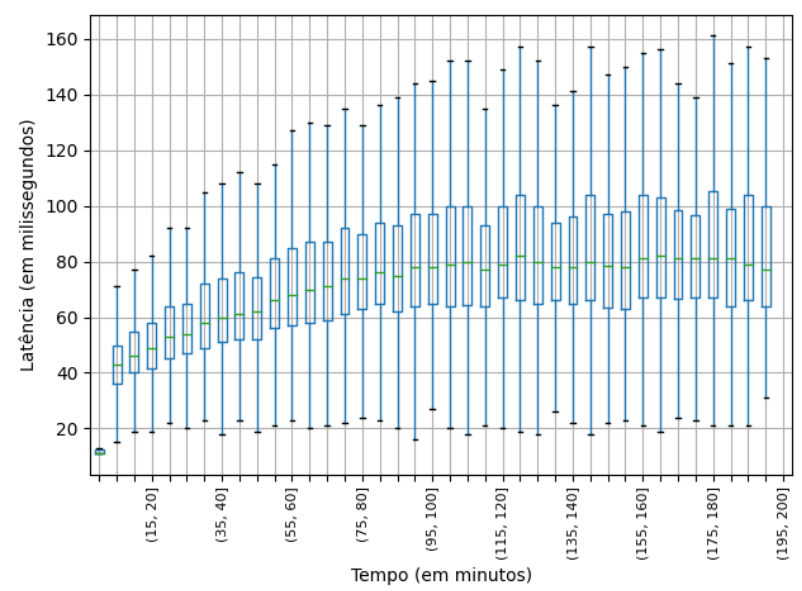

(d) Tipos de evento corr

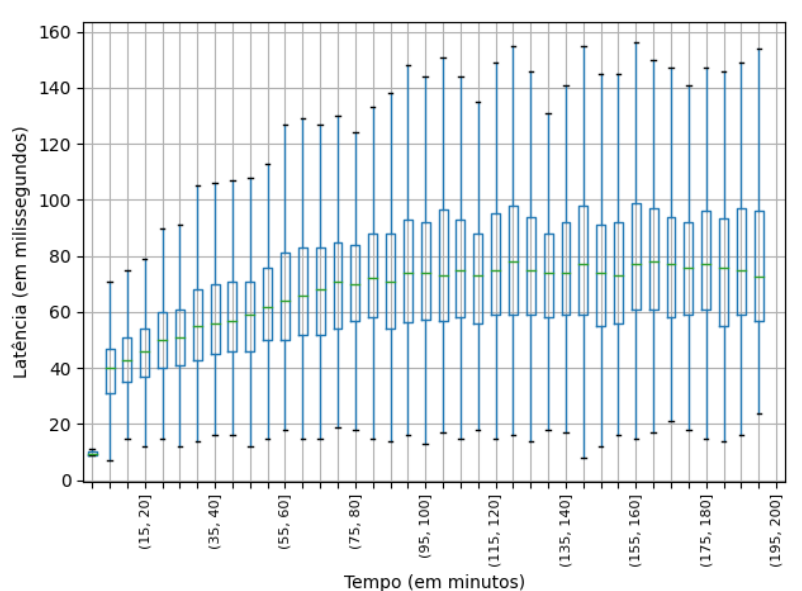

(c) Tipos de evento vel

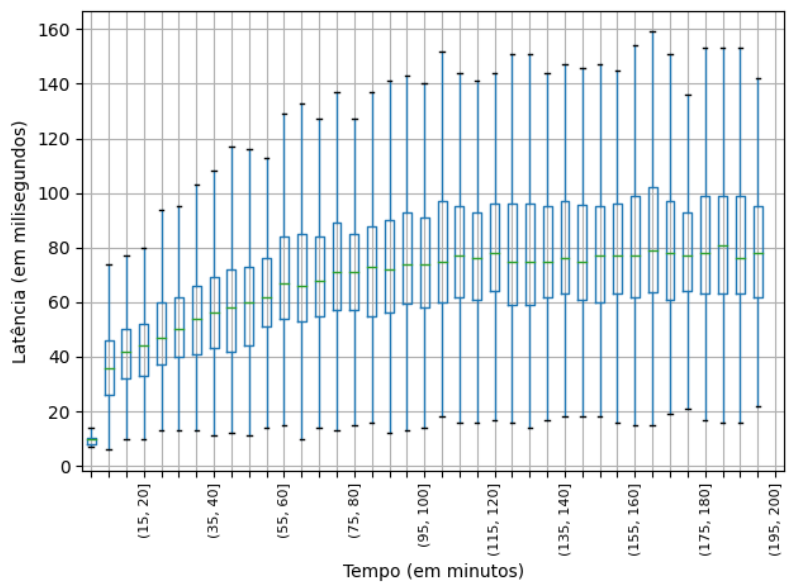

(e) Tipos de evento BusB

Figura A.12: Diagramas de caixa das latências por intervalos de cinco minutos ao longo da execução 2 do experimento utilizando o algoritmo de balanceamento de carga por Similaridade de Entrada. 


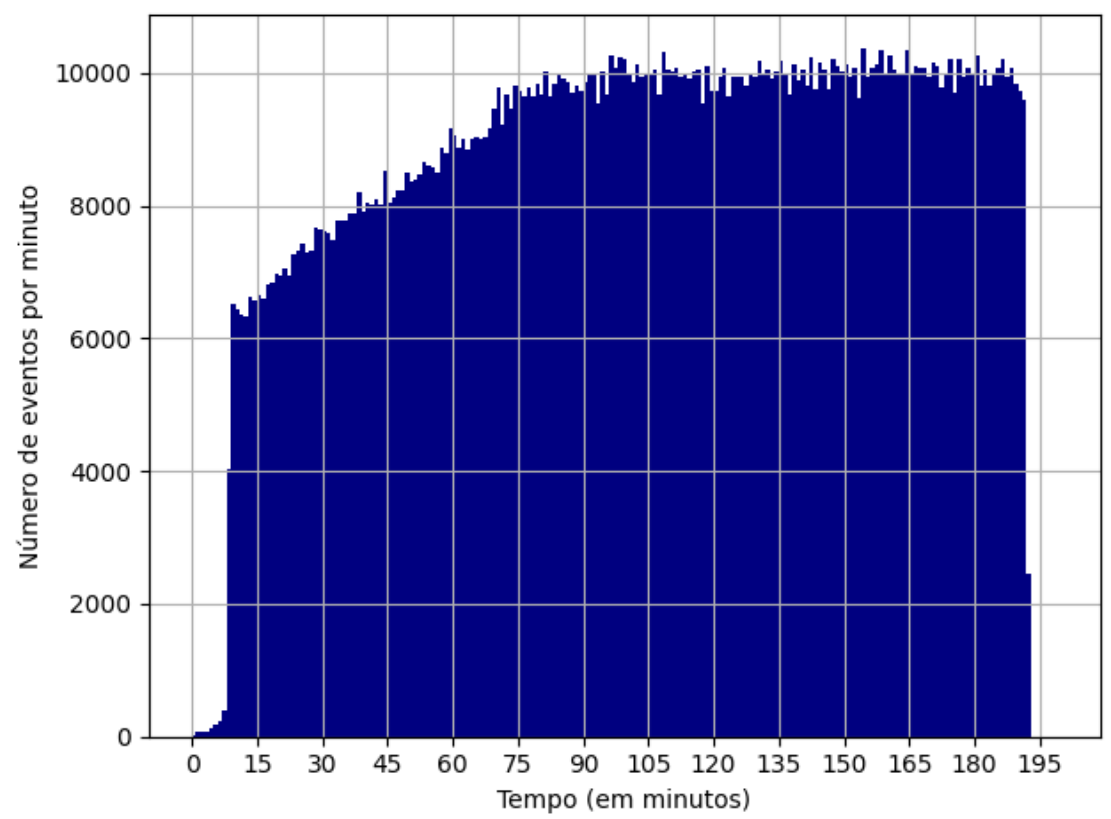

Figura A.13: Vazão de eventos detectados pelo sistema na execução 3 do experimento utilizando o algoritmo de balanceamento por Uso de Estado. 


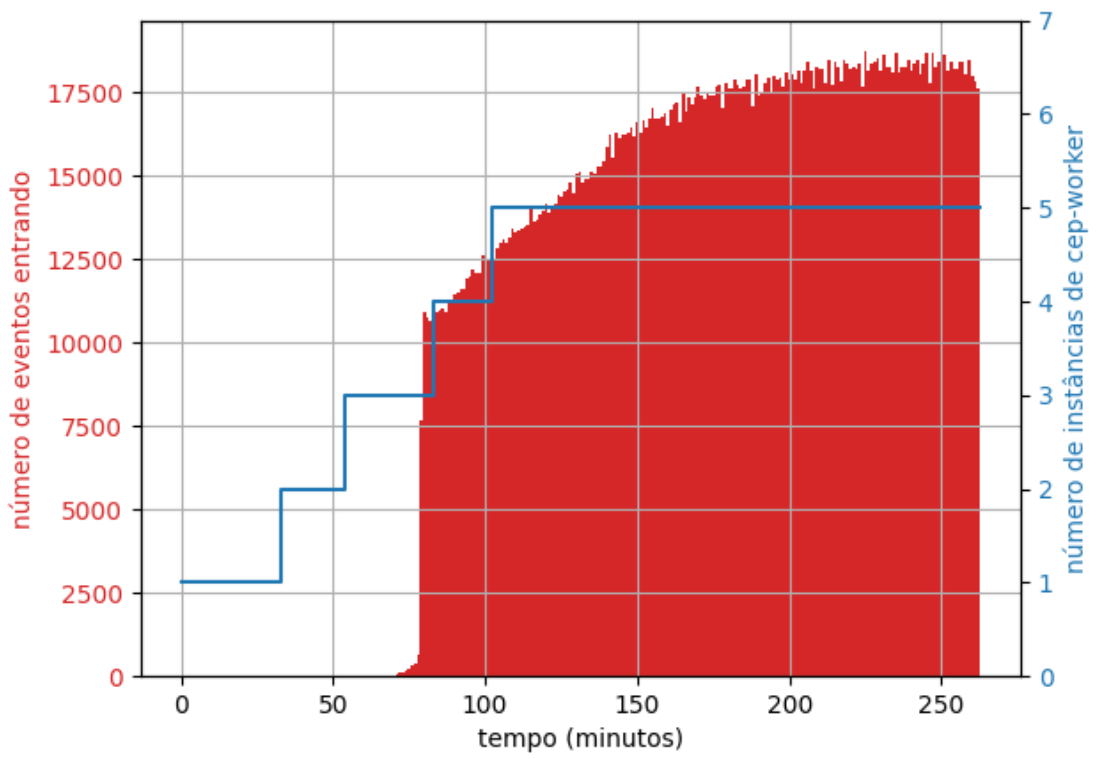

(a) Em função do tempo da execução

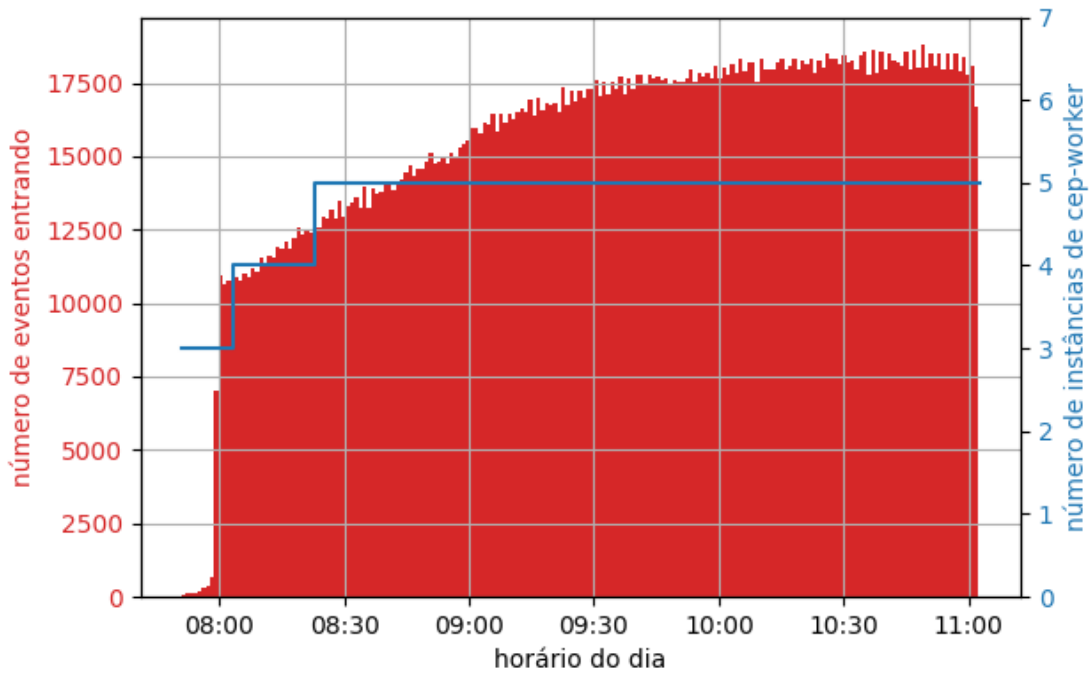

(b) Em função do horário do dia

Figura A.14: Número de eventos entrando no sistema (em vermelho) e número de instâncias de CEP Worker (em azul) na execução 3 do experimento utilizando o algoritmo de balanceamento de carga por Uso de Estado. Algumas instâncias são iniciadas antes do início do envio de eventos pois nesse período o cadastro de tipos de eventos já ocupa toda a memória disponível de algumas instâncias. 


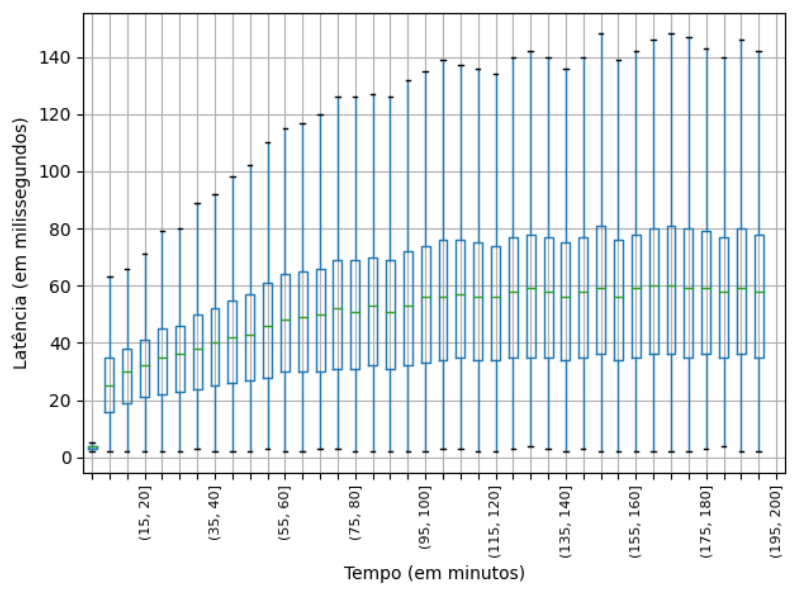

(a) Tipos de evento $v f$

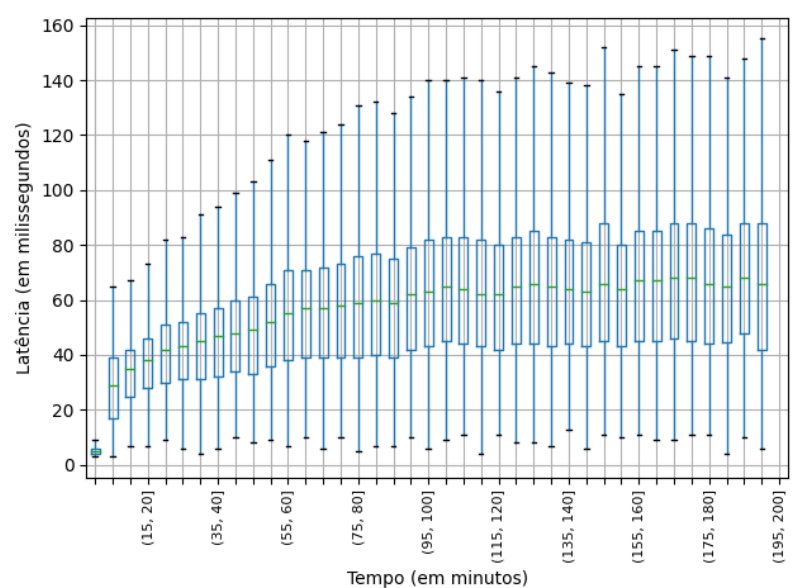

(b) Tipos de evento vi

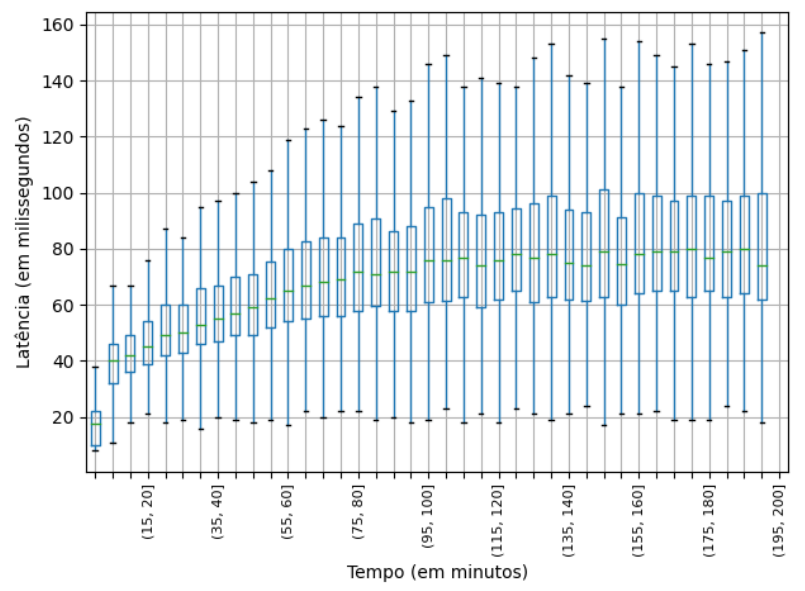

(d) Tipos de evento corr

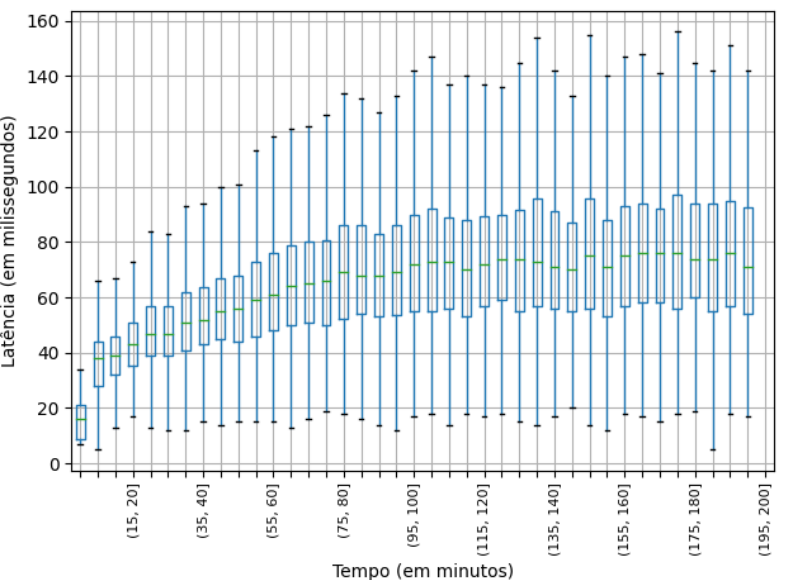

(c) Tipos de evento vel

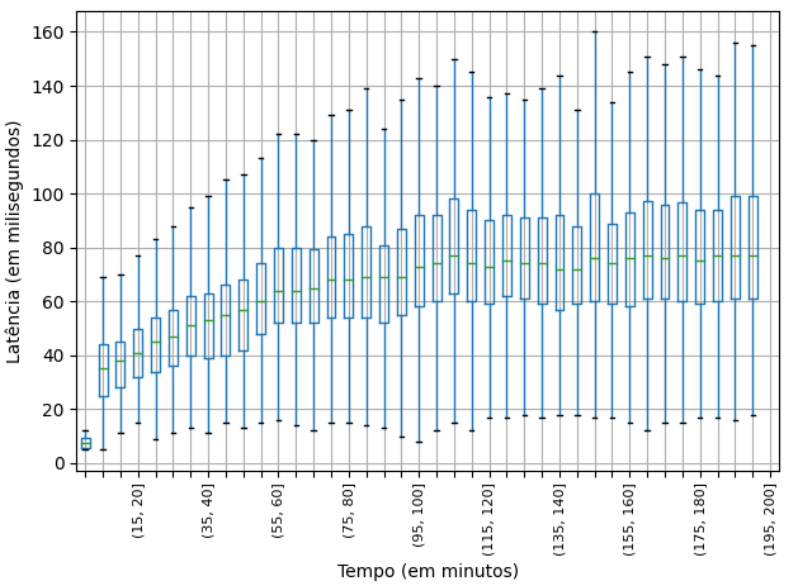

(e) Tipos de evento BusB

Figura A.15: Diagramas de caixa das latências por intervalos de cinco minutos ao longo da execução 3 do experimento utilizando o algoritmo de balanceamento de carga por Uso de Estado. 


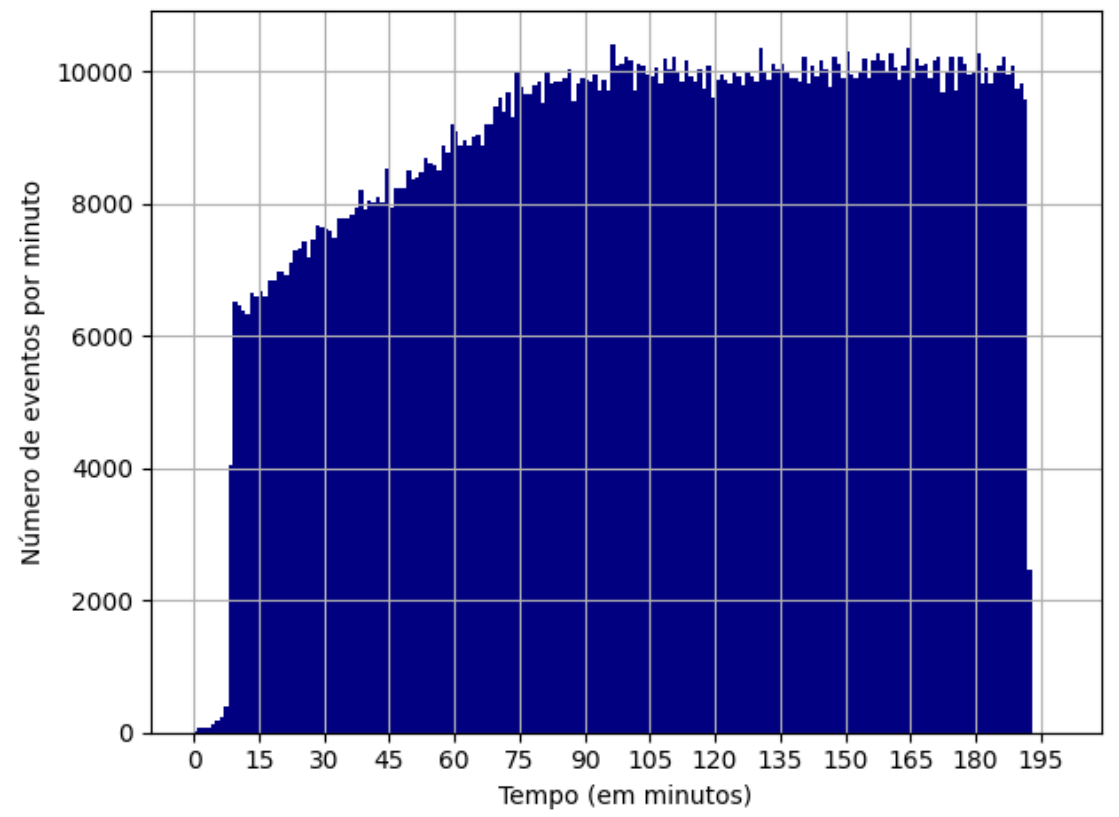

Figura A.16: Vazão de eventos detectados pelo sistema na execução 3 do experimento utilizando o algoritmo de balanceamento por Similaridade de Entrada. 


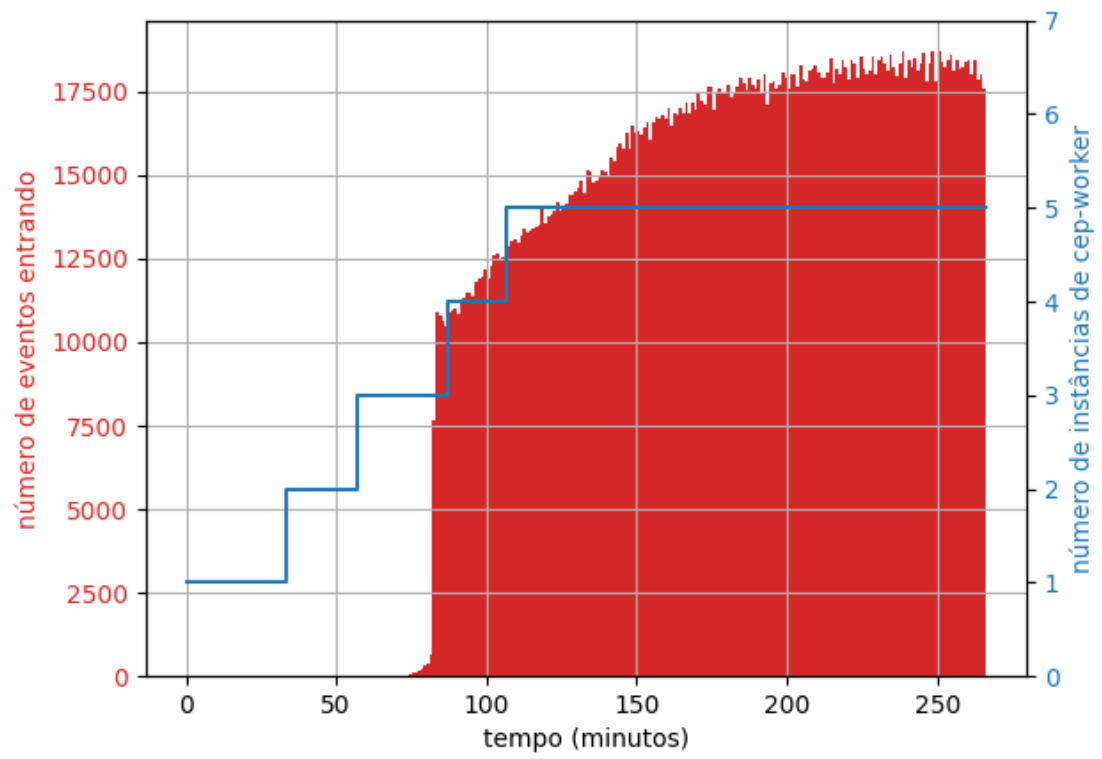

(a) Em função do tempo da execução

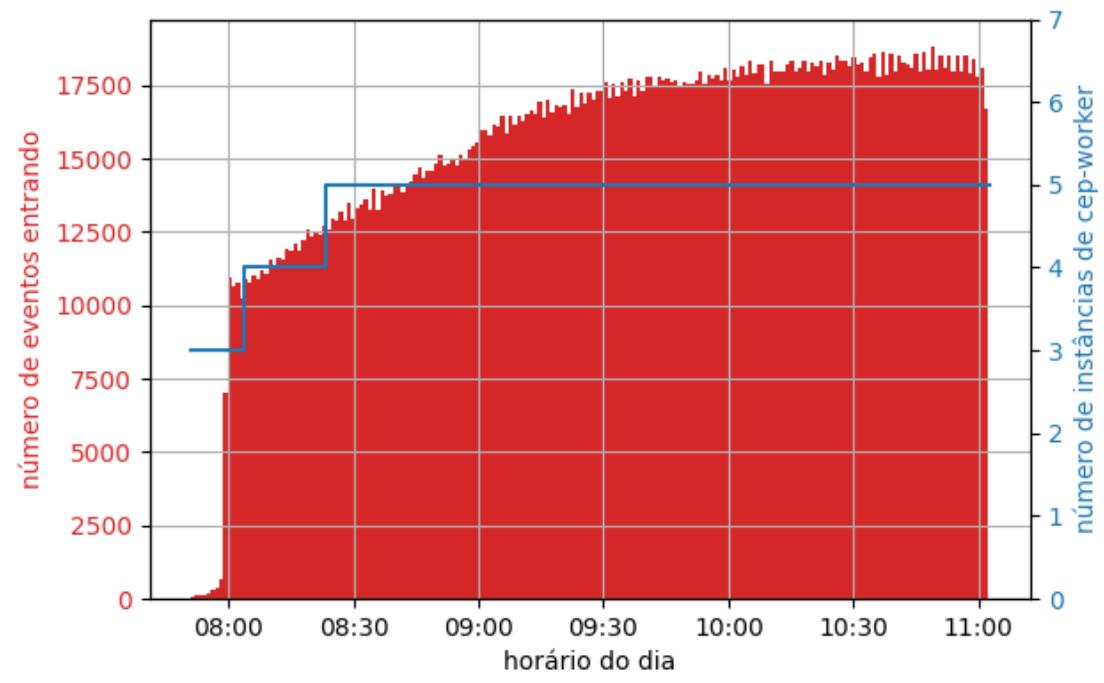

(b) Em função do horário do dia

Figura A.17: Número de eventos entrando no sistema (em vermelho) e número de instâncias de CEP Worker (em azul) na execução 3 do experimento utilizando o algoritmo de balanceamento de carga por Similaridade de Entrada. Algumas instâncias são iniciadas antes do início do envio de eventos pois nesse período o cadastro de tipos de eventos já ocupa toda a memória disponível de algumas instâncias. 


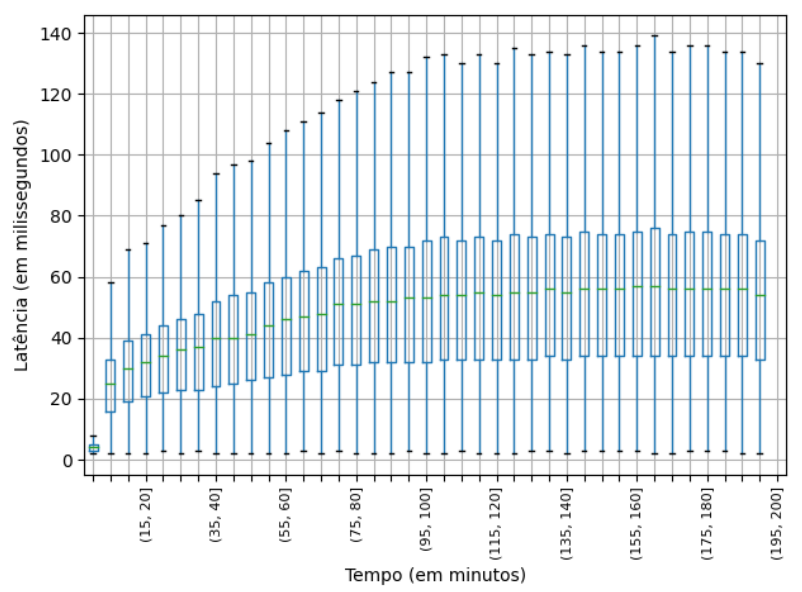

(a) Tipos de evento $\boldsymbol{v f}$

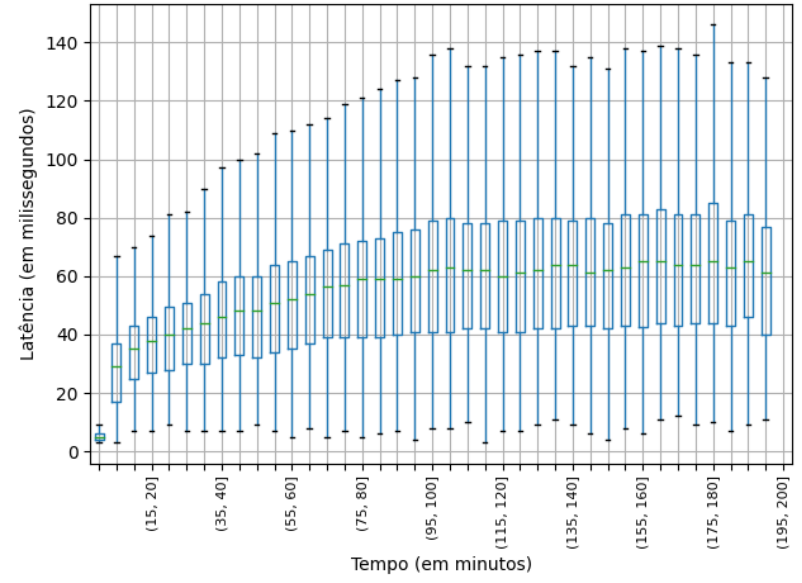

(b) Tipos de evento $\boldsymbol{v i}$

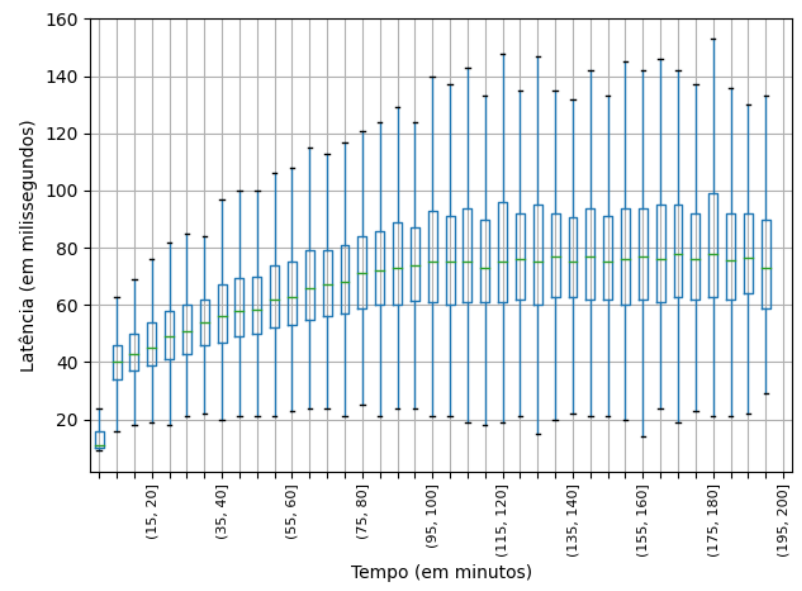

(d) Tipos de evento corr

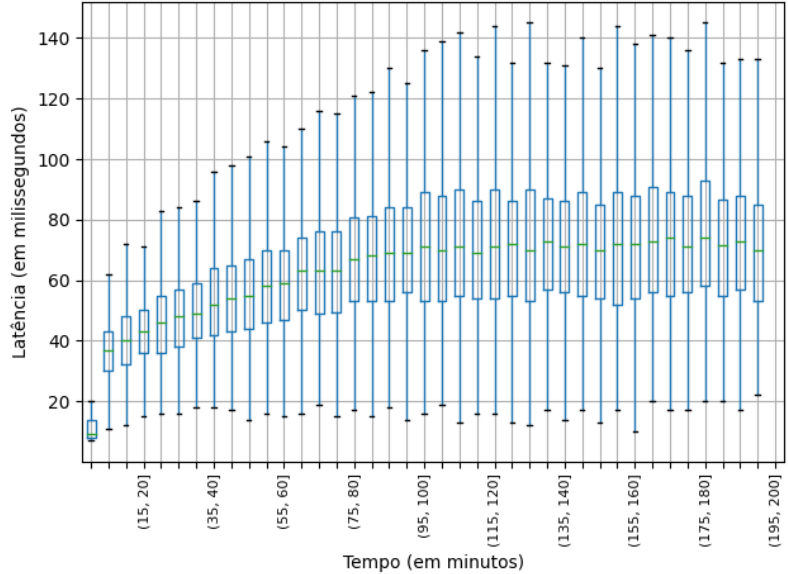

(c) Tipos de evento vel

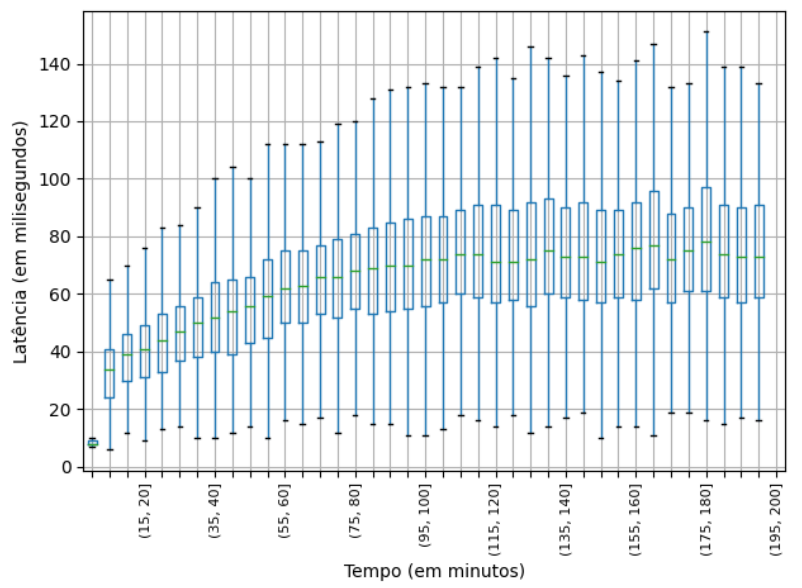

(e) Tipos de evento BusB

Figura A.18: Diagramas de caixa das latências por intervalos de cinco minutos ao longo da execução 3 do experimento utilizando o algoritmo de balanceamento de carga por Similaridade de Entrada. 


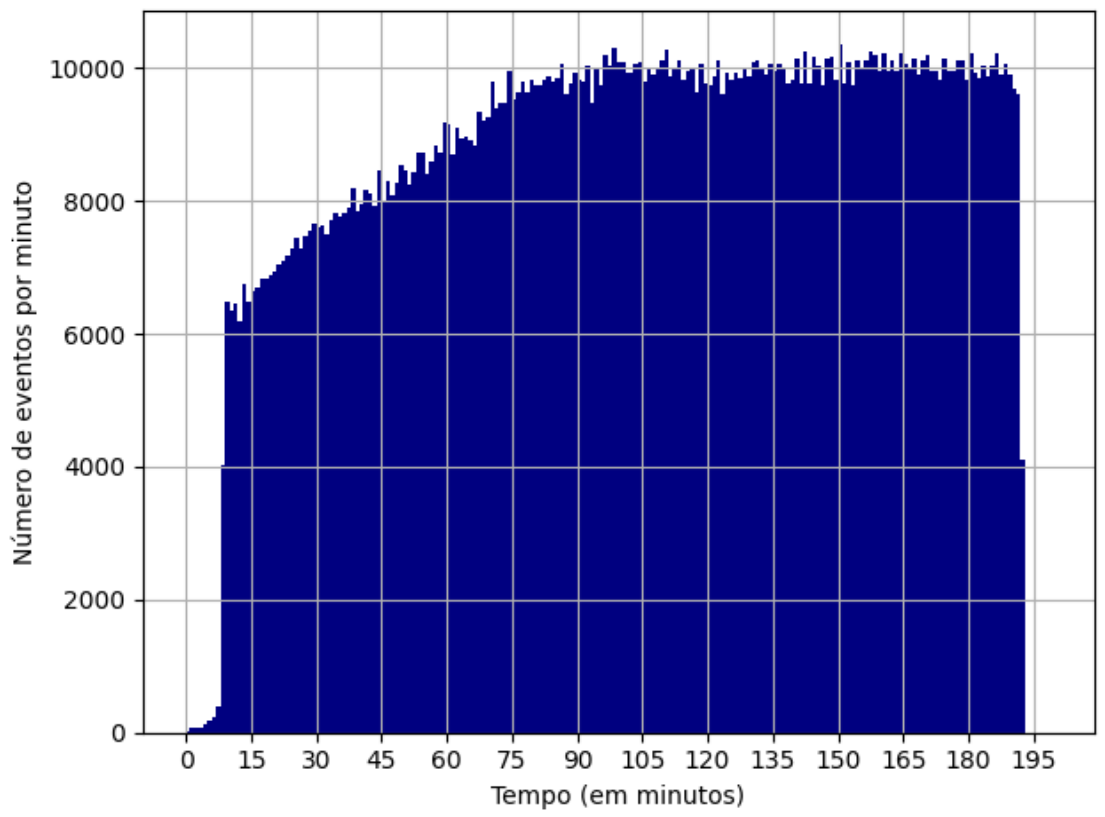

Figura A.19: Vazão de eventos detectados pelo sistema na execução 4 do experimento utilizando o algoritmo de balanceamento por Uso de Estado. 


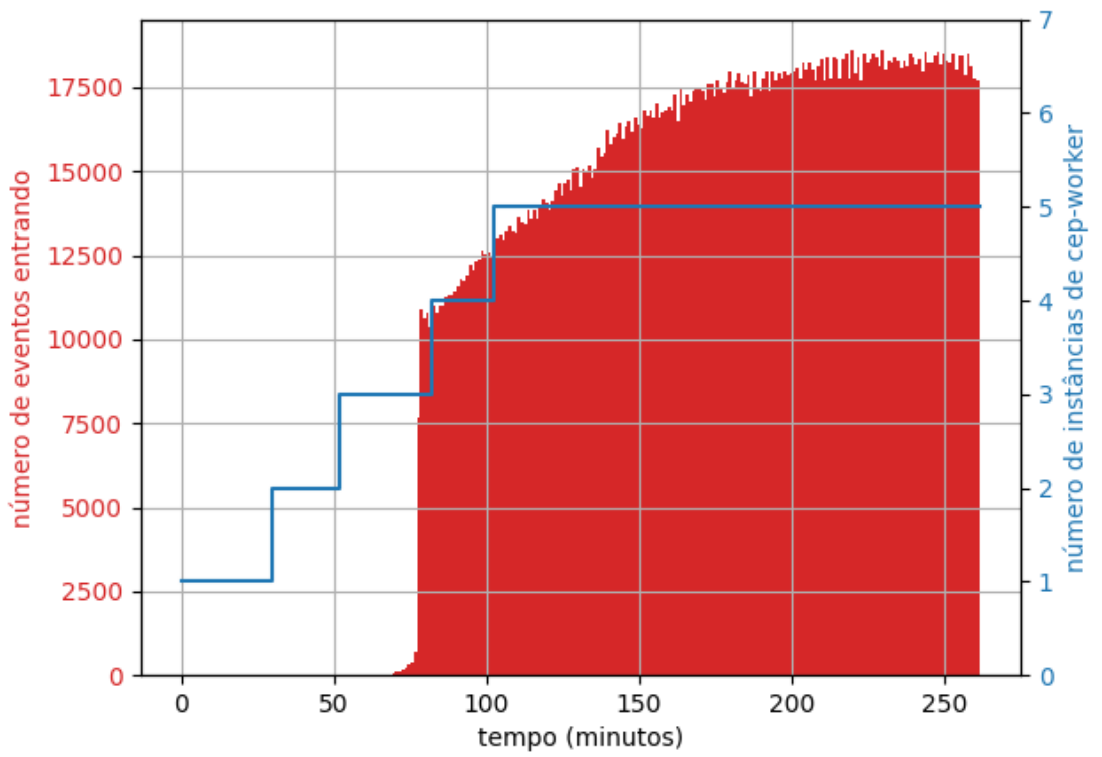

(a) Em função do tempo da execução

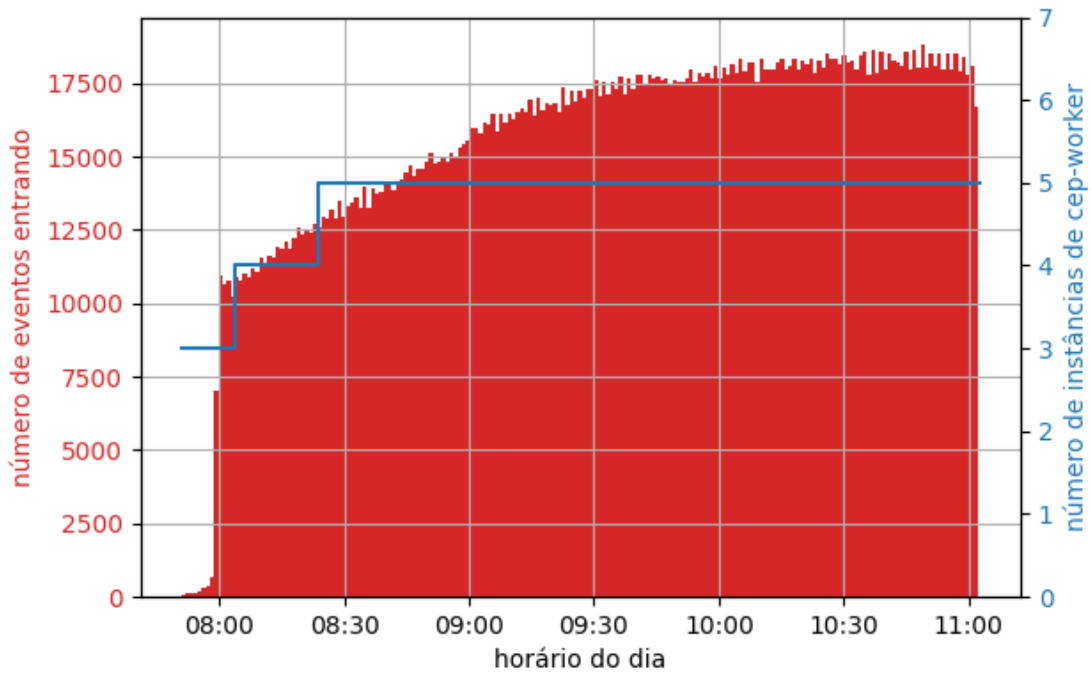

(b) Em função do horário do dia

Figura A.20: Número de eventos entrando no sistema (em vermelho) e número de instâncias de CEP Worker (em azul) na execução 4 do experimento utilizando o algoritmo de balanceamento de carga por Uso de Estado. Algumas instâncias são iniciadas antes do início do envio de eventos pois nesse período o cadastro de tipos de eventos já ocupa toda a memória disponível de algumas instâncias. 


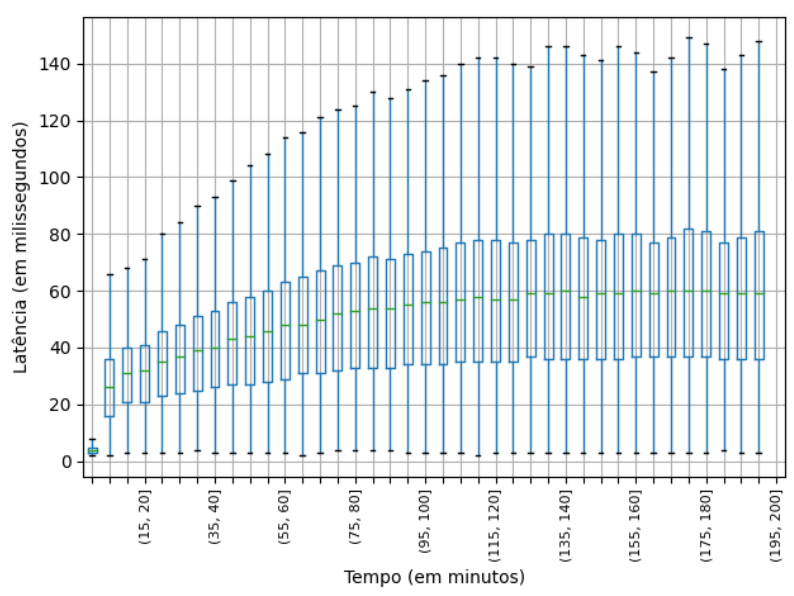

(a) Tipos de evento $\boldsymbol{v f}$

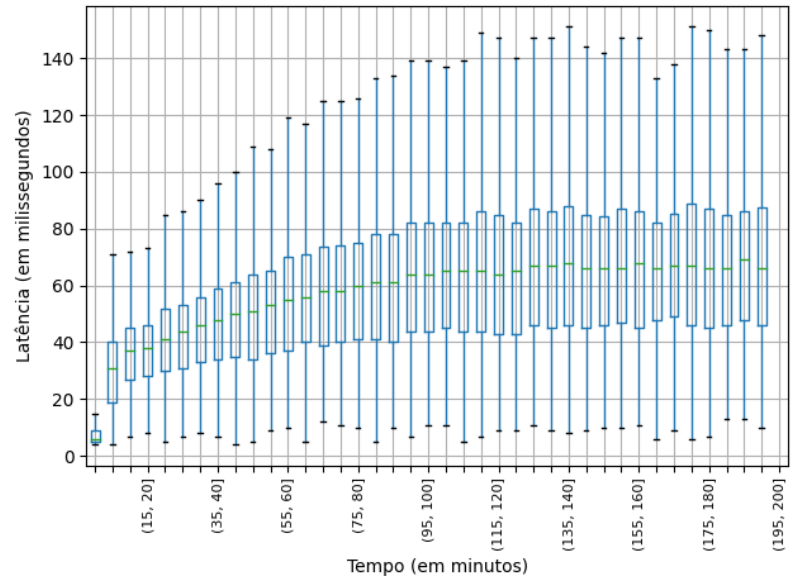

(b) Tipos de evento $\boldsymbol{v i}$

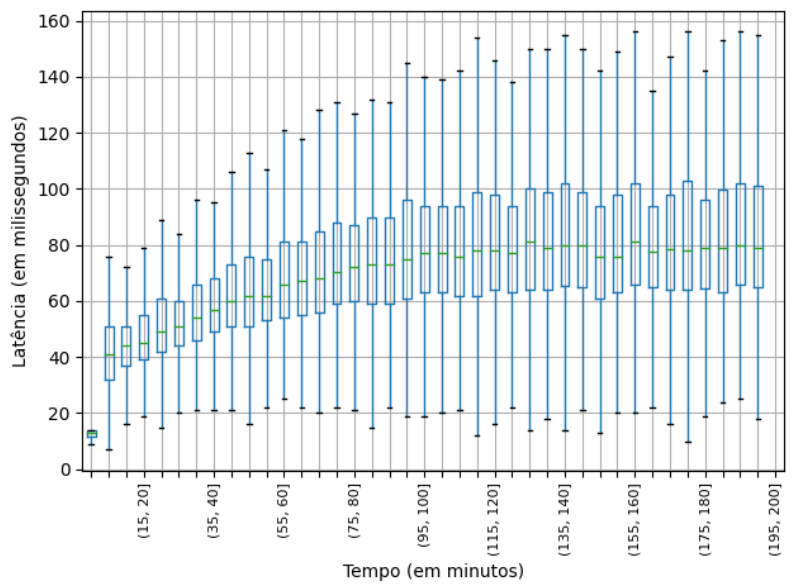

(d) Tipos de evento corr

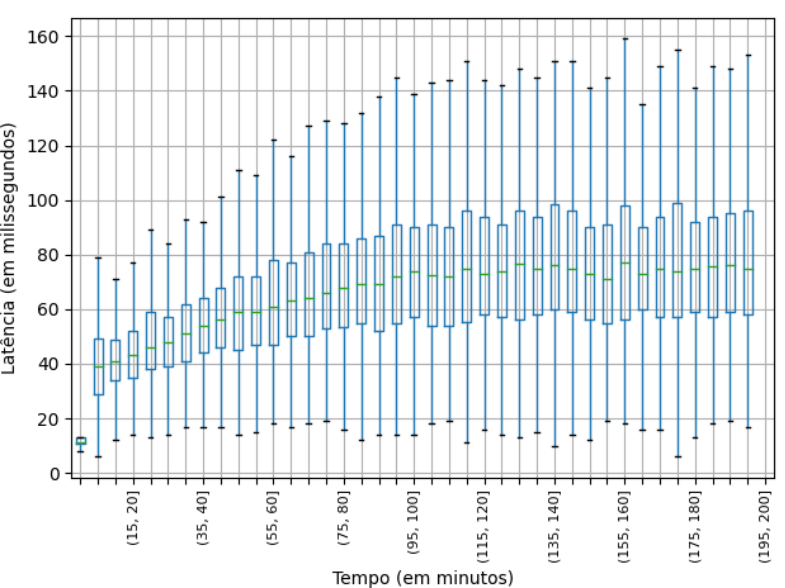

(c) Tipos de evento vel

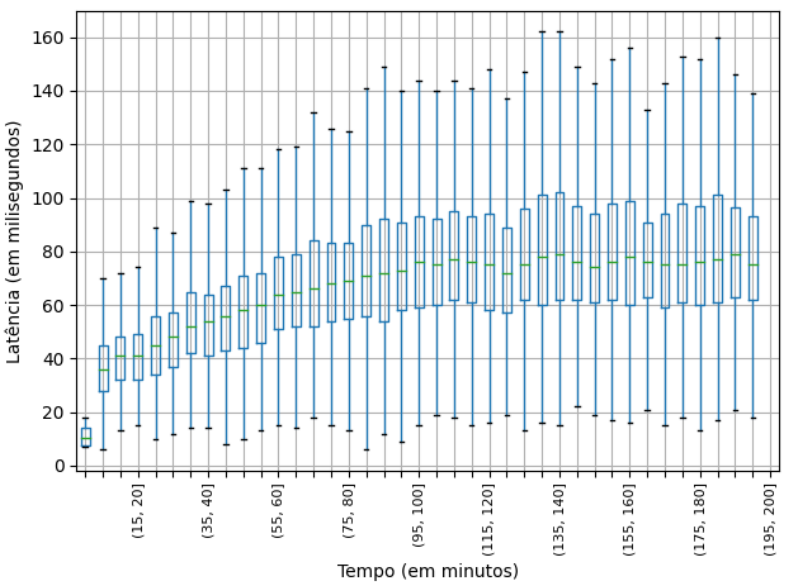

(e) Tipos de evento $\boldsymbol{B u s B}$

Figura A.21: Diagramas de caixa das latências por intervalos de cinco minutos ao longo da execução 4 do experimento utilizando o algoritmo de balanceamento de carga por Uso de Estado. 


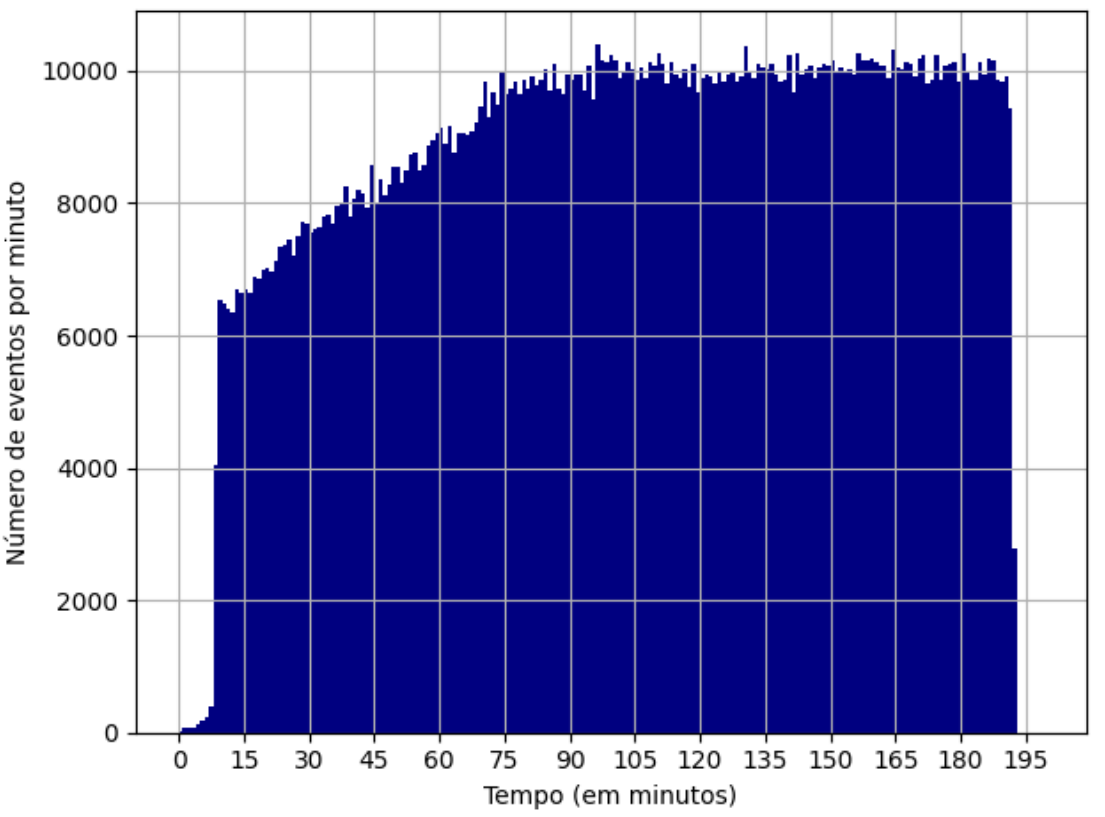

Figura A.22: Vazão de eventos detectados pelo sistema na execução 4 do experimento utilizando o algoritmo de balanceamento por Similaridade de Entrada. 


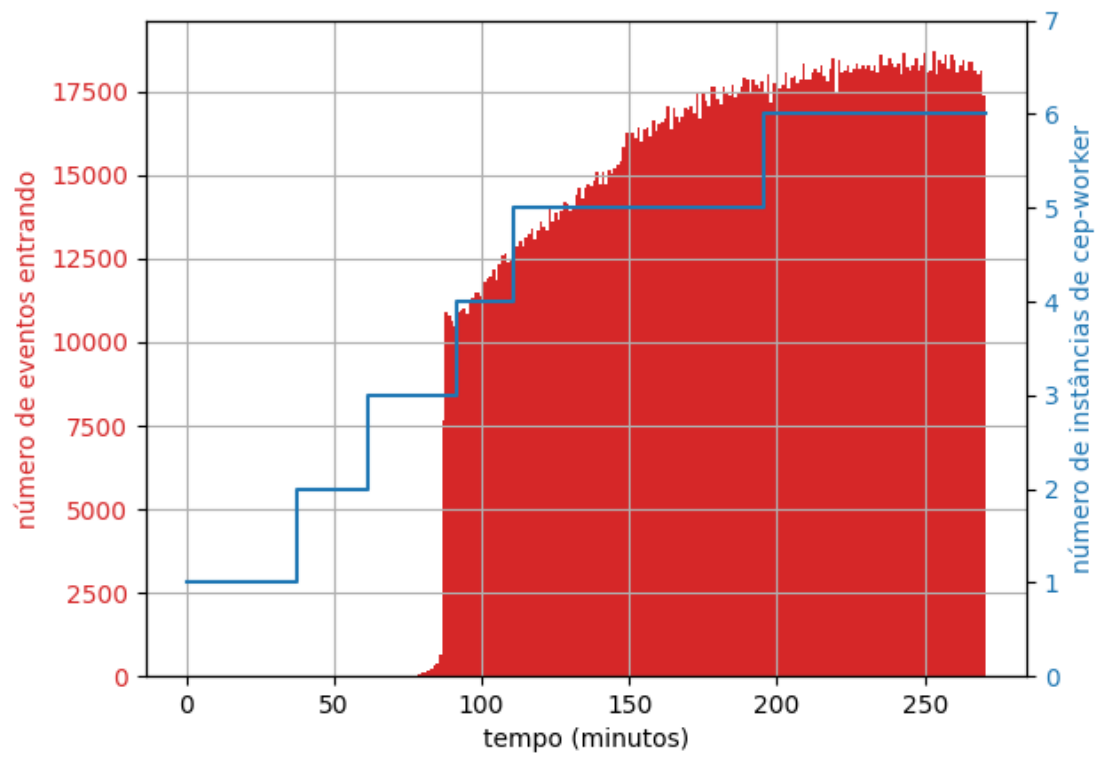

(a) Em função do tempo da execução

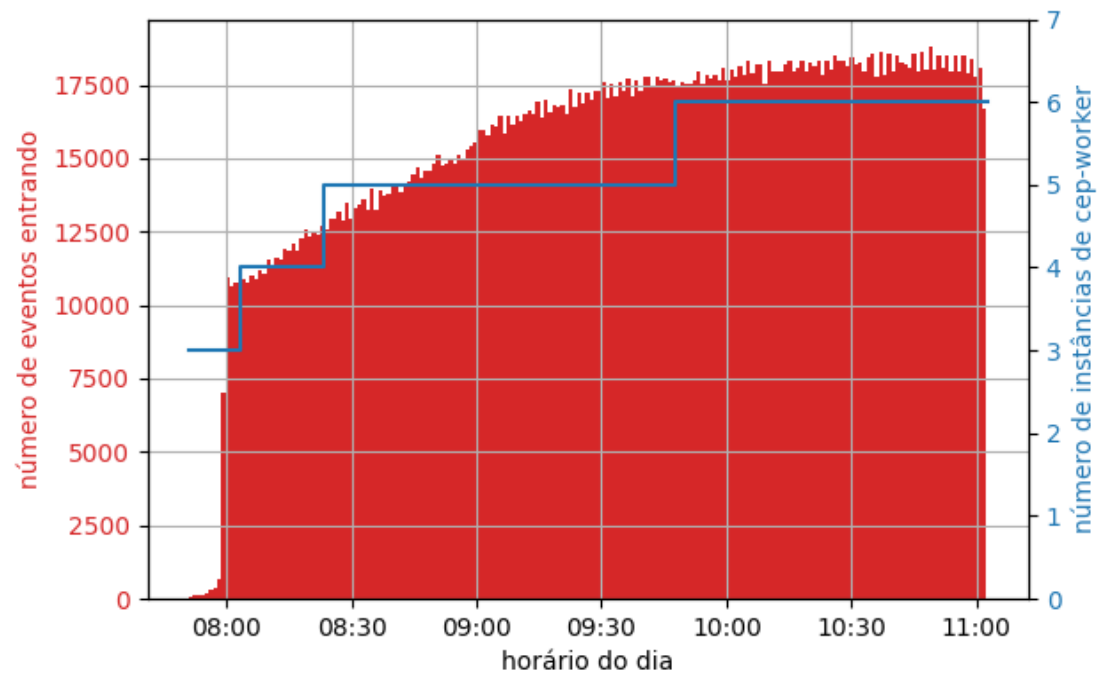

(b) Em função do horário do dia

Figura A.23: Número de eventos entrando no sistema (em vermelho) e número de instâncias de CEP Worker (em azul) na execução 4 do experimento utilizando o algoritmo de balanceamento de carga por Similaridade de Entrada. Algumas instâncias são iniciadas antes do início do envio de eventos pois nesse período o cadastro de tipos de eventos já ocupa toda a memória disponível de algumas instâncias. 


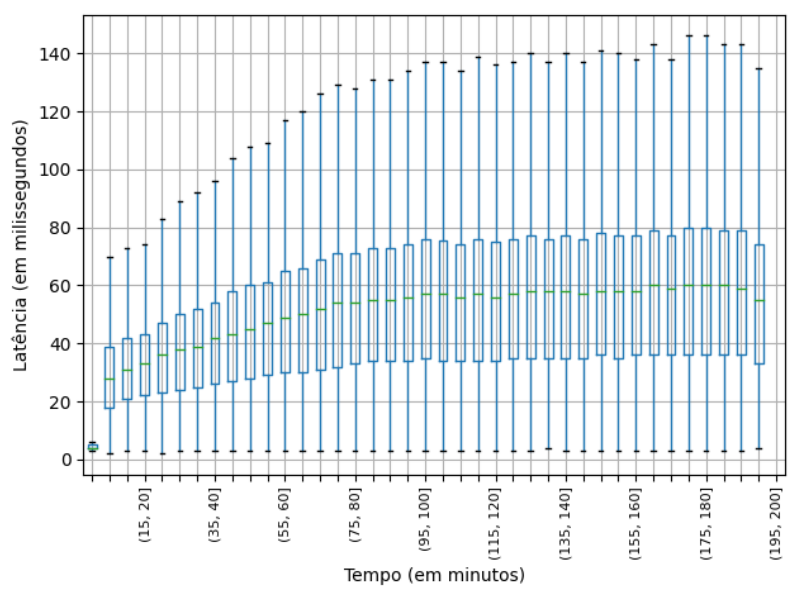

(a) Tipos de evento $\boldsymbol{v f}$

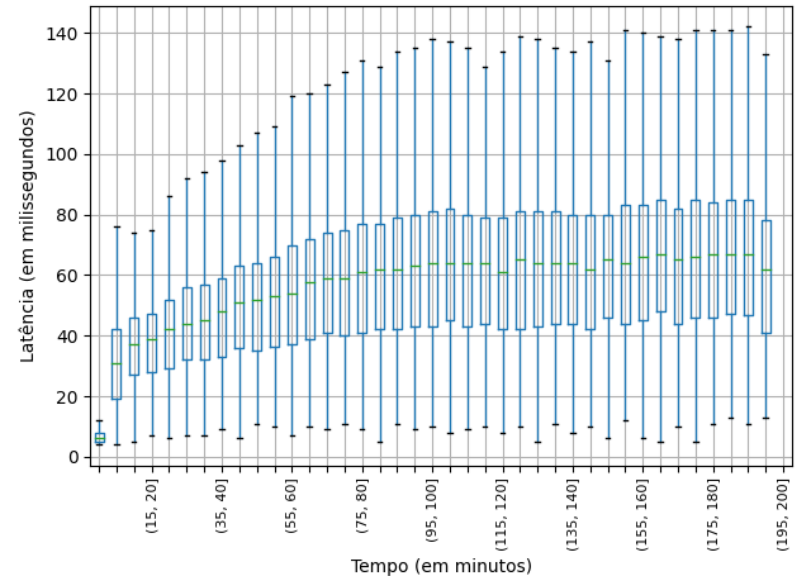

(b) Tipos de evento vi

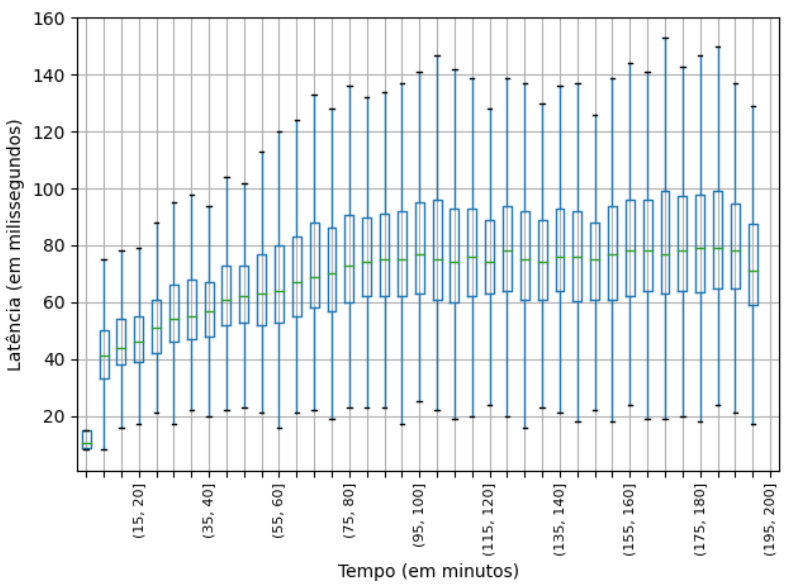

(d) Tipos de evento corr

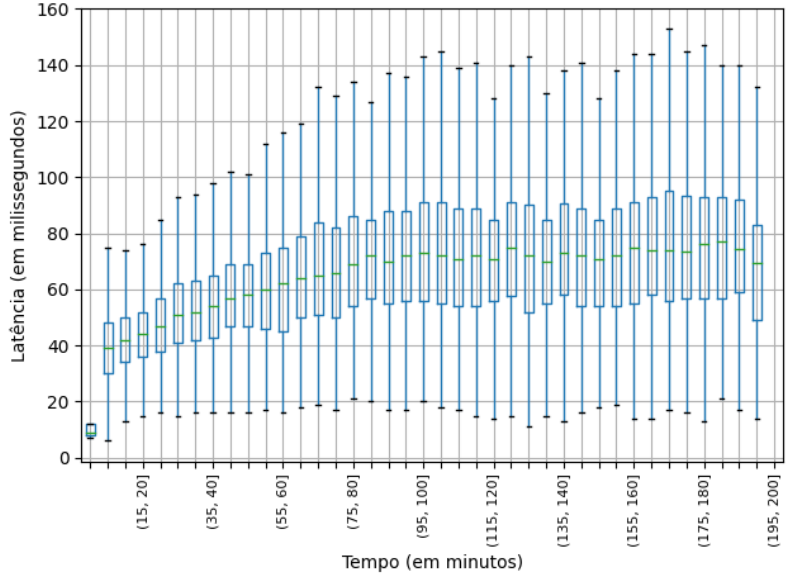

(c) Tipos de evento vel

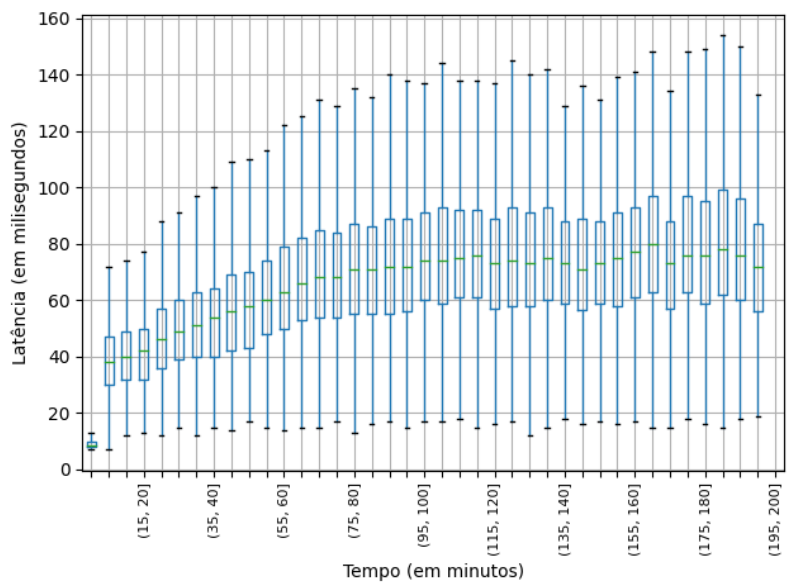

(e) Tipos de evento BusB

Figura A.24: Diagramas de caixa das latências por intervalos de cinco minutos ao longo da execução 4 do experimento utilizando o algoritmo de balanceamento de carga por Similaridade de Entrada. 


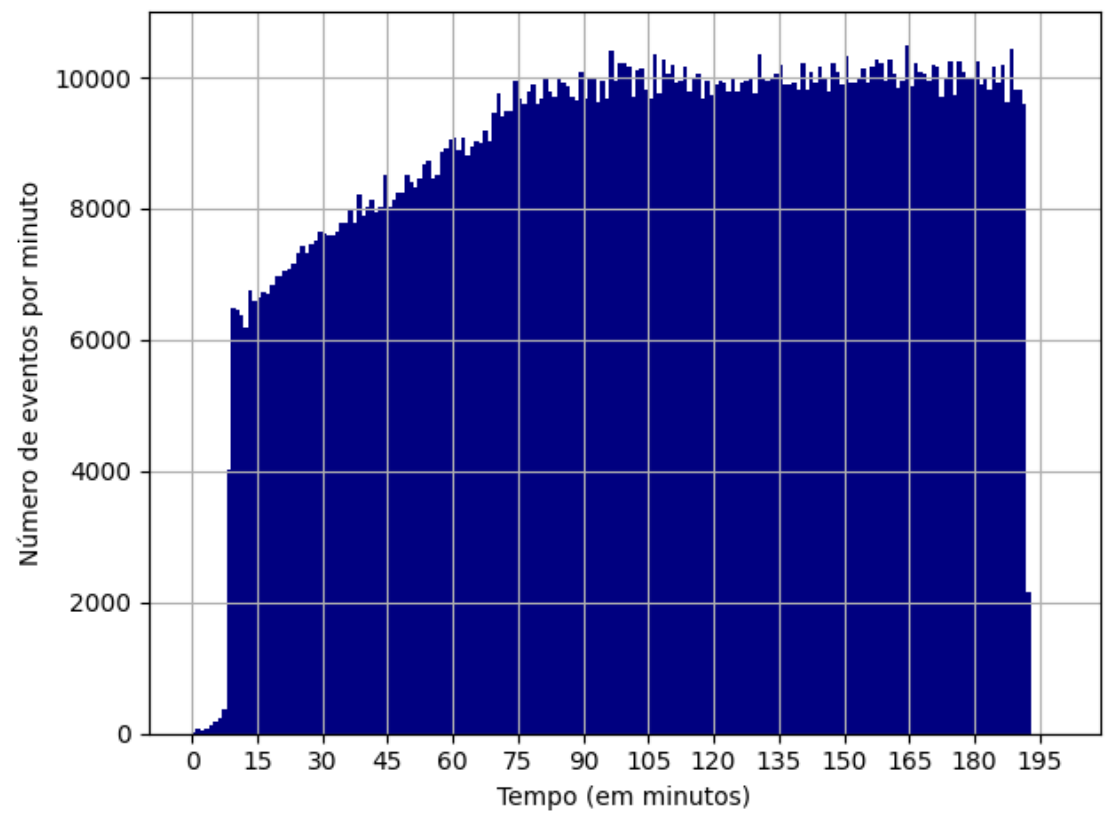

Figura A.25: Vazão de eventos detectados pelo sistema na execução 5 do experimento utilizando o algoritmo de balanceamento por Uso de Estado. 


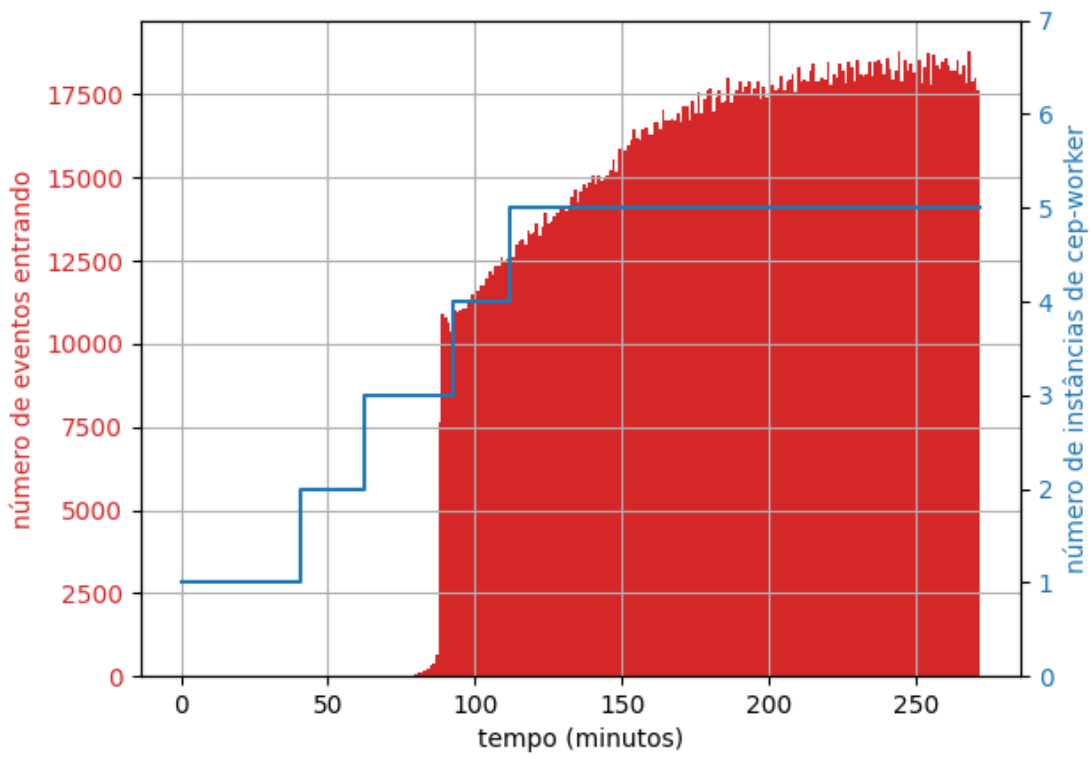

(a) Em função do tempo da execução

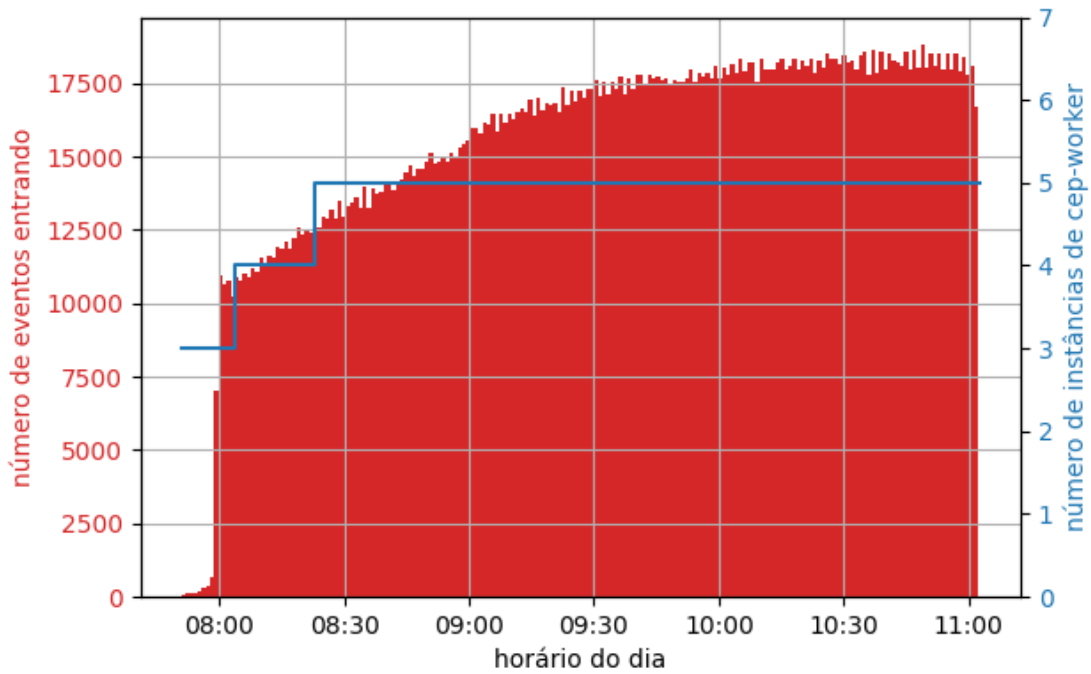

(b) Em função do horário do dia

Figura A.26: Número de eventos entrando no sistema (em vermelho) e número de instâncias de CEP Worker (em azul) na execução 5 do experimento utilizando o algoritmo de balanceamento de carga por Uso de Estado. Algumas instâncias são iniciadas antes do início do envio de eventos pois nesse período o cadastro de tipos de eventos já ocupa toda a memória disponível de algumas instâncias. 


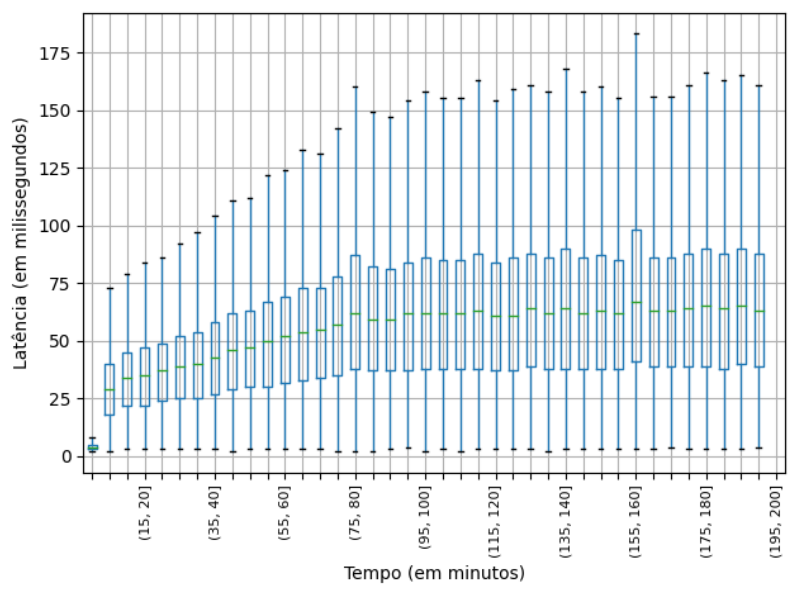

(a) Tipos de evento $v f$

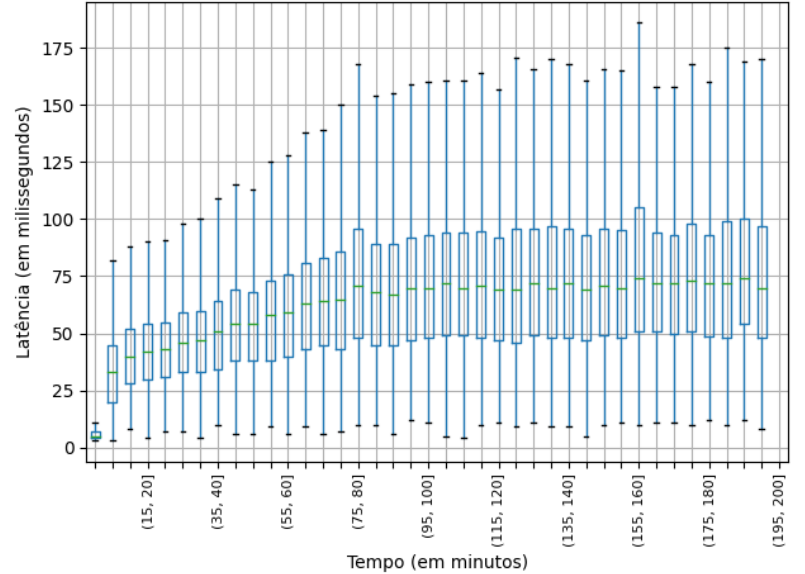

(b) Tipos de evento vi

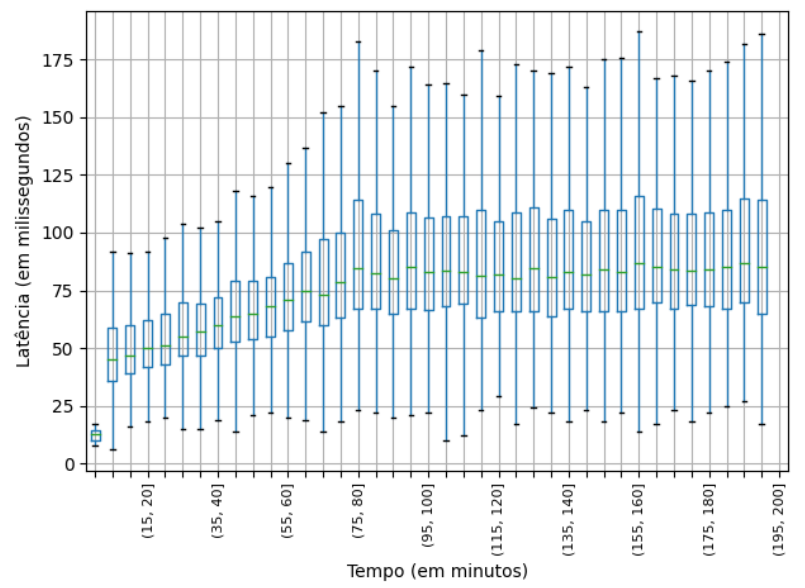

(d) Tipos de evento corr

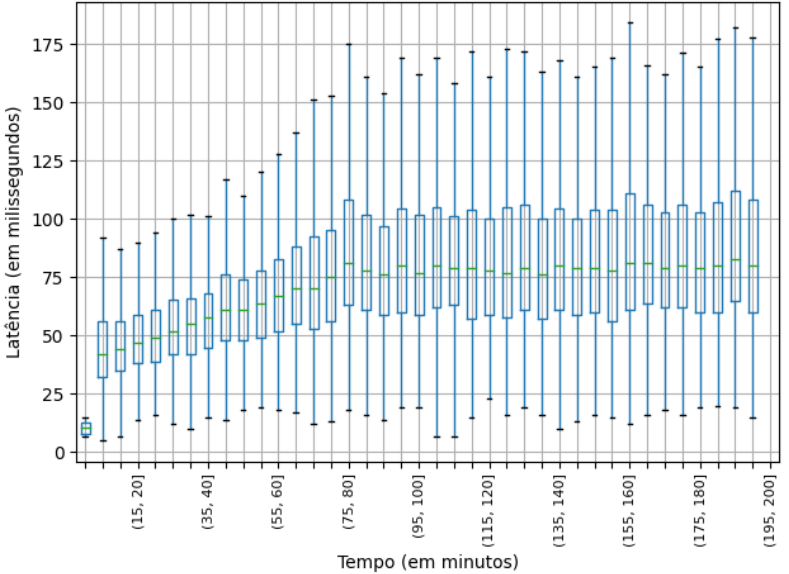

(c) Tipos de evento vel

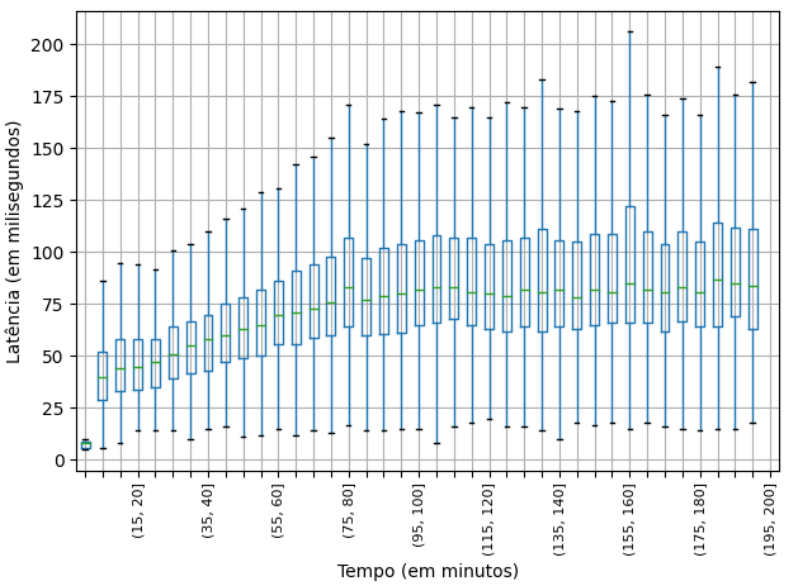

(e) Tipos de evento $\boldsymbol{B u s B}$

Figura A.27: Diagramas de caixa das latências por intervalos de cinco minutos ao longo da execução 5 do experimento utilizando o algoritmo de balanceamento de carga por Uso de Estado. 


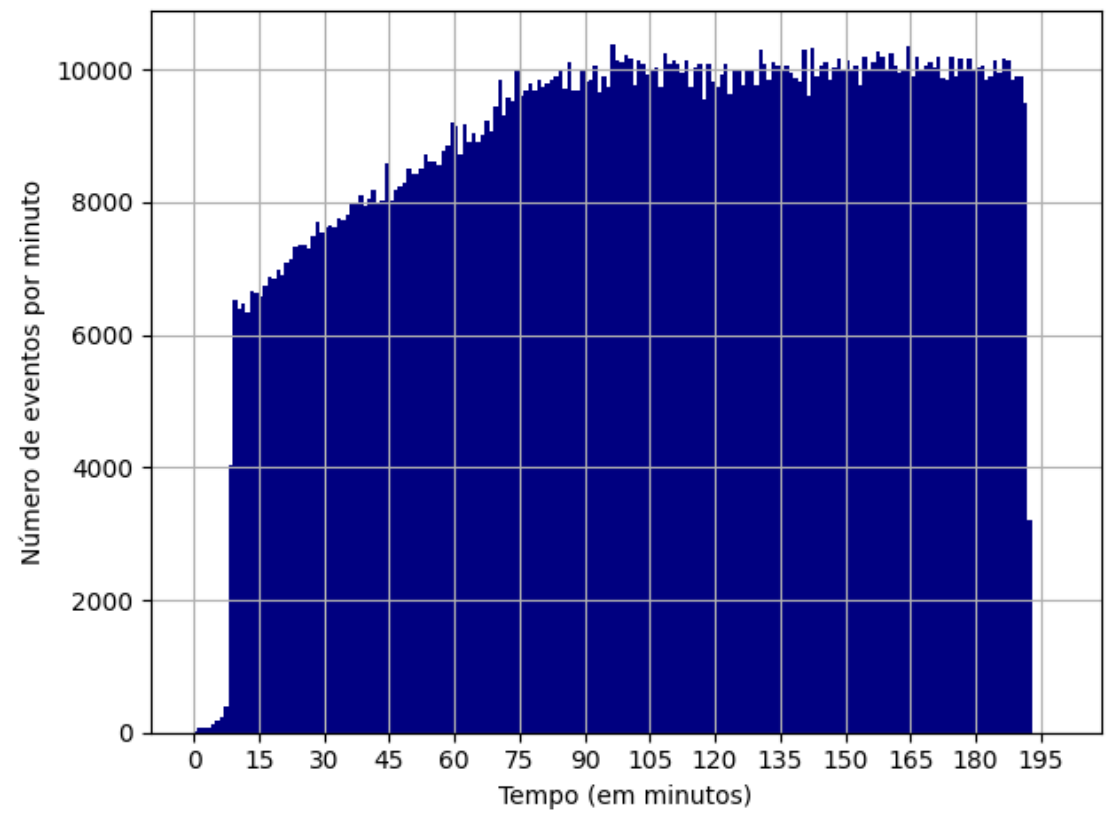

Figura A.28: Vazão de eventos detectados pelo sistema na execução 5 do experimento utilizando o algoritmo de balanceamento por Similaridade de Entrada. 


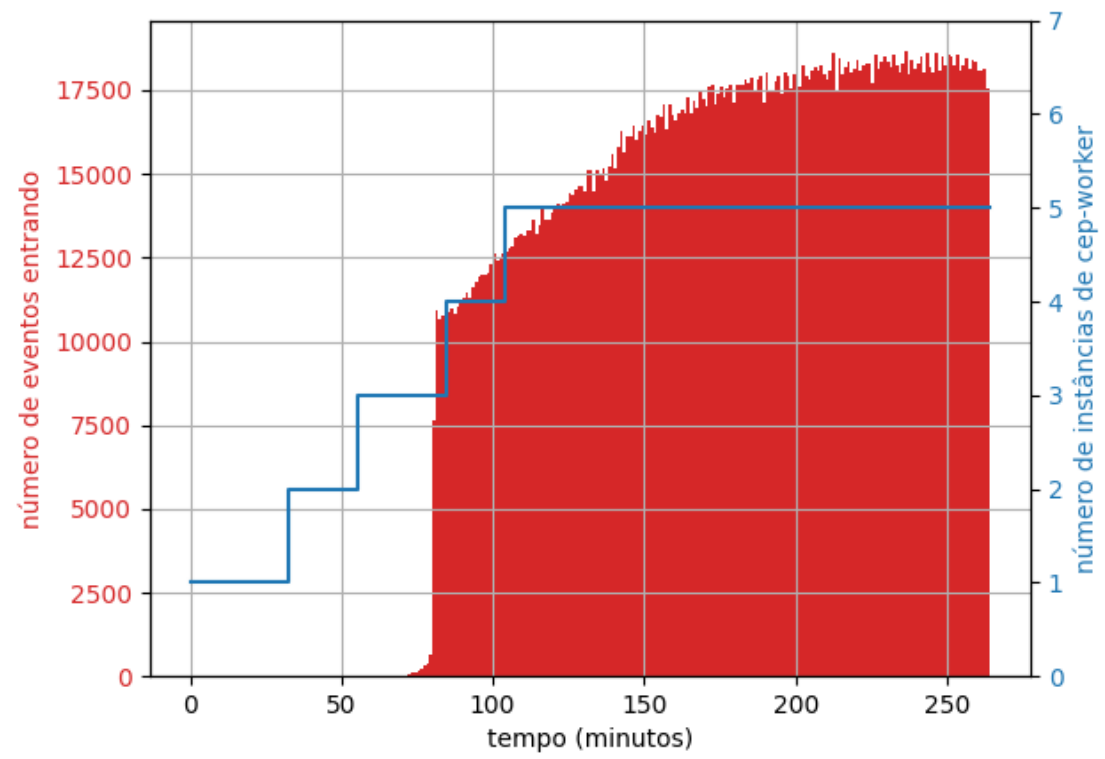

(a) Em função do tempo da execução

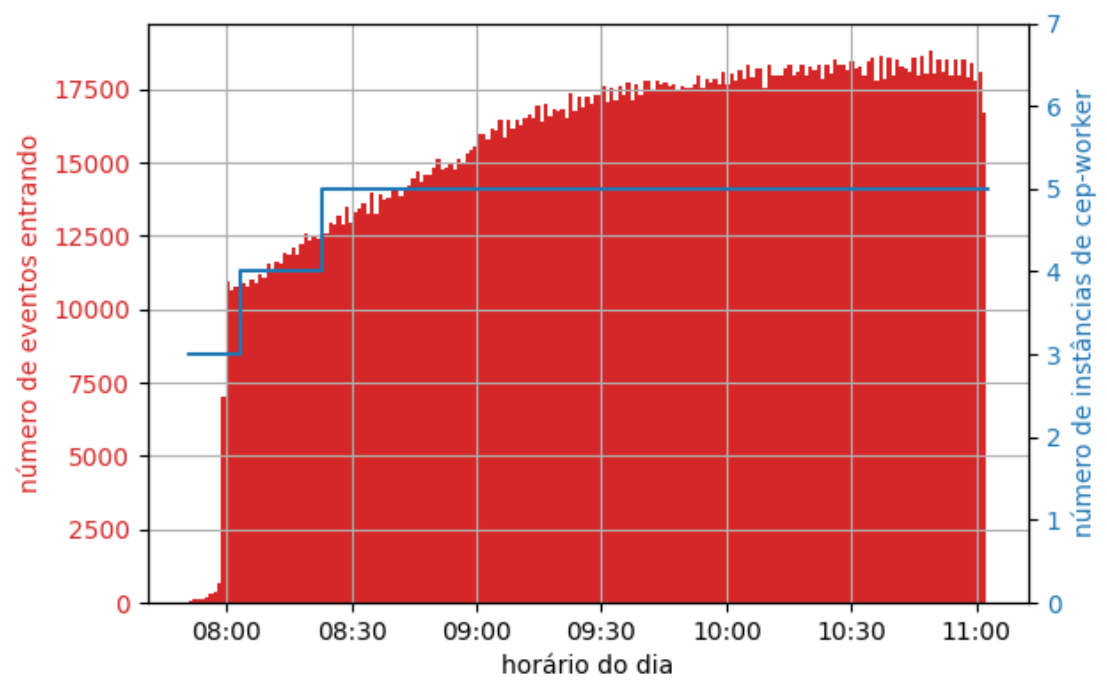

(b) Em função do horário do dia

Figura A.29: Número de eventos entrando no sistema (em vermelho) e número de instâncias de CEP Worker (em azul) na execução 5 do experimento utilizando o algoritmo de balanceamento de carga por Similaridade de Entrada. Algumas instâncias são iniciadas antes do início do envio de eventos pois nesse período o cadastro de tipos de eventos já ocupa toda a memória disponível de algumas instâncias. 


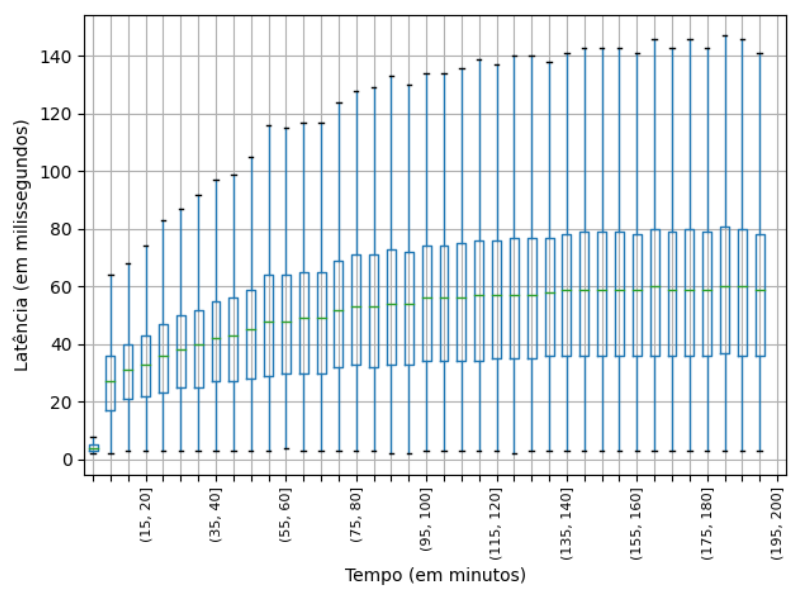

(a) Tipos de evento $\boldsymbol{v f}$

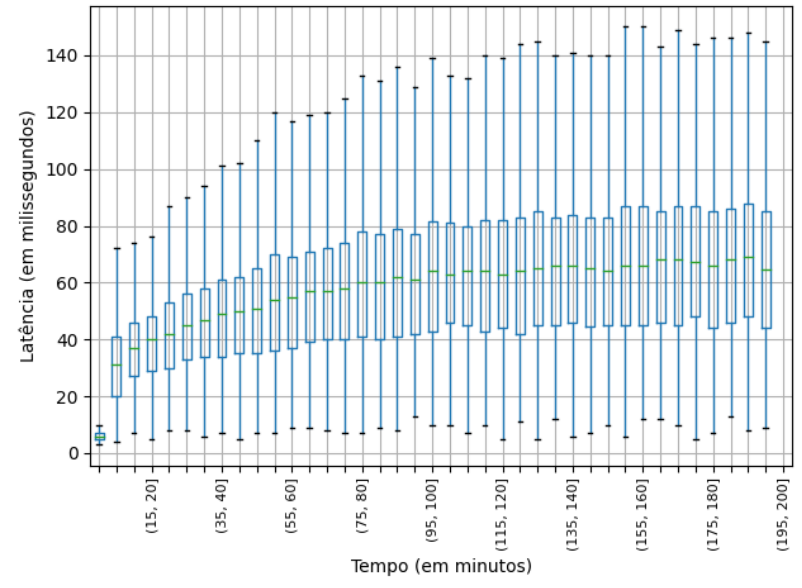

(b) Tipos de evento vi

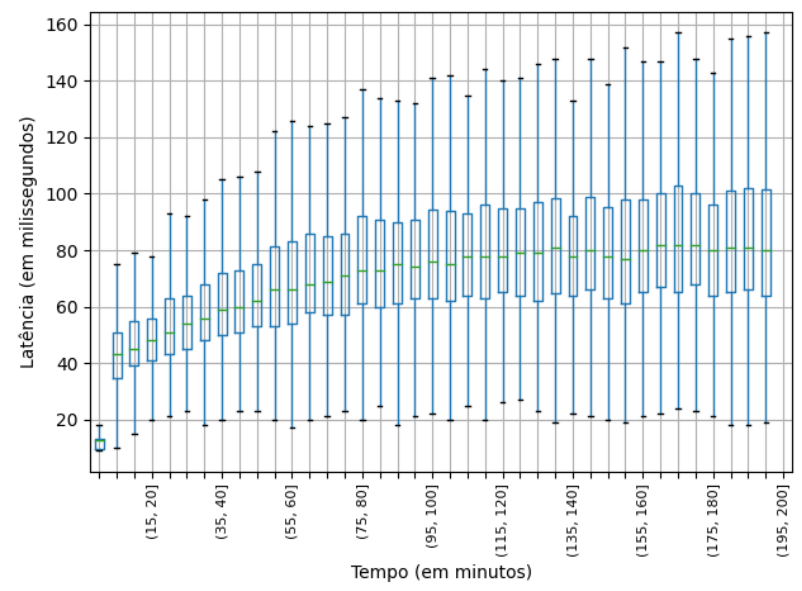

(d) Tipos de evento corr

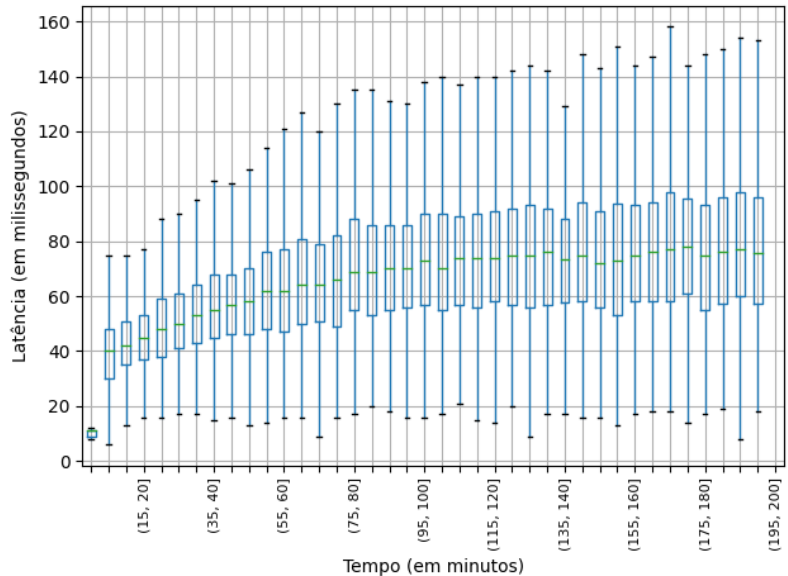

(c) Tipos de evento vel

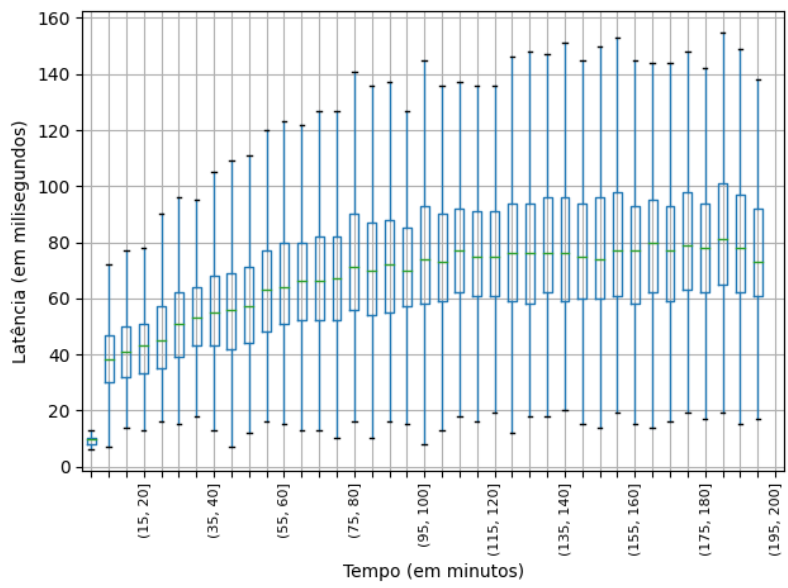

(e) Tipos de evento BusB

Figura A.30: Diagramas de caixa das latências por intervalos de cinco minutos ao longo da execução 5 do experimento utilizando o algoritmo de balanceamento de carga por Similaridade de Entrada. 


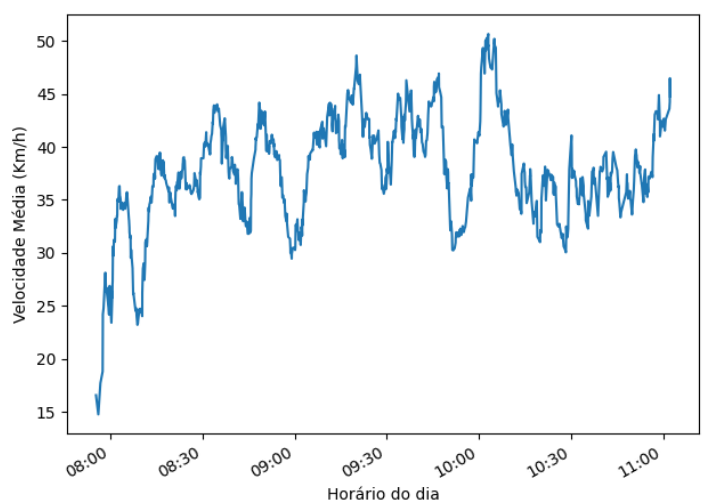

(a) Ibirapuera

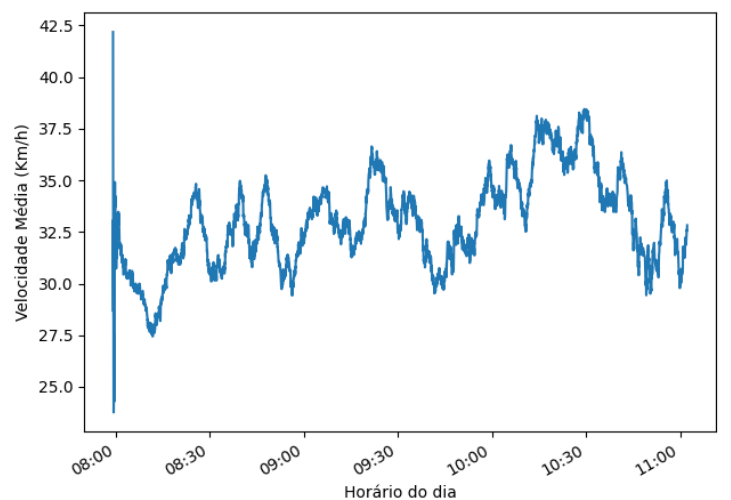

(c) Pirituba

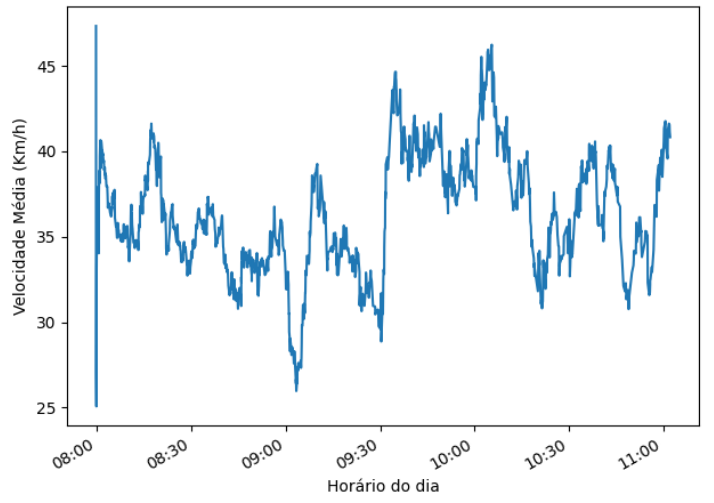

(e) Itapecirica

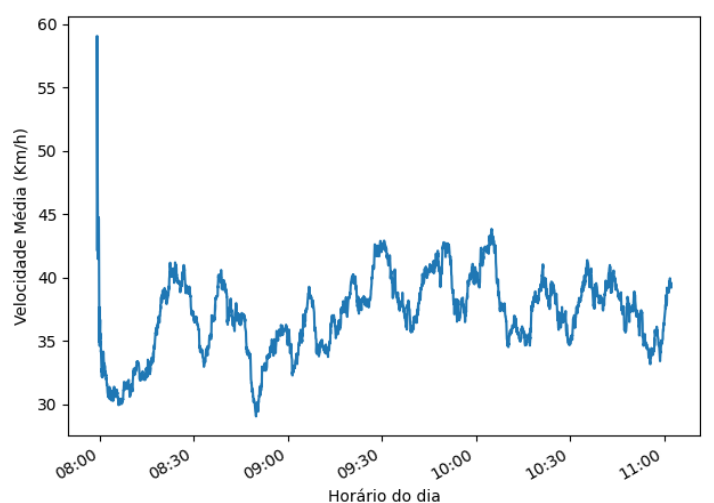

(b) Inajar

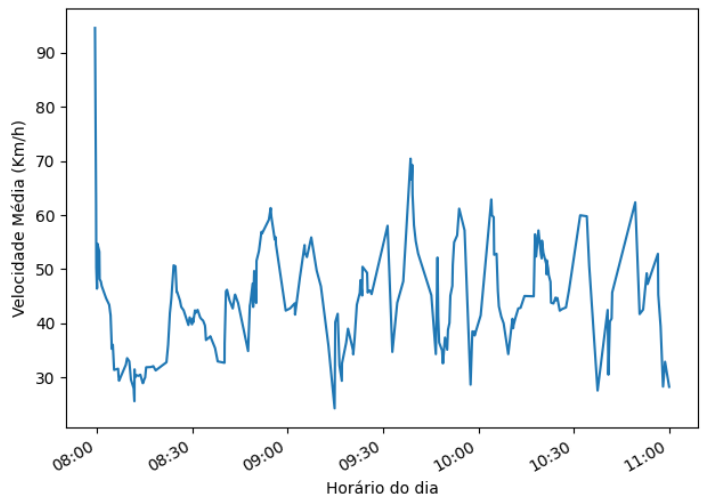

(d) Ponte Baixa

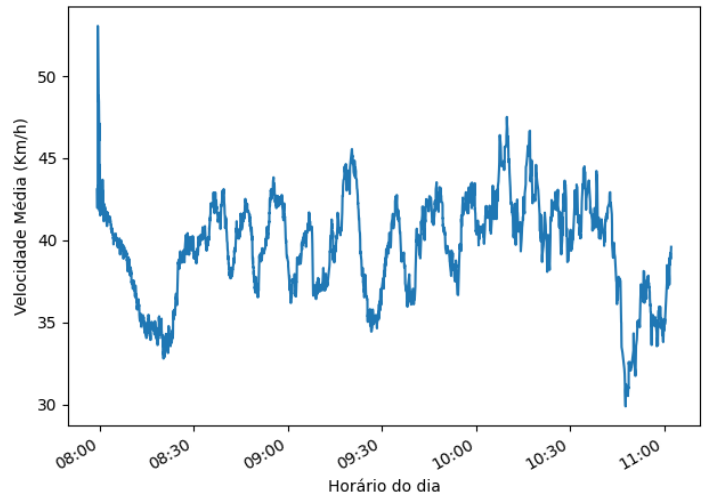

(f) Nove De Julho

Figura A.31: Velocidade média de cada corredor detectada pelos tipos de eventos da categoria corr ao longo do horário do dia de coleta dos dados. 


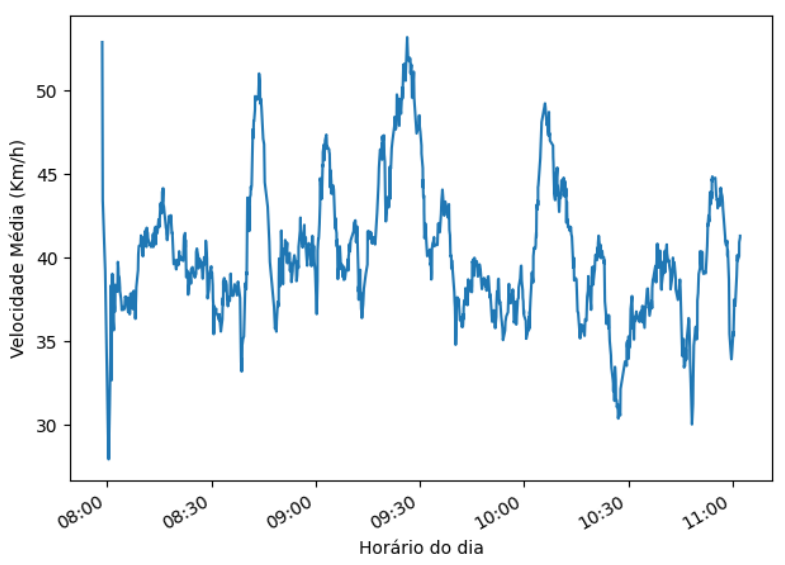

(a) Tiradentes

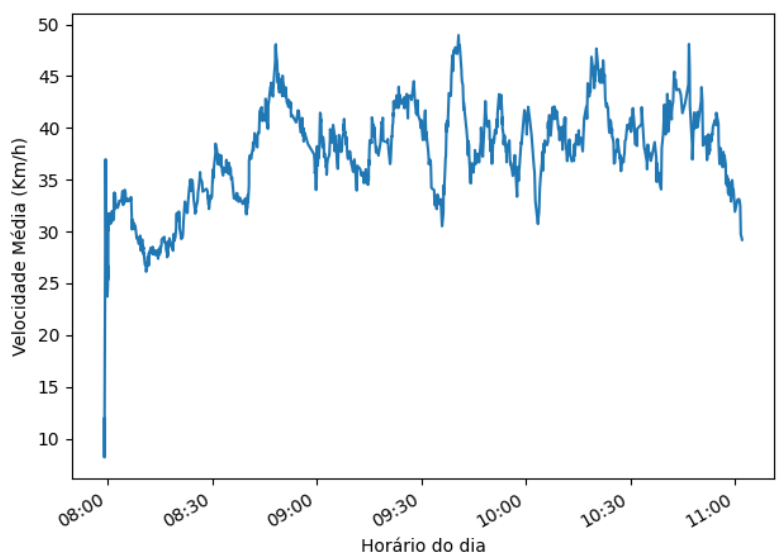

(c) Berrini.

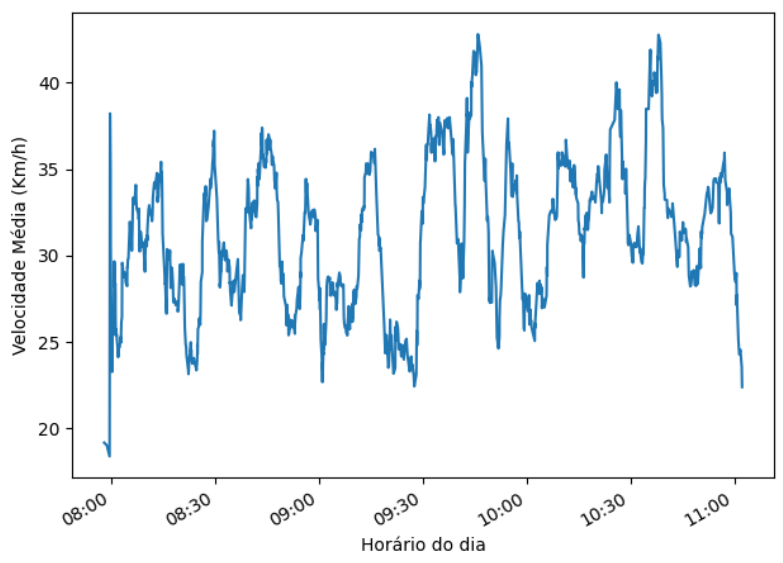

(e) Paes de Barros

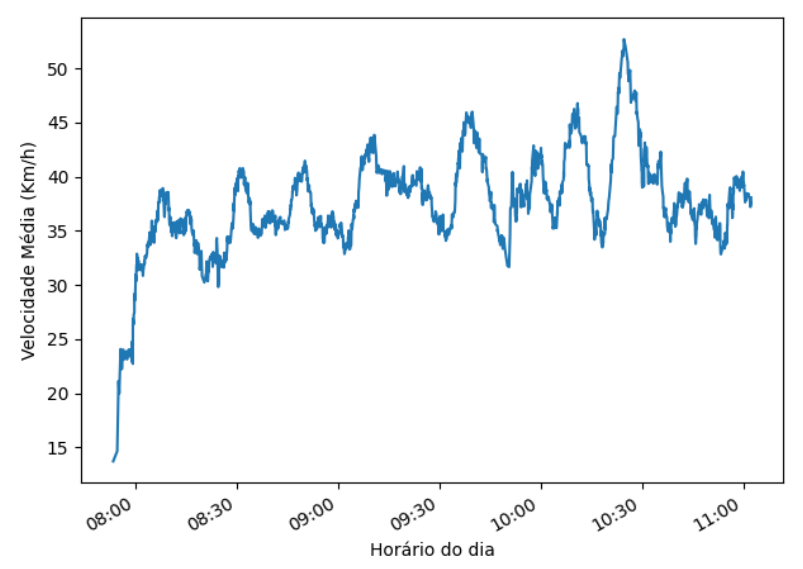

(b) Guarapiranga

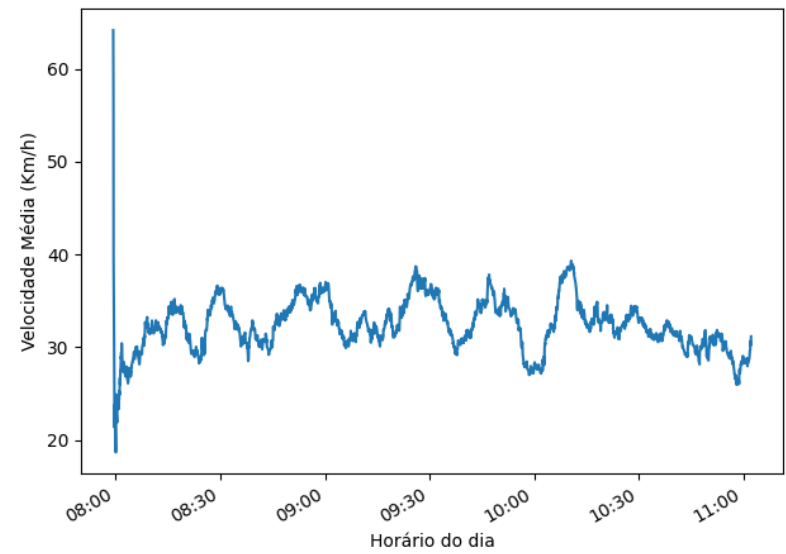

(d) Campo Limpo

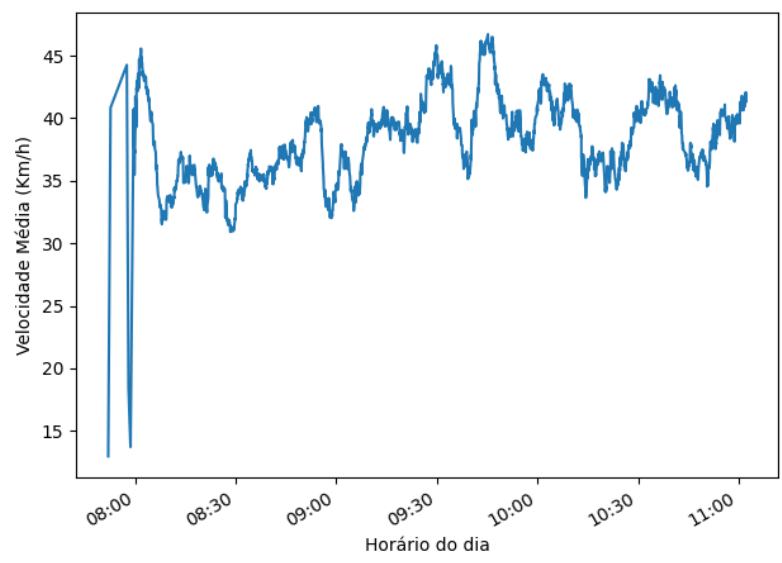

(f) Parelheiros

Figura A.32: Velocidade média de cada corredor detectada pelos tipos de eventos da categoria corr ao longo do horário do dia de coleta dos dados. 


\section{Referências Bibliográficas}

11578:1996(2020) ISO/IEC 11578:1996, 2020. URL https://www.itu.int/ITU-T/studygroups/ com17/oid.html. Último acesso em 20/12/2020. Citado na pág. 45

AWS-Instances(2020) AWS-Instances, 2020. URL https://aws.amazon.com/pt/ec2/ instance-types/. Último acesso em 20/12/2020. Citado na pág. 53

Balkesen et al.(2013) C. Balkesen, N. Dindar, M. Wetter e N. Tatbul. RIP: Run-based intra-query parallelism for scalable complex event processing. Em Proceedings of the 7th ACM International Conference on Distributed Event-based Systems, DEBS '13, páginas 3-14. ACM. Citado na pág. 2, 24,27

Bondi(2000) A. B. Bondi. Characteristics of scalability and their impact on performance. Em Proceedings of the 2Nd International Workshop on Software and Performance, WOSP '00, páginas 195-203. ACM. Citado na pág. 19

Caragliu et al.(2011) A. Caragliu, C. Del Bo e P. Nijkamp. Smart cities in Europe. Journal of Urban Technology, 18(2):65-82. Citado na pág. 1

Carbone et al.(2013) P. Carbone, K. Vandikas e F. Zaloshnja. Towards highly available complex event processing deployments in the cloud. Em 2013 Seventh International Conference on Next Generation Mobile Apps, Services and Technologies, páginas 153-158. Citado na pág. 25

Cloud Computing(2020) NIST Cloud Computing, 2020. URL https://nvlpubs.nist.gov/ nistpubs/Legacy/SP/nistspecialpublication800-145.pdf. Último acesso em 20/12/2020. Citado na pág. 16

Davis(2019) C. Davis. Cloud Native Patterns: Designing change-tolerant software. Manning Publications. Citado na pág. 28

Dean e Ghemawat(2010) J. Dean e S. Ghemawat. MapReduce: A flexible data processing tool. Communications of the ACM, 53(1):72-77. Citado na pág. 1

Dhillon et al.(2018) A. S. Dhillon, S. Majumdar, M. St-Hilaire e A. El-Haraki. A mobile complex event processing system for remote patient monitoring. Em 2018 IEEE International Congress on Internet of Things, ICIOT 2018, páginas 180-183. Citado na pág. 26

Dobbelaere e Esmaili(2017) P. Dobbelaere e K. S. Esmaili. Kafka versus RabbitMQ: A comparative study of two industry reference publish/subscribe implementations: Industry paper. Em Proceedings of the 11th ACM International Conference on Distributed and Event-based Systems, DEBS '17, páginas 227-238. ACM. Citado na pág. 44

ESPERDataWindows(2020) ESPERDataWindows, 2020. URL http://esper.espertech.com/ release-8.6.0/reference-esper/html/epl-views.html. Último acesso em 20/12/2020. Citado na pág. 43

EsperEventRepresentation(2020) EsperEventRepresentation, 2020. URL http://esper. espertech.com/release-8.6.0/reference-esper/html/event_representation.html\#eventrep_ comparing. Citado na pág. 42 
Esposte et al.(2019) A. D. de M Esposte, E. F.Z. Santana, L. Kanashiro, F. M. Costa, K. R. Braghetto, N. Lago e F. Kon. Design and evaluation of a scalable smart city software platform with large-scale simulations. Future Generation Computer Systems, 93:427-441. Citado na pág. 3, $41,52,74$

Esposte et al.(2017) A. M. Del Esposte, F. Kon, F. M. Costa e N. Lago. Interscity: A scalable microservice-based open source platform for smart cities. Em Proceedings of the 6th International Conference on Smart Cities and Green ICT Systems, páginas 35-46. Citado na pág. 20

Etzion e Niblett(2010) O. Etzion e P. Niblett. Event Processing in Action. Manning Publications, $1^{\mathrm{a}}$ edição. Citado na pág. 2, 6, 12, 13

Felter et al.(2015) W. Felter, A. Ferreira, R. Rajamony e J. Rubio. An updated performance comparison of virtual machines and linux containers. Em 2015 IEEE International Symposium on Performance Analysis of Systems and Software, ISPASS 2015, páginas 171-172. Citado na pág. 16

Fowler(2006) M. Fowler, 2006. URL https://martinfowler.com/eaaDev/EventNarrative.html. Último acesso em 20/12/2020. Citado na pág. 18

Francesco(2017) P. D. Francesco. Architecting microservices. Em 2017 IEEE International Conference on Software Architecture Workshops, ICSAW 2017, páginas 224-229. Citado na pág. 20

Fregly e Barth(2021) C. Fregly e A. Barth. Data Science on AWS: Implementing End-To-End, Continuous AI and Machine Learning Pipelines. O'Reilly Media, Inc. Citado na pág. 28

Garrison e Nova(2017) J. Garrison e K. Nova. Cloud Native Infrastructure: Patterns for Scalable Infrastructure and Applications in a Dynamic Environment. O'Reilly Media, Inc. Citado na pág. 2, $16,17,26,28$

Gilbert(2018) J. Gilbert. Cloud Native Development Patterns and Best Practices: Practical architectural patterns for building modern, distributed cloud-native systems. Packt Publishing. Citado na pág. 16,28

Gilbert e Lynch(2002) S. Gilbert e N. Lynch. Brewer's conjecture and the feasibility of consistent, available, partition-tolerant web services. SIGACT News, 33(2):51-59. Citado na pág. 20

Grant et al.(2020) T. Grant, H. Karau, B. Lublinsky, R. Liu e I. Filonenko. Kubeflow for Machine Learning. O'Reilly Media, Inc. Citado na pág. 28

Guo e Huang(2015) Qin Guo e Jiwei Huang. A complex event processing based approach of multisensor data fusion in iot sensing systems. Em 2015 th International Conference on Computer Science and Network Technology, ICCSNT 2015, páginas 548-551. Citado na pág. 26

Haversine(2020) Haversine, 2020. URL https://rosettacode.org/wiki/Haversine_formula. Último acesso em 20/12/2020. Citado na pág. 49

Higashino et al.(2016) W. A Higashino, M. AM Capretz e L. F. Bittencourt. CEPSim: Modelling and simulation of complex event processing systems in cloud environments. Future Generation Computer Systems, 65:122-139. Citado na pág. 26

IETF(2020) IETF, 2020. URL https://tools.ietf.org/html/rfc4122. Citado na pág. 45

Isoyama et al.(2012) K. Isoyama, Y. Kobayashi, T. Sato, K. Kida, M. Yoshida e H. Tagato. A scalable complex event processing system and evaluations of its performance. Em Proceedings of the 6th ACM International Conference on Distributed Event-Based Systems, DEBS '12, páginas 123-126. ACM. Citado na pág. 2, 23, 24, 27, 28, 36 
Jain(2008) R. Jain. The art of computer systems performance analysis: techniques for experimental design, measurement, simulation and modeling. John wiley \& Sons. Citado na pág. 64

Jayasekara et al.(2015) S. Jayasekara, S. Kannangara, T. Dahanayakage, I. Ranawaka, S. Perera e V. Nanayakkara. Wihidum: Distributed complex event processing. Journal of Parallel and Distributed Computing, 79-80(Supplement C):42 - 51. Special Issue on Scalable Systems for Big Data Management and Analytics. Citado na pág. 24, 27

Kobayashi et al.(2015) Y. Kobayashi, K. Isoyama, K. Kida e H. Tagato. A complex event processing for large-scale M2M services and its performance evaluations. Em Proceedings of the 9th ACM International Conference on Distributed Event-Based Systems, páginas 336-339. Citado na pág. 23,27

Kon e Santana(2016) F. Kon e E. F. Z. Santana. Cidades inteligentes: Conceitos, plataformas e desafios. Em Congresso da Sociedade Brasileira de Computação, páginas 2-49. Citado na pág. 1

Kritikos et al.(2019) K. Kritikos, C. Zeginis, J. Iranzo, R. S. Gonzalez, D. Seybold, F. Griesinger e J. Domaschka. Multi-cloud provisioning of business processes. Journal of Cloud Computing, 8 (1):1-29. Citado na pág. 26

López et al.(2020) P. G. López, A. Arjona, J. Sampé, A. Slominski e L. Villard. Triggerflow: Trigger-based orchestration of serverless workflows. Em Proceedings of the 14th ACM International Conference on Distributed and Event-Based Systems, DEBS '20, página 3-14. ACM. Citado na pág. 26

Luckham(2001) D. C. Luckham. The Power of Events: An Introduction to Complex Event Processing in Distributed Enterprise Systems. Addison-Wesley Longman Publishing Co., Inc. Citado na pág. 5

Luong et al.(2019) N. C. Luong, P. Wang, D. Niyato, Y. Liang, Z. Han e F. Hou. Applications of economic and pricing models for resource management in $5 \mathrm{G}$ wireless networks: A survey. IEEE Communications Surveys Tutorials, 21(4):3298-3339. Citado na pág. 26

Maeng et al.(2020) K. Maeng, J. Kim e J. Shin. Demand forecasting for the $5 \mathrm{G}$ service market considering consumer preference and purchase delay behavior. Telematics and Informatics, 47: 101327. Citado na pág. 26

Margara e Cugola(2011) A. Margara e G. Cugola. Processing flows of information: From data stream to complex event processing. Em Proceedings of the 5th ACM International Conference on Distributed Event-based System, DEBS '11, páginas 359-360. ACM. Citado na pág. 14, 15

Martins et al.(2014) P. Martins, M. Abbasi e P. Furtado. AuDy: Automatic dynamic least-weight balancing for stream workloads scalability. Em 2014 IEEE International Congress on Big Data, IEEE BigData 2014, páginas 176-183. Citado na pág. 2, 25, 27, 28, 36

Meslin et al.(2020) A. Meslin, N. Rodriguez e M. Endler. Scalable mobile sensing for smart cities: The MUSANet experience. IEEE Internet of Things Journal, 7(6):5202-5209. Citado na pág. 26

Metsch et al.(2015) T. Metsch, O. Ibidunmoye, V. Bayon-Molino, J. Butler, F. HernándezRodriguez e E. Elmroth. Apex Lake: A framework for enabling smart orchestration. Em Proceedings of the Industrial Track of the 16th International Middleware Conference, Middleware Industry '15, páginas 1-7. ACM. Citado na pág. 26

Michael et al.(2007) M. Michael, J. E. Moreira, D. Shiloach e R. W. Wisniewski. Scale-up x scaleout: A case study using Nutch/Lucene. Em 2007 IEEE International Parallel and Distributed Processing Symposium, IPDPS 2007, páginas 1-8. Citado na pág. 19 
Moldovan et al.(2014) D. Moldovan, G. Copil, H. Truong e S. Dustdar. Quelle - a framework for accelerating the development of elastic systems. Em Massimo Villari, Wolf Zimmermann e Kung-Kiu Lau, editors, Service-Oriented and Cloud Computing, páginas 93-107. Springer Berlin Heidelberg. Citado na pág. 26

Moniruzzaman e Hossain(2013) A. B. M. Moniruzzaman e S. A. Hossain. NoSQL database: New era of databases for big data analytics - classification, characteristics and comparison. CoRR, abs/1307.0191. Citado na pág. 1

Newman(2015) S. Newman. Building Microservices. O’Reilly Media, Inc., 1ª edição. Citado na pág. $2,17,18,19$

OSF(2020) OSF, 2020. URL https://pubs.opengroup.org/miscpubs/9629399/apdxa.htm. Citado na pág. 45

Pathak e Vaidehi(2015) R. Pathak e V. Vaidehi. An efficient rule balancing for scalable complex event processing. Em 2015 IEEE 28th Canadian Conference on Electrical and Computer Engineering, CCECE 2015, páginas 190-195. Citado na pág. 24, 27

Power e Kotonya(2020) A. Power e G. Kotonya. Bobocep: Distributed complex event processing for resilient fault-tolerance support in IoT. Em 2020 IEEE Sixth International Conference on Big Data Computing Service and Applications, BigDataService 2020, páginas 109-112. Citado na pág. 26

Rabl et al.(2012) T. Rabl, S. Gómez-Villamor, M. Sadoghi, V. Muntés-Mulero, H. Jacobsen e S. Mankovskii. Solving big data challenges for enterprise application performance management. Proceedings of the VLDB Endowment, 5(12):1724-1735. Citado na pág. 44

Randika e Ranathunga(2018) C. Randika e S. Ranathunga. Gathika: A dynamic query distribution mechanism for complex event processing systems. Em 2018 18th International Conference on Advances in ICT for Emerging Regions, ICTer 2018, páginas 54-61. IEEE. Citado na pág. 25

Randika et al.(2010) H. C. Randika, H. E. Martin, D. M. R. R. Sampath, D. S. Metihakwala, K. Sarveswaren e M. Wijekoon. Scalable fault tolerant architecture for complex event processing systems. Em 2010 International Conference on Advances in ICT for Emerging Regions (ICTer), páginas 86-96. Citado na pág. 25

Richardson(2018) C. Richardson. Microservices Patterns: With examples in Java. Manning Publications. Citado na pág. 28

S. Mullins(2018) C. S. Mullins. What are the database scalability methods?, 2018. URL https://www.nuodb.com/techblog/what-are-database-scalability-methods. Último acesso em 20/12/2020. Citado na pág. 20

Scattone e Braghetto(2018) F. F. Scattone e K. R. Braghetto. A microservices architecture for distributed complex event processing in smart cities. Em 2018 IEEE 37th International Symposium on Reliable Distributed Systems Workshops, SRDSW 2018, páginas 6-9. Citado na pág. 3

Scattone e Braghetto(2020) F. F. Scattone e K. R. Braghetto. Processamento distribuído de eventos complexos aplicado à deteç̧ão de eventos no trânsito em tempo real. Em $2020 S B C 11^{\underline{a}}$ Escola Regional de Alto Desempenho de São Paulo, ERAD-SP 2020. Citado na pág. 3

Schultz-Møller et al.(2009) N. P. Schultz-Møller, M. Migliavacca e P. Pietzuch. Distributed complex event processing with query rewriting. Em Proceedings of the Third ACM International Conference on Distributed Event-Based Systems, DEBS '09, páginas 4:1-4:12. ACM. Citado na pág. 24,27 
Shahrivari(2014) S. Shahrivari. Beyond batch processing: Towards real-time and streaming big data. Computers, 3(4):117-129. Citado na pág. 1

Shin et al.(2019) Y. Shin, S. Yoon, P. Trirat e J. Lee. Cep-wizard: Automatic deployment of distributed complex event processing. Em 2019 IEEE 35th International Conference on Data Engineering, ICDE 2019, páginas 2004-2007. IEEE. Citado na pág. 25

Truyen et al.(2019) E. Truyen, D. V. Landuyt, D. Preuveneers, B. Lagaisse e W. Joosen. A comprehensive feature comparison study of open-source container orchestration frameworks. Applied Sciences, 9(5):931. Citado na pág. 44

Villamizar et al.(2015) M. Villamizar, O. Garcés, H. Castro, M. Verano, L. Salamanca, R. Casallas e S. Gil. Evaluating the monolithic and the microservice architecture pattern to deploy web applications in the cloud. Em 2015 10th Computing Colombian Conference, 10CCC, páginas 583-590. Citado na pág. 20

Ward e Barker(2013) J. S. Ward e A. Barker. Undefined by data: A survey of big data definitions. CoRR, abs/1309.5821. Citado na pág. 1

WSO2FAQ(2020) WSO2FAQ, 2020. URL https://docs.wso2.com/display/SP410/FAQ. Último acesso em 20/12/2020. Citado na pág. 15

Xiao et al.(2017) F. Xiao, C. Zhan, H. Lai, L. Tao e Z. Qu. New parallel processing strategies in complex event processing systems with data streams. International Journal of Distributed Sensor Networks, 13(8):1550147717728626. Citado na pág. 24, 27

Zhao e Yang(2015) H. Zhao e Y. Yang. A data generation algorithm for Internet of Things based on complex event processing. Em 2015 IEEE International Conference on Smart City/SocialCom/SustainCom, SmartCity 2015, páginas 827-831. Citado na pág. 26 